Portland State University

PDXScholar

Spring 6-4-2013

\title{
The Impact of Knowledge Inflows on the Performance of National Laboratories in Technological Latecomer Countries
}

Pattravadee Ploykitikoon

Portland State University

Follow this and additional works at: https://pdxscholar.library.pdx.edu/open_access_etds

Part of the Industrial Technology Commons

Let us know how access to this document benefits you.

\section{Recommended Citation}

Ploykitikoon, Pattravadee, "The Impact of Knowledge Inflows on the Performance of National Laboratories in Technological Latecomer Countries" (2013). Dissertations and Theses. Paper 1071. https://doi.org/10.15760/etd.1071

This Dissertation is brought to you for free and open access. It has been accepted for inclusion in Dissertations and Theses by an authorized administrator of PDXScholar. Please contact us if we can make this document more accessible: pdxscholar@pdx.edu. 
The Impact of Knowledge Inflows on the Performance of

National Laboratories in Technological Latecomer Countries

by

Pattravadee Ploykitikoon

A dissertation submitted in partial fulfillment of the requirements for the degree of

\author{
Doctor of Philosophy \\ in \\ Technology Management
}

Dissertation Committee:

Charles M. Weber, Chair

Timothy R. Anderson

Robert L. Fountain

Antonie J. Jetter

Portland State University

2013 
C 2013 Pattravadee Ploykitikoon 


\begin{abstract}
The national laboratories (NLs) play a critical role in the economic and social development of technological latecomer countries, yet no academic study has ever quantified how knowledge inflows and internal knowledge impact the performance of the NLs. This dissertation identifies and ranks the importance of factors pertaining to knowledge inflows and project-internal knowledge, which determine the success or failure of research projects in the NLs of Thailand. A survey of 123 project managers in the NLs, which covers 208 R\&D projects, has been conducted. It consists of a questionnaire and unstructured interviews in which the project managers discuss their project(s). Data from the questionnaire are analyzed by factor analysis, multiple regression and logistic regression; qualitative data from the interviews are used to interpret the quantitative results from the questionnaire.
\end{abstract}

The research finds that, regardless of a project's mission, knowledge inflows from outside the project group impact performance more significantly than knowledge from inside the project group does. Second, the capacity of $R \& D$ project groups within the NLs to absorb knowledge from external sources is very selective. Absorptive capacity does not just pertain to prior related knowledge; it is also a function of the source of external knowledge, the knowledge pathway into the project group, the source of complementary or substitutive knowledge that resides within the project group, and the mission to which the knowledge contributes. Third, the NLs face an ambidexterity 
challenge that is commonly observed in private industry-exploiting current capabilities interferes with the national laboratories' capability to explore.

The discovery of selective absorption of knowledge provides practicing managers with a toolkit of micro-levers with which they can enhance performance as measured by a variety of metrics in highly specific ways. The dissertation also proposes and validates a theoretical framework for knowledge management that decomposes the national laboratory system into nine knowledge subsystems, which can be managed at a relatively low level of the organization. The methods by which this research has been conducted can be used as a tool to benchmark how knowledge management practices in different $R \& D$ organizations and environments impact performance. Guidelines for structural adjustments to the national innovation system, which are based on these contributions, should enable policymakers in most countries to implement an Open Innovation program for their national laboratories and enhance the ambidexterity of their organizations. 


\title{
DEDICATION
}

To my advisor, Dr. Charles M. Weber, who

believed there was something to my initial idea,

helped me dig deep to discover the phenomena,

and pointed out the contributions of these discoveries.

\begin{abstract}
Also,
to anyone who believes in and supports a new approach,

opens his/her mind to new ideas,

and works hard to make things better.
\end{abstract}




\section{ACKNOWLEDGMENTS}

This dissertation could not have been completed without help and support from my advisor, my committee members, the department of Engineering and Technology Management, Portland State University, my sponsors, my colleagues, my friends, and my family. It is my privilege to acknowledge all who have given me guidance, help and encouragement along the way.

My deepest gratitude is to my advisor, Dr. Charles M. Weber. I have been incredibly lucky to have him as my advisor. He gave me the freedom to explore on my own approach, and, at the same time, he guided me through the process. Without his guidance and persistent help this dissertation would absolutely not have been possible. Dr. Weber taught me how to organize and visualize ideas so that the readers of this dissertation would understand my approach to researching the subject matter that it contains. I hope to present the findings of this dissertation to as large an audience as possible. This will help me share all of valuable knowledge I have learned from working with him.

I would like to thank my committee members, Dr. Timothy R. Anderson, Dr. Robert L. Fountain and Dr. Antonie J. Jetter. Dr. Anderson and Dr. Fountain are the experts in multivariate analysis and research methodology. Direct and prolonged engagement these two experts helped me focus on my research topic. It also enhanced the validity and reliability of the findings of this dissertation. I especially thank Dr. Anderson for helping

me validate the questionnaire, for encouraging me to share my research to a broader 
audience, and for carefully reading and constructively commenting on the countless revisions of my dissertation. In addition, I would like to express my gratitude to Dr. Jetter, who helped me connect the dots between my prior work experience and academic study. Taking her courses and being her teaching assistant allowed me to transform all my experiences into the idea that underlies this dissertation.

I am also indebted to the department of Engineering and Technology Management (ETM), Portland State University. I would like to deeply thank Dr. Dundar Kocaoglu for giving me many opportunities. Being a member of ETM's family and helping ETM's professors with their courses and their research gave me valuable experiences that will be important in my professional career. I also thank Dr. Tugrul Daim for encouraging me to pursue my doctoral degree at the ETM.

I would also like to express my deeply felt gratitude to my officemates (Kenny, Songphon, Pattharaporn, Inthrayuth, and Jiting) and our group advisor (Liono) at the ETM Department. It has been my pleasure working with them. We shared a lot of good times and bad times together, and we were able to support each other over the years. In addition, I would like to thank the ETM's office manager, Shawn Wall, and ETM's PhD coordinator, Ann White, who always helped us with workplace issues and academic issues. They filled my years at ETM and PSU with memorable experiences.

I would like to express my sincere appreciation to Dr. Thaweesak Koanantakool, Dr. Chadamas Thuvasethakul, Assoc. Prof. Werasak Udomkijdecha, Dr. Kanyawim 
Kirtikara, Dr. Ladawan Krasachol, Mrs. Roongthip Kwantean, Dr. Pansak Siriruchatapong, Dr. Kwan Sitathani, Dr. Suthee Phoojaruenchanachai, Dr. Uthai Chareonwong, Dr. Piyawut Srichaikul, Mrs. Kullaprapa Navanugraha, Dr. Kalaya Udomvitid, and all of the R\&D project managers at National Science and Technology Development Agency who gave me their full support while I was validating my questionnaire and collecting data. I am especially grateful to Dr. Pansak, Dr. Kwan, and the Royal Thai Government Scholarship Program for giving me an unforgettable opportunity to study in the doctoral program.

Finally, I would express my gratitude to my mother, my father, my sisters (Suyanee, Dollawan, Anya, Kanitha), my brothers (Sathit and Peecha), my nephews (Weerapat and Panithan), my nieces (Koranat and Earn), and my friends (Atchariya, Jirapa, Nusara, Nitikul, Pattanan, Peeranan, Rungthip, Siripan, Sutham, Suthathip, Suwannee, Venice, and Yada), whose continuous support helped me through the hardship of studying in the doctoral program. My deepest thankfulness is expressed to my family and my longtime friends for their love, caring, and inspiration. Without their blessings and encouragement, I would not have been able to fulfill my dream and complete this dissertation. 


\section{TABLE OF CONTENTS}

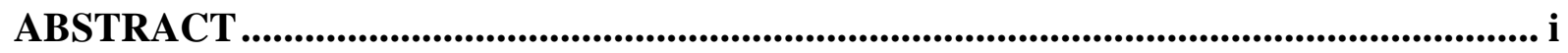

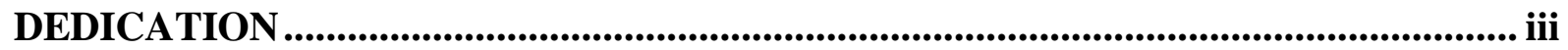

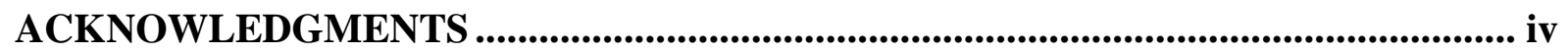

LIST OF TABLES...................................................................................................................

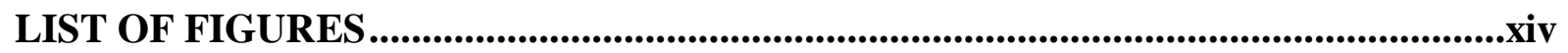

GLOSSARY OR LIST OF ABBREVIATIONS/SYMBOLS.............................................xi

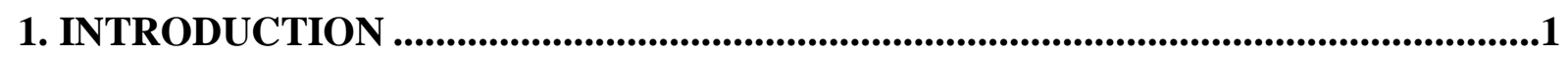

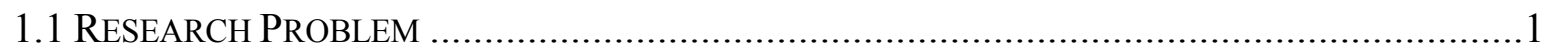

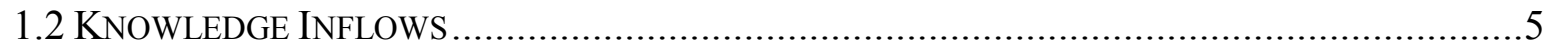

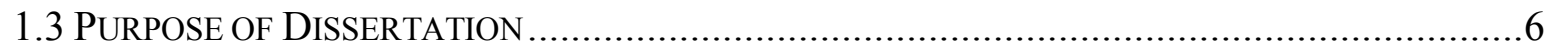

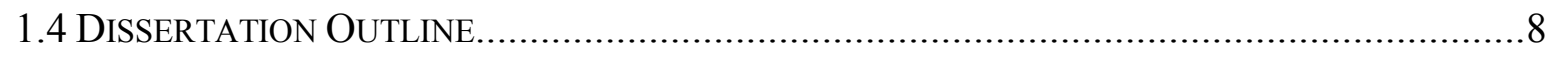

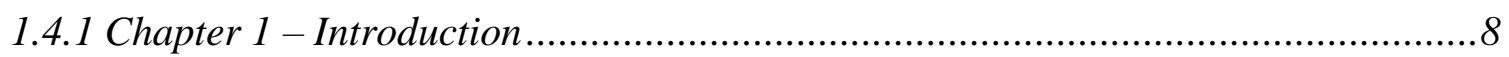

1.4.2 Chapter 2 - Literature Review.................................................................... 9

1.4.3 Chapter 3 -Hypotheses ............................................................................... 10

1.4.4 Chapter 4 - Research Methods.........................................................................10

1.4.5 Chapter 5 - Results ....................................................................................11

1.4.6 Chapter 6 - Conclusions ...........................................................................11

1.4.7 Chapter 7 - Summary, Contributions and Limitations .........................................12

2. LITERATURE REVIEW ..........................................................................................14

2.1 THE NATIONAL LABORATORIES WITHIN THE NATIONAL INNOVATION SYSTEMS OF

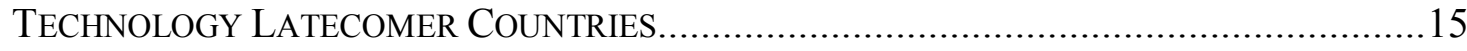

2.1.1 Mission 1: Adopt and Adapt ........................................................................20

2.1.2 Mission 2: Technology Commercialization ........................................................22 


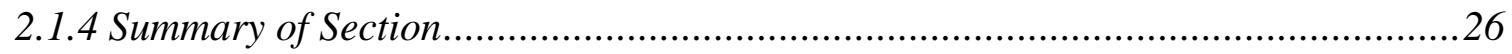

2.2 EXTERNAL AND INTERNAL KNOWLEDGE FOR NATIONAL LABORATORIES IN TECHNOLOGY

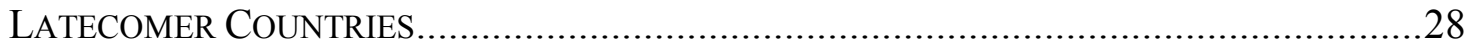

2.2.1 Sources of External Knowledge ................................................................29

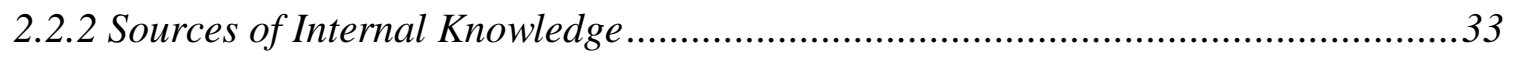

2.2.3 Pathways for Obtaining External Knowledge .................................................34

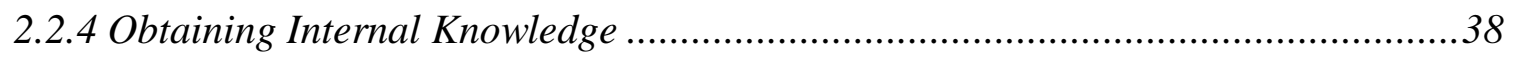

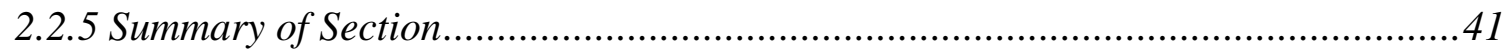

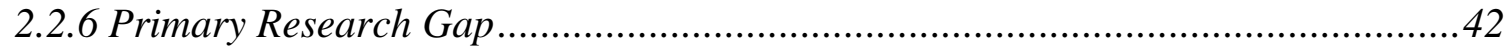

2.3 ThE IMPACT OF MANAGING KNOWLEDGE INFLOWS INTO R\&D ORGANIZATIONS ...........43

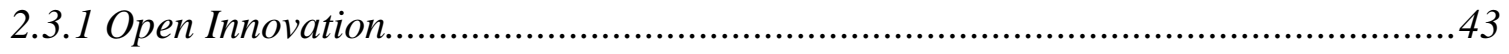

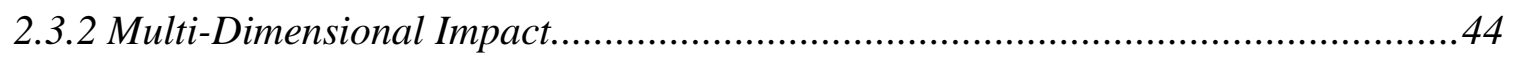

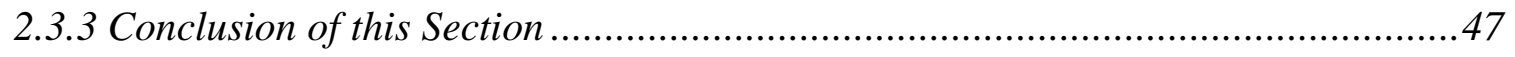

2.4 FACTORS THAT IMPACT KNOWLEDGE INFLOWS AT PROJECT LEVEL............................50

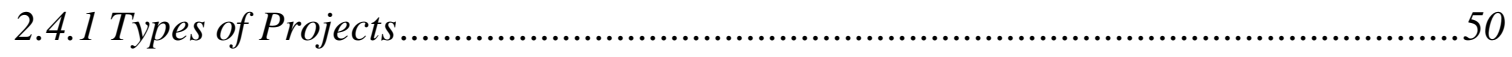

2.4.2 Project-Internal Factors.................................................................. 51

2.4.3 Choice of Pathway for Knowledge Inflows into a Project ..................................54

2.4.4 Sources of External Knowledge for a Project ................................................55

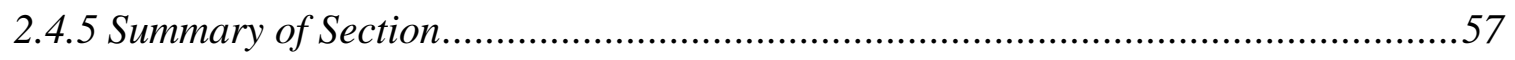

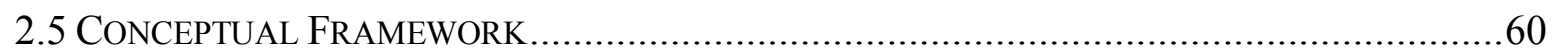

2.6 RESEARCH GAPS AND RESEARCH QUESTIONS ..................................................62

3. RESEARCH HYPOTHESES................................................................................................66

3.1 IMPACT OF ENGAGEMENT WITH OTHER R\&D PROJECT GROUPS WITHIN THE NATIONAL

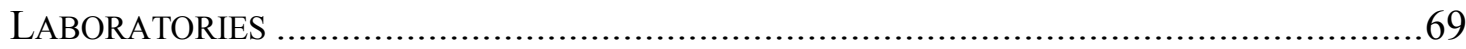

viii 
3.2 IMPACT OF ENGAGEMENT WITH DOMESTIC SOURCES ........................................... 71

3.3 IMPACT OF ENGAGEMENT WITH LOCAL TECHNOLOGY USERS................................... 73

3.4 IMPACT OF ENGAGEMENT WITH INTERNATIONAL SOURCES ..................................... 75

3.5 IMPACT OF PRIOR KNOWLEDGE (COMPLEMENT OR SUBSTITUTE) ...............................76

3.6 IMPACT OF PRIOR EXPERIENCE (COMPLEMENTARY) ..............................................78

3.7 IMPACT OF PROJECT-INTERNAL LEARNING ACTIVITIES (PILAS) (COMPLEMENT OR

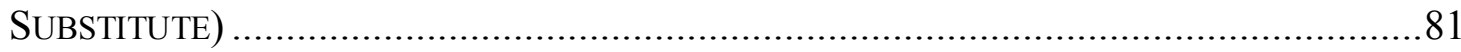

4. RESEARCH METHODOLOGY ...........................................................................884

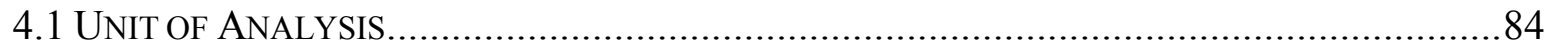

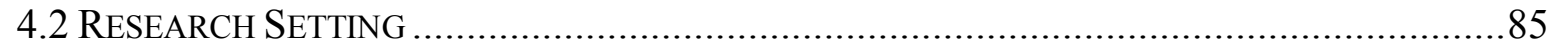

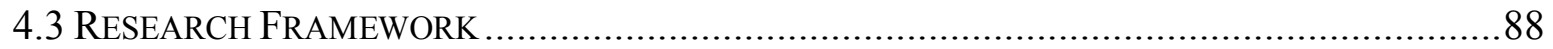

4.4 VALIDITY AND RELIABILITY OF MEASURES ...................................................... 89

4.4.1 Content Validity ..................................................................................... 90

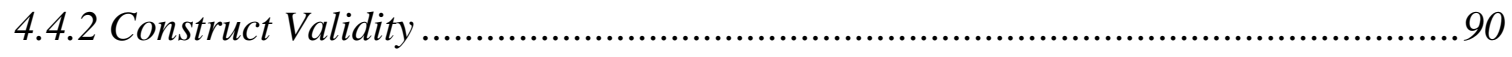

4.4 .3 Criterion-Related Validity ............................................................... 92

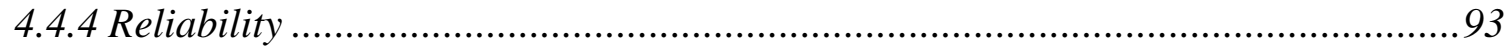

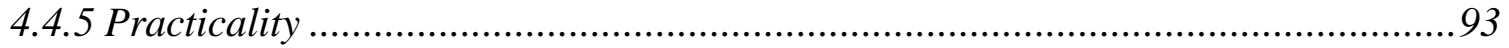

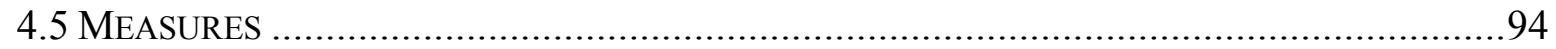

4.5.1 Measuring Independent Variables ......................................................... 95

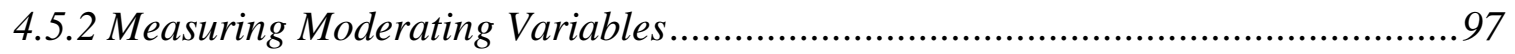

4.5.3 Measuring Dependent Variables .............................................................. 101

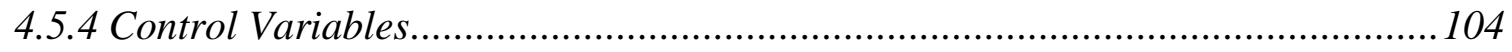

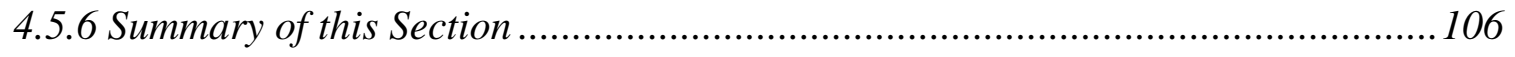

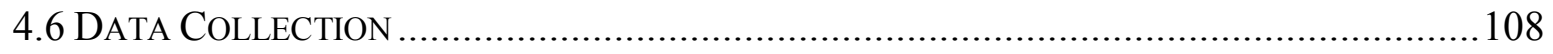

4.6.1 Obtaining Authorization to Perform the Study ............................................... 108 


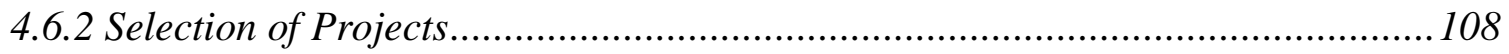

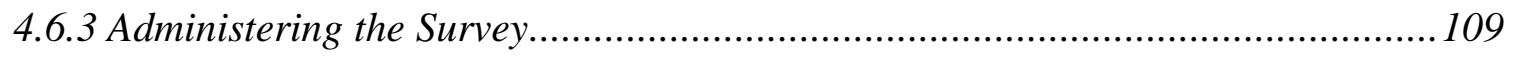

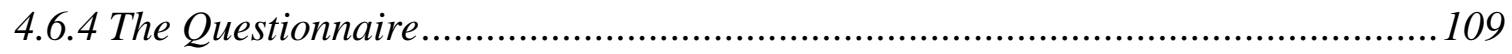

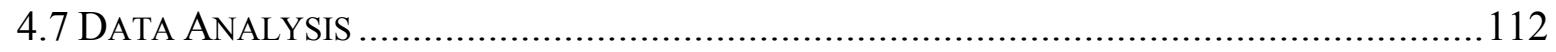

4.7.1 Descriptive Statistics .................................................................................112

4.7.2 Factor Analysis and Correlation Matrix........................................................112

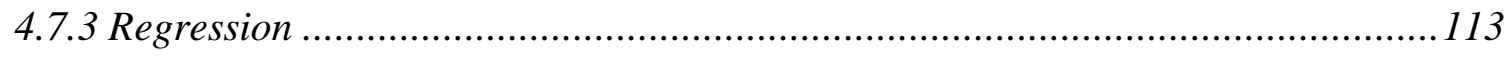

4.7.4 Modified Hierarchical Approach..................................................................... 114

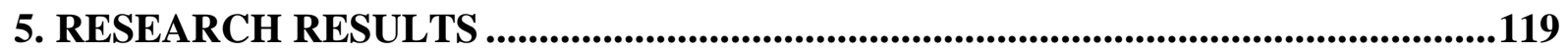

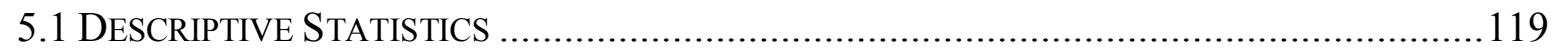

5.2 CORRELATION MATRIX AND FACTOR ANALYSIS ....................................................131

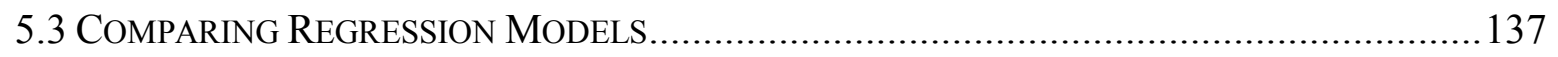

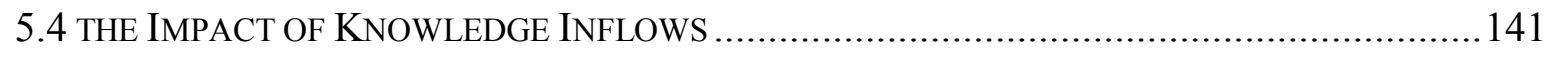

5.4.1 Engaging with other R\&D Project Groups in the National Laboratories ............ 141

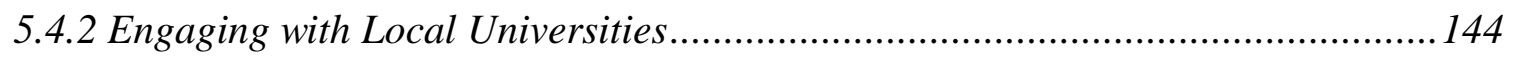

5.4.3 Engaging with Local Technology Users ....................................................... 147

5.4.4 Engaging with International Sources.............................................................. 150

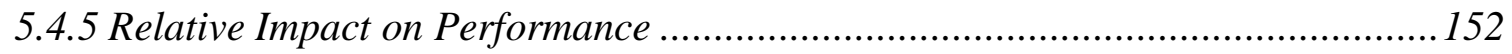

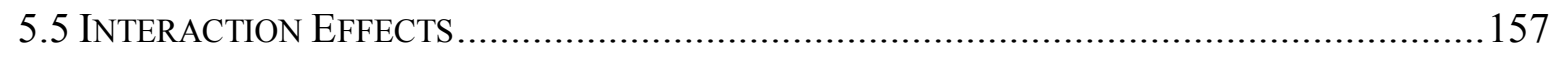

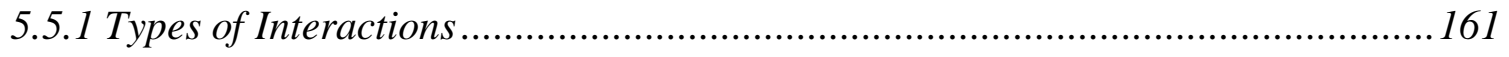

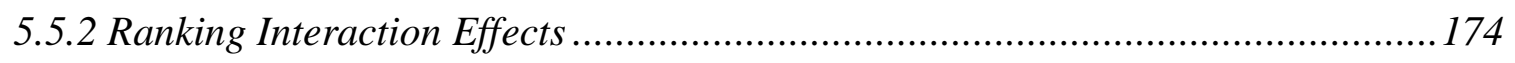

6. INTERPRETATION AND CONCLUSIONS .....................................................................178

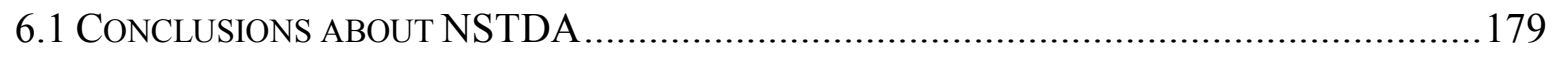

6.2. A FRAMEWORK FOR KNOWLEDGE FLOWS WITHIN THE NATIONAL INNOVATION SYSTEM 


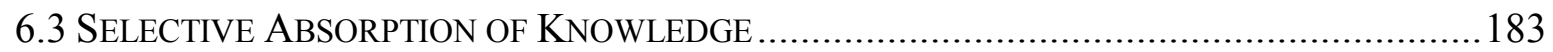

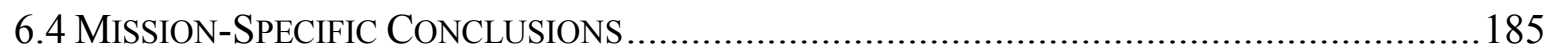

6.4.1 Conclusions Pertaining to User Satisfaction (Mission 1) .....................................185

6.4.2 Conclusions Pertaining to Commercialization (Mission 2) .................................. 189

6.4.3 Conclusions Pertaining to a Long-term R\&D Capability (Mission 3) ................. 197

6.5 Organizational AmbideXterity And Mission AlignMent ..................................206

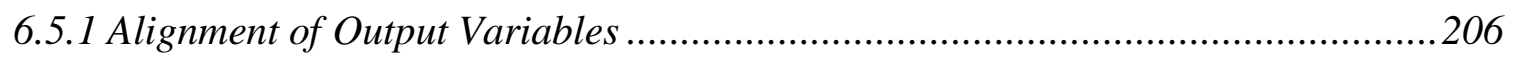

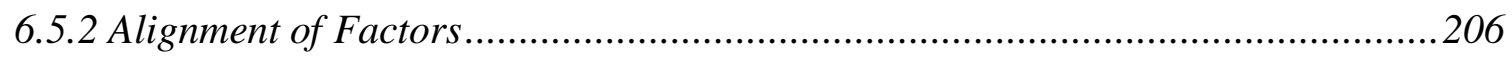

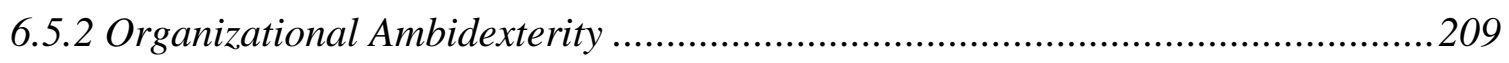

6.6 CONCLUSIONS ABOUT KNOWLEDGE INFLOWS AND INTERNAL KNOWLEDGE..................210

6.6.1 Conclusions about Knowledge Inflows. .........................................................210

6.6.2 Prior Knowledge about the Core Technology ……….......................................216

6.6.3 The Relative Importance of Internal and External Learning ..............................219

7. SUMMARY, CONTRIBUTIONS AND LIMITATIONS …….......................................222

7.1 Restating THE RESEARCH GAPS AND the RESEARCH QuESTIONS..............................222

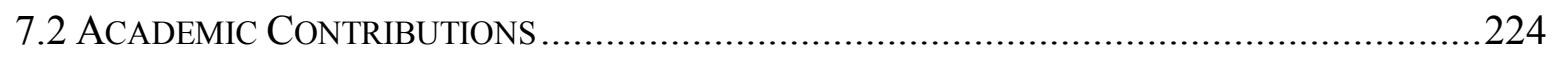

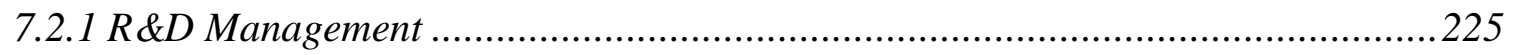

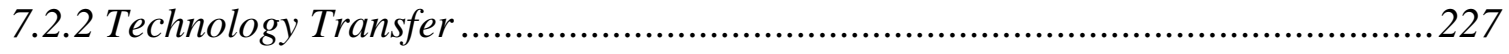

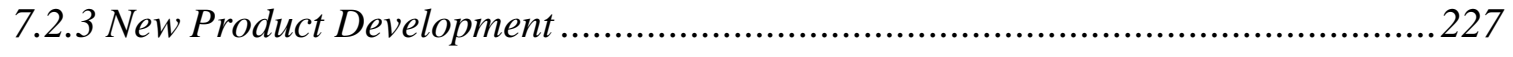

7.2.4 Organization Learning and Absorptive Capacity ...............................................228

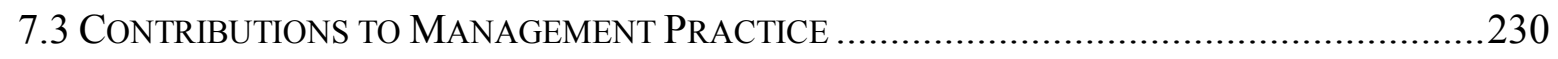

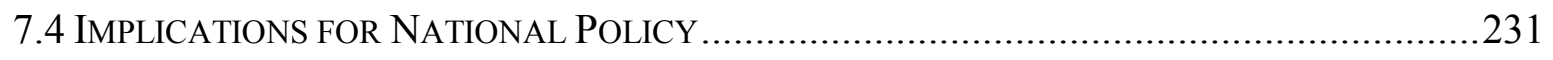

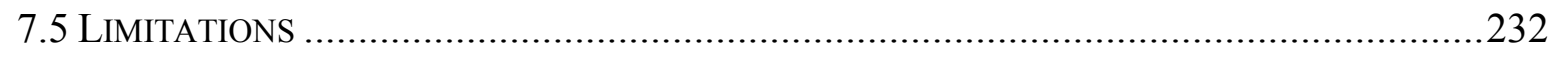

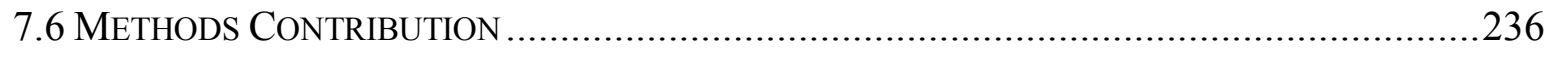

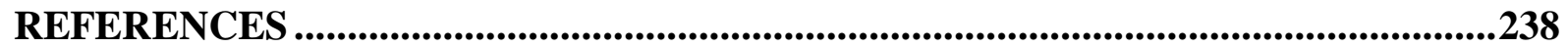


Appendix A: 17 Pathways to Facilitate KnOWLedge Transfer From Technology

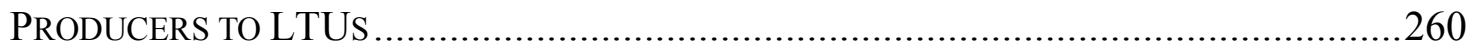

ApPendix B: Questionnaire for Project MANAGERs (Post-VALidation).................261

APPENDIX C: DATA ANALYSIS ....................................................................26

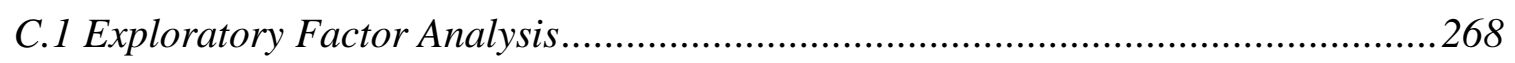

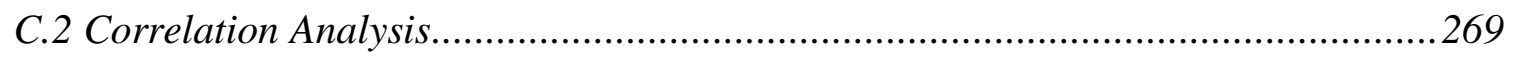

C.3 Regression Analysis: multiple regression and logistic regression .......................270

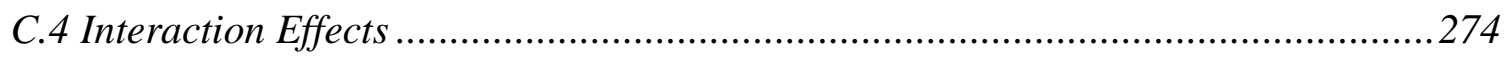

C.5. Benchmarking Metrics for Regression Models ............................................277

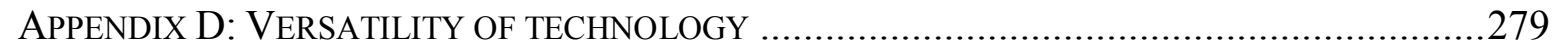

APPENDIX E: CORRELATION MATRIX ......................................................... 280

APPENDIX F: FACTOR ANALYSIS .................................................................... 282

APPENDIX G: REGRESSION ANALYSIS ...............................................................28

G.1 Regression Analysis for Mission-1: User Satisfaction......................................283

G.2 Regression Analysis for Mission 2: Probability of Commercialization of Technology

G.3 Regression Analysis for Mission-3--Criterion-1: Probability of Generating a

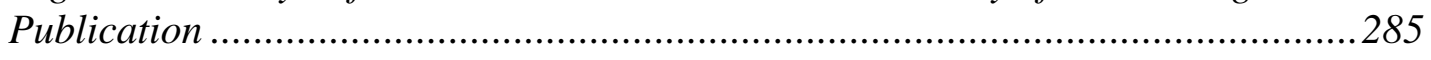

G.4 Regression Analysis for Mission-3--Criterion-2: Probability of Generating a Patent 286

G.5 Regression Analysis for Mission-3--Criterion-3: Versatility of Technology ..........287

G.6 Integrated Model of Knowledge Inflows and Internal Knowledge for Hypotheses 1 to

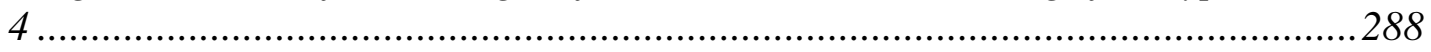

G.7 Regression analysis for Interaction Model................................................28 


\section{LIST OF TABLES}

Table 2.1: Performance measures in the existing literature and in my proposal (output variables) .

Table 2.2: Main literature pertaining to managing knowledge inflows at project level.

Table 2.3: Key factors that have been described in the existing literature and eleven candidate factors that I intend to cover in this dissertation .59

Table 4.1: Validity, reliability, and practicality of the survey questions .89

Table 4.2: Conclusion of Section on Measurement of Variables in this Dissertation ....107

Table 4.3: Reseach gaps, research questions, hypothesis and items on the questionnaire

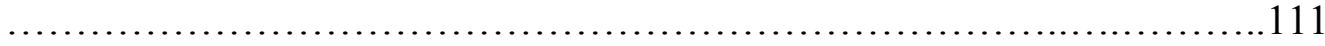

Table 4.4: Hierarchy of regression models .....................................116

Table 5.1: General information about projects in the national laboratories..............120

Table 5.2: Descriptive Statistics Pertaining to Output Variables ....................121

Table 5.3: Descriptive Statistics Pertaining to Contextual Learning Activities .........123

Table 5.4: Descriptive Statistics Pertaining to Vicarious Learning Activities ...........125

Table 5.5: Descriptive Statistics Pertaining to Prior Knowledge ....................127

Table 5.6: Descriptive Statistics Pertaining to Project-Internal Learning Activities .....128

Table 5.7: Descriptive Statistics Pertaining to Prior Experience .....................130

Table 5.8: Factor Analysis and Cumulative Variance Explained ..................... 135

Table 5.9: Correlation Matrix ....................................................... 136

Table 5.10: Summary of Predictive Power of Models 1 through 5 for all Output Variables

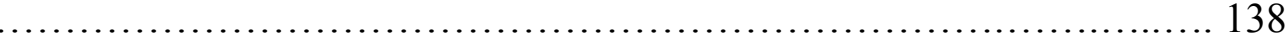

Table 5.11: Impact of Knowledge Inflows on the NLs' Performance ................. 152

Table 5.12: Impact of Interaction on the NLs' Performance .........................157

Table 5.13: Interaction Matrices for Missions 1, 2 and 3 ..........................159

Table 5.14: Ranking Interaction Effects .................................... 174 


\section{LIST OF FIGURES}

Figure 1.1: Sources of knowledge for a project group within the national laboratories in

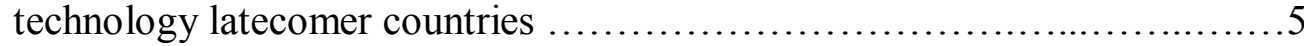

Figure 2.1: Integrating NLs with the innovation process of LTUs ...................21

Figure 2.2: The pathways for knowledge and technology flow out of NLs for each

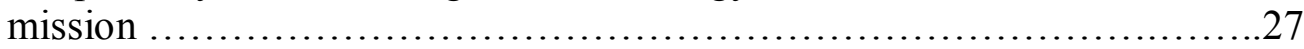

Figure 2.3: Knowledge inflow surrounding national laboratories $\ldots \ldots \ldots \ldots \ldots \ldots \ldots \ldots .42$

Figure 2.4: Taxonomy of knowledge pathways and knowledge generation mechanisms

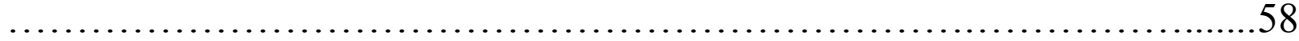

Figure 2.5: Conceptual framework of this dissertation

Figure 2.6: The relationship between management question, research objective, research gaps and research questions

Figure 3.1: Complementarity versus substitution of internal knowledge (prior

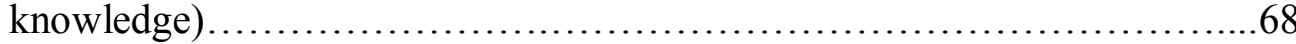

Figure 3.2: Pathways for knowledge flows within NLs in TLCs . ...................69

Figure 3.3: Pathways for local knowledge inflows to NLs in TLCs ..................71

Figure 3.4: The flow of knowledge between NLs and LTUs ......................73

Figure 3.5: Pathways for knowledge inflow from foreign sources $\ldots \ldots \ldots \ldots \ldots \ldots \ldots \ldots 75$

Figure 4.1: Research framework of this study .................................... 88

Figure 5.1: Types of interactions that were observed in this study $\ldots \ldots \ldots \ldots \ldots \ldots \ldots \ldots 1$

Figure 5.2: The impact of the interaction between contextual learning about local universities and having at least one team member with prior work experience at a local technology user on the probability of commercialization

Figure 5.3: The impact of the interaction between vicarious learning with other R\&D project groups within the national laboratories and having at least one team member with prior work experience in another R\&D project group within the national laboratories on the probability of generating at least one publication

from a project

Figure 5.4: The impact of the interaction between vicarious learning with other R\&D project groups and prior knowledge of the core technology on the probability of commercializing technology

Figure 5.5: The impact of the interaction between vicarious learning with local technology users that have production units and prior knowledge of the core technology on the probability of commercializing technology 
Figure 5.6: The impact of the interaction between vicarious learning with local technology users that are end users and prior knowledge of the core technology on the probability of commercializing technology.

Figure 5.7: The impact of the interaction between contextual learning with local technology users and prior knowledge of the core technology on the probability of commercializing technology.

Figure 6.1: Knowledge flows within the national innovation system, which pertain to the national laboratories

Figure 6.2: The knowledge management subsystem of the national laboratory system that contributes to user satisfaction.

Figure 6.3: The knowledge management subsystem of the national laboratory system that contributes to commercialization of technology.

Figure 6.4: The knowledge management subsystem of the national laboratory system that affects the probability of generating a publication from a particular project.

Figure 6.5: The knowledge management subsystem of the national laboratory system that contributes to versatility of technology.

Figure 6.6: The knowledge management subsystem of the national laboratory system that pertains to knowledge inflows from other R\&D project groups within the national laboratories

Figure 6.7: The knowledge management subsystem of the national laboratory system that pertains to knowledge inflows from local universities...............213

Figure 6.8: The knowledge management subsystem of the national laboratory system that pertains to knowledge inflows from local technology users.

Figure 6.9: The knowledge management subsystem of the national laboratory system that pertains to knowledge inflows from international sources.............215

Figure 6.10: The knowledge management subsystem of the national laboratory system that pertains to prior knowledge about the core technology 


\section{GLOSSARY OR LIST OF ABBREVIATIONS/SYMBOLS}

NLs $=$ national laboratories

LTUs $=$ Local Technology Users

TLCs $=$ Technology Latecomer Countries

ORDU $=$ Other Research and Development Units (Groups)

LocUniv $=$ Local Universities (Domestic Engagement)

InatSrc $=$ International Sources

PrExp $=$ Prior Experience

$\operatorname{PrKn}=$ Prior Knowledge

PILAs $=$ Project Internal Learning Activities

VLAs $=$ Vicarious Learning Activities

CLAs $=$ Contextual Learning Activities

NIS = National Innovation System

$\mathrm{IP}=$ Intellectual Property

NPSD $=$ New Product and Service Development

$\mathrm{RG}=$ Research gap

$\mathrm{RQ}=$ Research question

$\mathrm{HP}=$ Hypothesis

$\mathrm{DV}=$ Dependent variable

$\mathrm{IV}=$ Independent variable

FIV $=$ Factor of independent variables

$\mathrm{MV}=$ Moderating variable

$\mathrm{FMV}=$ Factor of moderating variables

NLKMS = National Laboratories Knowledge Management System

NLKMSS $=$ National Laboratories Knowledge Management Subsystems 


\section{INTRODUCTION}

\subsection{RESEARCH PROBLEM}

The national laboratories (NLs) in countries that are latecomers to advanced technological development are considered a significant source of scientific knowledge and technology for local industries that the national government deems strategic and for public agencies that are engaged in developing the country's infrastructure (e.g., L. Kim, 1997; P. L. Chang \& Hsu, 1998; Arnold et al., 1998; Gu, 1999; Intarakumnerd et al., 2002; Mazzoleni \& Nelson, 2007). In these countries, most private industrial firms and government agencies lack the financial and human capital to perform applied research and to develop technologies internally (L. Kim, 1993; Hou \& Gee, 1993; Intarakumnerd et al., 2002; Hipkin, 2004; Chaminade \& Vang, 2008). Therefore, the primary mission of the national laboratories is to adopt foreign (Arnold et al., 1998; King \& Nowack, 2003; Fu et al., 2011) and domestic (Nass et al., 2007; Mazzoleni \& Nelson, 2007; Fu et al., 2011) technological knowledge and adapt it to the needs of critical local users of technology (Howells, 1990; Lall, 1992; Mazzoleni \& Nelson, 2007). Local technology users (LTUs) in private industry rely on the availability of this customized knowledge to provide products and services for domestic consumption and for export (L. Kim, 1993; Hou \& Gee, 1993). Their profitability and international competitive position consequently depend upon how well the national laboratories perform their mission of knowledge adoption and adaptation. 
The national laboratories (NLs) in technology latecomer countries (TLCs) perform two other critical missions as well. They build capabilities in research and development that exceed the LTU's current needs, in order to generate an experience base for the demands of the future, when the country desires to be at a much more advanced level of economic and technological development (Mazzoleni \& Nelson, 2007). They also perform a mission in their own right - they transfer technology that they develop, providing the national laboratories with a source of revenue (Arnold et al., 1998).

To succeed at these three missions, the national laboratories must obtain knowledge from external sources by engaging in learning activities that span organizational boundaries (Ancona \& Caldwell, 1992; Freeman, 1995; Lundvall, 1992b; Lundvall, 2010). They must subsequently combine the knowledge gained from these inflows with knowledge that is already present or being created within their organizations and project groups. The resulting knowledge is integrated into the technologies that the national laboratories customize and subsequently transfer to LTUs; the technologies that they develop and commercialize; or the research capabilities that they build up for the future of the nation.

The national laboratories in technology latecomer countries are much more dependent on external sources of knowledge than their counterparts in more advanced countries because they have accumulated insufficient knowledge and experience to develop advanced technologies internally (L. Kim, 1993; Hou \& Gee, 1993; Intarakumnerd et al., 2002; Hipkin, 2004; Chaminade \& Vang, 2008). This deficit in internal expertise inhibits their ability to absorb knowledge from external sources (W. M. Cohen \& Levinthal, 1990; Lane \& Lubatkin, 1998; Zahra \& George, 2002; Mowery \& Oxley, 1995; Keller, 
1996; Todorova \& Durisin, 2007). As a result, the gap in performance between the national laboratories in technological latecomer countries and their counterparts in the more developed countries may be larger than one would expect.

If the national laboratories do not manage their knowledge inflows successfully, then they cannot succeed at the three previously mentioned critical missions. The knowledge that the NLs accumulate, the technologies that they develop for commercialization and the research capabilities that they build up for the future remain within their institutional boundaries and do not transfer to the organizational entities that put them to use. Or, even worse, the NLs may not even be able to adopt the scientific and technological knowledge that they need to customize for their LTUs. In either case the LTUs, the primary customers of the NLs, would not benefit from the efforts of the NLs. A substantial portion of the budget of the NLs would be regarded as misallocated, ${ }^{1}$ and the purpose of NLs in TLCs could be called into question.

Given the important role the national laboratories play in the economy of technology latecomer countries, it can be argued credibly that the performance of national laboratories has a significant impact on the welfare of the population and national economic development (Park, 1998; Mazzoleni \& Nelson, 2007; Fu et al., 2011). One would therefore surmise that the impact of knowledge inflow on the performance of national laboratories would be well understood, or at least have been a subject of

\footnotetext{
${ }^{1}$ In TLCs, gross domestic expenditure on research and development (GERD) amounts to about $0.25 \%$ of GDP, and the annual budgets for NLs constitute about 40\% of GERD (UNCTAD, 2005; UNESCO, 2011). A misallocation of a substantial portion of the budget of the NLs could be on the order of hundreds of millions of dollars over a period of a few years.
} 
extensive study. Yet, surprisingly, this is not the case. Instead, most studies related to the roles of national laboratories in latecomer countries have been investigated at the system level of national innovation by analyzing a single case (L. Kim, 1993; Intarakumnerd et al., 2002; P. K. Wong, 2003; Hadjimanolis \& Dickson, 2001) or by using multi-case analysis (Nelson, 1993; Dahlman \& Nelson, 1995; Arocena \& Sutz, 2000; Arocena \& Sutz, 2005; Gu, 1999; Lundvall et al., 2002). Some potential success factors have been identified (Arnold et al., 1998; Gu, 1999; Intarakumnerd et al., 2002; Mazzoleni \& Nelson, 2007), but not validated. It can thus be argued that the exogenous factors that drive the successes of national laboratories are not really understood to the extent where the NLs can prevent gross misallocation of resources, build up an enhanced national research capability or generate substantial revenue from commercializing technology that they have developed. Opportunities to investigate how external engagement by national laboratories impacts their performance consequently do not just abound - the need to conduct such research is compelling. 


\subsection{KNOWLEDGE INFLOWS}

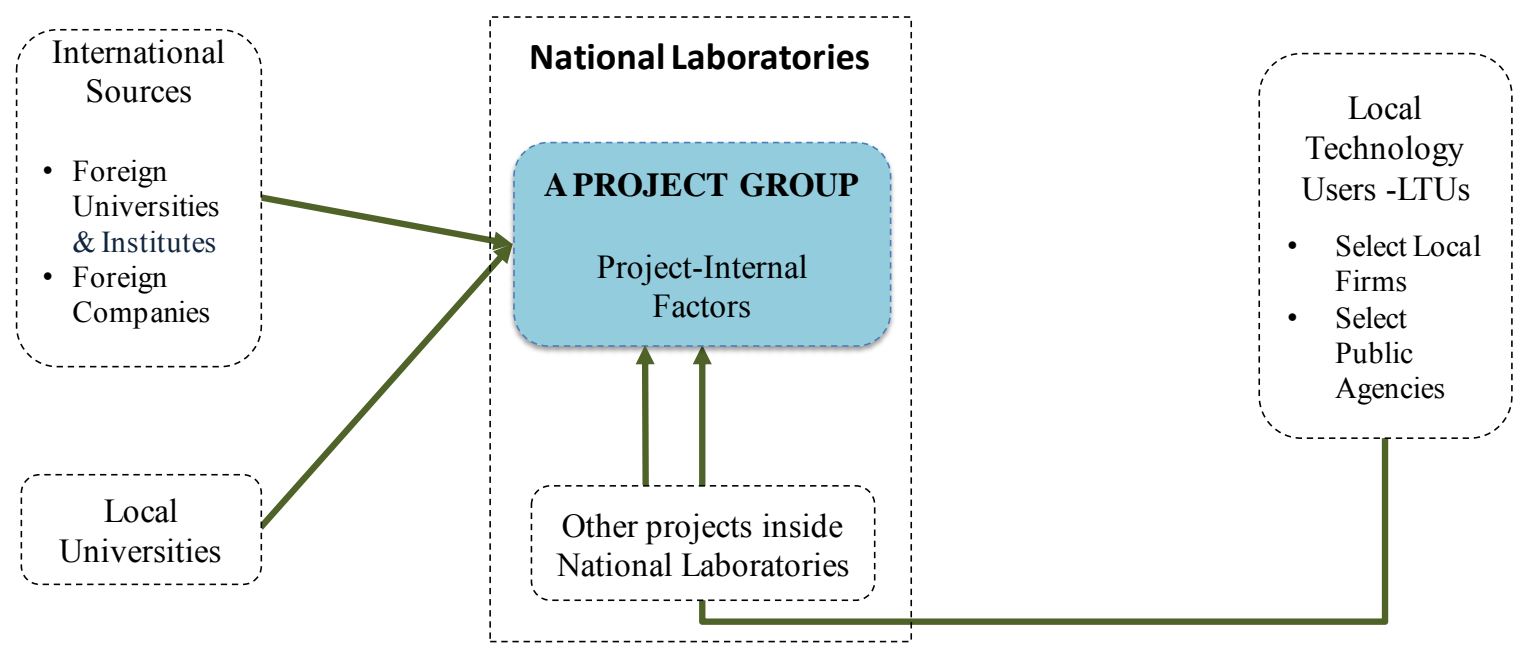

Figure 1.1: Sources of knowledge for a project group within the national laboratories in technology latecomer countries.

(integrated from Utterback, 1975; Mazzoleni \& Nelson, 2007; Hoekman et al., 2005; Encarnação, 2007; Lundvall, 2010; Ancona \& Caldwell, 1992).

Figure 1.1 depicts the critical sources of knowledge that are available to a project group within the national laboratories in technology latecomer countries. The arrows indicate knowledge inflows into a particular project group within the national laboratories. Figure 1 shows that knowledge can come from within the project group itself. It could have been available to the group prior to the beginning of the project (Huber, 1991), or it can be created by deliberate learning efforts while the project is ongoing (e.g., Adler \& Clark, 1991; Bohn, 1994; Lapré et al., 2000; Edmondson et al., 2003). Other projects within the national laboratories can serve as sources of knowledge, if project groups within the NLs 
engage in learning activities that span organizational boundaries (Ancona \& Caldwell, 1992; Freeman, 1995; Lundvall, 1992a; Lundvall, 2010). Knowledge can flow into project groups within the NLs from sources that are outside the NLs but within the country's national innovation system. These sources include local universities that provide local scientific and technological knowledge, as well as the LTUs, which provide feedback on the technologies that the NLs deliver and information about the use environment (von Hippel, 1988) of these technologies. ${ }^{2}$ Sources outside the national innovation system include foreign universities, national laboratories in other countries and multinational corporations (MNCs).

\subsection{PURPOSE OF DISSERTATION}

The purpose of this dissertation is to investigate how knowledge inflows into the national laboratories of technological latecomer countries affect the performance of national laboratories. In particular, I would like to identify factors pertaining to knowledge inflows that determine the success or failure of research projects in the national laboratories of latecomer countries. I am thus effectively addressing the following management question: "How can managing knowledge inflows improve the performance of research projects at the national laboratories in technological latecomer countries?"

\footnotetext{
${ }^{2}$ The academic literature does not consider local technology providers from the private sector that are not local technology users as a critical source of knowledge to the national laboratories in technology latecomer countries.
} 
The success of a national laboratory is contingent upon the number of research and development projects that it completes and the perceived impact that these projects have on the bottom-line of LTUs and the wellbeing of the country at large (L. Kim, 1980; L. Kim, 1997; P. L. Chang \& Hsu, 1998; K. Lee \& Lim, 2001). I consequently make the $R \& D$ project my unit of analysis, and I try to identify the factors that make these projects successful. My primary focus is to identify the success factors that involve knowledge inflows. However, I include sources of internal knowledge in my study, because they tend to impact the relationship between knowledge inflow and the performance of the research project. I am primarily interested in ranking the relative impact of success factors that affect the performance of research projects within national laboratories. This ranking will give project managers the ability to develop a strategy for engaging effectively with the various sources of knowledge that affect the project's performance. The managers will be able to prioritize their engagement with the various sources of knowledge that are at available to them.

It is well known that an organization's internal knowledge or internal learning activities can enhance the organization's capacity to absorb knowledge from external sources (W. M. Cohen \& Levinthal, 1990; Kogut \& Zander, 1992; Lane \& Lubatkin, 1998; Zahra \& George, 2002; Mowery \& Oxley, 1995; Keller, 1996; Todorova \& Durisin, 2007; Griffith \& Sawyer, 2009; Nemanich et al., 2010), and in an organization as complex as the national laboratories the sources of external knowledge and the sources of internal knowledge can be highly diverse. A study of knowledge inflows into the national laboratories must therefore consider the possibility that some forms or internal 
knowledge enhance the absorptive capacity for certain types of external knowledge more than others do. Some interactions could even diminish the capacity to absorb external knowledge. The performance of the national laboratories could thus depend upon a plethora of interactions between its various internal and external sources of knowledge. These interactions and their impact on performance have yet to clearly articulated or subjected to rigorous academic study, even though doing so could make a significant contribution to management practice. An improved understanding of which interactions have the strongest impact on performance would give the managers of the national laboratories a toolkit of micro-levers that they can pull selectively to achieve specific goals. It is also the purpose of this dissertation to identify these micro-levers.

\subsection{DISSERTATION OUTLINE}

The organization of the dissertation consist of an introduction, a literature review that leads to a conceptual framework, a set of testable hypotheses, a discussion of research methods, a chapter that presents the results of the study and another that presents its conclusions. The final chapter will identify some of the study's limitations. It will also review the study's contributions, discuss theoretical and practical implications of the study and make suggestions for further research.

\subsubsection{Chapter 1 - Introduction}

Chapter 1 familiarizes the reader to the dissertation topic. The first section describes the research problem, and the second introduces the concept of knowledge flows. Both 
sections argue that the study that the dissertation proposes should be performed. The purpose of the dissertation is discussed in the third section. The fourth section presents an outline of the dissertation.

\subsubsection{Chapter 2 - Literature Review}

Chapter 2 explains the academic background of the study. The literature review in this chapter covers six sections. The first section reviews the three missions of NLs within the National Innovation System (NIS) of technological latecomer countries (TLCs) in order to understand the purposes of NLs and how NLs assess their successes. The second section reviews sources of knowledge and pathways to gain knowledge from both internal and external sources of NLs in TLCs. The purpose of this section is to identify sources and pathways of knowledge inflows into NLs in TLCs. The third section discusses broadly based issues pertaining to how obtaining knowledge from external sources impacts the performance of research and development units at the organization level and at the project level. The purpose of this section is to show how prior studies have measured the impact of external knowledge on organizational performance. This section also identifies the overriding academic research gap for this dissertation. The fourth section of chapter 2 reviews factors that impact knowledge inflows at the project level. The purpose of this section is to refine the focus of this dissertation to the project level and to identify related gaps in the academic literature. The fifth section presents the theoretical framework that has emerged from the literature search. The empirical study that I shall conduct as part of this dissertation tests this theoretical framework. The sixth 
section summarizes the research gaps that have been identified in the literature review and states the research questions that pertain to these gaps.

\subsubsection{Chapter 3-Hypotheses}

Chapter 3 identifies the research hypotheses that will be tested empirically in this dissertation.These hypotheses focus on howknowledge inflows impact the performance of R\&D projects at the NLs in TLCs. In these hypotheses the degree of engagement with the source of external knowledge acts as a proxy measure for the amount of knowledge that flows into a particular project group from a particular source. Four external sources of knowledge will be considered: other R\&D project groups within NLs, local universities, local technology users (LTUs) and international sources of knowledge. In addition, this chapter sets up hypotheses pertaining to the degree that internal knowledge (knowledge that resides within or is created within the project group that performs the $R \& D$ ) influences the impact of external knowledge on the performance of $R \& D$ projects.

\subsubsection{Chapter 4 - Research Methods}

Chapter 4 describes the research methhods that I use in my dissertation. This description includes discussions of the unit of analysis (R\&D project groups); the setting of the study (the national laboratories of Thailand); variables and measures; data collection (survey plus interviews with project managers and project evaluators); validity and reliability; and the approaches to data analysis that are deployed in the study (factor analysis and a hierarchical approach to multiple regression). 


\subsubsection{Chapter 5 - Results}

Chapter 5 of this dissertation presents the results of the empirical study. The first section displays and describes the descriptive statistics. The second section details the output of a factor analysis that was performed on the predicting variables and a correlation matrix of predictors and output variables that reflect performance. The third section benchmarks the explanatory power of the multiple regressions and the logistic regressions that were conducted for each performance metric. The fourth section discusses the results of the hypothesis tests that characterize how factors that pertain to knowledge inflow and factors that pertain to internal knowledge affect performance. The fifth section discusses the interactions between these factors.

\subsubsection{Chapter 6 - Conclusions}

Chapter 6 draws conclusions by synthesizing quantitative results from chapter 5 with data that was obtained from interviews with project managers and project evaluators. In the first section, I draw conclusions that are specific to the setting of my study. In the second section, I present the overarching conclusion of this dissertation-a framework for knowledge flows for the part of the national innovation system that pertains to the national laboratories. In the third section, I conclude that absorption of knowledge is selective-it depends on the source of external knowledge, the source of internal knowledge enables the absorption of knowledge, the interaction between those sources, the type of knowledge inflow and the mission to which it is applied. I argue that knowledge flows, as they pertain to the national laboratories, can be organized into 
knowledge subsystems of the national innovation systems, which can be managed at a relatively low level within the national laboratories. In the fourth section, I present the knowledge subsystems that are associated with each of the output variables of my research, and I draw conclusions that are specific to each of the three primary missions of the national laboratories. The fifth section discusses the alignment of the mission-specific criteria and their linkage to organizational ambidexterity (e.g., Tushman \& O'Reilly, 1996). In the sixth and final section, I present conclusions about the knowledge subsystems of the national laboratories system that pertain to specific sources of knowledge, and I discuss the relative importance of external and internal sources of knowledge.

\subsubsection{Chapter 7 - Summary, Contributions and Limitations}

I summarize my research in the last chapter of my dissertation. In the first section, I restate the research questions and report on how they have been addressed by the findings of my research. In the second section, I examine the theoretical implications of the findings from my study. I discuss how this dissertation has contributed to academic research in various sub-fields of technology management and in other, related fields of study. In the third section, I show how findings from this dissertation have revealed management practices that are particularly useful for national research laboratories in technological latecomer countries. In the fourth section, I discuss how findings from this dissertation may have implications for national policy in technological latecomer countries, yet I make the argument that the findings of my study can be generalized beyond technological latecomer countries and beyond the national laboratories setting, if 
proper follow-on studies are conducted. In the fifth section, I identify some of my study's limitations, and I suggest how they can be overcome through further research using methods that I have in part developed in this dissertation. In the last section, I describe the methods contribution that should enable these follow-on studies. 


\section{LITERATURE REVIEW}

The management question that motivates this dissertation is: "How can managing knowledge inflows improve the performance of research projects at the national laboratories in technological latecomer countries?" This question is viewed in the context of the three most important missions of national laboratories (NLs) in technological latecomer countries (TLCs), which have been identified as

1) Adopt foreign and domestic technological knowledge and adapt it to the needs of critical LTUs;

2) Generate revenue for themselves by commercializing technology that they have developed; and

3) Build R\&D capabilities for the future needs of the country. This context raises a series of issues, which have been debated in the academic literature. ${ }^{3}$

${ }^{3}$ The following issues, which are addressed in section 2.1, are of particular interest to practicing managers within the NLs in TLCs:

1) How do NLs affect new product and service development in TLCs? (Mission 1)

2) How do NLs in TLCs generate revenue for themselves from the technology that they develop? (Mission 2)

3) How do NLs in TLCs retain and enhance their capabilities for the benefit of national technological and economic development? (Mission 3)

My focus on knowledge inflows raises the following issues, which are addressed in section 2.2:

4) What is the nature of the sources of knowledge for project groups within the NLs in TLCs?

5) What are the pathways for knowledge inflow into the project groups within the NLs in TLCs?

My research also raises some broadly based issues pertaining to knowledge inflow in research and product development, which are addressed in sections 2.3 and 2.4.

6) How does managing knowledge inflow impact the performance of research organizations and development organizations (section 2.3)?

7) How does managing knowledge inflow improve the performance of research and development at the project level (section 2.4)?

8) What factors are important to managing knowledge flow? For example, what organization-internal factors enable or hinder knowledge inflows, knowledge outflows and technology transfer (section 2.4)? 
In the review of the academic literature that follows, I hope to identify gaps in knowledge that warrant further scientific study. From these gaps, I shall generate research questions for my dissertation. The major contributions of this dissertation will be closing the gaps in knowledge that I identify in this chapter, and addressing the research questions that they generate.

In the following sections, I discuss each of the abovementioned issues one by one, and I identify the literature stream in which the issue has been discussed. The discussion of each issue leads to a model of the issue that is grounded in literature. At the end of the literature review, these individual models are assembled into a model of how knowledge flows into and out of the national laboratories of technology latecomer countries. This model will be tested in the empirical study that I propose for my dissertation.

\subsection{THE NATIONAL LABORATORIES WITHIN THE NATIONAL INNOVATION SYSTEMS OF TECHNOLOGY LATECOMER COUNTRIES ${ }^{4}$}

To succeed at their three critical missions, the national laboratories, in TLCs and elsewhere, must be linked to and interact effectively with their national innovation systems (NIS), "the network of institutions in the public and private sectors whose

\footnotetext{
${ }^{4}$ In this section of the literature review, I look at the role that national laboratories play within the national innovation systems of technology latecomer countries. I focus on the three critical missions of the NLs in TLCs. I address issues that are of particular interest to the managers of NLs in TLCs: how do NLs affect new product and service development in TLCs; how do NLs in TLCs retain and enhance their capabilities for the benefit of national technological and economic development; and how do NLs in TLCs generate revenue for themselves from the technology that they develop? Most of the articles that are reviewed in this section come from the literature on national innovation systems. However, I also draw on the literature on technology transfer, absorptive capacity and new product development.
} 
activities and interactions initiate, import, modify and diffuse new technologies" (Freeman, 1987, as cited by OECD, 1997). These linkages and interactions, within and across organizations that are located within or rooted inside the borders of a nation state, are a prerequisite for success in innovation - they produce, diffuse and use new economically useful knowledge (Lundvall, 1992a, p. 325). These linkages may be technological, commercial, legal, social and financial in nature, and they facilitate the "development, protection, financing or regulation of new science and technology" (Niosi et al., 1993 p. 139). As a result, "the interactions of these institutions determine," to a significant degree, "the innovative performance of national firms" (Nelson, 1993 p. 4). They are also said to enhance the national absorptive capability (Dahlman \& Nelson, 1995; Lall \& Narula, 2004; Narula, 2004; Roper \& Love, 2006), which Dahlman and Nelson (1995, p. 88) define as "'the ability to learn and implement the technologies and associated practices of already developed countries." The linkages and interactions within national innovation systems are critical to national economic development, because they improve learning efficiency, which is the source of innovativeness of a nation (Nelson \& Rosenberg, 1993; Lundvall, 1992a). They also allow innovation to occur more rapidly and in a direction that meets the needs of the people of the country (European_Commission, 2009).

The institutions within the national innovation system may vary by economic structure of each country, but normally include private industrial firms, the public sector, the financial sector and public research organizations (Lundvall, 2010, p. 14). Private firms can be local companies or multi-national corporations. They are considered production units 
that engage in interactive learning across organizational boundaries (B. H. Johnson, 1992). The public sector helps shape the institutional set-up and the overall structure of production within the NIS, and it will engage in occasional intervention. Its primary role is to promote self-organized learning by the various institutions that comprise the national innovation system; the intent is to make the NIS more open the rest of the world (Dalum, 1992). The public sector may also play the role of a very large user of various products, especially in situations of high technological uncertainty and market risk (Gregersen, 1992 in Lundvall 1992, pp. 133-150). It can also act as a competent lead user (von Hippel, 1986) that is able to communicate use information in a form that helps the providers of technology, the NLs, to adapt technology to the needs of mainstream users (Lundvall, 1985 cited by Gregersen, 1992; 2010, p. 134). Financial institutes are a source of loans for innovation. Government may collaborate with financial institutions to provide special interest rates or credit for investment in innovation (Christensen, 1992, pp. 146-168). Finally, public research organizations including universities and national laboratories act as sources of technology within NIS (Freeman, 1992, pp. 169-186).

Continuous interaction with the various elements of the national innovation system allows industrial firms continuously upgrade their technological competences. Unless they do so, "their profits and growth are likely to decline as markets continue to be captured by innovative firms in competitor nations. The speed and effectiveness of the flows of innovation into firms are critical determinants of the economic success not only of individual firms but also of groups of firms, localities and regions, nations and trading blocs of nations" (Dodgson \& Bessant, 1996, p. 11). Dodgson and Bessant (1996) also 
argue that effective innovation consists of an exchange of "knowledge of innovation between the 'science base' of research and development undertaking bodies -- higher education institutes, private and public sector research and technology organizations -and industrial firms," as well as "between firms of different sizes and character." Such exchanges are "essential for all these different economic agents to build up the competences they need to differentiate themselves in markets, and thereby to be competitive." (ibid, 1996, p. 11)

National governments in technology latecomer countries have been trying to advance national innovation systems as a framework for economic and social development (Nelson, 1993; Gu, 1999; Arocena \& Sutz, 2000; Lundvall et al., 2002; Intarakumnerd et al., 2002; Mazzoleni \& Nelson, 2007), as they believe that the potential of science and technology will lead to economic and social development in their countries (Gu, 1999). Government policies in TLCs are also designed to enhance the national absorptive capability (Dahlman \& Nelson, 1995; Lall \& Narula, 2004; Narula, 2004; Roper \& Love, 2006), allowing innovation to occur more rapidly and in a direction that meets the needs of the people of the country (European_Commission, 2009). The national laboratories in TLCs act as an enabler of technology within the TLC's national innovation system, like they do in many more advanced countries (Freeman, 1992, 2010, p. 173). In the process, they tend to play a lead role in the implementation of science and technology policies that the government considers beneficial to both the public sector and private industry (Nelson \& Rosenberg, 1993). 
The national laboratories in technology latecomer countries are much more dependent on external sources of knowledge than their counterparts in more advanced countries because they have accumulated insufficient knowledge and experience to develop advanced technologies internally (L. Kim, 1993; Hou \& Gee, 1993; Intarakumnerd et al., 2002; Hipkin, 2004; Chaminade \& Vang, 2008). This deficit in internal expertise inhibits their ability to absorb knowledge from external sources (W. M. Cohen \& Levinthal, 1990; Lane \& Lubatkin, 1998; Zahra \& George, 2002; Mowery \& Oxley, 1995; Keller, 1996; Todorova \& Durisin, 2007). As a result, the gap in performance between the national laboratories in technological latecomer countries and their counterparts in the more developed countries may be larger than one would expect.

The overall performance of national laboratories in technology latecomer countries depends upon how well they succeed at their three most important missions. If the NLs perform their first mission well, then they enhance LTUs ability to develop new products and new services both rapidly and effectively (Dodgson \& Bessant, 1996). If the NLs do well at the second mission, they are able to supplement their budget for discretionary activities. $^{5}$ If NLs in TLC perform the third mission well, then the NLs retain and enhance their own R\&D capabilities. These enhanced capabilities are expected to contribute to an accelerated national innovation rate that speeds up the technological and economic development of the TLC (L. Kim, 1980; L. Kim, 1997; K. Lee \& Lim, 2001). The performance of the national laboratories in technological latecomer countries must

\footnotetext{
${ }^{5}$ This allows them, for example, to provide incentives for researchers who are performing well in current R\&D projects to continue to do so (personal conversation with Dr. Kwan Sitathani, National Electronics and Computer Technology Center, Thailand).
} 
therefore be defined multi-dimensionally, for success at one mission may compromise another.

\subsubsection{Mission 1: Adopt and Adapt}

The national laboratories (NLs) in technological latecomer countries (TLCs) are an essential, exogenous component of the product development process of the local technology users (LTUs). The LTUs sequentially engage in idea generation, knowledge sourcing, R\&D activity and commercialization (see figure 2.1), in a manner that has been described extensively in the new product development literature (R. G. Cooper \& Kleinschmidt, 1986; R. G. Cooper, 1994; Ulrich \& Eppinger, 1995). At each stage, they also respectively absorb new ideas, new knowledge and new technologies from external sources, in the manner described by H. Kim \& Park, 2010. The national laboratories frequently act as an external source of these ideas, this knowledge and these technologies (W. M. Cohen et al., 2002), and the technology transfer literature suggests that they can flow from the NLs to the LTUs in at least 17 ways (see appendix A). The national laboratories also serve as "a domestic base of good scientists that can provide the basis for breaking into the international networks where new technologies are being originated" (Mazzoleni \& Nelson, 2007). Thus the NLs can act as a channel for LTUs to gain access to cutting-edge technology from international sources (Hemmert, 2004).However, to fulfill mission 1, the NLs in TLCs must develop technology that fits local requirements (Arnold et al., 1998) and can be absorbed by the LTUs (Intarakumnerd et al., 2002). The NLs integrate ideas, knowledge and technologies, and customize it for the needs of the LTUs prior to transfer (P. L. Chang \& Hsu, 1998; K. Lee 
\& Lim, 2001). The LTUs can develop radical/breakthrough innovations (Fey \& Birkinshaw, 2005)or improve their existing product lines incrementally, if they have the ability to absorb ideas, knowledge and technologies from external sources (Intarakumnerd et al., 2002; P. L. Chang \& Hsu, 1998; K. Lee \& Lim, 2001).

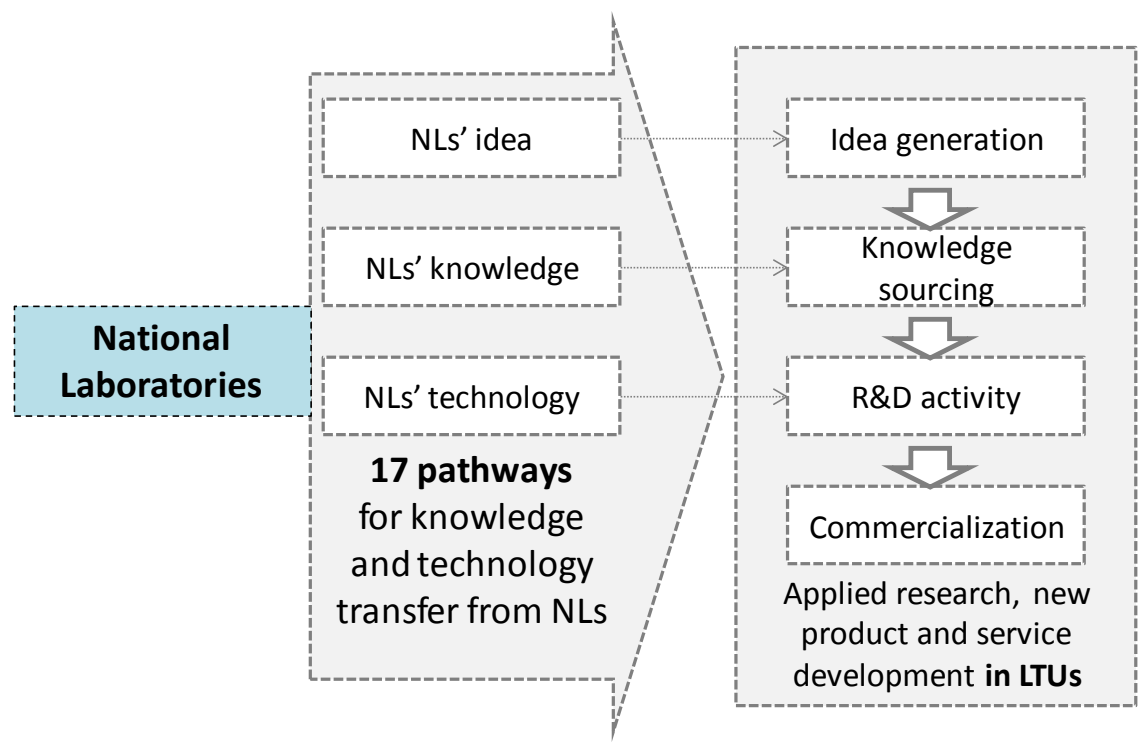

Figure 2.1: Integrating NLs with the innovation process of LTUs (adapted from H. Kim \& Park, 2010)

A variety of successful cases of adoption and adaptation by NLs have been discussed in the literature on national innovation systems (Freeman, 1992; Arnold et al., 1998; Lundvall, 1992a; Mazzoleni \& Nelson, 2007). In these successful cases, the NLs usually started to build their technological capabilities via assimilation and adaptation of foreign technology. They subsequently developed internal technological capabilities in designing and engineering that were considered a good fit with the technological demands of local industries, whose firms had developed the capabilities that were required to absorb the 
technologies from the NLs (Intarakumnerd et al., 2002; P. L. Chang \& Hsu, 1998; K. Lee \& Lim, 2001). For example, the Korean Institute of Science and Technology (KIST), established in 1966, was the result of collaboration between Korean national government and the Battelle Institute in the USA. KIST activities were aimed to ensure that government research projects can support the demands of local industries such as shipbuilding, steel and machinery industry (Dong-Won \& Leslie, 1998; Mazzoleni \& Nelson, 2007). A similar strategy was presented in the semiconductor industry in Taiwan. During the 1970s and 1980s,Taiwan's Industrial Technology Research Institute (ITRI) played a critical role in promoting technological collaboration with U.S. firms to adopt advanced technological knowledge from them and subsequently develop local technological capabilities in designing and engineering (P. L. Chang \& Hsu, 1998). The Brazilian Agricultural Research Corporation (EMBRAPA) was established in 1972 to coordinate R\&D activities and develop linkages between Brazilian research centers and foreign research centers. R\&D activities under EMBRAPA were aimed at adapting the research results from collaboration at national level to match the local production system (Mazzoleni \& Nelson, 2007). Biodiesel technological development is an example of the successful R\&D collaboration under EMBRAPA (Nass et al., 2007).

\subsubsection{Mission 2: Technology Commercialization}

Based on the technology transfer literature, ten out of the 17 pathways through which knowledge and technology transfer out of NLs by the means discussed in mission 1, can be channels through which the NLs can commercialize their knowledge and technologies. 
According to the technology transfer literature, commercialization can occur prior to or after conducting their R\&D activities (see appendix A).

Prior to conducting $R \& D$ activities, the NLs are likely to gain revenue from

- contract research (J. Lee \& Win, 2004);

- joint research between the NLs and LTUs (Zucker et al., 2002; Kulve \& Smit, 2003; J. Lee \& Win, 2004; Liu \& Jiang, 2001); or

- cooperative R\&D between NLs and LTUs (Rogers et al., 2001; Carayannis \& Gover, 2002; Agrawal, 2002; del Campo et al., 1999; Guan et al., 2006; Liu \& Jiang, 2001).

The channels through which R\&D organizations can commercialize their knowledge and technology after conducting their research and development include

- technology licensing (Rogers et al., 2001; Petroni \& Verbano, 2000; King \& Nowack, 2003; Feller et al., 2002; Agrawal, 2002; Feldman et al., 2002; Shane, 2002; Chapple et al., 2005; J. Lee \& Win, 2004; Siegel, 2004; Bercovitz, 2006; del Campo et al., 1999);

- consultancy services (Agrawal, 2002; Guan et al., 2006);

- services pertaining to seminars and conferences (Agrawal, 2002; J. Lee \& Win, 2004);

- training services (Hong, 1994; Guan et al., 2006);

- services pertaining to technology and business incubators (Phillips, 2002; Lofsten \& Lindelof, 2003; Markman et al., 2005); and 
- services in technology parks, science parks and other R\&D facilities (Lofsten \& Lindelof, 2003; Petroni \& Verbano, 2000; Markman et al., 2005; Liu \& Jiang, 2001; Feller et al., 2002).

In technology latecomer countries, commercialization acts as an alternative pathway through which NLs can benefit from technology that they have developed but that the LTUs will not develop.

\subsubsection{Mission 3: Retain and Enhance National Competitiveness}

The national laboratories (NLs) have served as a backbone to provide advanced research and development for the future needs of local technology users (LTUs) (L. Kim, 1997). On the one hand, the NLs in TLCs typically set up R\&D projects to solve current problems in existing technology areas (as discussed in mission 1). On the other hand, the NLs in TLCs need to initiate advanced R\&D projects to prepare for future problems in new technology areas, which tend to have a high risk of failure but provide a high economic impact. The NLs need to initiate highly advanced R\&D projects that are focused on elevating the long-term technological capability of LTUs (L. Kim, 1997, pp. 50-51). This approach allows NLs in TLCs to retain and enhance national competitiveness in science and technology. 
The level of technological capability ${ }^{6}$ of LTUs in TLCs tends to be at the level of technological imitators. LTUs in TLCs tend to acquire mature technology from abroad, and then implement it in their production process (L. Kim, 1980). At this stage, NLs may help LTUs in executing the acquisition, assimilation and improvement of the mature technology from the advanced technological countries (P. L. Chang \& Hsu, 1998). ITRI, for example, acquired medium-scale integrated (MSI) circuit process technology from abroad, and assimilated it to produce products that were differentiated from the foreign products that they were imitating.

Next, to sustain their competitiveness, LTUs need to make a few internal efforts induce technological change in both products and processes. However, LTUs in TLCs tend to lack the requisite technological capabilities and market incentives to develop their own technologies (L. Kim, 1980, p. 258). The LTUs also have inadequate advanced industrial research experience and perform only incremental and reactive learning (L. Kim, 1997, p. 85). At that stage of national economic development, the NLs have to take on the role of continuously accumulating internal technological capabilities that can help the LTUs continuously improve their products, process and services, or perhaps even generate radical innovation (L. Kim, 1997; P. L. Chang \& Hsu, 1998). ITRI, for example, built up technological capabilities to develop large-scale integrated (LSI) circuits, very large-scale integrated (VLSI) circuits, and ultra-large-scale integrated (ULSI) circuits to serve future

\footnotetext{
${ }^{6}$ Technological capability is determined by a function of prior knowledge and technological effort in research and development (L. Kim, 1997). Technological capability is generated as a by-product of a research and development activities particularly when advanced technological knowledge is less explicit, less codified, and more difficult to assimilate. According to L. Kim (1997, p.93), "the more difficult learning is, the more knowledge has to have been accumulated via R\&D for effective learning to occur".
} 
demands of their targeted industry after the successful adoption of medium-scale integration (MSI) (P. L. Chang \& Hsu, 1998).

As a technology producer within TLCs, the NLs must also take on an important role in helping LTUs retain and enhance their competitiveness, particularly in industries or technologies that have been targeted for development by their national governments (L. Kim, 1997; P. L. Chang \& Hsu, 1998). NLs typically help LTUs improve their technological capability by sponsoring and conducting research and development projects within the NLs and transferring them output of these projects to the LTUs.

\subsubsection{Summary of Section}

Figure 2.2 summarizes the findings of this section. The NLs' first mission as a technology adopter drives them to focus on adopting technological knowledge from abroad and adapting it to the LTUs' requirements for the benefit of the LTUs. NLs transfer many of the processes, products and services they have developed to the LTUs via 17 known pathways (see appendix A). The second mission, which is aimed at the commercialization of technology, drives the NLs to focus on generating revenue from the technologies that they have developed for the benefit of their own organizations. The NLs can commercialize these technologies and transfer them to the LTUs via 10 pathways. The NLs' third mission as a technology producer drives the NLs to build up their internal capabilities in research and development for retaining and sustaining national competitiveness in science and technology, i.e. the national laboratories are working for the future of the country. This knowledge also tends to be retained and flow within the 
NLs. It is embedded within individual researchers and project groups who have performed the abovementioned $\mathrm{R} \& \mathrm{D}$, and it acts as a form of prior knowledge that can be used in future projects.

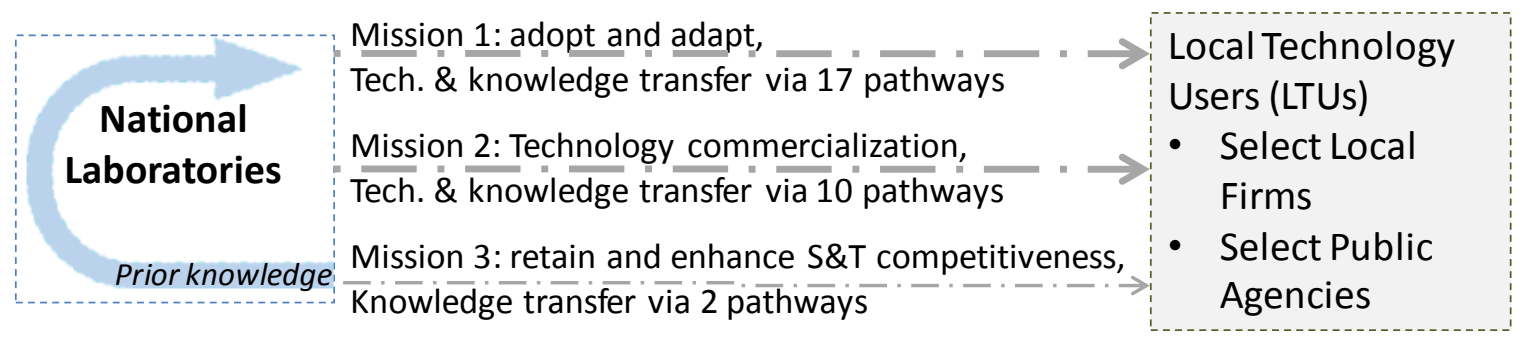

Figure 2.2: The pathways for knowledge and technology flow out of NLs for each mission

To succeed in the three missions, the NLs need to deliver many successful R\&D projects. They need to establish and strengthen their internal technological capability by setting up internal research and development projects. Internal R\&D project groups are considered as a source of internal knowledge that allows NLs to builds up their internal absorptive capacity (W. M. Cohen \& Levinthal, 1990). However, the NLs also need to engage with external sources of knowledge for acquiring new knowledge. The following section will discuss the internal and external sources of knowledge and the pathways through which NLs in TLCs can obtain knowledge. 


\subsection{EXTERNAL AND INTERNAL KNOWLEDGE FOR NATIONAL LABORATORIES IN TECHNOLOGY LATECOMER COUNTRIES ${ }^{7}$}

The sources of knowledge that are available to a project group at the national laboratories can come from inside the project group that is working on the projector from external sources of knowledge. The external sources include other project groups inside NLs, as well as other institutions both inside and outside national innovation system (NIS). There are two main pathways for obtaining external knowledge: contextual learning activities (CLAs) and vicarious learning activities (VLAs) (Bresman, 2010). The internal knowledge of a project group can be generated through grafting the prior experience of individual members of a project group (Huber, 1991) or from relevant knowledge that the project group has accumulated prior to the inception of an ongoing project (Nemanich et al., 2010). It can also be created by deliberate project internal learning activities that take place while the project is ongoing (e.g., Adler \& Clark, 1991; Bohn, 1994; Lapré et al., 2000, Edmondson et al., 2003). Integrating knowledge that flows into the project group with knowledge from internal sources allows the project group to create new technological knowledge, new technology, or innovative products and services (W. M. Cohen \& Levinthal, 1990).

\footnotetext{
${ }^{7}$ In this section of the literature review, I look at the external sources and internal sources of knowledge for research and development projects at national laboratories (NLs) in technology latecomer countries (TLCs). I focus on the four important sources of external knowledge for the NLs in TLCs, which I describe in detail to provide a better understanding of the sources of knowledge for the NLs in TLCs. I also review the pathways for obtaining external knowledge and mechanisms for generating internal knowledge for the NLs in TLCs. Most of the articles that are reviewed in this section come from the literature on technology transfer and organizational learning. However, I also draw on the literature on national innovation systems, Open Innovation and new product development.
} 


\subsubsection{Sources of External Knowledge}

External knowledge is knowledge that is not created within the project groups. It can flow into project groups within the NLs from other projects inside the NLs, from external sources that are outside NLs but inside national innovation system of TLCs, and from sources that are outside national innovation system of TLCs.

\subsubsection{Other Projects inside National Laboratories in Technology Latecomer}

\section{Countries}

Other projects within the national laboratories can serve as a source of knowledge, if project groups within the NLs engage in learning activities that span organizational boundaries (Ancona \& Caldwell, 1992; Haas \& Hansen, 2005; Haas \& Hansen, 2007). Project members may search for technical knowledge of other projects from organization databases (Haas \& Hansen, 2005; Haas \& Hansen, 2007). The project members may also interact with experts of other projects to learn from their experiences (Haas \& Hansen, 2005; Haas \& Hansen, 2007; Bresman, 2010). Knowledge gains from other projects inside NLs tends to allow project groups save time during their tasks (Haas \& Hansen, 2007) and may allow them to integrate technology that fits with customer requirements.

\subsubsection{Institutions inside the National Innovation Systems of Technology Latecomer Countries}

Knowledge can flow into project groups within the NLs from other institutions that are outside the NLs but within their national innovation systems. These sources include local 
universities that provide local scientific and technological knowledge, as well as the LTUs, which provide feedback on the technologies that the NLs deliver and information about the use environment (von Hippel, 1988) of these technologies.

\section{- 2.2.1.2.1Technological Knowledge from Domestic Sources}

A variety of empirical studies have shown that local universities play a preeminent role in technological development within the national innovation system (NIS) (Dahlman \& Frischtak, 1990; Geisler, 1995; Gelsing, 1992; Hou \& Gee, 1993; J. M. Katz \& Bercovich, 1993; L. Kim, 1993; Mowery \& Sampat, 2005; Teubal, 1993; Faulkner \& Senker, 1995; Etzkowitz, 2003). Pavitt, 1998 (p. 796) suggests that local universities provide 1) useful knowledge inputs that can lead directly to prospected applications; 2) engineering design tools and techniques that can help in designing and testing of complex technological systems; and 3) trained scientists and engineers who can apply their knowledge beyond academic research and can help to access to academic community via their informal network. NLs also can access to technological knowledge from local universities via these channels.

In some countries, governments may establish national laboratories to bridge the gap between academic research in university and industrial research in industry (Encarnação, 2007; KIST, 2011; Fraunhofer, 2011). Academic research in local universities tends to be less relevant to the requirements of industry (i.e., Intarakumnerd et al., 2002). Also, some research programs that are high risk tend to require resources on a large scale; need longterm commitment; or demand interdisciplinary $R \& D$ projects. Such programs need to be 
initiated by the national institutes (KIST, 2011). Government may encourage collaboration between local universities and the NLs, which may act as a pathway for knowledge flow from local universities into the NLs.

\section{- 2.2.1.2.2 User Knowledge from Local Technology Users}

LTUs tend to be a critical source of knowledge for research and development projects at NLs. LTUs provide feedback on the technologies that the NLs deliver and information about the use environment (von Hippel, 1988) of these technologies. In an NIS, Lundvall argues "the relationships between public research institutes that produce basic and applied research and industry as a user of science may be fruitfully analyzed as one specific form of user-producer interaction" (Lundvall, 2010, p. 51). The interaction between users and producers tend to create product innovations (Lundvall, 2010, p. 50). It also facilitates the flow of information for the producer (the NLs). There are two types of knowledge in this interaction: technical opportunities and user needs (Lundvall, 1992b). Therefore, LTUs are considered a critical source of external knowledge for NLs.

\subsubsection{Institutions outside the National Innovation Systems of Technology Latecomer}

\section{Countries}

Knowledge can flow into project groups within the NLs from sources outside their national innovation systems include foreign universities, national laboratories in other countries and multinational corporations (MNCs). At the country level, a latecomer country can access the international sources of technological knowledge by engaging in international technology transfer. The pathways for international technology transfer into 
a technological latecomer country include foreign direct investment (FDI) by multinational corporations (MNCs) (Hoekman et al., 2005; Simango, 2000; Guan et al., 2006; King \& Nowack, 2003; Farhang, 1997), movement of people from MNCs to local industries or from one country to another (Hoekman et al., 2005; Ploykitikoon \& Daim, 2010; Chen \& Sun, 2000; Gil et al., 2003), import of equipment and instruments (Hoekman et al., 2005) and technology licensing (King \& Nowack, 2003; Salicrup \& Fedorkova, 2006; Hoekman et al., 2005).

Moving people from one entity to another tends to be a major channel through which NLs in TLCs can gain access to advanced technological knowledge from abroad (Utterback, 1975; Mazzoleni \& Nelson, 2007). Hiring people who have studied or worked abroad or worked within the country at a foreign-owned corporation, even for a limited period of time, enables knowledge that was created outside the country to flow into technological latecomer countries (Hoekman et al., 2005; Utterback, 1975; Mazzoleni \& Nelson, 2007). In particular, moving people from abroad to technological latecomer countries has been considered a crucial pathway for international technology transfer (Ploykitikoon \& Daim, 2010). For example, the government of Taiwan succeeded in promoting the repatriation of scientists and engineers. This pathway helped Taiwan succeed in developing its electronics and semiconductor industries. More recently, the government of India has instituted a policy that promotes the temporary return of expatriates and encourages the returnees to conduct local research and develop local businesses (Hoekman et al., 2005). People with experience in working or studying abroad also enable knowledge transfer from advanced technological countries to national 
laboratories (Utterback, 1975; Mazzoleni \& Nelson, 2007). Thus, international sources of knowledge can be considered as a critical source of external knowledge for NLs.

\subsubsection{Sources of Internal Knowledge}

Knowledge that is relevant to the execution of a particular project may already be available to the project group at the outset of the project that it intends to pursue (Haas \& Hansen, 2005; Haas \& Hansen, 2007). This knowledge is henceforth classified as static because the project group can utilize this knowledge without doing anything during the execution of the project. Static knowledge can come from external experience that the members of the project group have accumulated prior to joining the group (Huber, 1991). ${ }^{8}$ Alternatively, it could have been created by the project group prior to the inception of the project that the group plans to pursue (Nemanich et al., 2010). By contrast, internal knowledge that is classified as dynamic is created through deliberate learning efforts that take place while the project is ongoing (e.g., Adler \& Clark, 1991; Bohn, 1994; Lapré et al., 2000; Edmondson et al., 2003). These activities allow the project group to renew its stock of knowledge, which may otherwise become obsolete (Nemanich et al., 2010).

\footnotetext{
${ }^{8}$ Huber (1991) talks about experience that has been accumulated prior to joining an organization. Such an organization can consist of many project teams. Huber's conclusions should apply to project teams within an organization that consists of many such teams.
} 


\subsubsection{Pathways for Obtaining External Knowledge}

Researchers tend to exchange knowledge (some of which may even be proprietary) across organizational boundaries (e.g.,Allen, 1977; Kreiner \& Schultz, 1993; von Hippel, 1987; Bouty, 2000, p. 50). Bouty, 2000, (p. 50) states that researchers "may meet at conferences or annual meetings or are classmates. They know each other, and they belong to networks. They call on each other for assistance in their daily work, when they confront an issue they are unsure about or cannot work out." Researchers activate their networks to exchange information and services with their colleagues, including those that are employed by their direct competitors (von Hippel, 1987; Bouty, 2000). Furthermore, Bouty, 2000, states that past research has proven that these informal interactions across organizational boundaries may constitute major learning processes that are of great consequence for innovation. For example, Allen, 1977, found that "about 40 percent of the messages resulting in ideas considered during the course of R\&D projects and 40 percent of the ideas considered as potential solutions stemmed from personal contacts outside the scientists' own firms," and these "resources also flow out of firms through these exchanges. Moreover, these exchanges are purely interpersonal (between individuals), ad hoc, and independent of organizational structure, policy, and formal collaborations" (Allen, 1977, pp. 45-64, 148, 155, 223, 225; Bouty, 2000).

In my study, knowledge from external sources such as the ones mentioned above can flow into organizations via two main pathways: contextual learning activities (CLAs) and vicarious learning activities (VLAs) (Bresman, 2010). 


\subsubsection{Contextual Learning Activities (CLAs) or Searching}

Contextual learning (Allen, 1977; Ancona \& Caldwell, 1992; Hansen, 1999; Bresman, 2010), which (Ancona \& Caldwell, 1992) originally named searching and scouting, can occur in two forms: scanning and focused search. Scanning (Huber, 1991) or broad search (Laursen \& Salter, 2006) refers to wide-range sensing of the organization's external environment (Huber, 1991). Focused search (Huber, 1991) or deep search (Laursen \& Salter, 2006) occurs when organizational units or their members actively search in a narrow segment of the organization's internal or external environment, often in response to actual or suspected problems or opportunities (Huber, 1991).

At the project level, contextual learning activities (Bresman, 2010) help a group learn about its context from external sources of knowledge. Contextual learning activities include scanning the environment for information and ideas about competitors, customers, and technological trends. They allow group members "to ensure that they are staying abreast with the competition, that they are working on a product that customers value, and they are not about to be leapfrogged by new technologies" (Bresman, 2010, p. 86). Group members scan the environment to keep track of its dynamic context and to adjust the group's practices to ensure they align with the context as it changes over time. Contextual learning activities tend to involve declarative knowledge ${ }^{9}$, which is explicit

\footnotetext{
${ }^{9}$ The differences between declarative and procedural knowledge have been addressed in the literature: (e.g., M. D. Cohen \& Bacdayan, 1994; Moorman \& Miner, 1998; Edmondson et al., 2003; Bresman, 2010): Declarative knowledge is about facts: 1) it is explicit; 2) can be accessed consciously; 3) it is easy to articulate and store; and 4) it is easy to apply across a variety of tasks. Procedural knowledge is about how
} 
and about facts. Thus, they are easier to communicate and record than vicarious learning activities (Bresman, 2010), which tend to be more tacit and procedural (Edmondson et $a l ., 2003)$. CLAs enable group members to enhance their awareness of current events that are taking place outside their organization. These events may pertain to new technology, the organization's competitors and the market space in which the organization participates. Awareness of these events may enter the organization via conferences and publications.

\subsubsection{Vicarious Learning Activities (VLAs)}

Vicarious learning acquires second-hand experience (Argote \& Ingram, 2000; Edmondson et al., 2003; Darr et al., 1995; Epple et al., 1991; Bresman, 2005; Bresman, 2010). Organizations engage in VLAs in an attempt to not just inform themselves about whether particular strategies, practices and technologies exist within other organizations. They are also interested in the processes that these organizations deploy to implement these strategies and practices, as well as to develop technology. For example, an organization is engaged in vicarious learning activities if it searches for information not just about what competitors are doing, but also how they are doing it (Porter, 1980; Sammon et al., 1984; Fuld, 1988; Gilad \& Gilad, 1988; cited by Huber, 1991, p. 96). Organizations can gain access to second-hand experiences via the same channels through which they engage in contextual learning: e.g. consultants, professional meetings, trade shows, publications, vendors, and suppliers. However, the knowledge that they obtain

things are done: 1) It is tacit, 2) it tends to be accessed unconsciously, 3) it tends to be difficult to articulate and store, and 4) it is likely to be difficult to apply across tasks. 
tends to be tacit and procedural rather than explicit and declarative. In addition, Huber, 1991, has suggested that networks of professionals in specific technology areas (see, for example, Almeida et al., 2003; Oliver \& Liebeskind, 1997; Almeida \& Kogut, 1997; Rosenkopf \& Tushman, 1998) can serve as a channel for vicarious learning activities that facilitates the inflow of knowledge in less competitive environments.

At the project level, vicarious learning activities constitute a set of group learning activities through which a group learns about its ongoing project from experienced outsiders. Vicarious learning activities can help group members "avoid repeating mistakes and reinventing practices, and skip unnecessary steps; identify important practices and procedures; and learn how to implement them" (Bresman, 2010, p. 84). A group may learn from the lessons others have learned by "inviting them to discuss past mistakes; reflecting experience of others on what has worked in the past; extracting lessons about the task; observing the work of others; and talking to others about way to improve the work process" (Bresman, 2005, p. 84). Vicarious learning activities involve both declarative (explicit) and procedural (tacit) knowledge; thus they require active engagement between knowledge providers and receivers. Success at vicarious learning activities can be achieved by "an iterative process of intense interpersonal interaction involving discussion, observation, and problem solving" (Bresman, 2010, p. 86). Vicarious learning activities also can be implemented by setting up advisory group or by exchanging experiences with other research groups who have had similar experiences (Bresman, 2010). 


\subsubsection{Obtaining Internal Knowledge}

Internal knowledge can come from prior experience of individual members of a project group (Huber, 1991) or from relevant knowledge that the project group has accumulated prior to the inception of an ongoing project (Nemanich et al., 2010). It can also be created by deliberate project-internal learning activities that take place while the project is ongoing (e.g., Adler \& Clark, 1991; Bohn, 1994; Lapré et al., 2000; Edmondson et al., 2003).

\subsubsection{Grafting Prior Experience}

Grafting on new members is a process through which an organization can rapidly gain new knowledge that has not been previously available within the organization. It primarily consists of moving people with relevant knowledge, experience and expertise from one organization or project group to another (Huber, 1991). An organization may acquire new knowledge from a strategic alliance partner (Mowery et al., 1996; Rosenkopf \& Almeida, 2003; Madhavaram \& McDonald, 2004; Nag et al., 2007; Segelod, 2001; Lyles \& Salk, 1996) by having people from the strategic alliance partner work jointly with people from its organization within the same project group. This practice enables the socialization processes that are required for knowledge transfer or the creation of new knowledge (Nonaka, 1994). Successful grafting can also occur by hiring additional scientists and engineers (Zucker et al., 1998; Almeida \& Kogut, 1999) from abroad (Antal \& Walker, 2011; Hoekman et al., 2005; Ploykitikoon \& Daim, 2010; Chen \& Sun, 2000; Gil et al., 2003), from inside the country but outside the organization 
(Huber, 1991) or from within the organization but outside the project group (Haas \& Hansen, 2005) and integrating them into the project group (see figure 1.1).

\subsubsection{Prior Knowledge}

Prior knowledge is an internal factor that tends to impact the relationship between knowledge inflows and organizational performance (W. M. Cohen \& Levinthal, 1990; Todorova \& Durisin, 2007; Szulanski, 1996; Simonin, 1999; Matusik, 2002; De Clercq \& Dimov, 2008). Prior knowledge includes "basic skills, a shared language, and knowledge of the most recent scientific or technological developments in a given field" (W. M. Cohen \& Levinthal, 1990, p. 131). Prior knowledge within an organization enables the assimilation and exploitation of external knowledge, especially if some portion of that prior knowledge is closely related to the new external knowledge to be assimilated (W. M. Cohen \& Levinthal, 1990).

An individual's prior knowledge comes from all the learning that he/she has done in the past. "Learning performance is greatest when the object of learning is related to what is already known" (W. M. Cohen \& Levinthal, 1990, p. 131), because it enhances the individual's ability to absorb new knowledge. An increase in absorptive capacity over one time period will permit the individual to absorb more knowledge in subsequent time periods. If multiple individuals develop absorptive capacity in their respective areas of expertise, and these areas of expertise are related to the mission of the organization, then the organization's capacity to absorb useful knowledge increases. The organization should consequently be able to increasingly exploit critical external knowledge as it 
becomes available (W. M. Cohen \& Levinthal, 1990, pp. 135-136), but only if the organization enables the individuals that work within it to engage in the socialization processes that are required for successful knowledge creation and knowledge transfer within the organization (Nonaka, 1994).

At project the level, prior knowledge has the tendency to affect the relationship between knowledge inflow and project performance (Griffith \& Sawyer, 2009; Nemanich et al., 2010). It enhances the combinative capabilities (Kogut \& Zander, 1992) of the project group, which can subsequently reorganize knowledge from various sources, be they external or internal, to achieve better results. Nemanich et al., 2010 also contend that prior knowledge facilitates a project group's ability to replicate actions that have produced successful results in the past. However, these authors present no empirical evidence that backs up this proposition.

\subsubsection{Project-Internal Learning Activities (PILAs)}

Project internal learning activities (PILAs) help project group members learn from experience as they execute their own projects (Edmondson, 1999; S. Wong, 2004; Bresman, 2010). The activities typically include "asking questions, seeking feedback, sharing information, experimenting, and talking about errors" (Bresman, 2010, p. 82). PILAs also play an important role for project members to absorb external knowledge that 
they have gained from technology gatekeepers. ${ }^{10}$ W. M. Cohen \& Levinthal, 1990, have argued that not all members of a project group need to interact with external entities at the group level. Instead, the project group may interact with its environment via a technology gatekeeper, who takes a lead role in the evaluation and assimilation of external knowledge. PILAs allow the gatekeeper to share knowledge inflows with their project members.

\subsubsection{Summary of Section}

Figure 2.3 represents the conclusion of this section. The literature review presents four main sources of external knowledge inflow into research and development projects of NLs. The sources of external knowledge include existing technological knowledge from other projects inside NLs, technological knowledge from local universities, user knowledge from LTUs, and technological knowledge from abroad. The knowledge from these four sources can flow into R\&D projects at NLs in TLCs via the three strategic pathways: grafting, vicarious learning activities, and contextual learning activities. In this study, grafting people is considered a mechanism that brings knowledge from external sources into the project group prior to the outset of a project. It is treated as an internal source of knowledge while the project is ongoing.

\footnotetext{
${ }^{10}$ Technology gatekeepers are employees that interact extensively with individuals and organizations outside their own (Allen, 1971; Tushman \& Katz, 1980; R. Katz \& Allen, 1982). They consequently bring technology into an organization from the outside. They have a reputation for technical competence in a particular field; they read the journals in the field; they have many external connections; and they are frequently promoted to first level supervisory positions. Gatekeepers of a particular technology tend to be organized in networks. They go to the same conferences, and they join the same professional societies. Gatekeepers of different technologies within the same organization also engage with each other, increasing their effectiveness in coupling their organization to the outside world (Allen, 1977, Ch. 6).
} 


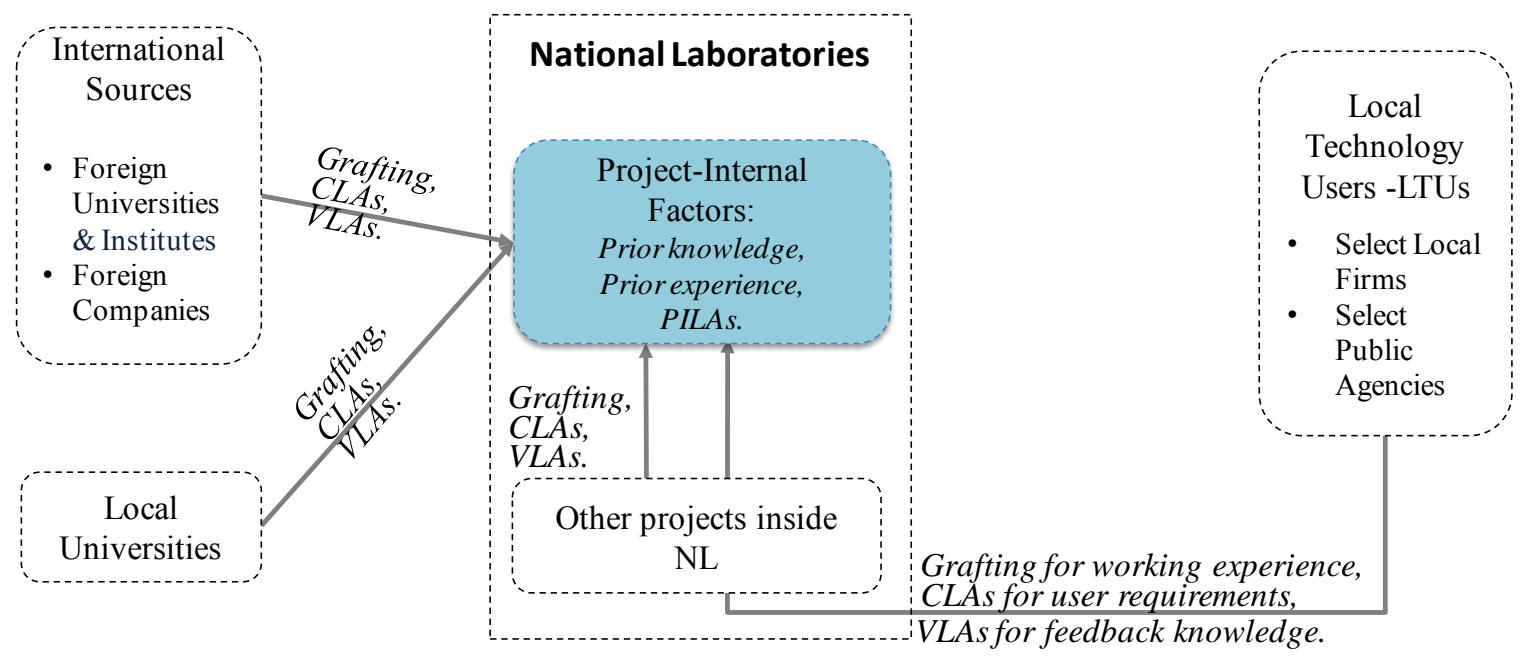

Figure 2.3: Knowledge inflow surrounding national laboratories. (integrated from Utterback, 1975; Mazzoleni \& Nelson, 2007; Hoekman et al., 2005; Encarnação, 2007; Lundvall, 2010; Ancona \& Caldwell, 1992).

\subsubsection{Primary Research Gap}

The literature that has been reviewed so far has identified the following primary research gap. Currently, to the best of my knowledge, no quantitative study on the impact of the four main sources of external knowledge and of the three main sources of internal knowledge on the performance of NLs has ever been done (Primary Research Gap). I intend to address this primary gap in the academic literature in my dissertation by investigating the impact of knowledge inflows on performance of NLs in TLCs.

To clarify the issues regarding the primary research gap, I review the literature concerning the impact of managing knowledge inflows into research and development 
organizations sections 2.3 and 2.4. By doing so, I identify various research gaps that are subordinate to the primary research gap.

\subsection{THE IMPACT OF MANAGING KNOWLEDGE INFLOWS INTO R\&D ORGANIZATIONS}

In this section of the literature review, I look at some broadly based issues pertaining to knowledge inflow in research and product development. I focus on how managing knowledge inflow impacts the performance of research organizations and development organizations, both at the organization level and at the project level. Managing knowledge inflows consists of deciding which external source of knowledge to tap as well as identifying the best pathway for knowledge inflow into the national laboratories and the various project groups that actually works on the R\&D projects. ${ }^{11}$

\subsubsection{Open Innovation}

Two studies by Chesbrough (Chesbrough, 2003; Chesbrough et al., 2006) (which utilize the case study research method) suggest that companies should consider managing knowledge inflows not only for obtaining new ideas, knowledge or technology, but also for commercializing them through a process of managing knowledge outflow (West \&

\footnotetext{
${ }^{11}$ The findings from this section will allow me to analyze in more detail the primary research gap that has been identified in section 2.2.6. Most of the articles that are reviewed in this section come from the literature on organization learning and absorptive capacity. However, I also draw on the literature on Open Innovation and new product development.
} 
Bogers, 2011). The process through which this is done is known as Open Innovation. Chesbrough et al. (2006) defines "Open Innovation" as the use of purposive inflows and outflows of knowledge to accelerate internal innovation, and expand the markets for external use of innovation, respectively.

Open Innovation is based on the principle that no company employs all talented people needed to gain competitive advantage, but that valuable knowledge also resides in external sources of knowledge. Open Innovation is a paradigm that assumes that firms can and should use external ideas as well as internal ideas, and internal and external paths to market, as they look to advance their technology (Chesbrough et al., 2006). Companies need to systematically identify and acquire external knowledge in order to accelerate internal innovation. This process is known as Inbound Open Innovation (Chesbrough et al., 2006). Furthermore, Chesbrough et al. (2006) suggests a similar approach to exploit internally generated knowledge. In addition to the "normal" way of commercializing knowledge through the company's own products and services. He suggests the companies should also target at generating value from other companies' use of the company's knowledge. This process is known as Outbound Open Innovation.

\subsubsection{Multi-Dimensional Impact}

Much of the academic literature that addresses how knowledge is obtained from external sources and transferred across organizational boundaries (e.g., Ancona \& Caldwell, 1992; Haas \& Hansen, 2007; Laursen \& Salter, 2006; Chiang \& Hung, 2010) suggests that said knowledge can have a significant, multi-dimensional impact on the performance of the 
organizations into which it flows. Successfully managing knowledge inflow can shorten development time and decrease the costs of developing an innovation (Chesbrough, 2003; Backer, 2008) (dimension -1). Knowledge inflows also tend to bring new innovative ideas into organizations (Chesbrough, 2003; Piller \& Walcher, 2006; Hill \& Birkinshaw, 2008). Systematically identifying and acquiring external knowledge, which can be combined with internal knowledge, is likely to improve the innovative performances of organizations when they try to develop advanced products or engage in process innovation (dimension -2) (Gassmann et al., 2006; Gassmann, 2006; McAdam et al., 2006; Reichstein \& Salter, 2006; Carson, 2007; Harryson et al., 2008; West \& Bogers, $\left.2011^{12}\right)$.

Organizations should also be able to gain additional benefits from commercializing technology that they have developed internally (dimension -3) (Zuniga \& Guellec, 2009; Lichtenthaler, 2008; Lichtenthaler, 2006a; West \& Bogers, 2011). The literature on Open Innovation discusses the three channels by which a company can gain benefits from the outflow of knowledge: divestment of a company's business units, IP management, and inter-organizational collaboration (e.g., Lichtenthaler, 2005; Chesbrough \& Garman, 2009). The divestment of a business unit involves the sale and transfer of all of the

\footnotetext{
${ }^{12}$ West \& Bogers, 2011, identified three plus one major steps for profiting from external innovations. Obtaining innovations include search, sourcing, enabling, incentivizing and contracting. Initially, we separated the search for external innovations from their acquisition, but we eventually concluded that for much of the sample, it was impossible to separate these processes and roles. Integrating innovations, including factors that enable integration, those that act as barriers to integration, and those that explain how that activity changes (and is changed by) the organization and its competencies. Commercializing innovations is often implied for Open Innovation research, but an explicit part of conventional models of industrial R\&D. To this three-step linear model West \& Bogers (2011) added a fourth category of nonrecursive paths, which involve reciprocal interactions with co-creation partners. The authors have termed this process a four-phase model of how firms utilize external innovations.
} 
company's relevant knowledge (intellectual property (IP) rights, physical assets and human resource assets) to a spin-off business unit (Lichtenthaler, 2005; Chesbrough, 2002; Chesbrough \& Rosenbloom, 2002). IP management includes activities such as licensing out, cross-licensing and IP donation (Elton et al., 2002; Davis \& Harrizon, 2001; Rivette \& Kline, 2000), which involves transfer of some of the company's relevant knowledge. Inter-organizational collaboration includes strategic alliances, joint ventures, and inter-organizational networks in which the IP rights are shared between the partners in the collaboration (Lichtenthaler, 2005).

To date, very few studies that measure the impact of knowledge inflow on the commercialization of technology have been conducted (West \& Bogers, 2011). The few studies that have addressed this subject are based on the case study research method, and they have chosen the organizational level as a unit of analysis (Chesbrough, 2003; Dodgson et al., 2006; Cooke, 2005). To date, to the best of my knowledge, the impact of knowledge inflow on revenue generation has not been studied quantitatively (Research Gap RG-1), neither in research and development organizations at NLs in TLCs nor elsewhere. In addition, the subject has not been investigated at the project level. Finally, I contend that the impact of managing knowledge inflow on the commercialization of technology that has been developed inside an organization or a project group has not been studied at all. 


\subsubsection{Conclusion of this Section}

Table 2.1: Performance measures in the existing literature and in my proposal (output variables)

\begin{tabular}{|c|c|c|c|c|c|c|}
\hline \multirow[b]{2}{*}{ Author(s) } & \multicolumn{6}{|c|}{ Performance Measures } \\
\hline & $\begin{array}{l}\text { Innova- } \\
\text { tiveness }\end{array}$ & Efficiency & $\begin{array}{l}\text { Bidding } \\
\text { success }\end{array}$ & $\begin{array}{c}\text { Client's } \\
\text { satisfaction }\end{array}$ & $\begin{array}{l}\text { Quantity \& } \\
\text { quality of } \\
\text { codified } \\
\text { knowledge }\end{array}$ & $\begin{array}{l}\text { Revenue } \\
\text { generated }\end{array}$ \\
\hline \multicolumn{7}{|c|}{ Performance dimensions at organizational level (based on conceptual framework or case studies) } \\
\hline $\begin{array}{l}\text { Chesbrough, 2003; } \\
\text { Backer, 2008; West \& } \\
\text { Bogers, 2011 }\end{array}$ & YES & YES & & & & YES \\
\hline $\begin{array}{l}\text { Gassmann, 2006; } \\
\text { McAdam et al., 2006; } \\
\text { Harryson et al., 2008 }\end{array}$ & YES & & & & & \\
\hline $\begin{array}{l}\text { Zuniga \& Guellec, } \\
\text { 2009; Lichtenthaler, } \\
\text { 2008; Lichtenthaler, } \\
\text { 2006a }\end{array}$ & & & & & & YES \\
\hline $\begin{array}{l}\text { My dissertation: NLs } \\
\text { in TLCs }\end{array}$ & & & & YES & YES & YES \\
\hline \multicolumn{7}{|c|}{ Performance dimensions at organizational level (based on large-scale empirical data) } \\
\hline $\begin{array}{l}\text { Laursen \& Salter, } \\
2006\end{array}$ & YES & & & & & \\
\hline Chiang \& Hung, 2010 & YES & & & & & \\
\hline \multicolumn{7}{|c|}{ Performance dimensions at project level (based on large-scale empirical data) } \\
\hline $\begin{array}{l}\text { Ancona \& Caldwell, } \\
1992\end{array}$ & YES & YES & & & & \\
\hline S. Wong, 2004 & YES & YES & & & & \\
\hline Haas \& Hansen, 2005 & & & YES & & & \\
\hline Haas \& Hansen, 2007 & & YES & & YES & & \\
\hline Bresman, 2010 & YES & YES & & & & \\
\hline $\begin{array}{l}\text { My dissertation: NLs } \\
\text { in TLCs }\end{array}$ & & & & YES & YES & YES \\
\hline
\end{tabular}

Note: The solid columns refer to the measures that are the primary concern of NLs in TLCs.

Table 2.1 represents the conclusion of this section. It presents the performance metrics that measure the impact of managing knowledge inflows at the organization level and the project level. In the research streams of Open Innovation, organizational learning and NPSD, knowledge inflows contribute to 1) innovativeness in products and services and 2) the efficiency of the innovation process. However, knowledge inflows also help 
organizations generate 3) innovations that satisfies the client; 4) codified knowledge for future uses; and 5) revenue from commercializing technology. Based on the literature review in this section, the last three dimensions, which are of critical importance to the three fundamental missions of NLs in TLCs, are the focus of the large-scale empirical research that I conduct as part of my dissertation. 
Table 2.2: Main literature pertaining to managing knowledge inflows at project level

\begin{tabular}{|c|c|c|c|c|c|c|}
\hline Author(s) & $\begin{array}{l}\text { Types of } \\
\text { projects }\end{array}$ & $\begin{array}{c}\text { Internal } \\
\text { knowledge } \\
\text { (internal } \\
\text { project } \\
\text { factors) }\end{array}$ & $\begin{array}{l}\text { External } \\
\text { knowledge } \\
\text { (experience- } \\
\text { sources) }\end{array}$ & $\begin{array}{c}\text { Pathways of } \\
\text { Knowledge inflows }\end{array}$ & $\begin{array}{l}\text { Performance } \\
\text { (dimensions) }\end{array}$ & Results \\
\hline $\begin{array}{l}\text { Ancona \& } \\
\text { Caldwell, } \\
1992\end{array}$ & $\begin{array}{l}\text { NPD } \\
\text { projects }\end{array}$ & None & $\begin{array}{l}\text { General } \\
\text { knowledge } \\
\text { outside project }\end{array}$ & CLAs & $\begin{array}{l}\text { - Innovativeness } \\
\text { - Efficiency }\end{array}$ & $\begin{array}{l}\text { - The CLAs impede group projects to } \\
\text { achieve both group innovativeness and } \\
\text { efficiency }\end{array}$ \\
\hline $\begin{array}{l}\text { S. Wong, } \\
2004\end{array}$ & $\begin{array}{l}\text { Diversified } \\
\text { teams }\end{array}$ & PILAs & $\begin{array}{l}\text { General } \\
\text { knowledge } \\
\text { outside project }\end{array}$ & CLAs & $\begin{array}{l}\text { - Innovativeness } \\
\text { - Efficiency }\end{array}$ & $\begin{array}{l}\text { - The CLAs promote group } \\
\text { innovativeness } \\
\text { - The PILAs promote group efficiency } \\
\text { - The CLAs impede PILAs for achieving } \\
\text { group efficiency (-) }\end{array}$ \\
\hline $\begin{array}{l}\text { Bresman, } \\
2010\end{array}$ & $\begin{array}{c}\text { In-sourcing } \\
\text { projects }\end{array}$ & PILAs & $\begin{array}{l}\text { General } \\
\text { knowledge } \\
\text { outside } \\
\text { organization }\end{array}$ & $\begin{array}{l}\text { CLAs } \\
\text { VLAs }\end{array}$ & $\begin{array}{l}\text { - Innovativeness } \\
\text { - Efficiency }\end{array}$ & $\begin{array}{l}\text { - CLA and VLA support group } \\
\text { innovativeness and efficiency } \\
\text { - PILAs complement VLA to enhance } \\
\text { group performance }(+) \\
\text { - When group performs VLA, lacking } \\
\text { PILAs can hurt group performance }\end{array}$ \\
\hline $\begin{array}{l}\text { Haas \& } \\
\text { Hansen, } \\
2005\end{array}$ & $\begin{array}{l}\text { Consulting } \\
\text { projects }\end{array}$ & $\begin{array}{l}\text { Prior } \\
\text { experience } \\
\text { in task }\end{array}$ & $\begin{array}{l}\text { Knowledge } \\
\text { outside project, } \\
\text { but inside } \\
\text { organization }\end{array}$ & $\begin{array}{l}\text { - CLAs from internal } \\
\text { codified knowledge } \\
\text { - VLAs from } \\
\text { internal personal } \\
\text { knowledge }\end{array}$ & $\begin{array}{l}\text { Binary numbers } \\
(\mathrm{O}=\text { not success, } \\
1=\text { success in } \\
\text { bidding) }\end{array}$ & $\begin{array}{l}\text { - Both CLAs and VLAs (that only new } \\
\text { for the team, but not new to the } \\
\text { organization) impedes the chance to } \\
\text { succeed in projects with high prior } \\
\text { experience (-) }\end{array}$ \\
\hline $\begin{array}{l}\text { Haas \& } \\
\text { Hansen, } \\
2007\end{array}$ & $\begin{array}{l}\text { Consulting } \\
\text { projects }\end{array}$ & None & $\begin{array}{l}\text { Knowledge } \\
\text { outside project, } \\
\text { but inside } \\
\text { organization }\end{array}$ & $\begin{array}{l}\text { - CLAs from internal } \\
\text { codified knowledge } \\
\text { - VLAs from internal } \\
\text { personal knowledge }\end{array}$ & $\begin{array}{l}\text { - Time } \\
\text { efficiency } \\
\text { - Client's } \\
\text { satisfaction } \\
\text { - Project } \\
\text { competency }\end{array}$ & $\begin{array}{l}\text { - CLAs saves time during the task, but } \\
\text { not improves client's satisfaction and } \\
\text { project competency } \\
\text { - VLAs improve improves client's } \\
\text { satisfaction and project competency, but } \\
\text { not saves time during the task }\end{array}$ \\
\hline $\begin{array}{l}\text { Nemanich } \\
\text { et al., } \\
2010\end{array}$ & $\begin{array}{l}\text { R\&D } \\
\text { projects }\end{array}$ & $\begin{array}{l}\text { Prior } \\
\text { knowledge } \\
\text { (\#patent) }\end{array}$ & $\begin{array}{l}\text { General } \\
\text { knowledge } \\
\text { outside } \\
\text { organization }\end{array}$ & Assimilation ability & $\begin{array}{l}\text { Exploitation } \\
\text { ability }\end{array}$ & $\begin{array}{l}\text { Assimilation ability is more important } \\
\text { to performance in projects with less } \\
\text { prior knowledge than in projects with } \\
\text { extensive prior knowledge }\end{array}$ \\
\hline
\end{tabular}

CLAs $=$ Contextual learning activities; VLAs $=$ Vicarious learning activities; PILAs $=$ Project internal learning activities 


\subsection{FACTORS THAT IMPACT KNOWLEDGE INFLOWS AT PROJECT LEVEL}

In this section of the literature review, I look at some broadly based issues pertaining to knowledge inflows in research and product development. I investigate which factors are important to managing knowledge inflows, and I focus on which organization-internal factors enable or hinder knowledge inflows. The findings from this section will allow me to address research gaps, research questions, and research hypotheses for my dissertation proposal. Most of the articles that are reviewed in this section come from the literature on organizational learning and absorptive capacity.

Table 2.2 presents the findings of the existing literature that addresses how knowledge inflows impact performance at the project level. The impact of knowledge inflows on project performance tends to vary by types of projects, according to internal project factors and by the choice of pathways and sources of knowledge inflows.

\subsubsection{Types of Projects}

The relationship between knowledge inflows and project performance is impacted by what type of project the project is. For example, the performance of new product development (NPD) projects tends to rely less on knowledge inflows via CLAs than insourcing projects and service development projects and manufacturing projects do. As presented in Table 2.2, CLAs tend to have a negative impact on efficiency and innovativeness in new product development project (Ancona \& Caldwell, 1992), but they have a positive impact on both efficiency and innovativeness in technology in-sourcing 
projects (Bresman, 2010). They have a positive impact on the innovativeness and no significant impact on the efficiency of service development projects and manufacturing projects (S. Wong, 2004).

To date, the impact of knowledge inflows on the performance of research and development projects of NLs in TLCs has not been measured. The literature review in section 2.2 suggests that the performance of NLs in TLCs tend to be highly related to knowledge inflows, particularly those from abroad. However, to date no empirical study has determined the degree to which the performance of $R \& D$ projects at NLs in TLCs relies on knowledge inflows. (Research Gap RG-1)

\subsubsection{Project-Internal Factors}

The literature review in sections 2.2.2 and 2.2.4 suggests that project-internal factors such as prior knowledge, prior experience and project-internal learning activities (PILAs) exert a significant influence on project performance. These three internal project factors allow project groups to build up their absorptive capacity, which can enhance the project groups' ability to evaluate, assimilate, and exploit knowledge from external sources (W. M. Cohen \& Levinthal, 1990). The existing literature discusses the factors that are internal to the project group and influence the project performance significantly, as the following subsections show. 


\subsubsection{Prior Knowledge and Prior Experience}

Prior knowledge and prior experience can either substitute or complement knowledge inflows (Haas \& Hansen, 2005; Argote \& Miron-Spektor, 2011; Haas \& Hansen, 2005; Nemanich et al., 2010). Knowledge inflows tend to be less important to projects with high prior knowledge (as measured by the cumulative numbers of patents) (Nemanich et al., 2010). Also, knowledge inflows from external sources tend to distract a project group from succeeding in its mission when this project group contains members that have worked extensively on prior projects whose subject matter was relevant to the ongoing project (Haas \& Hansen, 2005). This means that a high degree of prior knowledge or a high degree of prior experience can act as a substitute for knowledge inflows (Argote \& Miron-Spektor, 2011; Haas \& Hansen, 2005).

My review of the literature has caused me to raise two questions. First, does a project group with high prior knowledge generate higher performance when it engages with external sources? If so, is this true for all three critical missions of the national laboratories? To date, few studies that measure the impact of prior knowledge on the relationship between the inflows of knowledge from external sources and project performance have been conducted. It is consequently important to quantify the impact of prior knowledge on project performance because doing so can help us understand how the success of the NLs in mission 3 can contribute to the success in the two other missions. Finally, I contend that the impact of a project group's prior knowledge on its ability to absorb knowledge from external sources has not been quantified. (Research Gap RG-2) 
In addition, the existing literature has never addressed the impact of project group members' prior experience with external sources of knowledge on the relationship between the inflows of knowledge from the external sources and project performance. A project group member who has had experience in working or studying with an external source may facilitate (or complement) the inflow of knowledge from the external source. $\mathrm{He} / \mathrm{she}$ may consequently contribute to improving the performance of the project. Understanding the impact of prior experience with the external sources on project performance can help NLs design their strategy for hiring external experts, recruiting staff and promoting studying or working with the critical sources of knowledge for NLs in TLCs. Finally I contend that the impact of a project member's prior experience on its ability to absorb knowledge from external sources has not been quantified. (Research Gap RG-3)

\subsubsection{Project-Internal Learning activities (PILAs)}

Prior studies (S. Wong, 2004; Bresman, 2010) suggest that PILAs can either impede or encourage knowledge inflows from different pathways. If projects groups have high degree of PILAs, then encouraging project group members to participate more in CLAs can impede the project group's performance especially in project efficiency (S. Wong, 2004). However, CLAs distract from internal project learning in projects with high PILAs, which tends to decrease project efficiency. By contrast, a high degree of PILAs can encourage (or complement) knowledge inflows via VLAs, which enhances project performance (Bresman, 2010). Thus, PILAs are a critical enabler of vicarious learning activities (Bresman, 2010). 
To date, no academic study that measures the impact of internal project learning capabilities on the relationship between the inflows of knowledge from external sources and the project performance of NLs in TLCs has been conducted. R\&D project groups, which are highly engaged in project internal learning activities, may be critical to absorbing knowledge from international sources. In contrast, engagement with international sources of knowledge may distract the R\&D project groups, which are highly engaged in project internal learning activities to succeed in their missions. The findings pertaining to how a project's internal learning capabilities influence the relationship between knowledge inflows and project performance can help R\&D project managers design their strategies for interacting with the four main sources of external knowledge effectively. Finally, I address the impact of project-internal learning activities in ongoing projects on the relationship between the degree of engagement with external sources of knowledge and the performance of the projects. To date, this topic has not been studied in the context of NLs in TLCs. (Research Gap RG-4)

\subsubsection{Choice of Pathway for Knowledge Inflows into a Project}

The choice of pathway for knowledge inflows is another factor that impacts project performance. For example, knowledge inflows that result from searching activities that are related to contextual learning activities (CLAs) have a negative impact on efficiency and innovativeness in NPD projects (Ancona \& Caldwell, 1992), yet they have positive impact on innovativeness in service development and manufacturing projects (S. Wong, 
2004). Vicarious learning activities (VLAs) tend to have a positive impact on both efficiency and innovativeness in in-sourcing projects (Bresman, 2010).

To the best of my knowledge, no empirical research that characterizes the impact of knowledge inflow from each of the previously mentioned pathways on the performance of NLs in TLCs has been conducted to date. The anticipated empirical findings of this dissertation should be able to extend the understanding about how different pathways of knowledge inflows impact project performance as it pertains to the three critical missions of NLs in TLCs. Selection of pathways for knowledge inflow that align with the critical missions of NLs in TLCs should be able to help project managers gain additional benefits from knowledge inflow.

\subsubsection{Sources of External Knowledge for a Project}

Sources of external knowledge can also be a key factor that impacts project performance. For example, projects that obtain knowledge from inside their own organization (e.g., the content of electronic documents that have been archived within an organization's database) can improve the time efficiency of the projects (Haas \& Hansen, 2007). In contrast, projects that obtain knowledge from sources outside their organization tend to decrease project efficiency because these projects tend to have higher searching and learning costs (S. Wong, 2004).

The importance knowledge from external sources has been discussed in various research streams including absorptive capacity, organizational learning, NIS, Open Innovation and 
international technology transfer. The absorptive capacity literature and the organizational learning literature show that a project tends to acquire new knowledge from both inside and outside organization and integrates it with existing internal knowledge (Ancona \& Caldwell, 1992; S. Wong, 2004; Haas \& Hansen, 2005; Bresman, 2010; Nemanich et al., 2010). According to the literature on national innovation systems (NIS, discussed in section 2.2), institutions within the NIS, such as local universities, government research institutes and LTUs, can serve as sources of external knowledge. In addition, the research stream on international technology transfers (reviewed in section 2.2.1.3) addresses how important knowledge from advanced technological countries, i.e. knowledge from outside the NIS of TLCs, is to TLCs, including R\&D projects within NLs of TLCs.

Based upon the above literature review, I contend that the impact on the performance of R\&D projects of knowledge obtained from inside and outside the NIS has not been studied extensively (if at all). How the engagement with external entities inside and outside the NIS impacts the performance of R\&D projects should thus be the subject of further academic study. The results of such academic study may enhance the NLs understanding of knowledge flow to the point where the NLs can adjust their strategies, in order to engage with external institutions much more effectively. Also, policymakers in TLCs should be able to use the findings from this dissertation to make structural adjustments and policy modifications that promote interaction between institutions within the NIS and engagement with institutions outside the NIS. 


\subsubsection{Summary of Section}

Figure 2.4 depicts taxonomy of pathways through which knowledge can enter an R\&D project group and mechanisms through which knowledge can be generated internally. It shows that project groups typically gain internal static knowledge from prior experience of project members (grafting of people prior to the start of a project) (Huber, 1991) and from prior knowledge (W. M. Cohen \& Levinthal, 1990; Nemanich et al., 2010). When starting a new project, internal dynamic knowledge can be gained from project internal learning activities (PILAs) (Edmondson, 1999; S. Wong, 2004; Bresman, 2010), which allow group members and technology gatekeepers to share knowledge within their new project groups. Additional knowledge may be obtained from external sources, which include other projects inside organization, other institutes inside NIS, and other institutes outside the NIS. The pathways to obtain knowledge from the external sources can be contextual learning activities (CLAs) (Allen, 1977; Ancona \& Caldwell, 1992; Hansen, 1999; Bresman, 2010) or vicarious learning activities (VLAs) (Argote et al., 2000; Edmondson et al., 2003; Darr et al., 1995; Epple et al., 1991; Bresman, 2005; Bresman, 2010). R\&D projects tend to integrate knowledge from internal sources and external sources for the creation of new technology, innovative products and innovative services. 


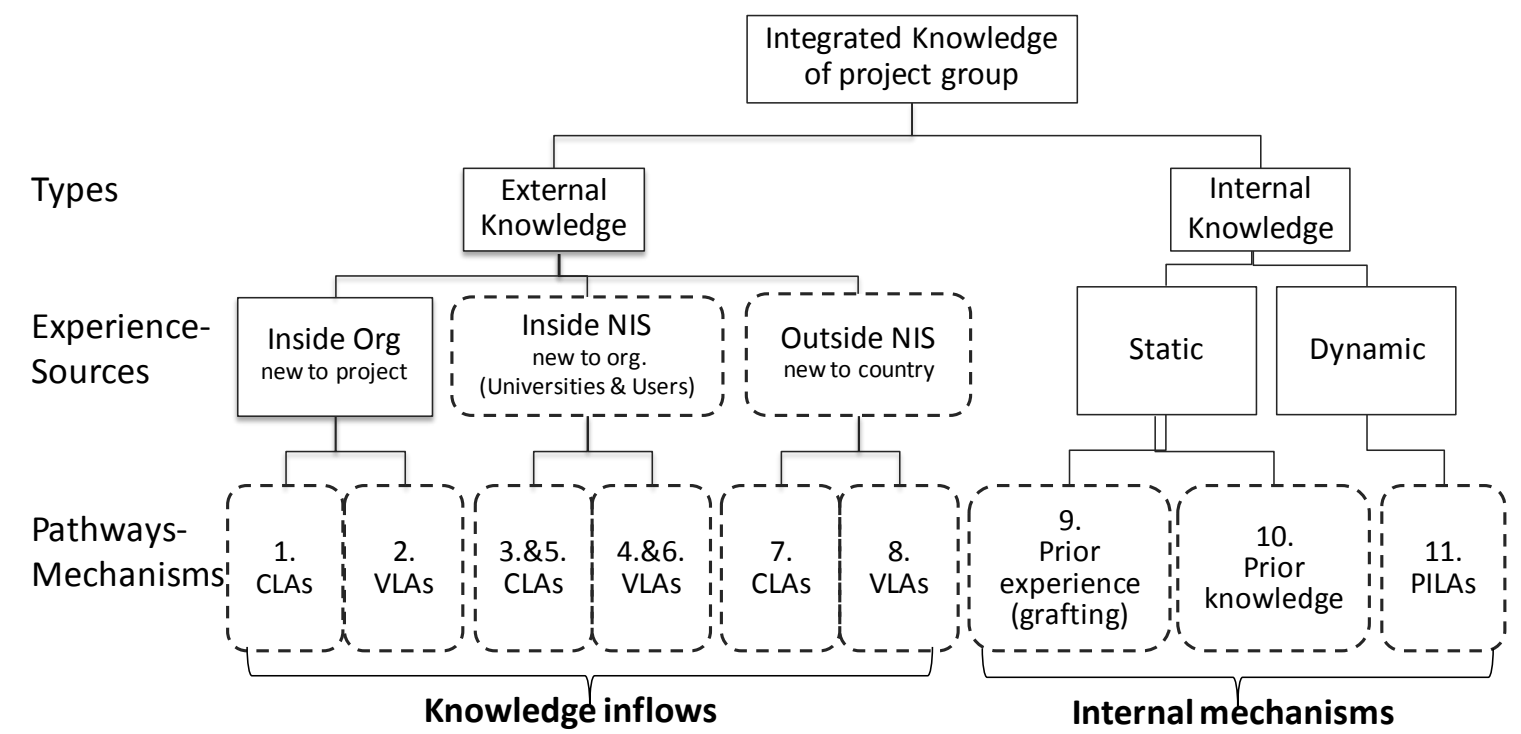

Figure 2.4: Taxonomy of knowledge pathways and knowledge generation mechanisms

Figure 2.4 represents the conclusion of this section. The figure depicts the key factors that tend to influence the impact of knowledge inflows on the performance or R\&D projects. The eleven dashed-rectangles in the figure 2.4 refer to subject matter that has yet to be studied extensively.

Table 2.3 clarifies why the eleven dashed-rectangles in figure 2.4 should be a subject for further research. They represent eleven candidate factors pertaining to knowledge inflows that have never been a subject of intensive study; studies about the impact of these candidate factors on the performance of projects within the NLs in TLCs have been lacking in particular. In addition, the impact of the three internal project factors (prior knowledge, prior experience and project internal learning activities) on the relationships 
between knowledge inflows from external sources and project performance of NLs in TLCs has never been studied.

Table 2.3: Key factors that have been described in the existing literature and eleven candidate factors that I intend to cover in this dissertation

\begin{tabular}{|c|c|c|c|c|c|c|}
\hline \multirow[b]{2}{*}{ Author (s) } & \multicolumn{4}{|c|}{ External Knowledge } & \multicolumn{2}{|c|}{ Internal Knowledge } \\
\hline & $\begin{array}{c}\text { New to the } \\
\text { project from } \\
\text { other } \\
\text { projects } \\
\text { inside org. }\end{array}$ & $\begin{array}{c}\text { New to the } \\
\text { project }\end{array}$ & $\begin{array}{c}\text { New to the } \\
\text { organization } \\
\text { from inside } \\
\text { NIS }\end{array}$ & $\begin{array}{l}\text { New to the } \\
\text { country } \\
\text { from } \\
\text { outside } \\
\text { NIS }\end{array}$ & $\begin{array}{c}\text { Static } \\
\text { experience }\end{array}$ & $\begin{array}{l}\text { Dynamic } \\
\text { experience }\end{array}$ \\
\hline $\begin{array}{l}\text { Ancona and } \\
\text { Caldwell, } \\
1992\end{array}$ & & - CLAs & & & & \\
\hline Wong, 2004 & & - CLAs & & & & - PILAs \\
\hline $\begin{array}{l}\text { Haas and } \\
\text { Hansen, } \\
2005\end{array}$ & $\begin{array}{l}\text { - Codified } \\
\text { knowledge } \\
\text { - Tacit } \\
\text { knowledge }\end{array}$ & & & & $\begin{array}{l}\text { - Prior } \\
\text { knowledge }\end{array}$ & \\
\hline $\begin{array}{l}\text { Haas and } \\
\text { Hansen, } \\
2007\end{array}$ & $\begin{array}{l}\text { - Codified } \\
\text { knowledge } \\
\text { - Tacit } \\
\text { knowledge }\end{array}$ & & & & & \\
\hline $\begin{array}{l}\text { Bresman, } \\
2010\end{array}$ & & $\begin{array}{l}\text { - CLAs } \\
\text { - VLAs }\end{array}$ & & & & - PILAs \\
\hline $\begin{array}{l}\text { Nemanich et } \\
\text { al., } 2010\end{array}$ & & $\begin{array}{l}\text {-Assimila- } \\
\text { tion } \\
\text { ability }\end{array}$ & & & $\begin{array}{l}\text { - Prior } \\
\text { knowledge }\end{array}$ & \\
\hline \multirow[t]{2}{*}{$\begin{array}{l}\text { Contribution } \\
\text { of my } \\
\text { dissertation }\end{array}$} & $\begin{array}{l}\text { 1. CLAs } \\
\text { inside NLs } \\
\text { 2. VLAs } \\
\text { inside NLs }\end{array}$ & & $\begin{array}{l}\text { 3. CLAs from } \\
\text { local } \\
\text { universities } \\
\text { 4. VLAs from } \\
\text { local } \\
\text { universities }\end{array}$ & $\begin{array}{l}\text { 7. CLAs } \\
\text { from } \\
\text { abroad } \\
\text { 8. VLAs } \\
\text { from } \\
\text { abroad }\end{array}$ & \multirow[t]{2}{*}{$\begin{array}{l}\text { 9. Prior } \\
\text { knowledge } \\
\text { 10. Prior } \\
\text { experience }\end{array}$} & \multirow[t]{2}{*}{ 11. PILAs } \\
\hline & & & $\begin{array}{l}\text { 5. CLAs with } \\
\text { LTUs } \\
\text { 6. VLAs with } \\
\text { LTUs }\end{array}$ & & & \\
\hline
\end{tabular}

CLAs $=$ Contextual learning activities;

VLAs $=$ Vicarious learning activities;

PILAs $=$ Project internal learning activities 


\subsection{CONCEPTUAL FRAMEWORK}

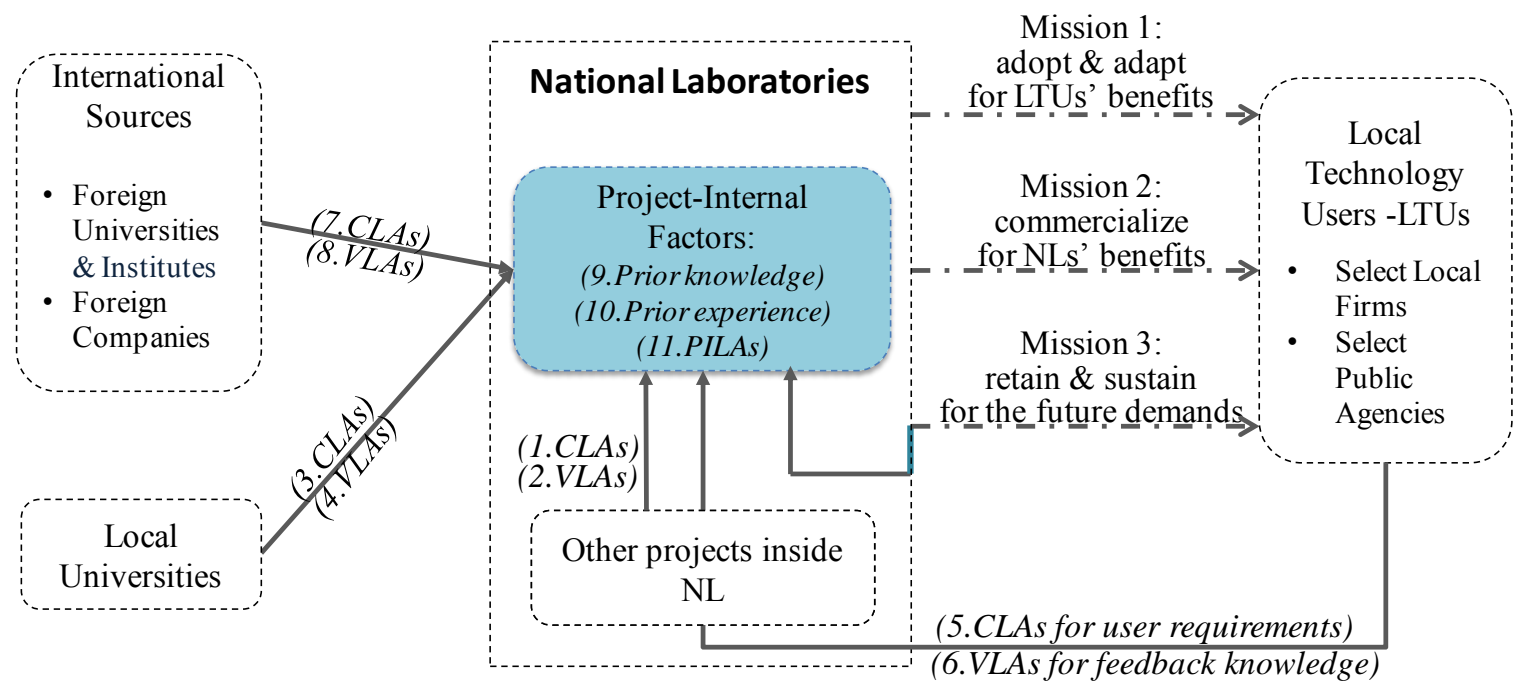

Figure 2.5: Conceptual framework of this dissertation.

Items in (parentheses) are the focus of this dissertation. (The numbers before the CLAs and VLAs refer to figure 2.4 and table 2.3.)

Figure 2.5 illustrates the conceptual framework for this study that has emerged from the literature review in this chapter. This conceptual framework integrates the model for knowledge outflow from figure 2.2 with the model for knowledge inflow from figure 2.3. The result is a model of knowledge flow that transpires within the national innovation systems of technology latecomer countries and is centered on the project groups of the national laboratories. 
Figure 2.5 shows that various kinds of knowledge flow into project groups within the NLs of TLCs come from four external sources. Technological knowledge comes from other research and development project groups within NLs and from local universities. User knowledge flows in from the LTUs. Advanced technological knowledge is imported from abroad. The project groups at the NLs in TLCs tend to obtain knowledge from the four external sources via engagement in external learning activities consisting of vicarious learning activities and contextual learning activities.

The knowledge inflows from the external sources can be integrated with the internal knowledge within research and development projects to generate new technological knowledge (W. M. Cohen \& Levinthal, 1990). The internal knowledge can come from prior experience of individual project members (through the grafting of people) and prior knowledge of the project groups, which could have been available to the group prior to the beginning of the projects (Huber, 1991). Also an internal source of knowledge can be created by project-internal learning activities (PILAs) while the project is ongoing (e.g., Adler \& Clark, 1991; Bohn, 1994; Lapré et al., 2000; Edmondson et al., 2003).

Figure 2.5 is an expansion of figure 1.1, which has been enabled by the literature review in this chapter. Just like figure 1.1, figure 2.5 depicts all the knowledge inflows. However, figure 2.5 also identifies the various mechanisms for knowledge inflows (CLAs and VLAs) and a variety of types of project-internal knowledge. It also shows that the knowledge output generated from the projects tends to flow out of the NLs to the LTUs, and that the impact of this knowledge outflow is mission specific. Performance may thus not only be a function of knowledge inflows, the various forms project-internal 
knowledge and the plethora of interactions between the various forms of inflow and project-internal knowledge. It is also likely to be mission specific, and it may depend on the type of inflow mechanism (CLA or VLA). This suggests that managers have a multitude of potential levers at their disposal to address very specific performance issues. However, the managers within the national laboratories are currently probably unable to identify these levers because the impact of knowledge inflows and project-internal knowledge on the performance of project groups has not yet been characterized.

\subsection{RESEARCH GAPS AND RESEARCH QUESTIONS}

In this section, I summarize research gaps pertaining to the impact of managing knowledge inflows on performance of NLs in TLCs, which have been discussed in section 2.1 to section 2.4. I subsequently pose research questions that address these gaps. The literature review shows that the importance of knowledge flow as it pertains to the performance of national laboratories in technology latecomer countries has not yet been established. The following primary research gap has been identified in particular (in section 2.2.6).

Primary Research Gap-- No quantitative study on the impact of the four main sources of external knowledge and of the three main sources of internal knowledge on the performance of NLs in TLCs has ever been done. 
The primary research gap breaks down into the following series of issues that have not yet been addressed in the academic literature. Every one of these issues comprises a research gap of its own. There are four research gaps in total.

- Research Gap RG-1 -- The impact of inflows from external sources of knowledge on the performance of project groups within national laboratories in technology latecomer countries has not been quantified. (Actually, this topic has not been studied at all.)

- Research Gap RG-2 --The impact of a project group's prior knowledge on its ability to absorb knowledge from external sources has not been quantified.

- Research Gap RG-3 -- The impact of a project group's prior experience on its ability to absorb knowledge from external sources has not been quantified.

- Research Gap RG-4 -- The impact of a project group's internal learning capabilities on its ability to absorb knowledge from the external sources has not been quantified.

There is a one-to-one correspondence between the research gaps from above and the following research questions.

Primary Research Question - To what degree does engagement with the external sources of knowledge affect the performance of national laboratories in technological latecomer countries? 
- Research Question RQ-1 - What is the relative impact on the performance of national laboratories in latecomer countries of engaging a) with other project groups within the same organization; $b$ ) with the sources of foreign knowledge; $c$ ) with sources of user knowledge and d) with other sources of domestic knowledge?

- Research Question RQ-2 -What is the effect of a project group's prior knowledge on the relationship between the project group's degree of engagement with external sources of knowledge and the project's performance?

- Research Question RQ-3 - What is the effect of a project group's prior experience on the relationship between the project group's degree of engagement with external sources of knowledge and the project's performance?

- Research Question RQ-4 - What is the effect of a project group's internal learning capability on the relationship between the project group's degree of engagement with external sources of knowledge and the project's performance?

Addressing these research questions will hopefully allow me to achieve my research objective, which has been stated as follows at the beginning of section 1.3: to identify factors pertaining to knowledge inflows that determine the success or failure of research projects in the national laboratories of latecomer countries. Figure 2.6 illustrates the relationship between my management question, my research objective, the gaps in the existing literature and my research questions. 
Management Question:

How do knowledge inflows into NLs of TLCs affect the performance of the NLs?

Research objective: To identify factors pertaining to knowledge inflows that determine the success or failure of research projects in the NLS of TLCS.

Primary research gap: No quantitative study on the impact of the four main sources of external knowledge and of the three main sources of internal knowledge on the performance of NLs has ever been done.

\begin{tabular}{|c|c|c|c|}
\hline $\begin{array}{l}\text { Research Gap RG-1 -- } \\
\text { The impact of inflows } \\
\text { from external sources of } \\
\text { knowledge on the } \\
\text { performance of project } \\
\text { teams within NLs in TLCS } \\
\text { has not been quantified. }\end{array}$ & $\begin{array}{l}\text { Research Gap RG-2 -- } \\
\text { The impact of a project } \\
\text { team's prior knowledge } \\
\text { on its ability to absorb } \\
\text { knowledge from external } \\
\text { sources has not been } \\
\text { quantified. }\end{array}$ & $\begin{array}{l}\text { Research Gap RG-3 -- } \\
\text { The impact of a project } \\
\text { team's prior experience } \\
\text { on its ability to absorb } \\
\text { knowledge from external } \\
\text { sources has not been } \\
\text { quantified. }\end{array}$ & $\begin{array}{l}\text { Research Gap RG-4 -- } \\
\text { The impact of a project } \\
\text { team's internal learning } \\
\text { capabilities on its ability } \\
\text { to absorb knowledge } \\
\text { from external sources } \\
\text { has not been quantified. }\end{array}$ \\
\hline$\downarrow$ & $\downarrow$ & $\downarrow$ & $\downarrow$ \\
\hline $\begin{array}{l}\text { Research Question RQ-1 } \\
\text { What is the relative } \\
\text { impact on the } \\
\text { performance of NLs in } \\
\text { TLCS of engaging with } \\
\text { the four main sources? }\end{array}$ & $\begin{array}{l}\text { Research Question RQ-2 } \\
\text { What is the effect of a } \\
\text { project team's prior } \\
\text { knowledge on the } \\
\text { relationship between the } \\
\text { project group's degree of } \\
\text { engagement with } \\
\text { external sources of } \\
\text { knowledge and the } \\
\text { project's performance? }\end{array}$ & $\begin{array}{l}\text { Research Question RQ-3 } \\
\text { What is the effect of a } \\
\text { project team's prior } \\
\text { experience on the } \\
\text { relationship between the } \\
\text { project group's degree of } \\
\text { engagement with } \\
\text { external sources of } \\
\text { knowledge and the } \\
\text { project's performance? }\end{array}$ & $\begin{array}{l}\text { Research Question RQ-4 } \\
\text { What is the effect of a } \\
\text { project team's internal } \\
\text { learning capability on } \\
\text { the relationship between } \\
\text { the project group's } \\
\text { degree of engagement } \\
\text { with external sources of } \\
\text { knowledge and the } \\
\text { project's performance? }\end{array}$ \\
\hline
\end{tabular}

Figure 2.6: The relationship between management question, research objective, research gaps and research questions. 


\section{RESEARCH HYPOTHESES}

This study intends to investigate the impact of the knowledge inflows gained from engagement with the external sources of knowledge on the project performance at the NLs in TLCs. The extent to which each project group engages with external sources of knowledge for the purpose of gaining knowledge inflows from these sources tends to vary from project to project. The different degree of engagement with the external sources of knowledge may affect the performance of each project differently. In addition, the level of internal knowledge of within the projects groups is likely to impact the performance of each project. It may also influence significantly how the degree of engagement with the external sources of knowledge impacts the performance of individual projects. The findings from this study can also help us understand how different degrees of inflow from the four sources of external knowledge into project groups within the NLs in TLCs impact the performance of the projects as they pertain to the three critical missions of the NLs. Finally, the findings of this study may shed light on how project-internal factors impact the performance of individual projects, and how project-internal factors impede or promote knowledge inflows into the NLs in TLCs.

In this chapter, I propose research hypotheses that allow me to investigate how the knowledge inflows into R\&D project groups and project-internal factors at the NLs in TLCs impact the performance of research projects, as it pertains to the three critical missions of the NLs. I also propose to assess how the project-internal factors impede or promote the knowledge inflows into NLs in TLCs. 
In the following sections, I deconstruct the theoretical framework from figure 2.5 into its conceptual components - the impact on the performance of projects of engagement with other R\&D project groups within NLs (section 3.1); engagement with domestic sources of technological knowledge (section 3.2); engagement with LTUs (section 3.3); engagement with international sources (section 3.4); prior knowledge (section 3.5); prior experience (section 3.6); and project internal learning activities (section 3.7). I design a set of testable hypotheses for each conceptual component. The sets of hypotheses that address engagement with external entities (sections 3.1 through 3.4 ) contain at least one hypothesis that pertains to each critical mission of the national laboratories. Sections 3.5 through 3.7 propose hypotheses, which suggest that internal knowledge either complements or acts as a substitute for knowledge that flows into a project group from external sources. A discussion on how to test all hypotheses that are proposed in this section follows in chapter 4 .

Figure 3.1 contrasts the effect of complementarity and substitution in an example that pertains to the NLs in TLCs. In figure 3.1a, prior knowledge complements the degree of engagement with international sources of knowledge; in figure $3.1 \mathrm{~b}$, prior knowledge acts as a substitute for the degree of engagement with international institutions. Revenue generation is the performance metric for figure $3.1 \mathrm{a}$ and for figure $3.1 \mathrm{~b}$.

In figure $3.1 \mathrm{a}$, revenue generation is a rapidly increasing function of the degree of engagement with international sources of knowledge when prior knowledge is high and a slowly increasing function of the degree of engagement with international sources of knowledge when prior knowledge is low. The direct impact on revenue generation is in 
the higher domain of engagement with international sources when the prior knowledge is high; the direct impact on revenue generation is in the lower domain of engagement with international sources when the prior knowledge is low.
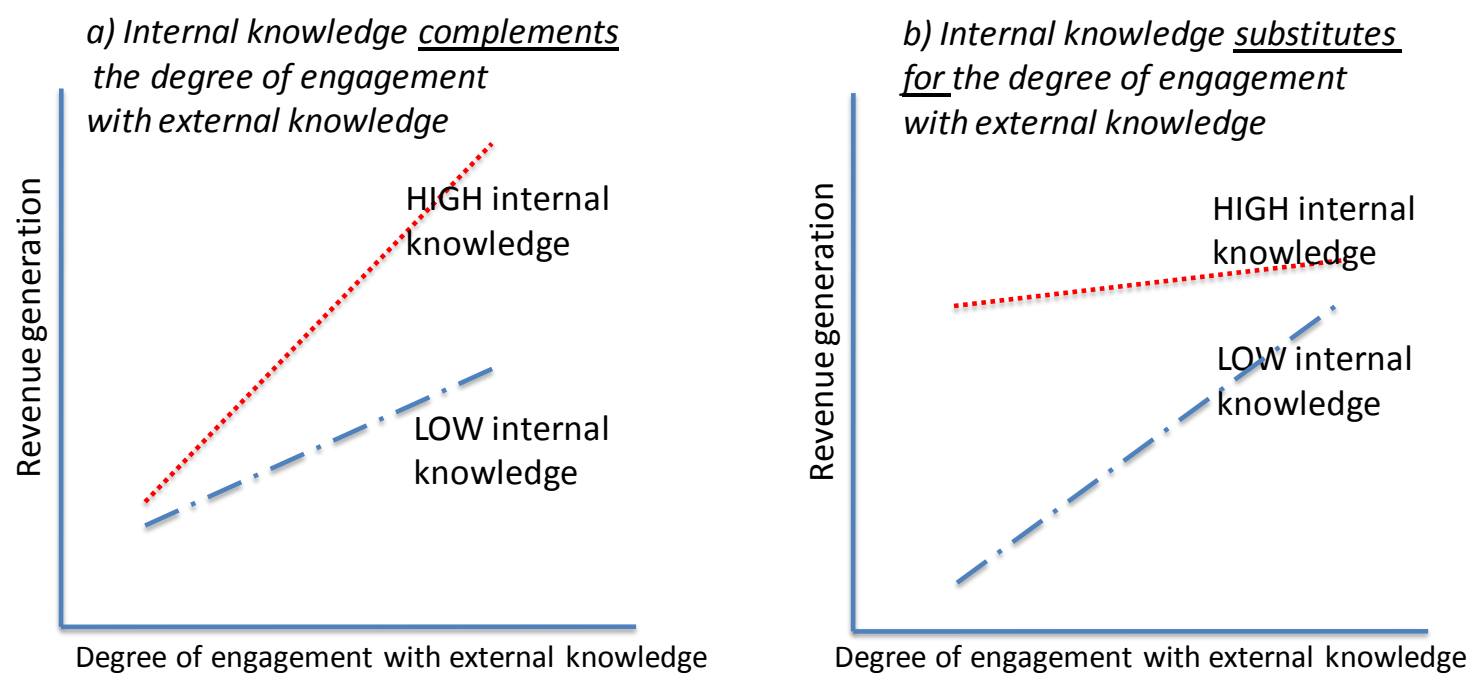

Figure 3.1: Complementarity versus substitution of internal knowledge (prior knowledge)

In figure $3.1 \mathrm{~b}$, revenue generation is a rapidly increasing function of the degree of engagement with international sources of knowledge when prior knowledge is low and a slowly increasing function of the degree of engagement with international sources of knowledge when prior knowledge is high. The direct impact on revenue generation is in the higher domain of engagement with international sources when the prior knowledge is high; the direct impact on revenue generation is in the lower domain of engagement with international sources when the prior knowledge is low.

It should be noted that in practice the intersection between the two trajectories in figure 3.1a and figure $3.1 \mathrm{~b}$ does not necessarily occur near the median of the distribution of the 
independent variable. More commonly, the intersection between the two trajectories occurs near the lower end of the distribution in a complementary interaction. By contrast, the intersection between the two trajectories occurs near the upper end of the distribution in a substitutive interaction.

\subsection{IMPACT OF ENGAGEMENT WITH OTHER R\&D PROJECT GROUPS WITHIN THE NATIONAL LABORATORIES}

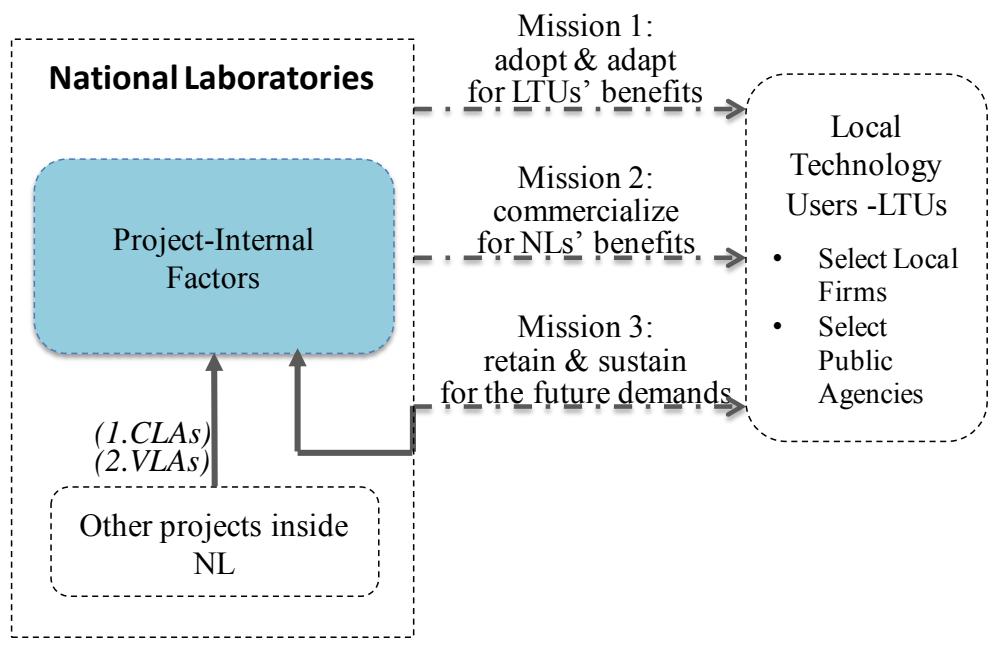

Figure 3.2: Pathways for knowledge flows within NLs in TLCs

Figure 3.2 illustrates how knowledge flows within the national laboratories and how internal knowledge impacts the national innovation system. Members of R\&D project groups (especially technology gatekeepers) may engage with other project groups inside NLs, in order to search for technological knowledge that can be integrated with internal knowledge from their ongoing projects. They may learn what other projects are doing by searching the organization's databases (Haas \& Hansen, 2005; Haas \& Hansen, 2007). 
(In my dissertation the NL's constitute 'the organization'.) The members of project groups may also interact with experts from other projects to learn from their experiences (Haas \& Hansen, 2005; Haas \& Hansen, 2007; Bresman, 2010). Knowledge gains from other projects inside the NLs tend to allow project groups to save time while their projects are ongoing (Haas \& Hansen, 2007) and allow them to develop technology that fits with customer requirements (Haas \& Hansen, 2007, section 2.3.3). Other project groups within the national laboratories can serve as sources of knowledge, if the project groups within the NLs engage in learning activities that span organizational boundaries (Ancona \& Caldwell, 1992; Haas \& Hansen, 2005; Haas \& Hansen, 2007). Therefore, engaging with other R\&D project groups the inside NLs should allow a project group to gain additional knowledge that is useful for its ongoing projects. Engagement with other R\&D project groups within the NLs may thus have a significant positive impact on how the project groups contribute to the three critical missions of the NLs.

Hypothesis 1a for Mission 1: Engagement with other $R \& D$ project groups within the NLs has a positive impact on the satisfaction of LTUs.

Hypothesis $1 b$ for Mission 2: Engagement with other $R \& D$ project groups within the NLs has a positive impact on the NLs' ability to generate revenue for themselves by commercializing technology that they have developed. 
Hypothesis 1c for Mission 3: Engagement with other $R \& D$ project groups within NLs has a positive impact on the NLs' ability to build $R \& D$ capabilities for the future needs of the country.

\subsection{IMPACT OF ENGAGEMENT WITH DOMESTIC SOURCES}

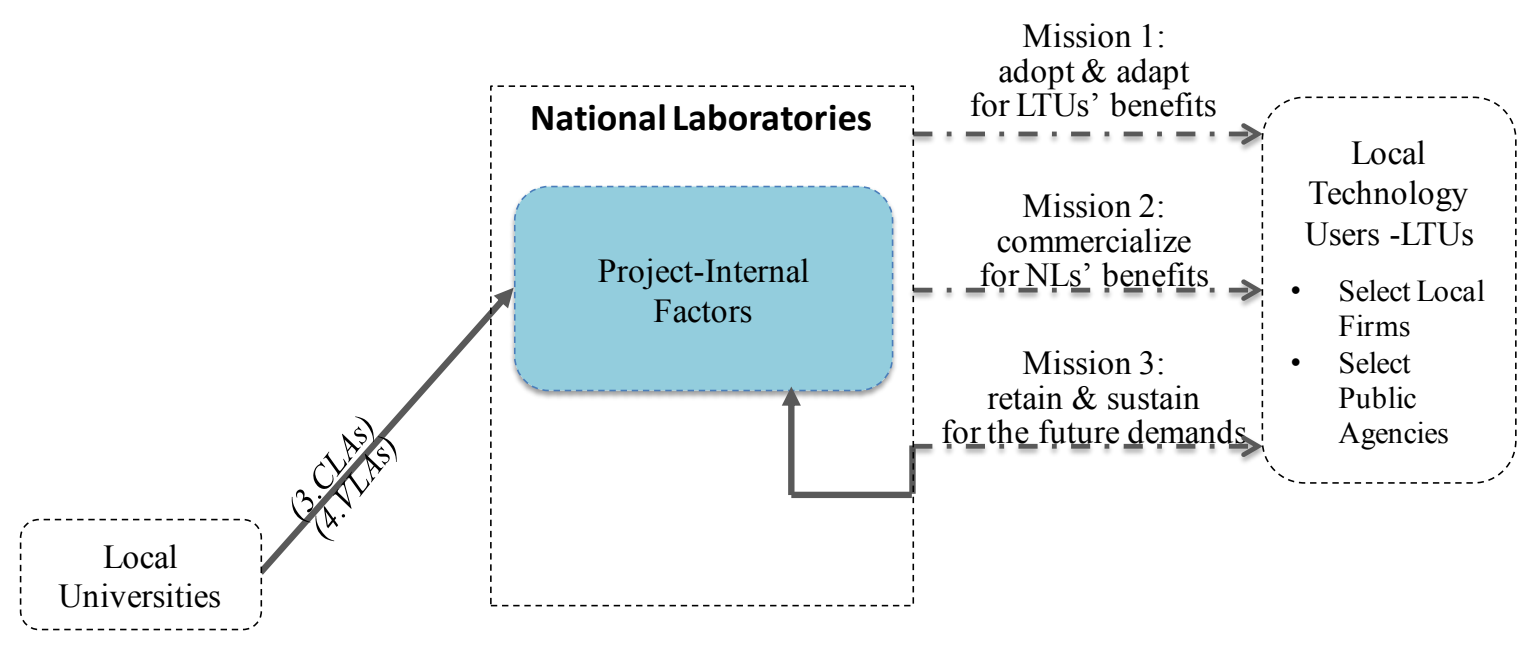

Figure 3.3: Pathways for local knowledge inflows to NLs in TLCs

According to figure 3.3, research projects at national laboratories may obtain knowledge from local universities by engaging in contextual learning activities and vicarious learning activities. (In my dissertation local universities constitute the only domestic sources of technical knowledge other than the LTUs.) Contextual learning activities include scanning the environment inside the country for technical ideas, collecting technical information or ideas from individuals inside the country, finding out how other R\&D project groups within the country but outside the NLs are managing similar projects. Vicarious learning activities include observing the work of researchers within 
local universities, inviting domestic experts from local universities to discuss how to avoid repeating past mistakes and talking to them to determine ways of improving the work process.

This study applies the items of contextual and vicarious learning activities from a study by Bresman, 2010), and proposes that knowledge from domestic sources has a positive impact on the performance of national laboratories in latecomer countries.

Hypothesis 2a for Mission 1: Engagement with local universities has a positive impact on the satisfaction of LTUs.

Hypothesis $2 b$ for Mission 2: Engagement with local universities has a positive impact on the NLs' ability to generate revenue for themselves by commercializing technology that they have developed.

Hypothesis 2c for Mission 3: Engagement with local universities has a positive impact on the NLs' ability to build R\&D capabilities for the future needs of the country. 


\subsection{IMPACT OF ENGAGEMENT WITH LOCAL TECHNOLOGY USERS}

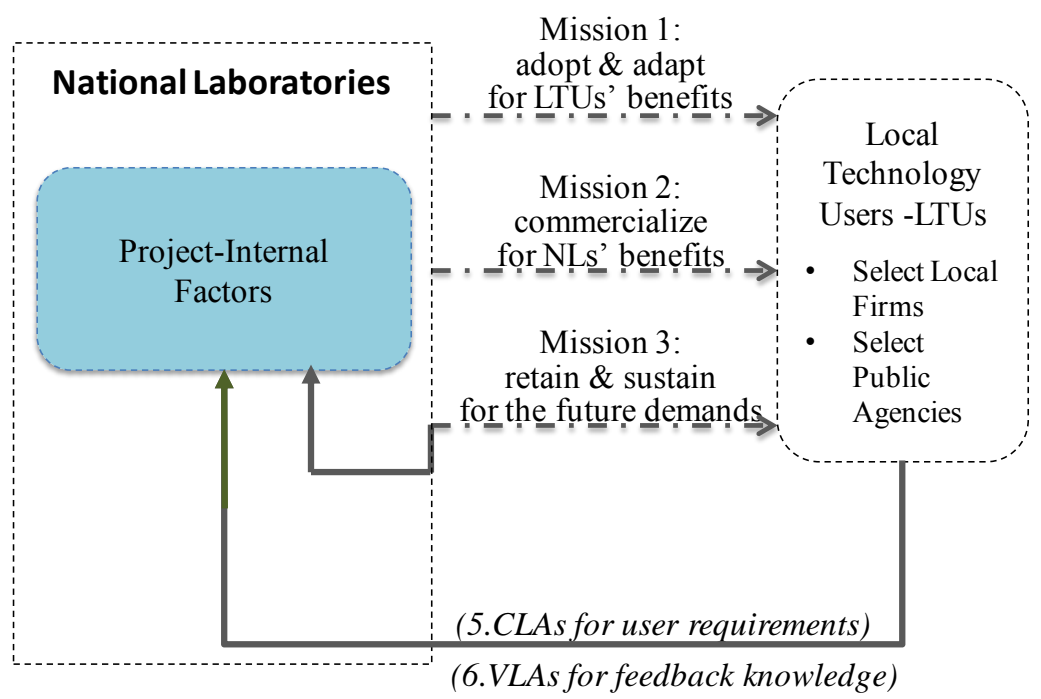

Figure 3.4: The flow of knowledge between NLs and LTUs

Figure 3.4 displays the two main pathways through which NLs are able to gain knowledge from local technology users (LTUs): vicarious learning activities and contextual learning activities. The pathway for knowledge inflow via contextual learning activities may occur when individuals in research and development projects scan, search, or explore information about LTUs' requirement (B. H. Johnson, 1992; Lundvall, 2010). The vicarious learning activities can be considered as a pathway for feedback knowledge from LTUs. For example, R\&D project groups within the NLs may invite or talk to the LTUs about how to improve ongoing projects or how to develop technology that is suitable for LTUs' requirements (Bresman, 2010).

Knowledge inflows from technology users are likely to help a research group understand requirements of technology users and lead to performance improvement (von Hippel, 
1988; Lundvall, 2010). Thus, this study proposes that knowledge from local users has a positive impact on the performance of national laboratories in latecomer countries.

Hypothesis 3a for Mission 1: Engagement with local users has a positive impact on the satisfaction of LTUs.

Hypothesis 3 for Mission 2: Engagement with local users has a positive impact on the NLs' ability to generate revenue for themselves by commercializing technology that they have developed.

However, most studies of technology users in latecomer countries show that the LTUs in these countries require technologies that help solve near-term, practical problems rather than long-term problems (Intarakumnerd et al., 2002), and they are not ready to adopt advanced technology (Intarakumnerd et al., 2002), because they lack the ability to develop or absorb advanced technology (W. M. Cohen \& Levinthal, 1990). Engagement with LTUs in latecomer countries may consequently decrease the performance of the research projects. Thus, I propose the following hypothesis.

Hypothesis 3c for Mission 3: Engagement with local users has a negative impact on the NLs' ability to build $R \& D$ capabilities for the future needs of the country. 


\subsection{IMPACT OF ENGAGEMENT WITH INTERNATIONAL SOURCES}

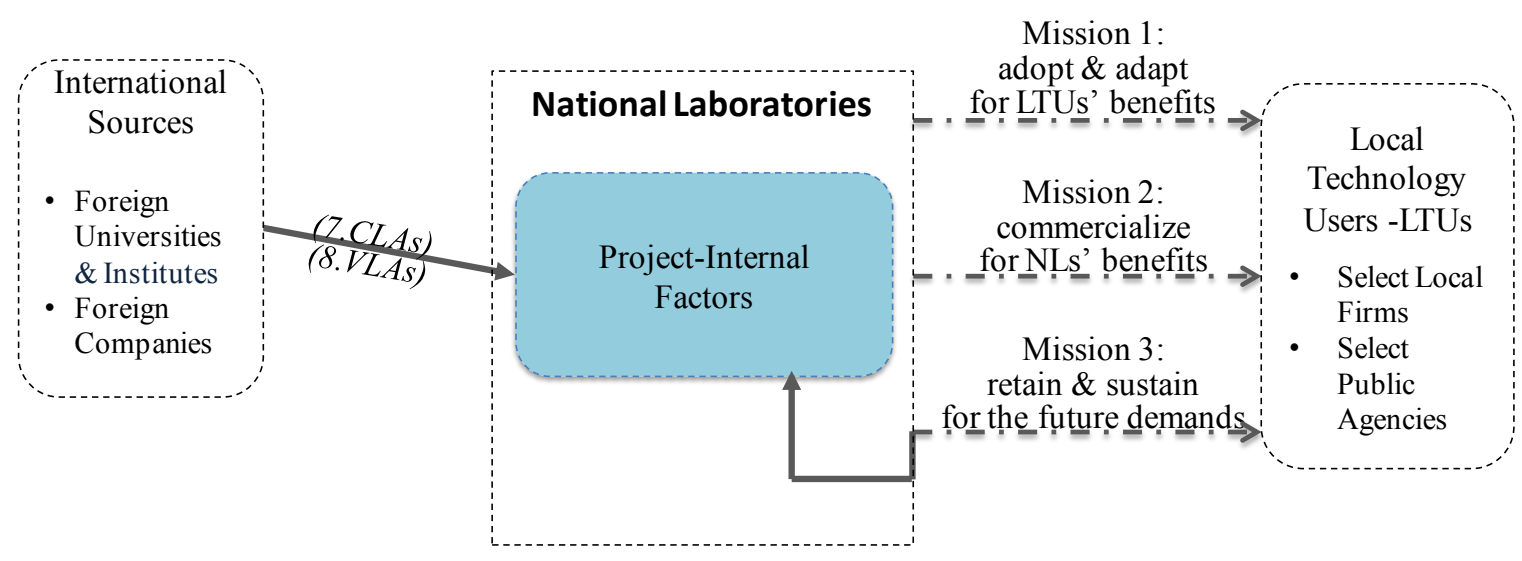

Figure 3.5: Pathways for knowledge inflow from foreign sources

Figure 3.5 shows that that advanced technological knowledge can flow from foreign sources into project groups within the NLs, if the project groups engage in contextual or vicarious learning activities. At the project level contextual learning activities are performed by individual researchers, project managers or technology gatekeepers who scan the environment outside the country for technical ideas, collect technical information or ideas from individuals abroad, and try to find out other research groups in the world are doing on similar projects by reading publications or participating in conferences (Bresman, 2010). Vicarious learning activities manifest themselves as formal collaboration in research and development or as informal information exchanges between members of the project group and their international network of peers (Allen, 1971; Tushman \& Katz, 1980; R. Katz \& Allen, 1982). These activities enable members of project groups to observe the work of their partners, to extract lessons to be applied to their projects, to invite experts from abroad to discuss how to avoid repeating past 
mistakes and to talk to experts from abroad about ways of improving the work process (Bresman, 2010).

This study proposes that knowledge from international sources that enters project groups within the NLs of TLCs through contextual and vicarious learning has a significant positive impact on the performance of projects that are conducted within the national laboratories in latecomer countries. Thus, I propose the following hypotheses.

Hypothesis 4a for Mission 1: Engagement with international sources has a positive impact on the satisfaction of LTUs.

Hypothesis $4 b$ for Mission 2: Engagement with international sources has a positive impact on the NLs' ability to generate revenue for themselves by commercializing technology that they have developed.

Hypothesis 4c for Mission 3: Engagement with international sources has a positive impact on the NLs' ability to build $R \& D$ capabilities for the future needs of the country.

\subsection{IMPACT OF PRIOR KNOWLEDGE (COMPLEMENT OR SUBSTITUTE)}

The most advanced technological knowledge that flows into the project groups within the NLs of TLCs tends to come from international sources. R\&D project groups within the 
NLs in TLCs, who want to utilize foreign technological knowledge effectively, may consequently require prior knowledge to absorb the more advanced knowledge (W. M. Cohen \& Levinthal, 1990). This suggests that prior knowledge complements the effect of engagement with international sources on NLs' performance. In contrast, knowledge from international sources that flows into a project group with a high degree of prior knowledge acts as a substitute for the prior knowledge, which would affect project performance adversely (Haas \& Hansen, 2005). Conversely, prior knowledge acts as a substitute for engaging with international sources.

Following the logic of figure 3.1, I propose the following hypothesis.

Hypothesis 5a: There is an interaction between engagement with international sources and prior knowledge, which affects project performance.

In principle, the same line of reasoning applies to inflows from other sources of knowledge that are exogenous to the project group. These sources include other R\&D project groups within the national laboratories (also known as other $\mathrm{R} \& \mathrm{D}$ units or ORDUs) and domestic sources, such as local technology users and local universities, which are part of the national innovation system but not part of the national laboratories. Knowledge that flows from these sources into a project group with a high degree of prior knowledge could act as a substitute for the prior knowledge, which would affect project performance adversely (Haas \& Hansen, 2005). Conversely, prior knowledge could act as a substitute for engaging with local universities, local technology users and other R\&D project groups within the national laboratories. On the other hand, internal knowledge 
could be complementary and enhance a project group's capacity to absorb knowledge from these sources (W. M. Cohen \& Levinthal, 1990); then the impact on performance would be positive.

Pursuing the logic of figure 3.1, I propose the following hypotheses.

Hypothesis 5b: There is an interaction between engagement with local universities and prior knowledge, which affects project performance.

Hypothesis 5c: There is an interaction between engagement with local technology users and prior knowledge, which affects project performance.

Hypothesis 5d: There is an interaction between engagement with other $R \& D$ project groups within the national laboratories and prior knowledge, which affects project performance.

\subsection{IMPACT OF PRIOR EXPERIENCE (COMPLEMENTARY)}

Project members who have experience in working on other R\&D projects inside the NLs can be considered an important pathway for the ongoing projects to gain access to new technological knowledge, because other projects inside the NLs may have accumulated experience in researching and developing technology that can complement the ongoing project (Haas \& Hansen, 2005; Haas \& Hansen, 2007; Bresman, 2010, section 2.4.2.2). 
This suggests that prior experience with other R\&D project groups inside NLs complements the effect of engagement with other R\&D project groups inside NLs on NLs' performance. Following the logic of figure 3.1, I propose the following hypothesis.

Hypothesis 6a: There is an interaction between engagement with other $R \& D$ project groups inside the NLs and prior experience, which affects project performance.

In addition, researchers within the NLs' who graduated from local universities or had working experience with them may move to work for the NLs. The NLs can gain academic knowledge in specific areas, which local professors have been researching or developing. This can be a pathway for access to local sources of knowledge via grafting (Huber, 1991). This suggests that prior experience with local universities complements the effect of engagement with local universities on the NLs' performance. Following the logic of figure 8 , I propose the following hypothesis.

Hypothesis 6b: There is an interaction between engagement with local universities and prior experience, which affects project performance.

Another strategic pathway to gain knowledge form LTUs via grafting may occur in some critical research and development projects. The NLs may consequently hire project managers or technology gatekeepers who have working experience in selected firms or in targeted public agencies. NLs may also recruit new members from or exchange people with LTUs. This suggests that prior experience with LTUs complements the effect of 
engagement with LTUs on NLs' performance. Following the logic of figure 8, I propose the following hypothesis.

Hypothesis 6c: There is an interaction between engagement with LTUs and prior experience, which affects project performance.

In addition, prior to the start of an R\&D project, the NLs also tend to gain advanced technological knowledge from outside the NIS by grafting people who have experience in working or studying abroad (Hoekman et al., 2005). These people may have informal relations with technology experts in specific areas (Gil et al., 2003) and can facilitate technology transfer from international to local institutions. Thus, prior experience with international sources of knowledge can facilitate knowledge inflows into NLs and can increase the impact of knowledge inflows on project performance. This suggests that prior experience with international sources complements the effect of engagement with international sources on NLs' performance. Following the logic of figure 3.1, I propose the following hypothesis.

Hypothesis 6d: There is an interaction between engagement with international sources and prior experience, which affects project performance. 


\subsection{IMPACT OF PROJECT-INTERNAL LEARNING ACTIVITIES (PILAs) (COMPLEMENT OR SUBSTITUTE)}

Two questions concerning knowledge inflows still need to be asked. First, do PILAs impede or encourage knowledge inflows from different sources of knowledge? If so, then to what degree do a project group's internal learning capabilities impact the group's ability to absorb knowledge from the external sources? Based on the literature review in chapter 2, project-internal learning activities (PILAs) help group members learn from experience within their own groups (Edmondson, 1999; S. Wong, 2004; Bresman, 2010). Projects that strongly engage in PILAs should thus be able to absorb more advanced technological knowledge from abroad. This suggests that project-internal learning activities complement the effect of engagement with international sources on NLs' performance. In contrast, Haas \& Hansen, 2005, have found that project internal learning activities act as a substitute for the effect of engagement with external sources on organizational performance. This suggests that project internal learning activities substitute for the effect of engagement with international sources on NLs' performance. Thus, I propose that the following hypotheses will be confirmed.

Hypothesis 7a: There is an interaction between engagement with international sources and project-internal learning activities, which affects project performance.

NLs in TLCs typically intend to promote collaborations between NLs and local universities, so that they can facilitate knowledge exchange between these two parties. 
Projects with higher degree of PILAs may thus be more motivated to engage in a joint learning process with local universities. This suggests that project internal learning activities complement the effect of engagement with local universities on NLs' performance. In contrast, interaction with domestic sources of knowledge may distract project groups with high PILAs from their internal project learning process and lead to a decrease in project performance (Haas \& Hansen, 2005). This suggests that project internal learning activities substitute for the effect of engagement with local universities on NLs' performance. Thus, I propose that the following hypotheses will be confirmed.

Hypothesis 7b: There is an interaction between engagement with local universities and project internal learning activities, which affects project performance.

The NLs in TLCs typically intend to develop technology that fits with local demands; thus interaction with LTUs is critical to their success. Group projects with high level of PILAs should be able to find suitable solutions for the LTUs, which are based on their internal learning processes. This suggests that project-internal learning activities complement the effect of engagement with local users on NLs' performance. Following the logic of figure 3.1, I propose the following hypothesis.

Hypothesis 7c: There is an interaction between engagement with local users and project internal learning activities, which affects project performance. 
A similar line of reasoning applies to prior experience and knowledge inflows from other $R \& D$ project groups within the national laboratories. Therefore, I propose the following hypothesis.

Hypothesis 7d: There is an interaction between engagement with other $R \& D$ project groups within the national laboratories and project internal learning activities, which affects project performance. 


\section{RESEARCH METHODOLOGY}

The research that has been conducted for this dissertation is survey based. I designed a questionnaire that consisted of questions pertaining to knowledge inflow, project-internal knowledge and various measures of organizational performance. I administered this questionnaire in person to 123 project managers within NSTDA, the national laboratories of Thailand. The survey data was entered into a spreadsheet and analyzed using the SPSS statistical analysis software. The results of the data analysis are presented in Chapter 5.

In this chapter, I discuss the research methodology that was used to conduct this study. First, I identify the unit of analysis and the research setting of the study. I subsequently propose a research framework and describe the variables that I intend to measure. Next, I address how to measure these variables and how to collect data for each variable. I also discuss the validity and reliability of the measures. At the end of this chapter, I describe my approach to data analysis.

\subsection{UNIT OF ANALYSIS}

The success of a national laboratory is contingent upon the number of projects that it completes and the perceived impact these projects have on the bottom-line of LTUs and the wellbeing of the country at large (L. Kim, 1980; L. Kim, 1997; P. L. Chang \& Hsu, 1998; K. Lee \& Lim, 2001, section 1.3). I consequently make the research project my unit of analysis. 


\subsection{RESEARCH SETTING}

In the study to be performed in this dissertation, I use data from Fagerberg, Srholec, and Knell (2007) and additional articles to assess the level of a country's economic development. I classify countries according to technological sophistication by comparing the number of patents, science articles and engineering articles they generate per citizen per year, as well as by their ranking on the ICT infrastructure index. I differentiate between 1) countries such as United States, Switzerland, Germany, Japan, Sweden, which are technologically advanced (Lall, 1992); 2) countries such as Korea, Taiwan, Singapore, which are "catching up" (Intarakumnerd et al., 2002) both technologically and economically; 3) technological latecomer countries such as Thailand, Indonesia, Chile and Pakistan, which lag behind the other groups of countries but are making efforts to advance (Fagerberg et al., 2007); 4) and technological laggards (e.g., most countries in sub-Saharan Africa), which until recently have made few efforts to advance technologically and, in general, are not viewed as technologically competitive (Fagerberg et al., 2007). In my dissertation research, I shall focus on technological latecomer countries, whose national laboratories and national innovation systems are likely to benefit more from my dissertation than countries in the other groups.

According to Intarakumnerd et al., 2002, technological latecomers are characterized as follows: 1) they possess very limited capabilities to facilitate and produce intensive technological learning; 2) the linkages between users and producers in technological latecomer countries are generally weak; 3) the co-operation of firms in the same and related industries is not strong, 4) technology spillover from multinational corporations to 
local industries tends to be low, and 5) the linkages between public research (at universities and national laboratories) and industries are weak. All five of these attributes of technological latecomer countries are within the scope of my research.

The National Science and Technology Development Agency (NSTDA) in Thailand has been chosen as a setting for the proposed study because is a typical example of a national laboratory in a latecomer country. The NSTDA is considered a significant source of scientific and technological knowledge for the country of Thailand. The NSTDA consists of four national research institutes: biotechnology, materials, electronics and computers, nanotechnology. These research centers operate 95 laboratories. The NSTDA's laboratories initiate about 400 new research projects per year to serve technological requirements of the country. Each laboratory runs multiple projects. Thus, a large sample of projects spanning a variety of industries and technologies is available for study.

Typically, the NSTDA's research projects can be categorized into a group of ten platform technologies, four cross-cutting programs and five areas that have been targeted for commercialization. Platform technologies tend to focus on basic research pertaining to technologies that feed the cross-cutting programs and the five target areas. Therefore, activities that transpire within the platform technology project groups are considered an early stage of an R\&D process that advances towards accomplishing the third critical mission of the national laboratories. The research projects that are conducted under these platforms also aim to advance the scientific and technical know-how of the country, thereby contributing significantly to the third critical mission of national laboratories. The ten platform technologies comprise genome technology; microbial biotechnology; agro- 
biotechnology; devices and systems technology; service informatics; computer aided design, engineering, and manufacturing; material design and production simulation; nano-coating; nano-encapsulation; and functional nanostructure (NSTDA, 2011).

Cross-cutting programs primarily consist of applied research projects that develop technologies based on the know-how of the NSTDA's or its external research partners. The NSTDA develops these technologies to a level of maturity at which they are ready for demonstration in the five target applications. The four cross-cutting programs sponsored by the NSTDA are functional materials; sensor and intelligent systems; digital engineering; and service research (NSTDA, 2011).

The last group of NSTDA projects aims to promote the five target areas that are considered to have a high impact on social and economic development of Thailand. The five target areas include agriculture and food; energy and environment; health and medicine; bio-resources, communities and the underprivileged; and manufacturing and service industries (e.g., hard disc drives, air conditioners and automobile parts). This group of projects is required to turn the internal know-how generated by the platform technologies and cross-cutting programs into products and services. This group also is requested to define external stakeholders, which should be able to support research groups in defining marketable research topics, bringing technologies to the market, and finance the research projects within the target areas (NSTDA, 2011). In Thailand these stakeholders are the LTUs. 


\subsection{RESEARCH FRAMEWORK}

\begin{tabular}{c} 
Independent variables \\
$\begin{array}{c}\text { Degree of engagement with } \\
\text { external sources of } \\
\text { knowledge via } \\
\text { Contextual and Vicarious } \\
\text { learning activities }\end{array}$ \\
\hline $\begin{array}{c}\text { Engagement with other R\&D } \\
\text { project groups inside NLs }\end{array}$ \\
\hline $\begin{array}{c}\text { Engagement with local } \\
\text { universities }\end{array}$ \\
\hline $\begin{array}{c}\text { Engagement with local } \\
\text { technology users }\end{array}$ \\
\hline $\begin{array}{c}\text { Engagement with } \\
\text { international sources }\end{array}$ \\
\hline
\end{tabular}

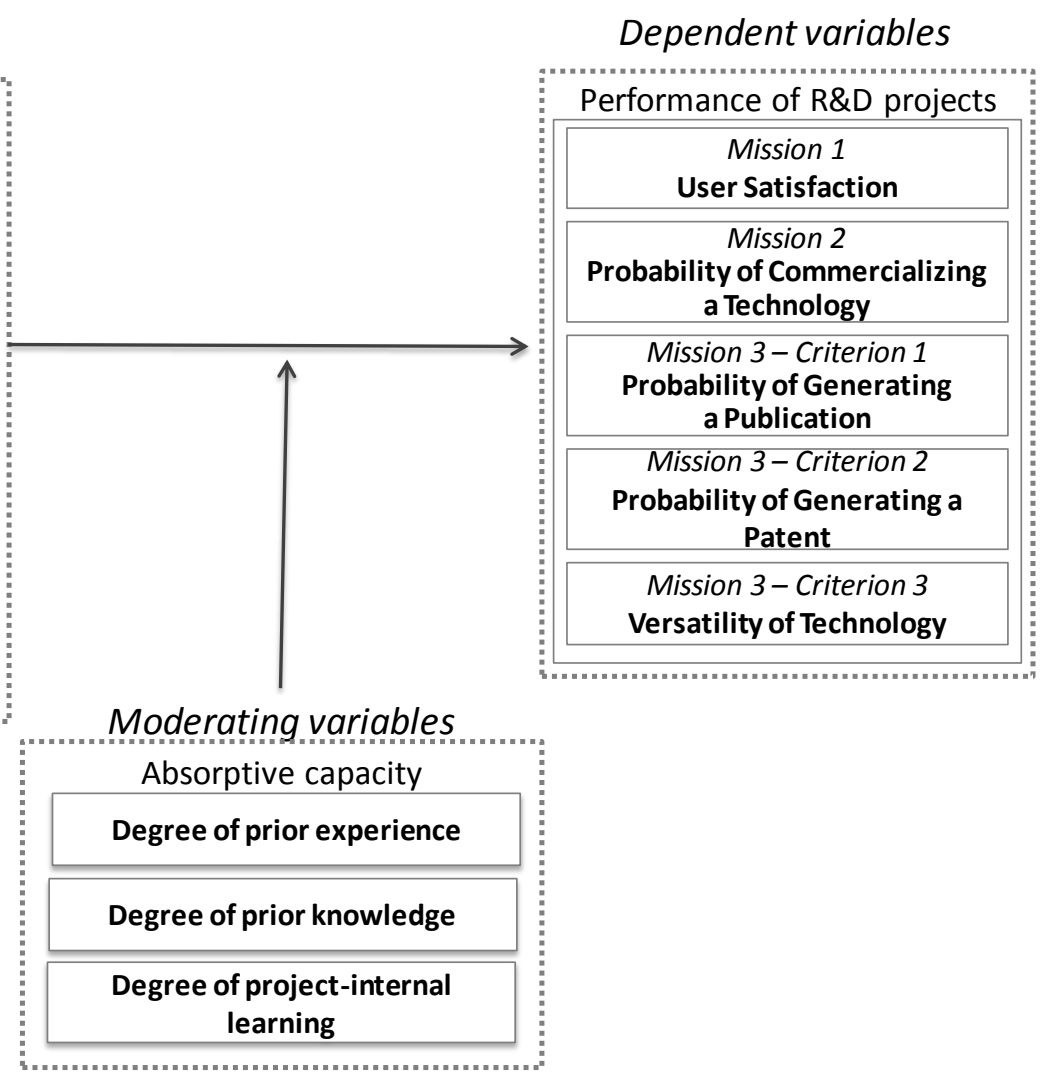

Figure 4.1: Research framework of this study

Figure 4.1 depicts the research framework of this study. This framework contains three sets of variables: independent variables to measure the degree of engagement with external sources of knowledge of each project group; moderating variables to measure the level of internal knowledge of each project group and dependent variables to measure the project performance. The details of measuring the variables are discussed in the section 4.5. In the following section, I discuss a research process that intends to guarantee validity and reliability of the measures. 


\subsection{VALIDITY AND RELIABILITY OF MEASURES}

The validity of measures is generally determined by examining whether or not two or more ways of measuring the same construct give the same results (Judd et al., 1991, p. 26). To develop a good measure, D. R. Cooper \& Emory, 1995, proposed that a researcher has to be concerned about content validity, construct validity, criterion validity, and reliability of the measure. Also, the research needs to consider whether administering the planned survey is practical.

Table 4.1: Validity, reliability, and practicality of the survey questions

\begin{tabular}{|c|c|c|}
\hline $\begin{array}{c}\text { Items } \\
(\text { Cooper and } \\
\text { Emory, 1995) }\end{array}$ & Purpose & How to test \\
\hline $\begin{array}{l}\text { I. Content } \\
\text { validity }\end{array}$ & $\begin{array}{l}\text { Measure the extent to which } \\
\text { the questions provide } \\
\text { adequate cover of the topic } \\
\text { under study }\end{array}$ & $\begin{array}{l}\text { Before conducting the survey: } \\
\text { - use experts' evaluation on the survey questions } \\
\text { - provide the purpose of the questions } \\
\text { - ask experts to comment the questions }\end{array}$ \\
\hline \multirow[t]{2}{*}{$\begin{array}{l}\text { II. Construct } \\
\text { validity }\end{array}$} & \multirow[t]{2}{*}{$\begin{array}{l}\text { Answer "how we measure } \\
\text { what we want to measure" } \\
\text { (Judd et.al., 1991, p. 29) }\end{array}$} & $\begin{array}{l}\text { Before conducting the survey: } \\
\text { - use item scales from literature review } \\
\text { - develop new item scales based on theoretical } \\
\text { review }\end{array}$ \\
\hline & & $\begin{array}{l}\text { After conducting the survey: } \\
\text { - use factor analysis (Cooper and Emory, 1995) }\end{array}$ \\
\hline $\begin{array}{l}\text { III. Criterion } \\
\text { validity }\end{array}$ & $\begin{array}{l}\text { Measure the degree to which } \\
\text { the predictor is adequate in } \\
\text { capturing the relevant } \\
\text { aspects of the criterion }\end{array}$ & $\begin{array}{l}\text { After conducting the survey: } \\
\text { - use correlation (Cooper and Emory, 1995) }\end{array}$ \\
\hline IV. Reliability & $\begin{array}{l}\text { Measure the degree to which } \\
\text { questions are homogeneous } \\
\text { and reflect the same } \\
\text { underlying constructs }\end{array}$ & $\begin{array}{l}\text { After conducting the survey: } \\
\text { - use internal consistency approach (Cooper and } \\
\text { Emory, 1995; Field, 2005) } \\
\text { - by measure Cronbach's Alpha Coefficient, } \\
\text { - which coefficient value should be higher } \\
\text { than } 0.7 \text { for reliable scales (Hair et al., 1995; } \\
\text { Field, 2005) }\end{array}$ \\
\hline V. Practicality & $\begin{array}{l}\text { Consider operational needs in } \\
\text { terms of economy, } \\
\text { convenience, and } \\
\text { interpretability }\end{array}$ & $\begin{array}{l}\text { Before conducting the survey: } \\
\text { - Expense for conducting the survey } \\
\text { - Easy to administer } \\
\text { - Response rate }\end{array}$ \\
\hline
\end{tabular}


Table 4.1 presents the purpose of testing the validity, reliability, and practicality of the survey questions and how to test these criteria. The following section will discuss these issues in detail.

\subsubsection{Content Validity}

Content validity measures the extent to which the questions provide adequate cover of the topic under study. A test of the validity of the content can be conducted prior to administering the survey. A researcher can use expert opinion to evaluate the survey questions (D. R. Cooper \& Emory, 1995). In this study, I will discuss the purpose of each survey question with experts who work in areas that are relevant to my research, and I ask them to comment on the questions.

\subsubsection{Construct Validity}

Construct validity pertains to "how we measure what we want to measure." It addresses the question "To what extent are the constructs of theoretical interest successfully operationalized in the research?” (Judd et al., 1991, p. 29) Trochim \& Donnelly, 2001, linked construct validity to the data gathering and the measurement stage in research. As mentioned earlier, the research performed in this study conducts hypothesis testing. In this type of research, the researcher has to design independent variables and dependent variables and know how to measure them (Judd et al., 1991).

To construct the proper items for independent and dependent variables, "researchers can choose among different alternatives, such as applying existing measurement scales, 
conducting exploratory preliminary studies, making theoretical considerations, or drawing on experiences from practice" (Homburg and Giering, 1996, p. 12, as cited by Herzog, 2008). The first approach of applying existing scale items comes with the major advantage that it allows for comparing results across different studies. Diller (2004) also proposed that "generating new scale items should be avoided whenever possible, because otherwise this will result in a plethora of different measurement scales in the underlying research fields" (Diller, 2004, p. 177 cited by Herzog, 2008). We can observe the second approach of conducting preliminary exploratory studies in the work of Ancona \& Caldwell, 1992 and Bresman, 2010. Their studies intend to identify activities pertaining to external engagement of individual group members. In addition, some research may use mixed approaches to construct items in questionnaire such as theoretical consideration and experience of experts (e.g. Daim, 1998); others generate a set of questions that is based on previously existing measurement scales and theoretical considerations (e.g. Lichtenthaler, 2006b; Herzog, 2008). In this study, I will apply the items scale from the exploratory studies of Ancona \& Caldwell, 1992, and Bresman, 2010, to measure external learning activities of R\&D projects. In cases where no validated scales exist, I develop new scales based on the theoretical descriptions provided in the literature as discussed in section 4.3 and validate them in a pilot test. In addition, after conducting the survey, this study uses factor analysis to address construct validity (D. R. Cooper \& Emory, 1995). Factor analysis helps determine whether the expected relationships among variables exist (Murphy \& Davidshofer, 1991, p. 103). See details in appendix C. 


\subsubsection{Criterion-Related Validity}

A criterion is a measure that can be used to determine the accuracy of a decision. It is also known as a dependent variable or an output variable. In psychometrics, the validity of a criterion is a measure of how well a variable or a set of variables predicts the outcomes based on data from other variables (Murphy \& Davidshofer, 1991; Pennington, 2003). Criterion validity measures the degree to which the predictor is adequate in capturing the relevant aspects of the criterion (D. R. Cooper \& Emory, 1995). The correlation between the predictor and a measure of the outcome (or the criterion) provides an overall measure of the accuracy of predictions. The correlation between the predictor scores and criterion scores can be considered as a measure of the validity of decision (Murphy \& Davidshofer, 1991). To confirm the criterion-related validity, a researcher can use correlation (D. R. Cooper \& Emory, 1995). In this study, the measures of project performance that contributes to the three missions of NLs serve as criteria for evaluating the success of $R \& D$ projects. The degree of engagement with the four main external sources of knowledge and the extent to which a project group can absorb inflows of these four external sources of knowledge constitute the predictors in this study. Thus, after conducting the survey, this study assesses the criterion-related validity from correlation coefficients between the predictors and the criteria. These coefficients can range, in absolute value, from 0.0 to 1.0 (Murphy \& Davidshofer, 1991); appendix C addresses how to interpret these coefficients. 


\subsubsection{Reliability}

This study will use Cronbach's alpha to assess the reliability of the items as presented in questionnaire B. Hair et al., 1995, and Field, 2005, suggested the value of Cronbach's alpha should be higher than .70 for a reliable scale. However, the threshold value may decrease to .60 in exploratory research (Hair et al., 1995).

\subsubsection{Practicality}

D. R. Cooper \& Emory, 1995, suggest that a researcher should consider operational needs in terms of economy, convenience, and interpretability before conducting the survey. The expense for conducting the survey, the ease of administering the survey, and the response rate should be criteria of practicality for a research study.

The practicality of conducting a survey is one of the two main reasons that I design to use R\&D project groups within the 95 laboratories of the NSTDA as the unit of analysis. (The other reason is that Thailand is a technology latecomer country.) I obtained authorization to conduct this research from I requested NSTDA's top management, which enabled me to administer my survey in person. As a result, I had no need to send out direct mail, and I achieved a near-100\% response rate. Delivering the survey in person also allowed me to make sure that the respondents interpreted the questions in the survey in a similar way. I validated the interpretability of the survey questions by a pilot study (for details, please see the following section). 


\subsection{MEASURES}

In this dissertation, most of the independent variables and moderating variables are measured using Likert scales; a few are measured by ordinal scales. Dependent variables are measured by using Likert scales and objective data. To ensure construct and content validity of the measures, I used a two-step design. First, I used item scales from the existing literature and developed new item scales based on theoretical review. This endeavor resulted in a first draft of a questionnaire, which has been presented in appendix B of my original research proposal (Ploykitikoon, 2012). I subsequently evaluated the measures by recruiting 25 experts who work in areas that are relevant to the subject of my dissertation. The experts were asked to evaluate measures in the survey questions with respect to ease of response. As a pilot test of the survey, I also asked the experts to answer the questions in the first draft of the questionnaire. The feedback from the experts was integrated into the final design of the questionnaire, which is presented in appendix $\mathrm{B}$ of this document. Details regarding the variables that were used as measures are given in the subsections of this section.

The experts that validated the measures came from three groups of people. The first group consisted of 10 project managers who are professors and students at Portland State University's Department of Engineering and Technology Management (ETM) who managed projects in private industry. These projects developed technology in the same technical areas that are under study in this dissertation. The second group was composed of 10 project managers who are project managers at national laboratories that are under study in my dissertation. They were excellent candidates for evaluating the ease of 
response of the survey, because the same survey would be administered to their peers. The last group 5 consisted experts who are program directors at national laboratories. They were excellent candidates for evaluating the ease of response of the output variables that measured the performance of project groups, in part because it is part of their job to evaluate the performance of projects within NSTDA.

\subsubsection{Measuring Independent Variables}

My approach to measuring independent variables follows that of Ancona \& Caldwell, 1992, and Bresman, 2010, who measure the impact of external sources of knowledge on organizational performance. These authors develop items scales that can be used to quantify the degree of engagement with external sources of knowledge, just like I did. However, in contrast to my proposed research, Ancona \& Caldwell, 1992, and Bresman, 2010, do not differentiate among a variety of external sources of knowledge. Furthermore, Ancona \& Caldwell, 1992, and Bresman, 2010 observed organizations in the private sector, whereas my dissertation research investigates an organizational environment comprised of public and private institutions. I believe that these differences in context are sufficiently minor for me to be able to apply the approaches used by Ancona \& Caldwell, 1992, and Bresman, 2010, to my research setting.

According to Ancona \& Caldwell, 1992, and Bresman, 2010, contextual learning consists of two main activities that enable knowledge inflows: 1) scanning the environment for information and 2) collecting information from the environment. Thus, I measure contextual learning with a two-item scale: one item elicits information from the 
respondent that quantifies a project group's propensity for scanning its environment for information; the other quantifies a project project's propensity to collect information about its environment. These measures act as proxies for the degree of knowledge inflow into the project group. I apply these items to all potential sources of knowledge under investigation: international sources such as foreign universities and foreign owned companies; domestic sources such as local universities and LTUs, and other project groups within the national laboratories. (Please see questions 11 through 18 in appendix B.) LTUs are referred to as targeted customers in the survey questions because NSTDA specifically targets local technology users as customers.

According to Bresman, 2010, vicarious learning includes two principal activities that facilitate knowledge inflows: 1) inviting experts to discuss how to avoid repeating past mistakes and 2) talking to experts to extract lessons learned to be applied to the project and to determine ways of improving the work process. I measure vicarious learning with a two-item scale: the first item quantifies a tendency to invite external experts for discussing lessons learned from the project's past experiences; the second item extracts the project group's propensity to talk to external experts, in order to discuss lessons learned from the experts' past experiences. In my questionnaire, I use these items as proxy measures for the degree of engagement with external sources of knowledge. Once again, I applied these items to all potential sources of knowledge under investigation: international sources such as foreign universities and foreign owned companies; domestic sources such as local universities and LTUs (which are referred as targeted customers in 
the survey questions), and other project groups within the national laboratories. The items pertaining to vicarious learning are elicited in questions 19 through 28 in appendix B.

Based upon input from the 20 experts in group 1 and 2, I decided to differentiate between two types of LTUs - those that own production units and those that act as end users. LTUs with production units tend to be private companies who have capabilities to scaleup technological knowledge from the national laboratories. End users tend to be persons, private companies or government agencies that are likely to be the customers of LTUs with production units; they have no capabilities to scale-up technological knowledge from the national laboratories. End users and LTUs with production units are not mutually exclusive categories. It is possible for and end user to have a production unit, but it is not possible for an LTU to not be an end user and not have a production unit.

\subsubsection{Measuring Moderating Variables}

It has been proposed in section 2.4.3, that the impact of external sources of knowledge on project performance is affected by the project group's capacity to absorb external knowledge. This absorptive capacity depends upon 1) the degree of relevant experience that the project group has obtained from grafting appropriate technical personnel, 2) the degree of relevant knowledge that the project group has accumulated from previous projects, and 3) the degree of internal learning activities that transpire while the project is active. Variables that measure prior experience, prior knowledge and internal learning activities are described in the following subsections. They are classified as moderating 
variables because they tend to impact the relationship between independent variables and dependent variables (see figure 13).

\subsubsection{Prior Experience}

The degree of relevant prior experience that a project group possesses at the outset of the project is measured by whether at least one group member has relevant prior experience and by the extent of that experience. A project group member's relevant prior experience can consist of post-graduate study or practical work experience in a field that is related to the subject matter covered by the project under study (Zucker et al., 1998; Almeida \& Kogut, 1999; Antal \& Walker, 2011; Hoekman et al., 2005; Ploykitikoon \& Daim, 2010; Chen \& Sun, 2000; Gil et al., 2003). Also, based on the principle of absorptive capacity, W. M. Cohen \& Levinthal, 1990, argue that not all members of a project group need to interact with external entities. Instead, the project group may interact with its environment via a technology gatekeeper (Allen, 1971; Tushman \& Katz, 1980), who takes a lead role in the evaluation and assimilation of external knowledge.

Five kinds of prior experience have been identified for the purpose of this study (in section: 1) post-graduate study at foreign institutions of higher learning; 2) post-graduate study at local universities; 3) work experience at a foreign-owned company; ${ }^{13}$ 4) work experience at local targeted customers; and 5) having worked on projects outside the project group but inside the national laboratories. I consequently propose to measure

\footnotetext{
${ }^{13}$ Work experience at a foreign-owned company could be overseas or within Thailand.
} 
prior experience with a five-item scale: the first item quantifies the extent of educational experience from abroad; the second item elicits the extent of educational experience at local universities; the third item draws out the extent of work experience at a foreignowned company; the fourth item quantifies the extent of work experience with targeted customers (LTUs); and the fifth item extracts the extent of work experience within other project groups inside the national laboratories. These items act as proxy measures for the extent of prior experience at external sources of knowledge that resides within an $R \& D$ project group at the outset of a project. The items are presented in questions 33 through 37 in Appendix B.

\subsubsection{Prior Knowledge}

Nonaka, 1994, argues that organizations create knowledge in a four-stage process that resembles a spiral. First, tacit knowledge is generated through socialization; this knowledge is subsequently converted to explicit knowledge in an externalization process, combined with other explicit knowledge and finally internalized (converted to tacit knowledge) by other parts of the organization. This process repeats, causing new knowledge to be created in and spread across the organization (Nonaka, 1994).

The total prior explicit knowledge within an $R \& D$ project group pertaining to subject matter related to the project under study can be estimated by the total number of patents, copyrights and publications pertaining to the study that the group has accumulated prior to the start of the project under study (Matusik \& Heeley, 2005; Smith et al., 2005 cited by Nemanich et al., 2010). After validating the questionnaire in the pilot test with 20 
experts from group 1 and 2, I decided ask the respondents to rate the total number of patents and publications that were related to the project and had been generated prior to the outset of the project on a 6-point Likert scale (see appendix B, question 38). I also elicited the number of patents and publications directly (see appendix B, questions 7 through 10).

The notion that prior knowledge about the core technology to be developed could affect project performance came up during the pilot test. The experts from group 2 indicated that this kind of knowledge could be important. I subsequently added a question that elicits the level of knowledge about the core technology on an ordinal scale to the questionnaire (see question 7 in appendix B). This question does not ascertain whether knowledge about the core technology is tacit or explicit.

\subsubsection{Project-internal learning activities (PILAs)}

According to Edmondson, 1999, and Bresman, 2010, internal project learning includes the four main project-internal learning activities (PILAs) that allow project groups to absorb knowledge inflows: 1) taking time to figure out ways to improve the work process; 2) reflecting on the group's work progress; 3) speaking up to test assumptions concerning issues that are under discussion among the project group members; and 4) identifying new information that leads to changes. I therefore propose to measure PILAs with a four-item scale. (Please see questions 29 through 32 in appendix B.) 


\subsubsection{Measuring Dependent Variables}

The dependent variables or output variables consist of performance measures that indicate how research and development projects contribute to the three basic missions of NLs in TLCs. The performance measures for each of these missions are discussed below.

\subsubsection{Measuring the Performance of Mission 1}

According to Spann et al., 1995, user satisfaction can be used to assess how effectively a research and development organization within a national laboratory transfers knowledge and technology out of the laboratory. In this study, LTUs are mentioned as the main technological users of NLs' technology. Therefore, the degree of satisfaction of the LTUs should be an excellent proxy measure for how well the NLs in TLCs are performing their first mission (adopting and adapting technology to suit with local demands). During the pilot test, I discovered that best approach for eliciting this information turned out to be asking project managers the following question (Q.39 in appendix B of this dissertation): Based on the results of this project, do you think that the targeted customers of this project will have another collaborative project with your project group in the near future? ${ }^{14}$ The output variable associated with this measure is henceforth referred to as OV1.

\footnotetext{
${ }^{14}$ Originally, I had proposed a two-item scale. I let the respondent rate how the users of the technological innovation that was developed in the project under study were satisfied with that technological innovation as compared to technological innovations generated in other projects. (Please see question 51 and 52 in appendix B of Ploykitikoon, 2012.) I subsequently validated the questionnaire during the pilot test with 5 program directors, who suggested that project managers should be able to provide a right answer for measuring user satisfaction since the project managers tend to have direct contact to the technology users. Then, the two-item scale was validated by asking the experts in group 2, who are 10 project managers at national laboratories. I found that the project managers have difficulty in providing an answer for the two
} 


\subsubsection{Measuring the Performance of Mission 2}

Success in commercializing a technology can help organizations gain additional revenues (Lichtenthaler, 2006b). The revenue generation rate can thus be a criterion to evaluate the NLs' success in mission 2. However, the pilot test revealed that for the revenue generation rate to be an appropriate measure of success in mission 2 , this study needed to control for the size of the project group, as well as for external factors such as the size of the targeted LTUs, many other attributes of the receiving LTUs and the mechanisms for technology transfer. To control for these factors, I used the probability of successfully commercializing a technology that is under development in the project as the performance measure for mission $2 .^{15}$ (Please see question 40 in appendix $\mathrm{B}$ of this dissertation.) The output variable that is associated with this performance measure is henceforth referred to as OV2.

questions that pertain to the degree of user satisfaction with their projects. However, they were able to provide an answer as to whether or not their targeted customers (who are the LTUs in this dissertation) plan to have a follow-on project or a new project with their project groups. I consequently reduced the two-item scale to measure user satisfaction into a one-item scale and integrated it into the questionnaire for project managers.

${ }^{15}$ In section 2.1.2, I had argued two points. First, a project group can generate revenue before the start of a project via a grant or through contract research. Second, a project group can generate revenue after the completion of a project through licensing, consulting and training. Thus, I had originally proposed one item that was based on objective data (please see question 8 in appendix B of Ploykitikoon, 2012), and a twoitem Likert scale as a proxy measure for assessing the performance of mission 2 (please see questions 49 and 50 in appendix B of Ploykitikoon, 2012). During the pilot test, I validated the questions with the experts from group 2 and group 3. I found that the revenue generated from research and development projects tended to depend on not only the size of the project group but also on other external factors. These external factors included type of the targeted customers, sizes of the targeted customers and type of mechanism for transferring technology. For example, technological knowledge developed by a project group can create $\$ 1 \mathrm{M}$ in revenue when it is transferred to a large-size private company or a government agency, which is willing to get exclusive right over the technology. In contrast, similar technological knowledge is likely to generate only $\$ 0.1 \mathrm{M}$, if it is commercialized for small companies. To control the impact of these and other external factors on the success of project groups in technology commercialization, I used the probability of successfully commercializing a technology from the project under development as a measure of mission 2. (Please see question 40 in appendix B.) 


\subsubsection{Measuring the Performance of Mission 3}

A variety of measures characterized the characterization of mission 3, whose purpose is to generate, retain and sustain a national $R \& D$ capability for the future of the country. The most common measure for R\&D output is intellectual property (IP) (Siegel, 2004; Agrawal, 2002; Zucker et al., 2002), which can manifest itself in the form of patents or copyrighted publications and has been shown to enhance the national competitiveness (Tong \& Frame, 1994; Pavitt, 1998; Furman \& Hayes, 2004; Furman et al., 2002; Fagerberg et al., 2007). ${ }^{16}$ During the pilot test, I discovered that most of research projects generate zero, one or two publications or patents per project. I consequently proposed two measures for mission 3: the probability that a project would generate a publication and the probability that a project would generate a patent. (Please see question 41 and 42 in appendix B.) The output variables associated with these measures are henceforth respectively referred to as OV3.1 and OV3.2.

The directors of the research programs (the five experts in group 3) pointed me to the third performance for mission 3-versatility of the technology under development. The

\footnotetext{
${ }^{16}$ Originally, I used the total number of patents, copyrights and publications as a measure of performance for retaining and sustaining national competitiveness in science and technology. However, Pavitt, 1998, contents that IP that is aligned with current and future national goals is more valuable than IP that is not. The degree of alignment of IP with organizational goals can be measured subjectively (Lichtenthaler, 2006b); however, once again, one needs to control for project size. I consequently proposed a two-item scale to assess a project's success in achieving mission 3. One item elicits the relative number of patents, copyrights and publications that the project under study has produced when compared to projects of similar size; the other tries to extract the degree of alignment with the roadmap of the national laboratories. (Please see questions 9.1, 9.2 and 47 of appendix B of Ploykitikoon, 2012.) During the pilot test, I found that the experts had difficulty answering questions pertaining to the number of patents, copyrights and publications that the project under study has produced if the answer was supposed to be normalized for project size. The experts had trouble even when they compared to projects of similar size. It was difficult for them to compare these measures on a Likert scale.
} 
output variable associated with this measure is henceforth referred to as OV3.3. To operationalize this variable, I obtained NSTDA's list of 25 strategic programs for longterm competitiveness, and I asked the project managers to identify as many strategic programs of the national laboratories to which the output of their projects could be applied. (Please see question 3 of appendix B.) ${ }^{17}$ The summation score of the strategic programs to which the output of their projects can be applied is used as a measure of the versatility of the technology that projects generate. The experts believed that this measure contributes towards mission 3 - generating, retaining and sustaining the technological capabilities of the national laboratories.

\subsubsection{Control Variables}

For the control variables, generally, in group studies, there are four variables that influence a project's performance: project size, project resources, project duration and project experience (Ancona \& Caldwell, 1992; Edmondson, 1999; MacCormack et al., 2001; Cummings, 2004; Bresman, 2010). Project size is determined by a count of the members of the project group. Project resources are determined by a count of the number of $\mathrm{PhD}$ researchers who are expected to play a leading role within the project or play the

\footnotetext{
${ }^{17}$ In the pilot test with the experts in group 3, I found that these experts had either difficulty answering the degree of alignment with the roadmap of the national laboratories, or they were likely to provide high score for the degree of alignment for each project under their jurisdiction. The experts proposed another way to ask the degree of contribution of a research project to long-term capabilities of national laboratories. I obtained a list of NSTDA'S 25 strategic programs for long-term competitiveness, and I asked project managers to identify as many strategic programs within the national laboratories as possible to which the output of their projects can be applied. (Please see question 3 of appendix B of this dissertation.) The summation score of strategic programs to which the output of their projects can be applied is used as a measure of the versatility of the technology that projects generate. The experts believed that this measure contributes towards the mission 3-generating, retaining and sustaining technological capabilities of national laboratories.
} 
role of technology gatekeeper. This study counts financial resources as an output variable because they reflect project performance as it pertains to mission 2. A project may gain these financial resources from contract research, collaborative research, or research funds from other government agencies. Project duration is given by the number of months from start to finish of the project. Project experience is a function of prior related knowledge, so this study will consider it as a moderating variable.

Machlup (1962 as cited by Godin, 2007) discussed three stages of technology development: 1) research, 2) applied research, and 3) development and demonstration. Each of the 95 laboratories under observation performs projects at which the technology under development is at one of the three stages of maturity defined by Machlup, 1962. I decided to have the respondents identify in the questionnaire the stage of development of the technology that they were working on in their project, because that item could in principle be correlated to performance.

Ease of learning, technological opportunity and appropriability have been shown to be a function of type of technology (W. M. Cohen \& Levinthal, 1990). Different technologies may also exhibit different degrees of stickiness (von Hippel, 1994; Szulanski, 1996) and asset specificity (Williamson, 1981), which tend to affect the ability to transfer knowledge and correlate to project performance. The 95 laboratories that were under study are in charge of one and only one of the following different groups of technologies-1) biotechnology; 2) materials and nano-materials; and 3) computer and information technology, which are very different from each other. I consequently decided to have the respondents identify the technology group to which their project 
belongs in the questionnaire because that item could in principle be correlated to performance.

\subsubsection{Summary of this Section}

Table 4.2 summarizes this section. It links the variables of this study as they are defined in figure 3.5 and table 2.3 to the corresponding questions in the validated questionnaire in appendix B. It also shows that all variables were validated by a theoretical review and a pilot test that involved up to 25 experts. Some variables were also corroborated by objective data from the NSTDA database. 
Table 4.2: Conclusion of Section on Measurement of Variables in this Dissertation

\begin{tabular}{|c|c|c|}
\hline \begin{tabular}{|c|} 
Variables \\
(Numbers before variables refer to Figure 3.5 and Table \\
$2.3)$
\end{tabular} & $\begin{array}{c}\text { Order in } \\
\text { question- } \\
\text { naire }\end{array}$ & Validation \\
\hline \multicolumn{3}{|l|}{ Measuring Independent Variables } \\
\hline $\begin{array}{l}\text { 1. Degree of engagement with other R\&D projects inside NLs } \\
\text { via contextual learning activities (1. CLAs) }\end{array}$ & Q.11, 15 & $\begin{array}{l}\text { Ancona and Caldwell, 1992; Bresman, } 2010 \\
\text { and pilot test with } 20 \text { experts }\end{array}$ \\
\hline $\begin{array}{l}\text { 2. Degree of engagement with other R\&D projects inside NLs } \\
\text { via vicarious learning activities (2. VLAs) }\end{array}$ & Q.19,20 & Bresman, 2010 and pilot test with 20 experts \\
\hline $\begin{array}{l}\text { 3. Degree of engagement with local universities inside NIS } \\
\text { via contextual learning activities (3. CLAs) }\end{array}$ & Q.12, 16 & $\begin{array}{l}\text { Ancona and Caldwell, 1992; Bresman, } 2010 \\
\text { and pilot test with } 20 \text { experts }\end{array}$ \\
\hline $\begin{array}{l}\text { 4. Degree of engagement with local universities inside NIS } \\
\text { via vicarious learning activities ( } 4 \text {. VLAs) }\end{array}$ & Q.20, 25 & Bresman, 2010 and pilot test with 20 experts \\
\hline $\begin{array}{l}\text { 5. Degree of engagement with local technology users inside } \\
\text { NIS via contextual learning activities (5. CLAs) }\end{array}$ & Q.14, 18 & $\begin{array}{l}\text { Ancona and Caldwell, 1992; Bresman, } 2010 \\
\text { and pilot test with } 20 \text { experts }\end{array}$ \\
\hline $\begin{array}{l}\text { 6. Degree of engagement with local technology users inside } \\
\text { NIS via vicarious learning activities (6. VLAs) }\end{array}$ & $\begin{array}{c}\text { Q.22, 23, } \\
27,28\end{array}$ & Bresman, 2010 and pilot test with 20 experts \\
\hline $\begin{array}{l}\text { 7. Degree of engagement with international sources outside } \\
\text { NIS via contextual learning activities (7. CLAs) } \\
\end{array}$ & Q.13, 17 & $\begin{array}{l}\text { Ancona and Caldwell, 1992; Bresman, } 2010 \\
\text { and pilot test with } 20 \text { experts }\end{array}$ \\
\hline $\begin{array}{l}\text { 8. Degree of engagement with international sources outside } \\
\text { NIS via vicarious learning activities ( } 8 \text {. VLAs) } \\
\end{array}$ & Q.21, 25 & Bresman, 2010 and pilot test with 20 experts \\
\hline \multicolumn{3}{|l|}{ Measuring Moderating Variables } \\
\hline 9. Degree of prior knowledge & \begin{tabular}{|l|} 
Q.7-Q.10, \\
Q.38
\end{tabular} & $\begin{array}{l}\text { Theoretical review based on e.g. Cohen and } \\
\text { Levinthal, 1990; Nemanich et al., } 2010 \text { and } \\
\text { pilot test with } 20 \text { experts }\end{array}$ \\
\hline 10. Degree of prior experience & Q.33-Q.3 & $\begin{array}{l}\text { Theoretical review based on e.g. Allen, 1971; } \\
\text { Huber, } 1991 \text { and pilot test with } 20 \text { experts }\end{array}$ \\
\hline 11. Degree of project internal learning activities (PILAs) & Q.29-Q.32 & $\begin{array}{l}\text { Edmondson, 1999, Bresman, } 2010 \text { and pilot } \\
\text { test with } 20 \text { experts }\end{array}$ \\
\hline \multicolumn{3}{|l|}{ Measuring Control Variables } \\
\hline Stage of technology development & Q.1 & $\begin{array}{l}\text { Theoretical review, pilot test with } 20 \text { experts } \\
\text { and objective data }\end{array}$ \\
\hline Types of technology & Q.2 & $\begin{array}{l}\text { Theoretical review, pilot test with } 20 \text { experts } \\
\text { and objective data }\end{array}$ \\
\hline $\begin{array}{l}\text { Total numbers of staff members working on the project under } \\
\text { study }\end{array}$ & Q.4 & $\begin{array}{l}\text { Theoretical review, pilot test with } 20 \text { experts } \\
\text { and objective data }\end{array}$ \\
\hline $\begin{array}{l}\text { Number of staff members working on the project under study } \\
\text { with Ph.D. as the highest degree }\end{array}$ & Q.5 & $\begin{array}{l}\text { Theoretical review, pilot test with } 20 \text { experts } \\
\text { and objective data }\end{array}$ \\
\hline \multicolumn{3}{|l|}{ Measuring Dependent Variables } \\
\hline $\begin{array}{l}\text { Mission } 1 \text { (OV1): The degree to which the LTUs are satisfied } \\
\text { with the project's performance. }\end{array}$ & Q.39 & $\begin{array}{l}\text { Theoretical review based on Spann et al., } \\
1995 \text { and pilot test with } 25 \text { experts }\end{array}$ \\
\hline $\begin{array}{l}\text { Mission } 2 \text { (OV2): The probability that the } \mathrm{R} \& \mathrm{D} \text { project will } \\
\text { generate revenue for the national laboratories. }\end{array}$ & Q.40 & $\begin{array}{l}\text { Theoretical review based on Lichtenthaler, } \\
\text { 2006, pilot test with } 25 \text { experts and } \\
\text { objective data }\end{array}$ \\
\hline $\begin{array}{l}\text { Mission 3: The degree to which the } R \& D \text { project contributes } \\
\text { to retaining and sustaining tech capabilities: }\end{array}$ & & \multirow{4}{*}{$\begin{array}{l}\text { Theoretical review based on e.g. Pavitt, } \\
\text { 1998; Siegel, 2004; Lichtenthaler, 2006, } \\
\text { pilot test with } 25 \text { experts and objective data }\end{array}$} \\
\hline $\begin{array}{l}\text { Mission } 3.1 \text { (OV3.1): The probability that the } R \& D \text { project } \\
\text { will generate at least one publication }\end{array}$ & Q.41 & \\
\hline $\begin{array}{l}\text { Mission } 3.2 \text { (OV3.2): The probability that the } \mathrm{R} \& \mathrm{D} \text { project } \\
\text { will generate at least one patent }\end{array}$ & Q.42 & \\
\hline $\begin{array}{l}\text { Mission } 3.3 \text { (OV3.3): the degree of versatility of projects } \\
\text { contributing for retaining and sustaining tech capabilities }\end{array}$ & Q.3 & \\
\hline
\end{tabular}




\subsection{DATA COLLECTION}

\subsubsection{Obtaining Authorization to Perform the Study}

I contacted the director of NSTDA, in order to obtain permission for data collection and to ask for lists of NSTDA's research and development projects. Then, I contacted the directors of the three national institutes within NSTDA that are in charge of the 95 laboratories under study, in order to obtain permission for data collection and to gain access to the lists of research projects that were under their jurisdiction. Upon receiving permission to conduct my research from the institute directors, I contacted 124 project managers via telephone to ask them to participate in this study. One hundred twenty-three out of $\mathbf{1 2 4}$ project managers participated in the study, which amounts to a response rate of more than $99 \%$.

\subsubsection{Selection of Projects}

Projects were selected according to two criteria:

1. Projects that have been completed within the past two years were included in this study because the managers should be able to recall the details of every recent project for which they were responsible.

2. The sample was limited to R\&D projects that varied in size from at least 1.5 to at most 7.0 members as calculated by FTE. This criterion controls for project size. 
This yielded a total of 208 projects for the study that fulfill the above project selection criteria.

\subsubsection{Administering the Survey}

The survey for this research was administered via face-to-face interviews with project managers. I was physically present when the respondents completed the survey. The first part of the survey consisted of a questionnaire that elicited quantitative data and had been validated by a process that has been discussed above. I also conducted unstructured interviews with the respondents about issues that concerned their specific projects. These interviews lasted from 30 to 120 minutes. The qualitative data that was gathered in these interviews was primarily used to interpret the quantitative data from the survey. To ensure confidentiality, the interviews were not recorded on video or audio, but I was allowed to take notes.

\subsubsection{The Questionnaire}

The validated questionnaire for project managers is presented in detail in appendix B. The questionnaire consists of three parts; general information in appendix B.1; data concerning the sources of knowledge in appendix B.2 and data concerning the project performance in part appendix B.3. ${ }^{18}$ Appendix B.1 of the questionnaire for project managers includes 10 questions that collect data for control variables (questions 1, 2, 4, 5 and 6); objective data for moderating variables (questions 7 through 10); and data for one

${ }^{18}$ Appendix B.3 asked the project managers about the expected results of their projects. 
dependent variable (OV3.3, question 3). Appendix B.2 consists of 29 items that elicit responses on a Likert scale. This part collects subjective data for independent variables, moderating variables and a dependent variable. The propensity of each project group to engage with external sources of knowledge is measured in questions 11 to 28 . Projectinternal factors are elicited in questions 29 to 38 . The degree of user satisfaction in mission 1 (OV1) is elicited in question 39. Appendix B.3 includes 3 questions concerning the expected results of the projects. Question 40 asks whether the project has generated revenue (OV2). Question 41 asks the respondents to estimate the probability that the project will generate at least one publication in an indexed journal (OV3.1). Question 42 asks the respondents to estimate the probability that the project will generate at least one patent.

Table 4.3 presents the relationships among questions in the questionnaires, research hypotheses, research questions and research gaps of this dissertation. 
Table 4.3: Reseach gaps, research questions, hypothesis and items on the questionnaire

\begin{tabular}{|c|c|c|c|c|c|c|c|c|c|}
\hline \multirow[b]{2}{*}{ RG. } & \multirow[b]{2}{*}{ RQ. } & \multirow[b]{2}{*}{ HP. } & \multicolumn{4}{|c|}{$\begin{array}{l}\text { Items from Conceptual Framwork } \\
\text { (Figure 2.5) }\end{array}$} & \multicolumn{3}{|c|}{ Questions in appendix B } \\
\hline & & & $\begin{array}{l}\text { Exo- } \\
\text { genous } \\
\text { Source }\end{array}$ & $\begin{array}{l}\text { Inflow/ } \\
\text { Internal } \\
\text { Mech- } \\
\text { anism } \\
\end{array}$ & $\begin{array}{l}\text { Critical } \\
\text { Mission }\end{array}$ & $\begin{array}{l}\text { Internal } \\
\text { Know- } \\
\text { ledge }\end{array}$ & $\begin{array}{c}\text { Input } \\
\text { Variables } \\
\text { (App. B) }\end{array}$ & $\begin{array}{c}\text { Mode- } \\
\text { rating } \\
\text { Variables } \\
\text { (App. B) }\end{array}$ & $\begin{array}{c}\text { Output } \\
\text { Variables } \\
\text { (Appendix C) }\end{array}$ \\
\hline \multirow{12}{*}{ RG-1 } & \multirow{12}{*}{ RQ-1 } & $1 \mathrm{a}$ & ORDU & $\begin{array}{l}\text { 1. CLAs } \\
\text { 2. VLAs }\end{array}$ & M1 & none & $\begin{array}{l}\text { Q11,15 } \\
\text { Q } 19,24\end{array}$ & none & Q39 \\
\hline & & $1 b$ & ORDU & $\begin{array}{l}\text { 1. CLAs } \\
\text { 2. VLAs }\end{array}$ & M2 & none & $\begin{array}{l}\text { Q11,15 } \\
\text { Q } 19,24\end{array}$ & none & Q40 \\
\hline & & $1 \mathrm{c}$ & ORDU & $\begin{array}{l}\text { 1. CLAs } \\
\text { 2. VLAs }\end{array}$ & M3 & none & $\begin{array}{l}\text { Q11,15 } \\
\text { Q } 19,24\end{array}$ & none & Q3,Q41,Q42 \\
\hline & & $2 \mathrm{a}$ & LocUniv & $\begin{array}{l}\text { 3. CLAs } \\
\text { 4. VLAs }\end{array}$ & M1 & none & $\begin{array}{l}\text { Q12,16 } \\
\text { Q } 20,25\end{array}$ & none & Q39 \\
\hline & & $2 b$ & LocUniv & $\begin{array}{l}\text { 3. CLAs } \\
\text { 4. VLAs }\end{array}$ & M2 & none & $\begin{array}{l}\text { Q12,16 } \\
\text { Q } 20,25 \\
\end{array}$ & none & Q40 \\
\hline & & $2 c$ & LocUniv & $\begin{array}{l}\text { 3. CLAs } \\
\text { 4. VLAs }\end{array}$ & M3 & none & $\begin{array}{l}\text { Q12,16 } \\
\text { Q 20,25 }\end{array}$ & none & Q3,Q41,Q42 \\
\hline & & $3 a$ & LTUs & $\begin{array}{l}\text { 5. CLAs } \\
\text { 6. VLAs }\end{array}$ & M1 & none & $\begin{array}{l}\text { Q14,18 } \\
\text { Q 22,23,27,28 }\end{array}$ & none & Q39 \\
\hline & & $3 b$ & LTUs & $\begin{array}{l}\text { 5. CLAs } \\
\text { 6. VLAs }\end{array}$ & M2 & none & $\begin{array}{l}\text { Q14,18 } \\
\text { Q 22,23,27,28 }\end{array}$ & none & Q40 \\
\hline & & $3 c$ & LTUs & $\begin{array}{l}\text { 5. CLAs } \\
\text { 6. VLAs }\end{array}$ & M3 & none & $\begin{array}{l}\text { Q14,18 } \\
\text { Q 22,23,27,28 }\end{array}$ & none & Q3,Q41,Q42 \\
\hline & & $4 a$ & InatSrc & $\begin{array}{l}\text { 7. CLAs } \\
\text { 8. VLAs }\end{array}$ & M1 & none & $\begin{array}{l}\text { Q13,17 } \\
\text { Q 21,26 }\end{array}$ & none & Q39 \\
\hline & & $4 b$ & InatSrc & $\begin{array}{l}\text { 7. CLAs } \\
\text { 8. VLAs }\end{array}$ & M2 & none & $\begin{array}{l}\text { Q13,17 } \\
\text { Q 21,26 }\end{array}$ & none & Q40 \\
\hline & & $4 c$ & InatSrc & $\begin{array}{l}\text { 7. CLAs } \\
\text { 8. VLAs }\end{array}$ & M3 & none & $\begin{array}{l}\text { Q13,17 } \\
\text { Q 21,26 }\end{array}$ & none & Q3,Q41,Q42 \\
\hline \multirow[b]{2}{*}{ RG-2 } & \multirow[b]{2}{*}{ RQ-2 } & $5 a$ & InatSrc & $\begin{array}{l}\text { 7. CLAs } \\
\text { 8. VLAs }\end{array}$ & $\mathrm{n} / \mathrm{s}$ & 9. PrKn & $\begin{array}{l}\text { Q13,17 } \\
\text { Q 21,26 }\end{array}$ & Q7-Q10,Q38 & Q3,Q39-Q42 \\
\hline & & $5 b$ & LocUniv & $\begin{array}{l}\text { 3. CLAs } \\
\text { 4. VLAs }\end{array}$ & $\mathrm{n} / \mathrm{s}$ & 9. PrKn & $\begin{array}{l}\text { Q12,16 } \\
\text { Q } 20,25\end{array}$ & Q7-Q10,Q38 & Q3,Q39-Q42 \\
\hline \multirow{4}{*}{ RG-3 } & \multirow{4}{*}{ RQ-3 } & $6 a$ & ORDU & $\begin{array}{l}\text { 1. CLAs } \\
\text { 2. VLAs }\end{array}$ & $\mathrm{n} / \mathrm{s}$ & 10. PrExp & $\begin{array}{l}\text { Q11,15 } \\
\text { Q } 19,24\end{array}$ & Q33-Q37 & Q3,Q39-Q42 \\
\hline & & $6 b$ & LocUniv & $\begin{array}{l}\text { 3. CLAs } \\
\text { 4. VLAs }\end{array}$ & $\mathrm{n} / \mathrm{s}$ & 10. PrExp & $\begin{array}{l}\text { Q12,16 } \\
\text { Q 20,25 }\end{array}$ & Q33-Q37 & Q3,Q39-Q42 \\
\hline & & $6 c$ & LTUs & $\begin{array}{l}\text { 5. CLAs } \\
\text { 6. VLAs }\end{array}$ & $\mathrm{n} / \mathrm{s}$ & 10. PrExp & $\begin{array}{l}\text { Q14,18 } \\
\text { Q 22,23,27,28 }\end{array}$ & Q33-Q37 & Q3,Q39-Q42 \\
\hline & & $6 d$ & InatSrc & $\begin{array}{l}\text { 7. CLAs } \\
\text { 8. VLAs }\end{array}$ & $\mathrm{n} / \mathrm{s}$ & 10. PrExp & $\begin{array}{l}\text { Q13,17 } \\
\text { Q } 21,26\end{array}$ & Q33-Q37 & Q3,Q39-Q42 \\
\hline \multirow{3}{*}{ RG-4 } & \multirow{3}{*}{ RQ-4 } & $7 \mathrm{a}$ & InatSrc & $\begin{array}{l}\text { 7. CLAs } \\
\text { 8. VLAs }\end{array}$ & $\mathrm{n} / \mathrm{s}$ & 11. PILAs & $\begin{array}{l}\text { Q13,17 } \\
\text { Q 21,26 }\end{array}$ & Q29-Q32 & Q3,Q39-Q42 \\
\hline & & $7 \mathrm{~b}$ & LocUniv & $\begin{array}{l}\text { 3. CLAs } \\
\text { 4. VLAs }\end{array}$ & $\mathrm{n} / \mathrm{s}$ & 11. PILAs & $\begin{array}{l}\text { Q12,16 } \\
\text { Q 20,25 }\end{array}$ & Q29-Q32 & Q3,Q39-Q42 \\
\hline & & $7 \mathrm{c}$ & LTUs & $\begin{array}{l}\text { 5. CLAs } \\
\text { 6. VLAs }\end{array}$ & $\mathrm{n} / \mathrm{s}$ & 11. PILAs & $\begin{array}{l}\text { Q14,18 } \\
\text { Q 22,23,27,28 }\end{array}$ & Q29-Q32 & Q3,Q39-Q42 \\
\hline
\end{tabular}

ORDU $=$ Other Research and Development Units (Groups) PrKn $=$ Prior Knowledge

LocUniv $=$ Local Universities (Domestic Engagement)

PILAs $=$ Project Internal Learnng Activities

LTUs $=$ Local Technology Users

obj. = objective data from archives

InatSrc $=$ International Sources

$\mathrm{n} / \mathrm{s}=$ not specific to any particular mission

PrExp $=$ Prior Experience 


\subsection{DATA ANALYSIS}

This section discusses the data analysis process. The data from the questionnaire were entered into a spread sheet and subsequently analyzed by the statistical package SPSS. First I generated the descriptive statistics. These were followed by a factor analysis and a correlation matrix. I subsequently generated a series of multiple regression models for all output variables, which I organized in a hierarchical fashion. Data are displayed in tables and in graphs.

\subsubsection{Descriptive Statistics}

I ran the descriptive statistics to summarize information on the sample. The descriptive statistics can be used to see sample size and distribution of each variable under study. The basic statistics for each variable consist of the sample size, the minimum score, the maximum score, the mean and the standard deviation.

\subsubsection{Factor Analysis and Correlation Matrix}

This study uses factor analysis to confirm construct validity of measurement after conducting the survey (D. R. Cooper \& Emory, 1995) and to reduce the number of variables into a manageable number of meaningful orthogonal factors. ${ }^{19}$ If the factors

\footnotetext{
19 The meaningful factors confirm construct validity of measurement in this study. Construct validity answers how we measure what we want to measure (Judd et al., 1991, p. 29). In general, we can use item scales from existing literature or develop new item scales based on theoretical review to ensure construct validity before conducting the survey, and we can use factor analysis to confirm construct validity after conducting the survey (D. R. Cooper \& Emory, 1995).
} 
that are generated by SPSS align with the hypothesis, then I can be sure that I am measuring what I want to measure (Judd et al., 1991, p. 29). According to Field, 2005, p. 634, "how many factors to extract will depend on why we're doing the analysis in the first place and if you're trying to overcome multi-collinearity problems in regression, then it might be better to extract too many factors then too few." Also, Hair el al. (1995) and Field (2005) suggest that to confirm reliability of measurement, Cronbach's alpha coefficient of each construct should higher than .6 for exploratory factor analysis (Hair et al., 1995; Field, 2005). Therefore, this study extracts the factors by considering the meaning of factors, percentage of the variance explained, and reliability of the construct of each factor.

The factors resulting from factor analysis is used to confirm criterion-related validity of the input factors via correlation analysis. Criterion-related validity measures the degree to which the predictor is adequate in capturing the relevant aspects of the criterion. In addition, we can use correlation analysis to confirm criterion-related validity after conducting the survey (D. R. Cooper \& Emory, 1995). The matrix of correlations helps us to assess the degree of interdependence between variables. It can also be used to ascertain whether there is multi-collinearity amongst the predictors (Field, 2005, p. 179).

\subsubsection{Regression}

To determine the relative impact of the independent variables on the dependent variable, this study uses multiple regression, which is " ... an extension of simple regression in which an outcome is predicted by a linear combination of two or more predictor 
variables" (Field, 2005, p. 738). I use multiple regression for OV1 and OV3.3, which are measured on a Likert scale. I use logistic regression, "a version of multiple regression in which the outcome is dichotomous" (Field, 2005, p. 736), for output variables OV2, OV3.1 and OV3.2, which measure the odds of whether a particular event occurs or not. The details of my use of multiple regression is given in appendix $\mathrm{C}$.

I use two approaches to regression in this study. In the first approach, I include all predictors in the model. In the second approach, I use the stepwise-backward function of SPSS. I choose the model that explains more of the variance of outcome (the highest adjusted $\mathrm{R}^{2}$ ). It turns out that the first approach works better for models that do not include interactions between input variables and moderating variables. Stepwisebackward works better for models that involve interactions between input variables and moderating variables. ${ }^{20}$

\subsubsection{Modified Hierarchical Approach}

The main purpose of this dissertation is to address its stated research questions. This can be done by deploying a hierarchical approach to regression, which consists of building a series of regression models that increase in complexity as new variables are added. Hierarchical approaches are considered standard practice for analyzing models with

\footnotetext{
20 The backward-stepwise method calculates the contribution of each predictor on the outcome by comparing the significance value or the t-test of each predictor against a removal criterion. If a predictor meets the removal criterion or does not improve the prediction power of the model, then it is removed from the analysis. Then the model re-assessed the remaining predictors. Field (2005) also mentioned "the backward method runs lower risk of missing a predictor that predicts the outcome than the forward method" (Field, 2005, pp. 160-161) and it works when the model contains many predictors.
} 
interaction effects (Aiken \& West, 1991; J. Cohen et al., 2003, Espinosa et al., 2007). They help us determine whether the explanatory power of a regression model can be augmented by adding additional blocks of variables. A hierarchical approach typically begins with a baseline model that consists of input variables and necessary control variables. Moderating variables are added as a block to determine whether they increase the explanatory power with respect to the baseline. The interactions between input variables and moderating variables are subsequently added as a block to discern any increase in explanatory power with respect to the model that has integrated the input variables and moderating variables.

The research in this dissertation deploys an extended version of a hierarchical approach to regression that allows me to address research questions RQ-1 through RQ-4 and the fundamental research question that has motivated this dissertation. This approach, which requires a total of five regression models per output variable, is depicted in figure 4.2.

Addressing RQ-1 involves a test of hypotheses H.1 through H.4, which pertain to knowledge inflow. This can be achieved by developing a knowledge inflow baseline (model 1), which includes input variables and input factors that pertain exclusively to knowledge inflow, in addition to some necessary control variables. The impact of internal sources of knowledge on performance can be assessed by generating an integrated model (Model 3), which includes the variables from the knowledge inflow baseline plus a block of moderating variables that pertain to knowledge that resides within or is developed in the various project groups within the national laboratories. If 
the total variance explained by the integrated model significantly exceeds that of the baseline model, then the moderating variables have a significant impact on performance.

Table 4.4: Hierarchy of regression models

\begin{tabular}{|l|c|c|c|c|c|}
\hline \multicolumn{1}{|c|}{ Factors } & $\begin{array}{c}\text { Model 1. } \\
\text { Knowledge } \\
\text { Inflow Baseline }\end{array}$ & $\begin{array}{c}\text { Model 2.1. } \\
\text { Project Group } \\
\text { Baseline }\end{array}$ & $\begin{array}{c}\text { Model 2.2. } \\
\text { Intra- } \\
\text { Organization } \\
\text { Baseline }\end{array}$ & $\begin{array}{c}\text { Model 3. } \\
\text { Integrated } \\
\text { Model }\end{array}$ & $\begin{array}{c}\text { Model 4. } \\
\text { Interaction } \\
\text { Model }\end{array}$ \\
\hline $\begin{array}{l}\text { Factor of moderating } \\
\text { variables } \\
\text { (internal knowledge) }\end{array}$ & Not incl. & Incl. & Incl. & Incl. & Incl. \\
\hline $\begin{array}{l}\text { Factor of independent } \\
\text { variables } \\
\text { (knowledge inflows) }\end{array}$ & Incl. & Not incl. & $\begin{array}{c}\text { Incl. ORDU } \\
\text { only }\end{array}$ & Incl. & Incl. \\
\hline $\begin{array}{l}\text { Interactions between } \\
\text { Factor of moderating } \\
\text { variables and Factor of } \\
\text { independent variables }\end{array}$ & Not incl. & Not incl. & Not incl. & Not incl. & Incl. \\
\hline
\end{tabular}

Research questions RQ-2, RQ-3 and RQ-4, which have given rise to hypotheses H.5, H.6 and H.7, respectively, address issues pertaining to the capacity to absorb knowledge from external sources. Investigating these issues inherently involves studying the interactions between the input variables/factors that pertain to external sources of knowledge and the moderating variables/factors that pertain to internal sources of knowledge. In a hierarchical approach this is best achieved by generating an interaction model (model 4) in which a block of variables that represent the interactions between the input variables/factors and the moderating variables/factors are added to the variables/factors that are already in the integrated model. 
In order to pursue the primary research question that has motivated this dissertation, I need to determine to what degree engagement with the external sources of knowledge affects the performance of $R \& D$ project groups within national laboratories in technological latecomer countries. This requirement calls for a comparison between the magnitude of the impact of knowledge inflows and the magnitude of the impact of knowledge that already exists within or is generated within the various project groups inside national laboratories. To make this comparison, I added an additional regression model to my hierarchy. This project group baseline (model 2.1) contains all the variables/factors that pertain to knowledge that is internal to the project group. I compare the total variance explained by this model to the total variance explained by the knowledge inflow baseline. This comparison gives the managers of the national laboratories insight into the relative impact of external and internal knowledge on the performance of R\&D project groups. This insight can help managers decide whether to allocate more resources to pursuing new $R \& D$ projects as opposed to funding partnerships with external sources of knowledge.

Managers of the national laboratories would also like to gain insight into the impact of collaboration between the various $R \& D$ project groups within their organization. I added an additional regression model to my arsenal of models for this purpose. This intraorganization baseline (model 4) includes all the variables/factors contained in the project group baseline plus variables/factors pertaining to knowledge inflows from other R\&D project groups (ORDUs) within the national laboratories. Managers of the laboratories can assess the impact of collaborative efforts on performance by comparing the total 
variance explained by the intra-organization baseline to the total variance explained by the project group baseline.

The impact of external and internal knowledge on performance may vary from mission to mission. For this reason, I ran all five regression models on all on all five output variables. I used normal multiple regression to quantify the impact on user satisfaction, the performance metric for mission 1 , and on the versatility of the technology that has been developed, one of three output variables associated with mission 3. I ran logistic multiple regressions to assess the impact on the probability of commercializing a technology, the performance metric for mission 2. I also ran logistic multiple regressions to assess the impact on the probability of generating a publication and the probability of generating a patent. Both these output variables are associated with mission 3. I used the $\mathrm{R}^{2}$, the adjusted $\mathrm{R}^{2}$ and the F-ratio to benchmark the variance explained by and the significance of the regular multiple regressions. I used the Cox \& Snell $\mathrm{R}^{2}$, the Nagelkerke's $\mathrm{R}^{2}$, the chi-square and '\% correct' to compare the variance explained by and the significance of the logistic multiple regressions. All of these criteria are described in more detail in appendix $\mathrm{C}$. 


\section{RESEARCH RESULTS}

This chapter presents in five sections the results of the empirical study that has been conducted for this dissertation. After reporting the descriptive statistics in section 5.1, I discuss the results of the factor analysis and the correlation matrix in section 5.2. Section 5.3 compares the various regression models that I have run for the purpose of data analysis. Section 5.4 the findings that pertains to research question RQ-1 (hypotheses 1 through 4). The final section (5.5) covers research questions RQ-2, RQ-3 and RQ-4 (hypotheses 5, 6 and 7, respectively). It discusses results that concern interactions between factors pertaining to knowledge inflows and factors pertaining to project-internal knowledge.

\subsection{DESCRIPTIVE STATISTICS}

This section discusses the descriptive statistics of the most important variables of this study. Tables 5.1 thorough 5.7 display these descriptive statistics on a line-by-line basis. Every line in these tables contains the variable's name, its code, the basic statistics that pertain to the variable, and the corresponding item in the questionnaire in appendix B. This approach allows the reader to trace an individual statistic to the corresponding item in the questionnaire through which data for the statistic has been elicited. All items in table 5.1 through table 5.7 exhibit sufficient variability to enable further statistical analysis. 
Table 5.1: General information about projects in the national laboratories

\begin{tabular}{|c|c|c|c|c|c|c|c|}
\hline & Code & $\mathrm{N}$ & Min & Max & Mean & $\begin{array}{l}\text { Std. } \\
\text { Dev. }\end{array}$ & $\begin{array}{l}\text { Questions' order in } \\
\text { questionnaire }\end{array}$ \\
\hline Project ID & Project ID & & & & & & \\
\hline Basic research & Basic_stg. & 208 & 0 & 1 & .13 & .342 & $\begin{array}{l}\text { Q.1 R\&D strategy: Please } \\
\text { classify the project by stage } \\
\text { of technological development } \\
\text { by using the definitions from } \\
\text { below. }\end{array}$ \\
\hline $\begin{array}{l}\text { Applied } \\
\text { research }\end{array}$ & App_stg. & 208 & 0 & 1 & .25 & .437 & \\
\hline $\begin{array}{l}\text { Development } \\
\text { and } \\
\text { demonstration }\end{array}$ & DD_stg. & 208 & 0 & 1 & .62 & .488 & \\
\hline Bio technology & Bio_tech. & 208 & 0 & 1 & .28 & .450 & $\begin{array}{l}\text { Q.2 Please classify the project } \\
\text { by technology type. }\end{array}$ \\
\hline $\begin{array}{l}\text { Material and } \\
\text { Nano } \\
\text { technology }\end{array}$ & MN_tech. & 208 & 0 & 1 & .36 & .481 & \\
\hline $\begin{array}{l}\text { Computer and } \\
\text { software } \\
\text { technology }\end{array}$ & ES_tech. & 208 & 0 & 1 & .36 & .481 & \\
\hline $\begin{array}{l}\text { Number of } \\
\text { project group } \\
\text { members }\end{array}$ & NO_mem & 208 & 1.5 & 7.0 & 2.319 & .597 & $\begin{array}{l}\text { Q.4 Number of full-time } \\
\text { members working on this } \\
\text { project }\end{array}$ \\
\hline $\begin{array}{l}\text { Number of } \mathrm{PhD} \\
\text { in project } \\
\text { group }\end{array}$ & NO_PhD & 208 & .0 & 5.0 & 1.538 & 1.133 & $\begin{array}{l}\text { Q.5 Number of full-time } \\
\text { members working on this } \\
\text { project with Ph.D. as the } \\
\text { highest degree }\end{array}$ \\
\hline $\begin{array}{l}\text { Number of MSc } \\
\text { in project } \\
\text { group }\end{array}$ & NO_MSc & 208 & .0 & 7.0 & 1.793 & 1.319 & $\begin{array}{l}\text { Q.6 Number of full-time } \\
\text { members working on this } \\
\text { project with Masters as the } \\
\text { highest degree }\end{array}$ \\
\hline
\end{tabular}

Table 5.1 provides general information about the projects in the national laboratories. These include the development stage of the project and the technology group to which the project belongs. However, the sample size was not large enough to draw any conclusions that were specific the technology group or stage of development. Table 5.1 also displays data pertaining to project staffing and the level of education of the staff that works on the project. 
Table 5.2: Descriptive Statistics Pertaining to Output Variables

\begin{tabular}{|c|c|c|c|c|c|c|c|}
\hline & Code & $\mathrm{N}$ & Min & Max & Mean & $\begin{array}{l}\text { Std. } \\
\text { Dev. }\end{array}$ & $\begin{array}{l}\text { Questions' order in } \\
\text { questionnaire }\end{array}$ \\
\hline $\begin{array}{l}\text { Mission 1: } \\
\text { User } \\
\text { Satisfaction }\end{array}$ & $\begin{array}{c}\text { OV1_Sat_- } \\
\text { LTUSs }\end{array}$ & 194 & 1.0 & 6.0 & 3.982 & 1.510 & $\begin{array}{l}\text { Q.39 Based on the results of } \\
\text { this project, do you think } \\
\text { that the targeted customers } \\
\text { of this project will have } \\
\text { another collaborative project } \\
\text { with your project group in } \\
\text { the near future? }\end{array}$ \\
\hline $\begin{array}{l}\text { Mission 2: } \\
\text { Probability } \\
\text { of Commer- } \\
\text { cialization } \\
\text { of } \\
\text { Technology }\end{array}$ & $\begin{array}{l}\text { OV2_Prob_ } \\
\text { Rev }\end{array}$ & 208 & .00 & 1.00 & .476 & .501 & $\begin{array}{l}\text { Q.40 Has any income (in kind } \\
\text { or in cash) resulted from this } \\
\text { project? And, is any income } \\
\text { expected to result from this } \\
\text { project? }\end{array}$ \\
\hline $\begin{array}{l}\text { Mission 3.1: } \\
\text { Probability } \\
\text { of } \\
\text { Generating } \\
\text { Publication }\end{array}$ & $\begin{array}{l}\text { OV3.1_Prob } \\
\text { JrPub }\end{array}$ & 208 & .0 & 1.0 & .322 & .468 & $\begin{array}{l}\text { Q.41 Have any publications in } \\
\text { peer-reviewed journals } \\
\text { resulted from this project? } \\
\text { Have you submitted any } \\
\text { manuscripts for publication } \\
\text { in peer-reviewed journals? } \\
\text { And, do you expect this } \\
\text { project to yield any } \\
\text { publications in peer- } \\
\text { reviewed journals? }\end{array}$ \\
\hline $\begin{array}{l}\text { Mission 3.2: } \\
\text { Probability } \\
\text { of } \\
\text { Generating } \\
\text { Intellectual } \\
\text { Property }\end{array}$ & $\begin{array}{l}\text { OV3.2_Prob_ } \\
\text { Patent }\end{array}$ & 208 & .00 & 1.00 & .375 & .485 & $\begin{array}{l}\text { Q.42 Did any patents resulted } \\
\text { from this project? Have you } \\
\text { filed for any patents that are } \\
\text { based on work that was } \\
\text { conducted for this project? } \\
\text { And, do you expect this } \\
\text { project to yield any patents? }\end{array}$ \\
\hline $\begin{array}{l}\text { Mission 3.3: } \\
\text { Versatility } \\
\text { of } \\
\text { Technology }\end{array}$ & $\begin{array}{l}\text { OV3.3_Ver_ } \\
\text { Tech }\end{array}$ & 208 & .0 & 14.0 & 2.370 & 1.712 & $\begin{array}{l}\text { Q.3 Please identify as many } \\
\text { strategic programs of } \\
\text { NSTDA as possible, to } \\
\text { which the output of this } \\
\text { project can be applied. }\end{array}$ \\
\hline
\end{tabular}

Table 5.2 summarizes the descriptive statistics that pertain to the output variables for all critical missions. The results for mission 1 show that the project managers tend to agree that, on average, their targeted local technology users are somewhat satisfied with the collaborative efforts between the users and projects within the national laboratories. (The 
lower sample size of 194 samples for OV1 results from respondents not being able to answer all questions in the survey.) As for mission 2, the descriptive statistics show that $47.6 \%$ of all projects in the sample were able to commercialize at least one technology over the two-year period that preceded the survey. The NSTDA database validates this conclusion.

The scores for the output variables for mission 3 suggest that a substantial effort was being put into developing a long-term R\&D capability. At least one publication (journal article with citation index, Q.41.1-41.3) was expected from $32.2 \%$ of all projects that were completed within the two-year period that preceded the survey, and at least one item of patent was expected from $37.5 \%$ of all projects over the two-year period that preceded the survey. Finally, the mean score of 2.37 means a project that has been completed within the last two years should yield technology that can be applied in between 2 to 3 technologies on average. This score comes from multiple choices for industry applications in up to 20 strategic programs (strategic program ' $a$ ' to ' $t$ ' as described in appendix B). In this dissertation, the number of strategic programs, in which the output of the project can be applied, is translated into an ordinal scale for further statistical analysis (see appendix D). 
Table 5.3: Descriptive Statistics Pertaining to Contextual Learning Activities

\begin{tabular}{|c|c|c|c|c|c|c|c|}
\hline & Code & $\overline{\mathrm{N}}$ & Min & Max & Mean & $\begin{array}{l}\text { Std. } \\
\text { Dev. }\end{array}$ & $\begin{array}{l}\text { Questions' order in } \\
\text { questionnaire }\end{array}$ \\
\hline $\begin{array}{l}\text { Contextual } \\
\text { learning with } \\
\text { other R\&D } \\
\text { units } 1\end{array}$ & $\begin{array}{l}\text { IV1_ORDU_ } \\
\text { CLA1 }\end{array}$ & 208 & 1.0 & 6.0 & 1.875 & 1.0918 & $\begin{array}{l}\text { Q.11 At least some } \\
\text { members of our project } \\
\text { group looked for technical } \\
\text { ideas in internal reports } \\
\text { inside NSTDA. }\end{array}$ \\
\hline $\begin{array}{l}\text { Contextual } \\
\text { learning with } \\
\text { local } \\
\text { universities } 1\end{array}$ & $\begin{array}{l}\text { IV2_LocUniv_ } \\
\text { CLA1 }\end{array}$ & 208 & 1.0 & 6.0 & 2.111 & 1.1174 & $\begin{array}{l}\text { Q.12 At least some } \\
\text { members of our project } \\
\text { group looked for technical } \\
\text { ideas in papers, reports } \\
\text { and websites published by } \\
\text { universities inside } \\
\text { Thailand. }\end{array}$ \\
\hline $\begin{array}{l}\text { Contextual } \\
\text { learning with } \\
\text { internatinal } \\
\text { sources } 1\end{array}$ & $\begin{array}{l}\text { IV3_InatSrc } \\
\text { CLA1 }\end{array}$ & 208 & 1.0 & 6.0 & 4.250 & 1.4159 & $\begin{array}{l}\text { Q.13 At least some } \\
\text { members of our project } \\
\text { group looked for technical } \\
\text { ideas in papers, reports } \\
\text { and websites that were } \\
\text { published by foreign } \\
\text { universities and foreign- } \\
\text { owned companies. }\end{array}$ \\
\hline $\begin{array}{l}\text { Contextual } \\
\text { learning with } \\
\text { technology } \\
\text { users } 1\end{array}$ & $\begin{array}{l}\text { IV4_LTUs } \\
\text { CLA1 }\end{array}$ & 208 & 1.0 & 6.0 & 3.212 & 1.4657 & $\begin{array}{l}\text { Q.14 To understand the } \\
\text { needs of our targeted } \\
\text { customers, at least some } \\
\text { members of our project } \\
\text { group looked for technical } \\
\text { requirements in industry } \\
\text { newsletters, bulletins, } \\
\text { websites and trade } \\
\text { journals. }\end{array}$ \\
\hline $\begin{array}{l}\text { Contextual } \\
\text { learning with } \\
\text { other R\&D } \\
\text { units } 2\end{array}$ & $\begin{array}{l}\text { IV5_ORDU_ } \\
\text { CLA2 }\end{array}$ & 208 & 1.0 & 6.0 & 2.236 & 1.1619 & $\begin{array}{l}\text { Q.15 At least some } \\
\text { members of our project } \\
\text { group looked for data on } \\
\text { what other teams inside } \\
\text { NSTDA were doing on } \\
\text { similar or complementary } \\
\text { projects. }\end{array}$ \\
\hline $\begin{array}{l}\text { Contextual } \\
\text { learning with } \\
\text { local } \\
\text { universities } 2\end{array}$ & $\begin{array}{l}\text { IV6_LocUniv_ } \\
\text { CLA2 }\end{array}$ & 208 & 1.0 & 6.0 & 2.438 & 1.1992 & $\begin{array}{l}\text { Q.16 At least some } \\
\text { members of our project } \\
\text { group looked for data on } \\
\text { what other teams at } \\
\text { universities inside } \\
\text { Thailand were doing on } \\
\text { similar or complementary } \\
\text { projects. }\end{array}$ \\
\hline $\begin{array}{l}\text { Contextual } \\
\text { learning with } \\
\text { internatinal } \\
\text { sources } 2\end{array}$ & $\begin{array}{l}\text { IV7_InatSrc } \\
\text { CLA2 }\end{array}$ & 208 & 1.0 & 6.0 & 4.029 & 1.3483 & $\begin{array}{l}\text { Q.17 At least some } \\
\text { members of our project } \\
\text { group looked for data on } \\
\text { what other teams at } \\
\text { foreign universities and }\end{array}$ \\
\hline
\end{tabular}




\begin{tabular}{|l|c|c|c|c|c|c|c|}
\hline & Code & N & Min & Max & Mean & $\begin{array}{c}\text { Std. } \\
\text { Dev. }\end{array}$ & $\begin{array}{c}\text { Questions' order in } \\
\text { questionnaire }\end{array}$ \\
\hline & & & & & & & $\begin{array}{l}\text { foreign-owned companies } \\
\text { were doing on similar or } \\
\text { complementary projects. }\end{array}$ \\
\hline $\begin{array}{l}\text { Contextual } \\
\text { learning with } \\
\text { technology } \\
\text { users 2 }\end{array}$ & $\begin{array}{c}\text { IV8_LTUs_ } \\
\text { CLA2 }\end{array}$ & 208 & 1.0 & 6.0 & 3.250 & 1.5180 & $\begin{array}{l}\text { Q.18 At least some } \\
\text { members of our project } \\
\text { group looked for data on } \\
\text { what our targeted } \\
\text { customers were doing on } \\
\text { similar or complementary } \\
\text { projects. }\end{array}$ \\
\hline
\end{tabular}

Table 5.3 explains descriptive statistics pertaining to contextual learning activities (CLAs). The questions regarding contextual learning activities with the four main sources of knowledge are measured in 6-point Likert Scale (see appendix B). The sources of knowledge include other R\&D project groups within laboratories (ORDU); local sources of knowledge such as LTUs and local universities (Loc_Univ); and international sources of knowledge (InatSrc) such as foreign universities and foreign-owned companies. The results show that the score for contextual learning activities with international sources of knowledge is high on average, whereas the score for contextual learning activities with local universities and other R\&D units within the national laboratories is low on average. In particular, on average, the score for looking for new ideas in internal reports produced by other project groups within the national laboratories is rather low. For example, on average the project groups engage in contextual learning with international sources $1(\mathrm{M}$ $=4.250, \mathrm{SE}=.098)$, significantly greater than other $\mathrm{R} \& \mathrm{D}$ project groups within laboratories $1(\mathrm{M}=1.875, \mathrm{SE}=.076, \mathrm{t}(207)=18.72, \mathrm{p}<.001)$; local universities $1 \quad(\mathrm{M}=$ 2.111, $\mathrm{SE}=.077, \mathrm{t}(207)=18.26, \mathrm{p}<.001)$ and LTUs1 $(\mathrm{M}=3.21, \mathrm{SE}=.101, \mathrm{t}(207)=$ $7.76, \mathrm{p}<.001)$. 
Table 5.4: Descriptive Statistics Pertaining to Vicarious Learning Activities

\begin{tabular}{|c|c|c|c|c|c|c|c|}
\hline & Code & $\mathrm{N}$ & Min & Max & Mean & $\begin{array}{l}\text { Std. } \\
\text { Dev. }\end{array}$ & $\begin{array}{l}\text { Questions' order in } \\
\text { questionnaire }\end{array}$ \\
\hline $\begin{array}{l}\text { Vicarious } \\
\text { learning with } \\
\text { other R\&D } \\
\text { units } 1\end{array}$ & $\begin{array}{l}\text { IV9_ORDU_ } \\
\text { VLA1 }\end{array}$ & 208 & 1.0 & 6.0 & 2.531 & 1.436 & $\begin{array}{l}\text { Q.19 Experts within } \\
\text { NSTDA talked to our } \\
\text { project group about the } \\
\text { lessons learned from } \\
\text { their past experiences. }\end{array}$ \\
\hline $\begin{array}{l}\text { Vicarious } \\
\text { learning with } \\
\text { local } \\
\text { universities 1 }\end{array}$ & $\begin{array}{l}\text { IV10_LocUniv_ } \\
\text { VLA } 1\end{array}$ & 208 & 1.0 & 6.0 & 2.543 & 1.375 & $\begin{array}{l}\text { Q.20 Experts from } \\
\text { universities inside } \\
\text { Thailand talked to our } \\
\text { project group about the } \\
\text { lessons learned from } \\
\text { their past experiences. }\end{array}$ \\
\hline $\begin{array}{l}\text { Vicarious } \\
\text { learning with } \\
\text { internatinal } \\
\text { sources } 1\end{array}$ & $\begin{array}{l}\text { IV11_InatSrc_ } \\
\text { VLA1 }\end{array}$ & 208 & 1.0 & 6.0 & 2.005 & 1.309 & $\begin{array}{l}\text { Q.21 Experts from foreign } \\
\text { universities and foreign- } \\
\text { owned companies talked } \\
\text { to our project group } \\
\text { about the lessons } \\
\text { learned from their past } \\
\text { experiences. }\end{array}$ \\
\hline $\begin{array}{l}\text { Vicarious } \\
\text { learning with } \\
\text { production } \\
\text { units } 1\end{array}$ & $\begin{array}{l}\text { IV12_LTUsPU_ } \\
\text { VLA1 }\end{array}$ & 208 & 1.0 & 6.0 & 3.053 & 1.754 & $\begin{array}{l}\text { Q.22 Our targeted } \\
\text { customers who have } \\
\text { production units talked } \\
\text { to our project group } \\
\text { about how to develop } \\
\text { technology that is } \\
\text { suitable for their } \\
\text { requirements. }\end{array}$ \\
\hline $\begin{array}{l}\text { Vicarious } \\
\text { learning within } \\
\text { end users } 1\end{array}$ & $\begin{array}{l}\text { IV13_LTUsEU_ } \\
\text { VLA1 }\end{array}$ & 208 & 1.0 & 6.0 & 2.817 & 1.547 & $\begin{array}{l}\text { Q.23 Our targeted } \\
\text { customers who are end } \\
\text { users talked to our } \\
\text { project group about how } \\
\text { to develop technology } \\
\text { that is suitable for their } \\
\text { requirements. }\end{array}$ \\
\hline $\begin{array}{l}\text { Vicarious } \\
\text { learning with } \\
\text { other R\&D } \\
\text { units } 2\end{array}$ & $\begin{array}{l}\text { IV14_ORDU_ } \\
\text { VLA2 }\end{array}$ & 208 & 1.0 & 6.0 & 2.519 & 1.411 & $\begin{array}{l}\text { Q.24 At least some } \\
\text { members of our project } \\
\text { group talked to experts } \\
\text { within NSTDA about } \\
\text { lessons learned from our } \\
\text { past experiences. }\end{array}$ \\
\hline $\begin{array}{l}\text { Vicarious } \\
\text { learning with } \\
\text { local } \\
\text { universities } 2\end{array}$ & $\begin{array}{l}\text { IV15_LocUniv_ } \\
\text { VLA2 }\end{array}$ & 208 & 1.0 & 6.0 & 2.606 & 1.369 & $\begin{array}{l}\text { Q.25 At least some } \\
\text { members of our project } \\
\text { group talked to experts } \\
\text { within universities } \\
\text { inside Thailand about } \\
\text { lessons learned from our } \\
\text { past experiences. }\end{array}$ \\
\hline $\begin{array}{l}\text { Vicarious } \\
\text { learning with } \\
\text { internatinal } \\
\text { sources } 2\end{array}$ & $\begin{array}{l}\text { IV16_InatSrc } \\
\text { VLA } 2\end{array}$ & 208 & 1.0 & 6.0 & 2.077 & 1.205 & $\begin{array}{l}\text { Q.26 At least some } \\
\text { members of our project } \\
\text { group talked to experts } \\
\text { from foreign universities }\end{array}$ \\
\hline
\end{tabular}




\begin{tabular}{|c|c|c|c|c|c|c|c|}
\hline & Code & $\mathrm{N}$ & Min & Max & Mean & $\begin{array}{l}\text { Std. } \\
\text { Dev. }\end{array}$ & $\begin{array}{c}\text { Questions' order in } \\
\text { questionnaire }\end{array}$ \\
\hline & & & & & & & $\begin{array}{l}\text { and foreign-owned } \\
\text { companies about lessons } \\
\text { learned from our past } \\
\text { experiences. }\end{array}$ \\
\hline $\begin{array}{l}\text { Vicarious } \\
\text { learning with } \\
\text { production } \\
\text { units } 2\end{array}$ & $\begin{array}{l}\text { IV17_LTUsPU } \\
\text { VLA } 2\end{array}$ & 208 & 1.0 & 6.0 & 3.216 & 1.798 & $\begin{array}{l}\text { Q.27 At least some } \\
\text { members of our project } \\
\text { group talked to our } \\
\text { targeted customers who } \\
\text { have production units to } \\
\text { determine ways to } \\
\text { improve our project. }\end{array}$ \\
\hline $\begin{array}{l}\text { Vicarious } \\
\text { learning with } \\
\text { end users } 2\end{array}$ & $\begin{array}{l}\text { IV18_LTUsEU } \\
\text { VLA } 2\end{array}$ & 208 & 1.0 & 6.0 & 3.053 & 1.677 & $\begin{array}{l}\text { Q.28 At least some } \\
\text { members of our project } \\
\text { group talked to our } \\
\text { targeted customers who } \\
\text { are end users to } \\
\text { determine ways to } \\
\text { improve our project. }\end{array}$ \\
\hline
\end{tabular}

Table 5.4 depicts the descriptive statistics pertaining to vicarious learning activities (VLAs). The questions regarding vicarious learning activities with the four main sources of knowledge are measured in 6-point Likert Scale (see appendix B). The sources of knowledge include knowledge inflows from other $R \& D$ project groups within laboratories (ORDU), local universities (Loc_Univ), international sources of knowledge (InatSrc), and local sources of knowledge LTUs. The study also classifies vicarious learning activities with LTUs into two types: vicarious learning with LTUs who have production units and vicarious learning with LTUs who are end users.

The results in table 5.4 suggest that the project groups within the national laboratories, on average, tend not to pursue vicarious learning very aggressively with any external source of knowledge. The mean for all scores for vicarious learning was below the midpoint of 3.5 . 
Table 5.5: Descriptive Statistics Pertaining to Prior Knowledge

\begin{tabular}{|l|l|c|c|c|c|c|c|}
\hline & Code & N & Min & Max & Mean & $\begin{array}{c}\text { Std. } \\
\text { Dev. }\end{array}$ & $\begin{array}{c}\text { Questions' order in } \\
\text { questionnaire }\end{array}$ \\
\hline $\begin{array}{l}\text { Prior } \\
\text { knowledge in } \\
\text { core } \\
\text { technology }\end{array}$ & $\begin{array}{l}\text { MV1_PrKn_ } \\
\text { Core }\end{array}$ & 208 & 1.0 & 6.0 & 4.971 & 1.7581 & $\begin{array}{l}\text { Q.7 How long was your group } \\
\text { developing technology that } \\
\text { is directly relevant or useful } \\
\text { to this project? }\end{array}$ \\
\hline $\begin{array}{l}\text { Prior } \\
\text { knowledge in } \\
\text { journal } \\
\text { publications }\end{array}$ & MV2_PrKn_Jr & 208 & 1.0 & 6.0 & 2.156 & 1.8286 & $\begin{array}{l}\text { Q.8 How many journal } \\
\text { publications that were } \\
\text { directly relevant or useful to } \\
\text { this project did your project } \\
\text { group generate before this } \\
\text { project began? }\end{array}$ \\
\hline $\begin{array}{l}\text { Prior } \\
\text { knowledge in } \\
\text { patents }\end{array}$ & $\begin{array}{c}\text { MV4_PrKn_- } \\
\text { Pat }\end{array}$ & 208 & 1.0 & 6.0 & 1.611 & 1.2384 & $\begin{array}{l}\text { Q.10 How many patents that } \\
\text { were directly relevant or } \\
\text { useful to this project did } \\
\text { your project group generate } \\
\text { before this project began? }\end{array}$ \\
\hline $\begin{array}{l}\text { Prior } \\
\text { knowledge } \\
\text { level of } \\
\text { project group } \\
\text { project, our project group } \\
\text { generated a lot of patents } \\
\text { and publications that are } \\
\text { relevant to this project. }\end{array}$ \\
\hline
\end{tabular}

Table 5.5 presents the descriptive statistics that pertain to prior knowledge (PrKn), which is considered a type of internal knowledge in this study. Three of the four questions regarding prior knowledge (Q.7, Q.8, and Q.10 in appendix B) are also measured in ordinal scale, and the other (Q.38 in appendix B) is measured on a 6-point Likert Scale. Knowledge gained before the project starts is measured in a variety of forms including years of experience in developing the core technology (PrKn_Core), number of cumulative journal publications (PrKn_Jr), number of cumulative patents ( $\left.\mathrm{PrKn} \_\mathrm{Pat}\right)$, and the perspective of project managers on knowledge level of their project groups (PrKn_Lev). The results show that on average the score for PrKn_Core $(\mathrm{M}=4.971, \mathrm{SE}=$ .1219), is significantly higher than the scores for cumulative journal publications ( $\mathrm{M}=$ $2.156, \mathrm{SE}=.1268, \mathrm{t}(207)=18.64, \mathrm{p}<.001)$, total number of patents $(\mathrm{M}=1.611, \mathrm{SE}=$ 
$.0859, \mathrm{t}(207)=24.44, \mathrm{p}<.001)$, and the managers' rating of prior knowledge $(\mathrm{M}=2.904$, $\mathrm{SE}=.1075, \mathrm{t}(207)=15.18, \mathrm{p}<.001)$. This result underlines the importance of PrKn_Core in NLs.

Table 5.6: Descriptive Statistics Pertaining to Project-Internal Learning Activities

\begin{tabular}{|c|c|c|c|c|c|c|c|}
\hline & Code & N & Min & Max & Mean & $\begin{array}{c}\text { Std. } \\
\text { Dev. }\end{array}$ & $\begin{array}{c}\text { Questions' order in } \\
\text { questionnaire }\end{array}$ \\
\hline $\begin{array}{c}\text { Project-internal } \\
\text { learning } \\
\text { activity 1 }\end{array}$ & MV5_PILA1 & 208 & 1.0 & 6.0 & 4.125 & 1.144 & $\begin{array}{l}\text { Q.29 Our project group took } \\
\text { time to figure out ways to } \\
\text { improve our work process. }\end{array}$ \\
\hline $\begin{array}{c}\text { Project-internal } \\
\text { learning } \\
\text { activity 2 }\end{array}$ & MV6_PILA2 & 208 & 1.0 & 6.0 & 4.298 & 1.045 & $\begin{array}{l}\text { Q.30 Our project group took } \\
\text { time to monitor our project's } \\
\text { work progress. }\end{array}$ \\
\hline $\begin{array}{c}\text { Project-internal } \\
\text { learning } \\
\text { activity 3 }\end{array}$ & MV7_PILA3 & 208 & 2.0 & 6.0 & 4.320 & 1.040 & $\begin{array}{l}\text { Q.31 Individuals within our } \\
\text { project group spoke up to } \\
\text { challenge technical } \\
\text { assumptions concerning } \\
\text { issues that were under } \\
\text { discussion among members } \\
\text { of our project group. }\end{array}$ \\
\hline $\begin{array}{c}\text { Project-internal } \\
\text { learning } \\
\text { activity 4 }\end{array}$ & MV8_PILA4 & 208 & 2.0 & 6.0 & 4.442 & 1.009 & $\begin{array}{l}\text { Q.32 The project group } \\
\text { implemented suggestions } \\
\text { made by team members. }\end{array}$ \\
\hline
\end{tabular}

Table 5.6 presents descriptive statistics pertaining to project-internal learning activities (PILAs). The questions regarding PILAs are measured in 6-point Likert Scale (see Q.2932 in appendix B). PILAs include taking time to figure out ways to improve work process of the project (PILA1), taking time to monitor project's work progress (PILA2), speaking up of project members to challenge technical assumptions concerning issues that were under discussion among members of the project group (PILA3) and implementation of suggestions made by team members (PILA 4). The results show that the scores for the questions regarding PILAs in the sample are high on average. This suggests that the 
project managers tend to believe that there is a high degree of interaction among members of their project groups.

Table 5.7 presents descriptive statistics pertaining to prior experience (PrExp), another type of internal knowledge. This study classifies prior experiences of the project groups into five categories and measures them on a 6-point Likert Scale. Prior experience constitutes either advanced education or work experience. The results presented in table 5.7 underscore that, on average, project managers believe that their project groups contain many individuals with a prior advanced education experience that is relevant to the R\&D project. This advanced education may have taken place at international sources of knowledge (foreign universities) or domestic sources of knowledge (local universities). In contrast, the results indicate that the scores for the questions regarding working experiences in the sample are slightly low on average. This suggests that the project managers tend to believe that there is a slightly low degree of work experience at external sources of knowledge among members of their project groups.

A t-test of the pertinent variables shows that project managers believe that prior education on relevant subject matter was more common than relevant prior work experience. For example, relevant prior education at local universities (Q.34; $M=4.476$, $\mathrm{SE}=1.054)$ scored significantly higher than prior work experience at international sources of knowledge $(\mathrm{Q} .35 ; \mathrm{M}=3.024, \mathrm{SE}=1.73, \mathrm{t}(207)=10.76, \mathrm{p}<.001)$, at local technology users $(\mathrm{Q} .36 ; \mathrm{M}=3.32, \mathrm{SE}=1.86, \mathrm{t}(207)=8.53, \mathrm{p}<.001)$ and at other $\mathrm{R} \& \mathrm{D}$ units within the national laboratories (Q.37; $\mathrm{M}=3.26, \mathrm{SE}=1.63, \mathrm{t}(207)=9.94, \mathrm{p}<.001)$. Also, relevant prior education at foreign universities (Q.33; $\mathrm{M}=4.423, \mathrm{SE}=.113)$ scored 
significantly higher than prior work experience at international sources of knowledge (Q.35; $\mathrm{M}=3.024, \mathrm{SE}=.119, \mathrm{t}(207)=11.15, \mathrm{p}<.001)$, at local technology users (Q.36; $\mathrm{M}=3.32, \mathrm{SE}=.129, \mathrm{t}(207)=6.69, \mathrm{p}<.001)$ and at other $\mathrm{R} \& \mathrm{D}$ units within the national laboratories (Q.37; $\mathrm{M}=3.26, \mathrm{SE}=.113, \mathrm{t}(207)=7.08, \mathrm{p}<.001)$.

Table 5.7: Descriptive Statistics Pertaining to Prior Experience

\begin{tabular}{|c|c|c|c|c|c|c|c|}
\hline & Code & $\mathrm{N}$ & Min & Max & Mean & $\begin{array}{l}\text { Std. } \\
\text { Dev. }\end{array}$ & $\begin{array}{l}\text { Questions' order in } \\
\text { questionnaire }\end{array}$ \\
\hline $\begin{array}{l}\text { Prior } \\
\text { experience } \\
\text { in education } \\
\text { from } \\
\text { international } \\
\text { sources of } \\
\text { knowledge }\end{array}$ & $\begin{array}{l}\text { MV9_PrExp } \\
\text { Ed_InatSrc }\end{array}$ & 208 & 1.0 & 6.0 & 4.423 & 1.628 & $\begin{array}{l}\text { Q.33 At least one of our } \\
\text { project group members has } \\
\text { had very extensive } \\
\text { educational experience at a } \\
\text { foreign university on subject } \\
\text { matter that is relevant to this } \\
\text { project. }\end{array}$ \\
\hline $\begin{array}{l}\text { Prior } \\
\text { experience } \\
\text { in education } \\
\text { from local } \\
\text { sources of } \\
\text { knowledge }\end{array}$ & $\begin{array}{l}\text { MV10_PrExp_ } \\
\text { Ed_- } \\
\text { LocUniv }\end{array}$ & 208 & 1.0 & 6.0 & 4.476 & 1.054 & $\begin{array}{l}\text { Q.34 At least one of our } \\
\text { project group members had } \\
\text { very extensive educational } \\
\text { experience at a domestic } \\
\text { university on subject matter } \\
\text { that is relevant to this } \\
\text { project. }\end{array}$ \\
\hline $\begin{array}{l}\text { Prior } \\
\text { experience } \\
\text { in working } \\
\text { from } \\
\text { international } \\
\text { sources of } \\
\text { knowledge } \\
\end{array}$ & $\begin{array}{l}\text { MV11_PrExp_ } \\
\text { Wk_InatSrc }\end{array}$ & 208 & 1.0 & 6.0 & 3.024 & 1.729 & $\begin{array}{l}\text { Q.35 At least one of our } \\
\text { project group members had } \\
\text { very extensive working } \\
\text { experience abroad on subject } \\
\text { matter that relevant to this } \\
\text { project. }\end{array}$ \\
\hline $\begin{array}{l}\text { Prior } \\
\text { experience } \\
\text { in working } \\
\text { with local } \\
\text { technology } \\
\text { users }\end{array}$ & $\begin{array}{c}\text { MV12_PrExp_ } \\
\text { Wk_LTUs }\end{array}$ & 208 & $\overline{1.0}$ & 6.0 & 3.317 & 1.859 & $\begin{array}{l}\text { Q.36 At least one of our } \\
\text { project group members had } \\
\text { very extensive working } \\
\text { experience with our targeted } \\
\text { customers on subject matter } \\
\text { that is relevant to this } \\
\text { project. }\end{array}$ \\
\hline $\begin{array}{l}\text { Prior } \\
\text { experience } \\
\text { in working } \\
\text { with other } \\
\text { R\&D units }\end{array}$ & $\begin{array}{c}\text { MV13_PrExp_ } \\
\text { Wk_ORDU }\end{array}$ & 208 & 1.0 & 6.0 & 3.260 & 1.629 & $\begin{array}{l}\text { Q.37 At least one of our } \\
\text { project group members had } \\
\text { very extensive working } \\
\text { experience with other } \\
\text { projects within NSTDA on } \\
\text { subject matter that is } \\
\text { relevant to this project. }\end{array}$ \\
\hline
\end{tabular}


In summary, the descriptive statistics show that, on average, the project managers of $R \& D$ project groups in NLs in TLCs believe that their project groups engage with international sources of knowledge via contextual learning. They scan for ideas for their projects and for data on what other teams were doing on similar or complementary projects. They also rely on internal knowledge gained from project-internal learning activities and the prior education experiences of their team members to complete their $R \& D$ projects. In contrast, the project managers believe that the degree of engagement with external sources of knowledge via vicarious learning activities and the degree of internal knowledge gained from the prior work experience of the team members is not very high.

\subsection{CORRELATION MATRIX AND FACTOR ANALYSIS}

This section presents the results of the correlation analysis of the variables under study and the factor analysis. The correlation analysis for all variables under study is presented in appendix E. Factor analysis has been used to cluster the input variables pertaining to knowledge inflows and the moderating variables pertaining to internal knowledge. A correlation analysis is subsequently performed on the output variables and the factors that emerge from the factor analysis.

In general, a rule of thumb for factor analysis, which is easily learned, easily applied and used as a default in SPSS, suggests that factors with an eigenvalue greater than or equal to 1 can be included in the analysis (Kaiser, 1960). This rule is accurate or reliable when the number of variables in the analysis is lower than 30 variables and the sample size is 
higher than 250 (Jolliffe, 1972, 1986; J. P. Stevens, 1992). Some researchers also suggest to include factors above the point of inflexion in the scree plot (Cattell, 1966; Jolliffe, 1972, 1986; J. P. Stevens, 1992). Others stress that it is important to consider the meaning of the factors after extraction (Dunteman, 1989, pp. 22-23; Field, 2005, p. 630; Nardo et al., 2005, p. 21; R. A. Johnson \& Wichern, 2007, p. 444) and internal consistency of factors (Hair, et al., 1995; Field, 2005). In some instances, it may be necessary to extend the factor analysis to the point where $80 \%$ to $90 \%$ of the variance is explained (Dunteman, 1989, pp. 22-23; Nardo et al., 2005, p. 21; R. A. Johnson \& Wichern, 2007, p. 444). This will result in the emergence of some factors with little explanatory power. However, these factors cannot be ignored because they may have a strong and highly significant impact on the criterion.

This dissertation wants to include all of sources of knowledge that are potentially critical for a national laboratory in a technological latecomer country in the analysis. Thus, this study follows a guideline of stopping rules for factor analysis suggested by Dunteman, 1989, pp. 22-23; Nardo et al., 2005, p. 21; and R. A. Johnson \& Wichern, 2007, p. 444, in which $90 \%$ of the variance is explained. When this rule is applied to the dataset that has been collected for this dissertation, the factors that emerge from the factor analysis when $90 \%$ of the variance is explained are meaningful and interpretable in real world practice (Dunteman, 1989, pp. 22-23; Field, 2005, p. 630; Nardo et al., 2005, p. 21; R. A. Johnson \& Wichern, 2007, p. 444).

Table 5.8 displays the results of the factor analysis and the total variance explained by the analysis. A total of 17 input factors, which explain $90 \%$ of the variance, have been 
identified. The factors can be classified into two groups: factors pertaining to input variables (FIVs) and factors pertaining to moderating variables (FMVs). The former group results from clustering variables pertaining to knowledge inflows, whereas the latter group results from clustering variables pertaining to internal knowledge. Appendix F illustrates which variables comprise which factors.

SPSS has identified a total of nine FIVs. Four of these are associated with contextual learning activities: the degree of engagement with other R\&D project groups via CLAs [FIV8_ORDU_CLAs, $\alpha=.760]$; the degree of engagement with local universities via CLAs [FIV9_LocUniv_CLAs, $\alpha=.723$ ]; the degree of engagement with international sources via CLAs [FIV6_InatSrc_CLAs, $\alpha=.816]$; and the degree of engagement with LTUs via CLAs [FIV7_LTUs_CLAs, $\alpha=.769$ ]. The five remaining factors are associated with vicarious learning activities: the degree of engagement with other R\&D project groups via VLAs [FIV5_ORDU_VLAs, $\alpha=.867$ ]; the degree of engagement with local universities via VLAs [FIV3_LocUniv_VLAs, $\alpha=.891]$; the degree of engagement with international sources via VLAs [FIV2_InatSrc_VLAs, $\alpha=.859$ ]; the degree of engagement via VLAs with local technology users that have production units [FIV1_LTUsPU_VLAs, $\alpha=.946]$; and the degree of engagement via VLAs with LTUs that are end users [FIV4_LTUsEU_VLAs, $\alpha=.916]$.

SPSS has identified a total of eight FMVs. One factor pertains to project-internal learning activities [FMV1_PILAs, $\alpha=.887]$. Two factors are associated with prior knowledge: [FMV2_PrKn_PJ, $\alpha=.773]$ covers subject matter pertaining to the context of the project, whereas [FMV5_PrKn_Core] measures prior knowledge about the core technology. Five 
factors pertain to prior experience, including prior experience in working with other $R \& D$ units [FMV4_PrExp_Wk_ORDU]; prior experience in working at international sources of knowledge [FMV8_PrExp_Wk_InatSrc]; prior experience in working with local technology users [FMV3_PrExp_Wk_LTUs]; prior experience in education at local universities [FMV6_PrExp_Ed_LocUniv]; and prior experience in education from international sources of knowledge [FMV7_PrExp_Ed_InatSrc], i.e. foreign universities.

Table 5.8 shows that no truly dominant factor or small group of factors explains most of the variation. PILA is the most significant factor; the next five factors pertain to vicarious learning activity. These vicarious learning factors are followed by a group of five factors that are either associated with contextual learning or prior knowledge about the subject matter. The list of factors is closed out by six single variables that are either associated with prior experience of various kinds or prior knowledge about the core technology that is under development.

In summary, the factor analysis identifies 17 factors, which include all input variables and moderating variables under study. The input factors are orthogonal, which means mutually independent, non-redundant and non-overlapping. There is no collinearity between any of the factors, which helps overcome multi-collinearity problems in a regression (Field, 2005). The constructs of the first 11 factors are also reliable with Cronbach's alpha always being greater than 0.7. The last six factors report no Cronbach's alpha since they are individual variables. 
Table 5.8: Factor Analysis and Cumulative Variance Explained

\begin{tabular}{|c|c|c|c|c|c|c|c|}
\hline \multirow[t]{2}{*}{$\begin{array}{c}\text { Factor } \\
\#\end{array}$} & \multicolumn{2}{|c|}{ Initial Eigenvalues } & \multicolumn{2}{|c|}{$\begin{array}{l}\text { Rotation Sums of } \\
\text { Squared Loadings }\end{array}$} & \multirow{2}{*}{$\begin{array}{l}\text { Factors of Moderating Variables } \\
\text { (FMV) and Factors of } \\
\text { Independent Variables (FIV) }\end{array}$} & \multirow[t]{2}{*}{ Description } & \multirow[t]{2}{*}{$\begin{array}{l}\text { Cronbach's } \\
\text { Alpha }\end{array}$} \\
\hline & $\begin{array}{c}\% \text { of } \\
\text { Variance }\end{array}$ & $\begin{array}{l}\text { Cumula- } \\
\text { tive } \%\end{array}$ & $\begin{array}{c}\% \text { of } \\
\text { Variance }\end{array}$ & $\begin{array}{l}\text { Cumula- } \\
\text { tive } \%\end{array}$ & & & \\
\hline 1 & 16.212 & 16.212 & 10.383 & 10.383 & [FMV1_PILAs] & FMV1: Project internal learning activities & $(\alpha=.887)$ \\
\hline 2 & 14.298 & 30.510 & 7.005 & 17.389 & [FIV1_LTUsPU_VLAs] & FIV1: Engage with LTUsPU via VLAs & $(\alpha=.946)$ \\
\hline 3 & 11.461 & 41.972 & 6.678 & 24.067 & [FIV2_InatSrc_VLAs] & FIV2: Engage with InatSrc via VLAs & $(\alpha=.859)$ \\
\hline 4 & 7.003 & 48.975 & 6.525 & 30.592 & [FIV3_LocUniv_VLAs] & FIV3: Engage with LocUniv via VLAs & $(\alpha=.891)$ \\
\hline 5 & 6.306 & 55.281 & 6.445 & 37.037 & [FIV4_LTUsEU_VLAs] & FIV4: Engage with LTUsEU via VLAs & $(\alpha=.916)$ \\
\hline 6 & 5.325 & 60.605 & 6.435 & 43.473 & [FIV5_ORDU_VLAs] & FIV5: Engagement with ORDU via VLAs & $(\alpha=.867)$ \\
\hline 7 & 4.535 & 65.140 & 5.827 & 49.299 & [FIV6_InatSrc_CLAs] & FIV6: Engage with InatSrc via CLAs & $(\alpha=.816)$ \\
\hline 8 & 4.091 & 69.231 & 5.743 & 55.043 & [FMV2_PrKn_PJ] & $\begin{array}{l}\text { FMV2: Prior knowledge about the subject } \\
\text { matter pertaining to the project }\end{array}$ & $(\alpha=.773)$ \\
\hline 9 & 3.358 & 72.590 & 5.295 & 60.337 & [FIV7_LTUs_CLAs] & FIV7: Engage with LTUs CLAs & $(\alpha=.769)$ \\
\hline 10 & 3.184 & 75.774 & 5.215 & 65.553 & [FIV8_ORDU_CLAs] & FIV8: Engagement with ORDU_CLAs & $(\alpha=.760)$ \\
\hline 11 & 2.866 & 78.640 & 5.061 & 70.613 & [FIV9_LocUniv_CLAs] & FIV9: Engage with LocUniv via CLAs & $(\alpha=.723)$ \\
\hline 12 & 2.336 & 80.976 & 3.587 & 74.200 & [FMV3_PrExp_Wk_LTUs] & $\begin{array}{l}\text { FMV3: Prior experience in working with local } \\
\text { technology users }\end{array}$ & - \\
\hline 13 & 2.225 & 83.201 & 3.504 & 77.704 & [FMV4_PrExp_Wk_ORDU] & $\begin{array}{l}\text { FMV4: Prior experience in working with other } \\
\text { R\&D units }\end{array}$ & - \\
\hline 14 & 1.983 & 85.184 & 3.353 & 81.057 & [FMV5_PrKn_Core] & FMV5: Prior knowledge in core technology & - \\
\hline 15 & 1.832 & 87.016 & 3.322 & 84.379 & [FMV6_PrExp_Ed_LocUniv] & $\begin{array}{l}\text { FMV6: Prior experience in education from local } \\
\text { sources of knowledge }\end{array}$ & - \\
\hline 16 & 1.668 & 88.684 & 3.287 & 87.666 & [FMV7_PrExp_Ed_InatSrc] & $\begin{array}{l}\text { FMV7: Prior experience in education from } \\
\text { international sources of knowledge }\end{array}$ & - \\
\hline 17 & 1.494 & 90.178 & 2.042 & 89.708 & [FMV8_PrExp_Wk_InatSrc] & $\begin{array}{l}\text { FMV8: Prior experience in working at } \\
\text { international sources of knowledge }\end{array}$ & - \\
\hline
\end{tabular}


Table 5.9: Correlation Matrix

\begin{tabular}{|c|c|c|c|c|c|c|}
\hline & Output Variable / Factor & OV1 & OV2 & OV3.1 & OV3.2 & OV3.3 \\
\hline \multirow{5}{*}{ 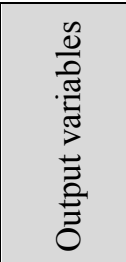 } & OV1_Sat_LTUs & 1.000 & & \multirow[b]{3}{*}{1.000} & \multirow{5}{*}{$\begin{array}{l}1.000 \\
0.050\end{array}$} & \multirow[b]{5}{*}{1.000} \\
\hline & OV2_Prob_Rev & $.580^{* * *}$ & 1.000 & & & \\
\hline & OV3.1_Prob_JrPub & $-.206^{* *}$ & $389 * * *$ & & & \\
\hline & OV3.2_Prob_Patent & -0.077 & $-.162 *$ & $.167 *$ & & \\
\hline & OV3.3_Ver_Tech & -0.061 & -0.123 & $.224 * *$ & & \\
\hline \multirow{8}{*}{ 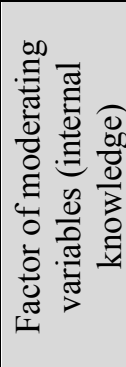 } & FMV1_PILAs & 0.081 & 0.025 & 0.016 & 0.024 & 0.113 \\
\hline & FMV2_PrKn_PJ & -0.033 & -0.088 & $.281 * * *$ & -0.121 & 0.065 \\
\hline & FMV3_PrExp_Wk_LTUs & $.223 * * *$ & $.272 * * *$ & -0.071 & $-.182 * *$ & 0.066 \\
\hline & FMV4_PrExp_Wk_ORDU & -0.017 & 0.128 & -0.065 & 0.021 & -0.059 \\
\hline & FMV5_PrKn_Core & $.140 *$ & 0.110 & $.146^{*}$ & 0.094 & 0.077 \\
\hline & FMV6_PrExp_Ed_LocUniv & 0.100 & 0.029 & -0.025 & 0.087 & -0.034 \\
\hline & FMV7_PrExp_Ed_InatSrc & -0.041 & -0.048 & 0.005 & 0.080 & 0.032 \\
\hline & FMV8_PrExp_Wk_InatSrc & -0.053 & -0.007 & $.141 *$ & 0.005 & $.212 * * *$ \\
\hline \multirow{9}{*}{ 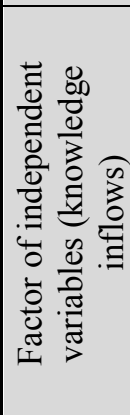 } & FIV1_LTUsPU_VLAs & $.446^{* * *}$ & $.550 * * *$ & $-.189 * *$ & -0.050 & -0.096 \\
\hline & FIV2_InatSrc_VLAs & -0.097 & -0.078 & $.192 * *$ & -0.119 & $.168^{*}$ \\
\hline & FIV3_LocUniv_VLAs & -0.037 & 0.016 & $.183 * *$ & 0.052 & 0.066 \\
\hline & FIV4_LTUsEU_VLAs & $.371 * * *$ & $.274 * * *$ & $-.213 * *$ & 0.008 & 0.086 \\
\hline & FIV5_ORDU_VLAs & -0.051 & $-.171 *$ & $.162 *$ & 0.113 & $.150^{*}$ \\
\hline & FIV6_InatSrc_CLAs & 0.017 & -0.033 & $.232 * *$ & 0.075 & $.135^{*}$ \\
\hline & FIV7_LTUs_CLAs & $.298 * * *$ & 0.110 & -0.046 & 0.064 & -0.077 \\
\hline & FIV8_ORDU_CLAs & -0.044 & 0.019 & 0.038 & 0.024 & $.149^{*}$ \\
\hline & FIV9_LocUniv_CLAs & 0.107 & 0.048 & 0.041 & -0.006 & -0.095 \\
\hline \multirow{4}{*}{\multicolumn{5}{|c|}{$\begin{array}{l}* * * \text { Correlation is significant at the } \mathrm{p}<0.001 \text { level (2-tailed). } \\
* * \text { Correlation is significant at the } \mathrm{p}<0.01 \text { level (2-tailed). } \\
* \quad \text { Correlation is significant at the } \mathrm{p}<0.05 \text { level (2-tailed). }\end{array}$}} & Positive & Negative \\
\hline & & & & & $* * *$ & $* * *$ \\
\hline & & & & & $* *$ & ** \\
\hline & & & & & * & * \\
\hline
\end{tabular}

Table 5.9 presents the correlation matrix of the 17 input factors and the five output variables. Due to the orthogonality of factors, the interactions between all input and moderating variables equal zero and are thus not displayed in table 5.9. The matrix confirms criterion-related validity of the input factors. For example, user satisfaction (OV1_Sat_LTUs) has significantly positive correlations to all factors pertaining to LTUs, but has significantly negative correlation to probability of generating a publication (OV3.1_Prob_JrPub). This shows that the input factors are adequate for capturing the relevant aspects of output variables. 


\subsection{COMPARING REGRESSION MODELS}

This section presents the results of regression analyses that investigate the relative impact of internal and external sources of knowledge on the performance of the national laboratories. Five regression models have been built for each output variable. Model 1, the knowledge inflow baseline, includes factors from outside the project group, only. Model 2.1, the project group baseline, contains factors from inside the project group, only. Model 2.2, the intra-organization baseline, includes factors from inside the national laboratories, i.e., project internal factors and factors pertaining to external learning from other R\&D project groups. Model 3, the integrated model, covers all factors from model 1 and 2.1. Model 4, the interaction model, includes almost ${ }^{21}$ all factors from model 1 and model 2, as well as their interactions.

The predictive power of all models for all output variables is summarized in table 5.10. The summary statistics of the models for each output variable are given in appendix G.1 through G.5. Appendix G.1 presents regression results for mission 1 (OV1) -- user satisfaction. Appendix G.2 summarizes regression results for mission 2 (OV2) -- the probability of commercialization. Appendixes G.3 to G.5 respectively display regression results for the output variables that pertain to mission 3: probability of publication (OV3.1); probability of generating a patent (OV3.2); and versatility of technology (OV3.3).

\footnotetext{
${ }^{21}$ The interaction model does not cover FIV8, contextual learning about other R\&D project groups within the national laboratories; FMV6, prior education at local universities; and FMV7, prior education at foreign universities.
} 
Table 5.10: Summary of Predictive Power of Models 1 through 5 for all Output Variables

\begin{tabular}{|c|c|c|c|c|c|}
\hline$\underline{\text { Criteria }}$ & $\begin{array}{c}\text { Model } 1 . \\
\text { Knowledge } \\
\text { Inflow Baseline }\end{array}$ & $\begin{array}{l}\text { Model 2.1. } \\
\text { Project Group } \\
\text { Baseline }\end{array}$ & $\begin{array}{c}\text { Model } 2.2 . \\
\text { Intra- } \\
\text { Organization } \\
\text { Baseline }\end{array}$ & $\begin{array}{l}\text { Model } 3 . \\
\text { Integrated } \\
\text { Model }\end{array}$ & $\begin{array}{l}\text { Model } 4 . \\
\text { Interaction } \\
\text { Model }\end{array}$ \\
\hline \multicolumn{6}{|c|}{ Mission-1: User Satisfaction } \\
\hline $\mathrm{R}^{2}$ & .469 & .069 & .069 & .571 & .703 \\
\hline $\mathrm{R}^{2}$ adjust & .458 & .059 & .059 & .550 & .665 \\
\hline $\mathrm{F}$ & $41.705 * * *$ & $7.042 * *$ & $7.042 * *$ & $27.175^{* * *}$ & $18.385^{* * *}$ \\
\hline No. & 193 & 193 & 193 & 193 & 193 \\
\hline$\Delta \mathrm{R}^{2}$ adjust & - & - & 0.000 & 0.491 & 0.606 \\
\hline
\end{tabular}

Mission-2: Probability of Commercializing a Technology

\begin{tabular}{|l|r|r|r|r|r|}
\hline Cox \& Snell R $\mathrm{R}^{2}$ & 0.384 & 0.102 & .133 & 0.485 & .604 \\
\hline Nagelkerke's R $\mathrm{R}^{2}$ & 0.512 & 0.136 & .177 & 0.648 & .807 \\
\hline Chi-square & $100.728^{* * *}$ & $22.419^{* * *}$ & $29.568^{* * *}$ & $138.714^{* * *}$ & $192.909^{* * *}$ \\
\hline Percentage correct & 80.3 & 66.3 & 69.7 & 86.1 & 92.3 \\
\hline No. & 208 & 208 & 208 & 208 & 208 \\
\hline$\Delta$ Cox \& Snell R & - & - & 0.031 & 0.383 & 0.502 \\
\hline$\Delta$ Nagelkerke's $R^{2}$ & - & - & 0.041 & 0.512 & 0.671 \\
\hline
\end{tabular}

Mission-3.1: Probability of Generating a Publication

\begin{tabular}{|l|r|r|r|r|r|}
\hline Cox \& Snell R $\mathrm{R}^{2}$ & 0.236 & 0.115 & .141 & 0.338 & 0.447 \\
\hline Nagelkerke's R & 0.329 & 0.161 & .197 & 0.472 & 0.625 \\
\hline Chi-square & $55.922^{* * *}$ & $25.390^{* * *}$ & $31.553^{* * *}$ & $85.665^{* * *}$ & $123.321^{* * *}$ \\
\hline Percentage correct & 78.8 & 73.1 & 74 & 81.3 & 86.1 \\
\hline No. & 208 & 208 & 208 & 208 & 208 \\
\hline$\Delta$ Cox \& Snell R & - & - & 0.026 & 0.223 & 0.332 \\
\hline$\Delta$ Nagelkerke's R & - & - & 0.036 & 0.311 & 0.464 \\
\hline
\end{tabular}

Mission-3.2: Probability of Generating a Patent

\begin{tabular}{|l|r|r|r|r|r|}
\hline Cox \& Snell R $\mathrm{R}^{2}$ & .015 & .048 & .061 & .075 & 0.237 \\
\hline Nagelkerke's R & .020 & .065 & .083 & .102 & 0.323 \\
\hline Chi-square & 3.041 & $10.199^{* *}$ & $13.044^{* *}$ & $16.167^{* *}$ & $56.182^{* * *}$ \\
\hline Percentage correct & 62.5 & 65.9 & 63.9 & 63.9 & 72.1 \\
\hline No. & 208 & 208 & 208 & 208 & 208 \\
\hline$\Delta$ Cox \& Snell R & - & - & 0.013 & 0.027 & 0.189 \\
\hline$\Delta$ Nagelkerke's R & - & - & 0.018 & 0.037 & 0.258 \\
\hline
\end{tabular}

Mission-3.3: Versatility of Technology

\begin{tabular}{|l|r|r|r|r|r|}
\hline $\mathrm{R}^{2}$ & .091 & .058 & .102 & .149 & 0.311 \\
\hline $\mathrm{R}^{2}$ adjust & .073 & .048 & .085 & .123 & 0.25 \\
\hline $\mathrm{F}$ & $5.099^{* *}$ & $6.256^{* *}$ & $5.777^{* * *}$ & $5.857^{* * *}$ & $5.056^{* * *}$ \\
\hline No. & 207 & 207 & 207 & 207 & 207 \\
\hline$\Delta \mathrm{R}^{2}$ adjust & - & - & 0.037 & 0.075 & 0.202 \\
\hline
\end{tabular}

Note: 1) $\Delta \mathrm{R}^{2}$ adjust, $\Delta$ Cox $\&$ Snell $\mathrm{R}^{2}$ and $\Delta$ Nagelkerke's $\mathrm{R}^{2}$ are based on model 2.1

$2) * * *$ Significant at the $p<0.001$ level (2-tailed).

** Significant at the $\mathrm{p}<0.01$ level (2-tailed).

* $\quad$ Significant at the $\mathrm{p}<0.05$ level (2-tailed). 
This study benchmarks the total variance explained and prediction power of each model for all five output variables. The benchmarking criteria include $\mathrm{R}^{2}$, Adjusted $\mathrm{R}^{2}$, and Fratio for multiple regressions in mission 1 (OV1) and 3 (OV3.3). In addition, the Cox \& Snell $\mathrm{R}^{2}$, the Nagelkerke's $\mathrm{R}^{2}$, the Chi-Square and the percentage correct are used for benchmarking the prediction power of multiple logistic regressions in missions 2 (OV2) and 3 (OV3.1 and OV3.2) (see appendix $\mathrm{C}$ for an explanation of these measures of explanatory power).

Table 5.10 illustrates the results of this exercise. It shows that the five output variables have different predictive power and explanatory power, and that the regression models that include knowledge inflows tend to have greater explanatory power than the ones that do not. I also benchmark the adjusted $\mathrm{R}^{2}$, the Cox $\&$ Snell $\mathrm{R}^{2}$ and the Nagelkerke's $\mathrm{R}^{2}$, of the intra-organization baseline (model 2.2), the integrated model (model 3) and the interaction model (model 4) to that of the project group baseline (model 2.1). This effort provides an indicator as to how much the inclusion of additional variables improves the predictive and explanatory power of the models.

Output variable OV3.2 - the probability of generating at least one item of patent from a project — clearly has the lowest predictive power of all five output variables. The Cox \& Snell $\mathrm{R}^{2}$ and the Nagelkerke's $\mathrm{R}^{2}$ are below 0.2 for models 1 through 4 , meaning that these models cannot explain $20 \%$ of the variance. In model 1 , the Chi-Square is not significant at the level of $\mathrm{p}<0.05$. This observation suggests that generating a patent is not a strong function of knowledge inflows. Other factors (perhaps economic incentives) 
drive the generation of a patent. OV3.2 will henceforth not be used as an indicator for measuring the impact of managing knowledge inflows from various sources on the national laboratories' ability to build a long-term R\&D capability for the country.

The remaining output variables -- OV1, OV2, OV3.1 and OV3.3 -- have a relatively high explanatory power, at least for models that involve knowledge inflow. However, models 2.1 and 2.2, which exclude all factors that are exogenous to the national laboratories, have a significantly lower explanatory power. When compared to model 1 , models 2.1 and 2.2 are particularly weak indicators of user satisfaction, probability of commercialization and probability of publication. This suggests user satisfaction, commercialization and publication are highly dependent on knowledge inflow into the national laboratories. Not surprisingly, the explanatory power of the regression models increases as more variables are added. Model 3, the integrated model, has a greater explanatory power than models $1,2.1$ and 2.2 ; model 4, the interaction model, has a greater explanatory power than model 3 .

It should be noted that for output variables OV1, OV2, OV3.1 and OV3.3, model 2.2, the intra-organization baseline, is not much of an improvement over model 2.1, the project group baseline. Evidently, including knowledge inflows from other R\&D project groups in a regression model does not significantly increase the explanatory power of the model. This implies that the impact of collaborative efforts between $R \& D$ project groups within the national laboratories is limited. The national laboratories under study must manage inflows from exogenous sources of knowledge to achieve dramatic improvements in performance. 


\subsection{THE IMPACT OF KNOWLEDGE INFLOWS}

In this section, I present the results that address research question RQ-1: What is the relative impact on the performance of national laboratories in latecomer countries of engaging with other project groups within the same organization (hypotheses H.1a, H.1b, H.1c); with local universities (hypotheses H.2a, H.2b, H.2c); with local technology users (hypotheses H.3a, H.3b, H.3c); and with international sources of knowledge (hypotheses H.4a, H.4b, H.4c)? Results cover user satisfaction (mission 1, OV1; hypotheses H.1a, H.2a, H.3a and H.4a); probability of commercializing a technology (mission 2, OV2; Hypotheses H.1b, H.2b, H.3b and H.4b); probability of generating at least one publication (mission 3, OV3.1); and versatility of technology (mission 3, OV3.1). Hypotheses H.1c, H.2c, H.3c and H.4c). I have used the integrated regression model to test the relevant hypotheses, whose results are displayed in appendix G.6. In all of the following hypothesis tests, I use $\mathrm{p}<0.05$ as the threshold for statistical significance.

\subsubsection{Engaging with other R\&D Project Groups in the National Laboratories ${ }^{22}$}

Hypothesis 1a for Mission 1: Engagement with other $R \& D$ project groups within the NLs has a positive impact on the satisfaction of LTUs.

\footnotetext{
${ }^{22}$ Hypotheses $1 \mathrm{a}, 1 \mathrm{~b}$ and $1 \mathrm{c}$ pertain to external learning with other R\&D project groups in the national laboratories, which are also known as other R\&D units or ORDUs. Hypotheses $1 \mathrm{a}, 1 \mathrm{~b}$ and $1 \mathrm{c}$ respectively pertain to missions 1,2 and 3.
} 
Hypothesis 1a could not be confirmed (the null hypothesis could not be rejected, $\mathrm{p}>.05$ ). The degree of engagement in external learning activities with other R\&D units (project groups) within the national laboratories as a whole does not correlate with statistical significance to user satisfaction. This implies that engagement with other $R \& D$ project groups within the NLs has no significant impact on user satisfaction, regardless of whether these learning activities are contextual or vicarious.

Hypothesis $1 b$ for Mission 2: Engagement with other $R \& D$ project groups within the NLs has a positive impact on the NLs' ability to generate revenue for themselves by commercializing technology that they have developed.

Hypothesis $1 \mathrm{~b}$ could not be confirmed (the null hypothesis could not be rejected, $\mathrm{p}>.05$ ) for contextual learning. The degree of engagement in contextual learning activities with other R\&D units (project groups) within the national laboratories is not correlated with statistical significance to the probability of commercializing at least one technology from one particular R\&D project. This implies that contextual learning activities with other $R \& D$ units (project groups) within the national laboratories have no significant impact on commercialization of technology.

Hypothesis $1 \mathrm{~b}$ has been refuted (the null hypothesis has been rejected, $\mathrm{p}=.002$ ) for vicarious learning. The degree of engagement in vicarious learning activities with other $R \& D$ units (project groups) within the national laboratories is inversely correlated to the probability of commercializing at least one technology from a particular project. This 
implies that vicarious learning with other R\&D units (project groups) has a negative impact on commercialization of technology.

Hypothesis 1c for Mission 3: Engagement with other R\&D project groups within NLs has a positive impact on the NLs' ability to build $R \& D$ capabilities for the future needs of the country.

Hypothesis $1 \mathrm{c}$ could not be confirmed (the null hypothesis could not be rejected, $\mathrm{p}>.05$ ) for contextual learning, if performance is measured by the probability of publication. The degree of engagement in contextual learning activities with other R\&D units (project groups) within the national laboratories is not correlated with statistical significance to the probability of generating at least one publication from a particular project. This implies that contextual learning activities with other $R \& D$ units (project groups) within the national laboratories have no significant impact on developing a long-term R\&D capability of the national laboratories.

Hypothesis $1 \mathrm{c}$ has been confirmed (the null hypothesis has been rejected, $\mathrm{p}=.023$ ) for contextual learning with other R\&D units (project groups) within the national laboratories, is performance is measured by versatility of technology. The degree of engagement in external learning activities with other $R \& D$ units (project groups) within the national laboratories is positively correlated to the versatility of the technology under development. This implies that engaging in contextual learning about other R\&D units (project groups) within the national laboratories has a positive impact on the ability to 
find additional applications for the technology and should thus enhance the national laboratories' ability to develop a long-term R\&D capability.

Hypothesis $1 \mathrm{c}$ has been confirmed (the null hypothesis has been rejected, $\mathrm{p}=.004$ and $\mathrm{p}$ $=.023$ ) for vicarious learning with other R\&D units (project groups) within the national laboratories. The degree of engagement in external learning activities with other R\&D units (project groups) within the national laboratories is positively correlated to the probability of generating at least one publication from a particular project and to the versatility of the technology under development in a particular project. This implies that engaging in vicarious learning with other R\&D units (project groups) within the national laboratories has a positive impact on the ability to generate publications and the versatility of technology under development. Vicarious learning with other R\&D project groups within the national laboratories should thus enhance the national laboratories' ability to develop a long-term R\&D capability.

\subsubsection{Engaging with Local Universities ${ }^{23}$}

Hypothesis 2a for Mission 1: Engagement with local universities has a positive impact on the satisfaction of LTUs.

Hypothesis $2 \mathrm{a}$ has been confirmed (the null hypothesis has been rejected, $\mathrm{p}=.031$ ) for contextual learning with local universities. The degree of engagement in contextual

\footnotetext{
${ }^{23}$ Hypotheses $2 \mathrm{a}, 2 \mathrm{~b}$ and $2 \mathrm{c}$ pertain to external learning with local universities. Hypotheses $2 \mathrm{a}, 2 \mathrm{~b}$ and $2 \mathrm{c}$ respectively pertain to missions 1,2 and 3 .
} 
learning activities with local universities is positively correlated to user satisfaction. This implies that contextual learning with local universities has a positive impact on user satisfaction.

Hypothesis $2 \mathrm{a}$ could not be confirmed (the null hypothesis could not be rejected, $\mathrm{p}>.05$ ) for vicarious learning. The degree of engagement in vicarious learning activities with local universities not is correlated with any statistical significance to user satisfaction. This implies that vicarious learning from local universities has no statistically significant impact on user satisfaction.

Hypothesis $2 b$ for Mission 2: Engagement with local universities has a positive impact on the NLs' ability to generate revenue for themselves by commercializing technology that they have developed.

Hypothesis $2 b$ could not be confirmed (the null hypothesis could not be rejected, $p>.05$ ) for contextual learning. The degree of engagement in contextual learning activities with local universities is not correlated with statistical significance to the probability of commercializing at least one technology from one particular R\&D project. This implies that contextual learning activities with local universities have no statistically significant impact on commercialization of technology.

Hypothesis $2 b$ could not be confirmed (the null hypothesis could not be rejected, $p>.05$ ) for vicarious learning. The degree of engagement in vicarious learning activities with local universities is not correlated with statistical significance to the probability of 
commercializing at least one technology from one particular R\&D project. This implies that vicarious learning activities with local universities have no significant impact on commercialization of technology.

Hypothesis 2c for Mission 3: Engagement with local universities has a positive impact on the NLs' ability to build R\&D capabilities for the future needs of the country.

Hypothesis $2 \mathrm{c}$ has been confirmed (the null hypothesis has been rejected, $\mathrm{p}=.001$ ) for external learning as a whole, when performance is measured by the probability of publication. The degree of engagement in external learning activities with local universities is positively correlated to the probability of generating at least one publication from a particular project. This implies that engaging in external learning activities with local universities has a positive impact on the ability to generate publications. Engaging in external learning activities with local universities should thus enhance the national laboratories' ability to develop a long-term R\&D capability.

Hypothesis $2 \mathrm{c}$ could not be confirmed (the null hypothesis could not be rejected, $\mathrm{p}>.05$ ) for external learning, if performance is measured by versatility of technology. The degree of engagement in external learning activities with local universities is not correlated with statistical significance to the versatility of the technology that is under development within one particular R\&D project. This implies that external learning activities with local universities have no statistically significant impact on versatility of technology. 


\subsubsection{Engaging with Local Technology Users ${ }^{24}$}

Hypothesis 3a for Mission 1: Engagement with local users has a positive impact on the satisfaction of LTUs.

Hypothesis $3 \mathrm{a}$ has been confirmed (the null hypothesis has been rejected, $\mathrm{p}<.001$ ) for external learning with local technology users with production units. The degree of engagement in external learning activities with local technology users that have production units is positively correlated to user satisfaction, regardless of whether these learning activities are contextual or vicarious. This implies that external learning with local technology users that have production units has a positive impact on user satisfaction.

Hypothesis $3 \mathrm{a}$ has been confirmed (the null hypothesis has been rejected, $\mathrm{p}<.001$ ) for vicarious learning with local technology users that are end users. The degree of engagement in vicarious learning activities with local technology users that are end users is positively correlated to user satisfaction. This implies that vicarious learning with local technology users that are end users has a positive impact on user satisfaction.

Hypothesis 3 f for Mission 2: Engagement with local users has a positive impact on the NLs' ability to generate revenue for themselves by commercializing technology that they have developed.

\footnotetext{
${ }^{24}$ Hypotheses $3 \mathrm{a}, 3 \mathrm{~b}$ and $3 \mathrm{c}$ pertain to external learning with local technology users. Hypotheses $3 \mathrm{a}, 3 \mathrm{~b}$ and $3 \mathrm{c}$ respectively pertain to missions 1,2 and 3 .
} 
Hypothesis $3 \mathrm{~b}$ could not be confirmed (the null hypothesis could not be rejected, $\mathrm{p}>.05$ ) for contextual learning about local technology users. There was no statistically significant correlation between the degree of engagement in contextual learning activities with local technology users and the probability of commercializing at least one technology from a particular project. This implies that engaging in contextual learning activities with local technology users has no significant impact on commercialization of technology.

Hypothesis $3 \mathrm{~b}$ has been confirmed (the null hypothesis has been rejected, $\mathrm{p}<.001$ ) for vicarious learning with local technology users that have production units and with local technology users that are end users. The degree of engagement in vicarious learning activities with local technology users is positively correlated to the probability of commercializing at least one technology from a particular R\&D project. This implies that engaging in vicarious learning activities with local technology users has a positive impact on commercialization of technology.

Hypothesis 3c for Mission 3: Engagement with local users has a negative impact on the NLs' ability to build R\&D capabilities for the future needs of the country.

Hypothesis $3 \mathrm{c}$ could not be confirmed (the null hypothesis could not be rejected, $\mathrm{p}>.05$ ) for contextual learning. The degree of engagement in contextual learning activities with local technology users is not correlated with statistical significance to the probability of generating at least one publication from a particular project. This implies that contextual learning activities with local technology users have no statistically significant impact on developing a long-term R\&D capability of the national laboratories. 
Hypothesis $3 \mathrm{c}$ has been confirmed (the null hypothesis has been rejected, $\mathrm{p}<.001$ ) for vicarious learning activities with local technology users that have production units and with LTUs that are end users, if performance is measured by the probability of publication. The degree of engagement in vicarious learning activities with local technology users is inversely correlated to the probability of generating at least one publication from a particular project. This implies that engaging in vicarious learning activities with local technology users that are production units and end users has a negative impact on the ability to generate publications. Engaging in vicarious learning activities with local technology users should thus inhibit the national laboratories' ability to develop a long-term R\&D capability.

Hypothesis $3 \mathrm{c}$ could not be confirmed (the null hypothesis could not be rejected, $\mathrm{p}>.05$ ) for vicarious learning, if performance is measured by versatility of technology. The degree of engagement in vicarious learning activities with local technology users is not correlated with statistical significance to the versatility of the technology that under development in a particular project. This implies that vicarious learning activities with local technology users have no statistically significant impact on developing a long-term R\&D capability of the national laboratories. 


\subsubsection{Engaging with International Sources ${ }^{25}$}

Hypothesis 4a for Mission 1: Engagement with international sources has a positive impact on the satisfaction of LTUs.

Hypothesis $4 \mathrm{a}$ could not be confirmed (the null hypothesis could not be rejected, $\mathrm{p}>.05$ ) for contextual learning. The degree of engagement in contextual learning activities with international sources is not correlated with statistical significance to user satisfaction. This implies contextual learning from international sources has no significant impact on user satisfaction.

Hypothesis $4 \mathrm{a}$ could not be confirmed (the null hypothesis could not be rejected, $\mathrm{p}>.05$ ) for vicarious learning. The degree of engagement in vicarious learning activities with international sources is not correlated with statistical significance to user satisfaction. This implies vicarious learning from international sources has no significant impact on user satisfaction.

Hypothesis $4 b$ for Mission 2: Engagement with international sources has a positive impact on the NLs' ability to generate revenue for themselves by commercializing technology that they have developed.

Hypothesis $4 \mathrm{~b}$ could not be confirmed (the null hypothesis could not be rejected, $\mathrm{p}>.05$ ). The degree of engagement in external learning activities of any kind with international

\footnotetext{
${ }^{25}$ Hypotheses $4 \mathrm{a}, 4 \mathrm{~b}$ and $4 \mathrm{c}$ pertain to external learning with international sources. Hypotheses $4 \mathrm{a}, 4 \mathrm{~b}$ and $4 \mathrm{c}$ respectively pertain to missions 1,2 and 3
} 
sources is not correlated with statistical significance to the probability of commercializing at least one technology from a particular project. This implies that external learning activities with international sources have no statistically significant impact on commercialization of technology.

Hypothesis4c for Mission 3: Engagement with international sources has a positive impact on the NLs' ability to build R\&D capabilities for the future needs of the country.

Hypothesis 4c has been confirmed (the null hypothesis has been rejected), for external learning with international sources $(\mathrm{p}<.001$ for contextual and $\mathrm{p}=.01$ for vicarious). The degree of engagement in external learning activities with international sources is positively correlated to the probability of generating at least one publication from a particular project and to the versatility of the technology under development. This implies that engaging in external learning activities with international sources has a positive impact on the ability to generate publications, regardless of whether these learning activities are contextual or vicarious. In addition engaging in external learning activities, be they contextual or vicarious, increases the versatility of the technology under development. Engaging in external learning activities with international sources should thus enhance the national laboratories' ability to develop a long-term R\&D capability. 


\subsubsection{Relative Impact on Performance}

Table 5.11: Impact of Knowledge Inflows on the NLs' Performance

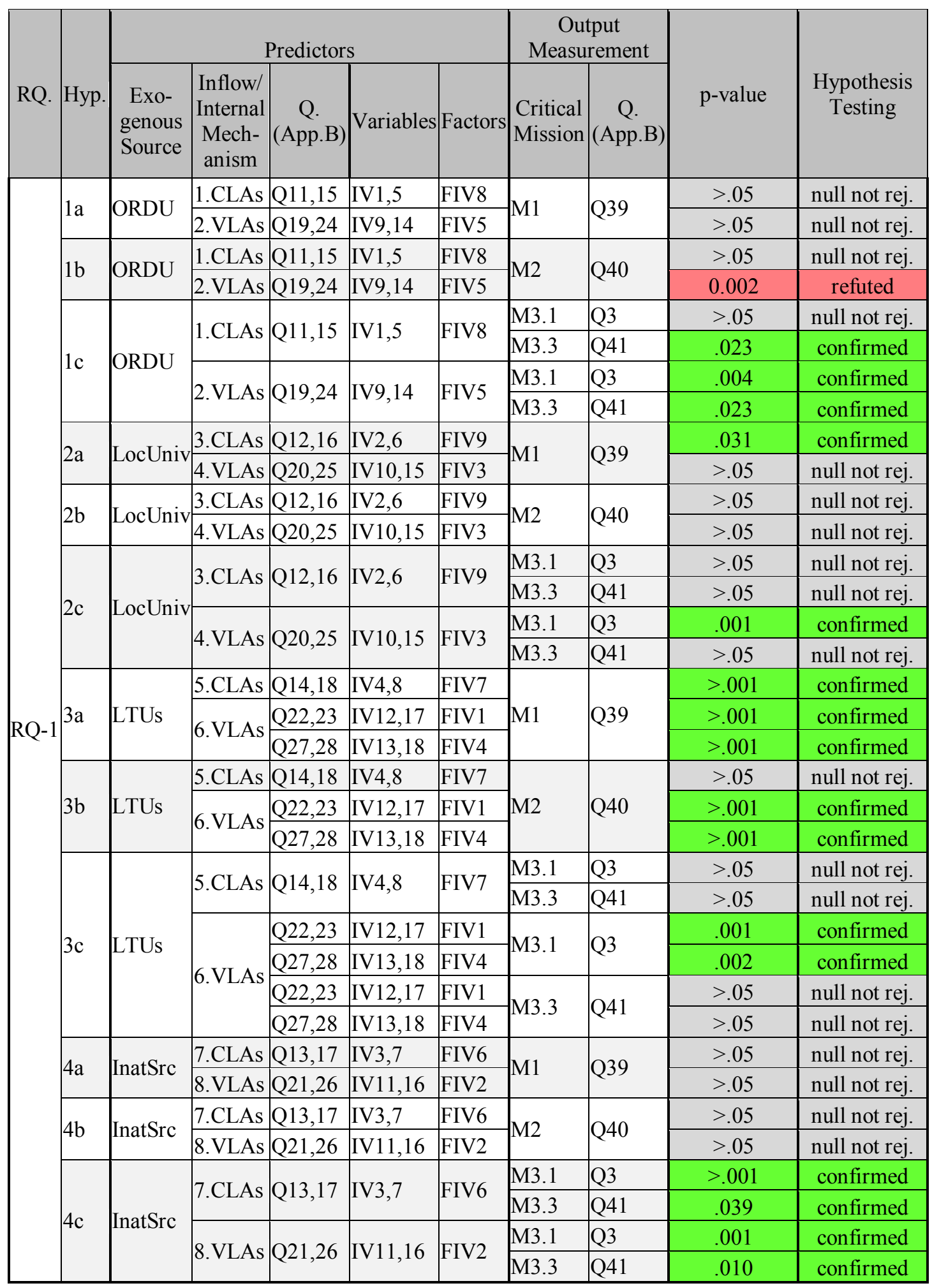


Table 5.11 summarizes the results that pertain to research question RQ-1. Initially, this study proposed 12 hypotheses, out of which 8 hypotheses were statistically significant. Also, table 5.11 shows that the results are nuanced and differentiated. Out of 36 results that pertained to RQ-1, 17 were statistically significant. Out of these 14,13 confirmed the stated hypothesis and one refuted it. The difference between a statistically significant and a statistically insignificant result could depend on the mission and on whether learning was contextual or vicarious.

The relative impact of input factors and moderating factors on performance can be deduced by comparing the correlation coefficients of the statistically significant factors in the various models in appendixes G.1 to G.4. For example, the integrated model for mission 1 (appendix G.1) ranks the relative positive impact of statistically significant factors on user satisfaction as follows:

1. FIV1_LTUsPU_VLAs (Vicarious Learning with LTUs with production units $) \quad(B=0.710)$

2. FIV4_LTUsEU_VLAs (Vicarious Learning with LTUs that are end users) $\quad(\mathrm{B}=0.591)$

3. FIV7_LTUs_CLAs (Contextual Learning about local technology users) $\quad(B=0.513)$

4. FMV3_PrExp_Wk_LTUs (Prior work experience at a local technology user) $\quad(\mathrm{B}=0.366)$

Clearly and not surprisingly, acquiring knowledge from local technology users through vicarious learning, contextual learning and grafting had the biggest impact on user satisfaction. However, the following factors should also not be neglected. They indicate in conjunction with the four dominant factors from above that very local phenomena drive user satisfaction. 
5. FMV6_PrExp_Ed_LocUniv (Prior education at a local university)

$(\mathrm{B}=0.178)$

6. FMV5_PrKn_Core (Prior knowledge about the core technology)

$(\mathrm{B}=0.170)$

7. FIV9_LocUniv_CLAs (Contextual learning about a local university)

$(\mathrm{B}=0.159)$

8. FMV1_PILAs (Project-internal learning activities)

$(\mathrm{B}=0.153)$

The integrated model for mission 2 (logistic regression, appendix G.2) ranks the relative positive impact of statistically significant factors on the probability of commercialization as follows:

$\begin{array}{ll}\text { 1. FIV1_LTUsPU_VLAs (Vicarious Learning with LTUs with production units) } & (\mathrm{B}=1.820) \\ \begin{array}{ll}\text { 2. FIV4_LTUsEU_VLAs (Vicarious Learning with LTUs that are end users) } & (\mathrm{B}=1.072) \\ \text { 3. FMV3_PrExp_Wk_LTUs (Prior work experience at a local technology user) } & (\mathrm{B}=1.006)\end{array}\end{array}$

Acquiring knowledge from local technology users through vicarious learning and grafting had the biggest impact on the probability of commercialization. However, the following factors should not be neglected, and two of them even appear in conflict. Vicarious learning with other R\&D project groups within the national laboratories had a negative impact on the probability of commercialization, whereas inviting someone from another project group had a positive impact.

4. FIV5_ORDU_VLAs (Vicarious learning with other groups within the labs) $\quad(\mathrm{B}=-0.700)$

5. FMV4_PrExp_Wk_ORDU (Prior work experience at other groups within labs $) \quad(\mathrm{B}=+0.509)$

6. FMV5_PrKn_Core (Prior knowledge about the core technology) $\quad(\mathrm{B}=+0.415)$ 
The integrated model for mission 3--OV3.1 (logistic regression, appendix G.3) ranks the relative positive impact of statistically significant factors on the probability of generating a publication as follows:

1. FMV2_PrKn_PJ (Prior knowledge of the context of the project)

$$
(\mathrm{B}=0.833)
$$

2. FIV6_InatSrc_CLAs (Contextual learning about international sources )

$$
(\mathrm{B}=0.802)
$$

3. FIV3_LocUniv_VLAs (Vicarious learning activities with local universities)

$$
(\mathrm{B}=0.713)
$$

4. FIV2_InatSrc_VLAs (Vicarious learning activities with international sources) $\quad(B=0.601)$

5. FIV5_ORDU_VLAs (Vicarious learning with other groups within labs)

$$
(\mathrm{B}=0.572)
$$

6. FMV5_PrKn_Core (Prior knowledge about the core technology)

$$
(\mathrm{B}=0.446)
$$

7. FMV8_PrExp_Wk_InatSrc (Prior work experience with international sources $) \quad(B=0.416)$

Two factors have a negative impact on the probability of generating a publication.

8. FIV4_LTUsEU_VLAs (Vicarious Learning with LTUs that are end users) $\quad(\mathrm{B}=-0.588)$

9. FIV1_LTUsPU_VLAs (Vicarious Learning with LTUs with production units) $\quad(\mathrm{B}=-0.637)$

The integrated model for mission 3, criterion 3 (OV3.3, multiple regression, appendix G.4) ranks the relative positive impact of statistically significant factors on the versatility of the technology under development as follows:

1. FMV8_PrExp_Wk_InatSrc (Prior work experience with international sources $) \quad(B=0.262)$

2. FIV2_InatSrc_VLAs (Vicarious learning activities with international sources $) \quad(\mathrm{B}=0.208)$

3. FIV5_ORDU_VLAs (Vicarious learning with other groups within labs) $\quad(\mathrm{B}=0.185)$

4. FIV8_ORDU_CLAs (Contextual learning activities with other groups within labs) $(\mathrm{B}=0.184)$

5. FIV6_InatSrc_CLAs (Contextual learning about international sources $) \quad(B=0.167)$ 
This ranking implies that the versatility of the technology under development in a project is primarily a function of engaging with international sources and engaging with other $\mathrm{R} \& \mathrm{D}$ project groups within the national laboratories.

The ranking for mission 3 is very different from that of mission 1 and that of mission 2 . Knowledge from or about local technology users is the dominant theme of missions 1 and 2 , regardless whether it is obtained through contextual learning, vicarious learning or grafting. Mission 3 relies heavily on international sources of knowledge through contextual learning, vicarious learning and grafting. Prior externalized knowledge and prior knowledge about the core technology is also important, as is vicarious learning with other R\&D project groups. Vicarious learning with local technology users has a negative impact on publication, and it limits the versatility of the technology under development.

It should also be noted that in missions 1 and 2 vicarious learning has a stronger impact on performance than contextual learning. This is not necessarily true for mission 3 . Finally, there is an alignment between vicarious learning and grafting in all missions. In missions 1 and 2, vicarious learning with and grafting people with experience from local technology users both exhibit a positive correlation to performance. In mission 3, vicarious learning with and grafting people with experience from international sources both exhibit a positive correlation to performance. 


\subsection{INTERACTION EFFECTS}

Table 5.12: Regression analysis for Interaction Model (Research Questions 2, 3 \& 4; Hypotheses 5, 6 \& 7)

\begin{tabular}{|c|c|c|c|c|c|c|c|c|c|}
\hline \multirow[b]{2}{*}{ RQ. } & \multirow[b]{2}{*}{ Нyp. } & \multicolumn{5}{|c|}{ Predictors } & \multicolumn{2}{|c|}{$\begin{array}{c}\text { Output } \\
\text { Measurement }\end{array}$} & \multirow[b]{2}{*}{$\begin{array}{l}\text { Hypothesis } \\
\text { Testing }\end{array}$} \\
\hline & & $\begin{array}{l}\text { Exo- } \\
\text { genous } \\
\text { Source }\end{array}$ & $\begin{array}{c}\text { Inflow/ } \\
\text { Internal } \\
\text { Mech- } \\
\text { anism } \\
\end{array}$ & Q. (App.B) & Variables & Factors & $\begin{array}{l}\text { Critical } \\
\text { Mission }\end{array}$ & $\mid \begin{array}{c}\text { Q. } \\
\text { (App.B) }\end{array}$ & \\
\hline \multirow{12}{*}{ RQ-2 } & \multirow{3}{*}{ 5.a } & \multirow{3}{*}{ InatSrc } & 7.CLAs & Q13,17 & IV3,7 & \multirow{3}{*}{$\begin{array}{l}\text { FIV6 } \\
\text { FIV2 } \\
\text { FMV2,5 } \\
\end{array}$} & M1 & Q39 & confirmed \\
\hline & & & 8.VLAs & $\mathrm{Q} 21,26$ & IV11,16 & & M2 & Q40 & confirmed \\
\hline & & & 9.PrKn & Q7-Q10,Q38 & MV2,14,1 & & M3.1, 3.3 & Q3,Q41 & confirmed \\
\hline & \multirow{3}{*}{$5 . \mathrm{b}$} & \multirow{3}{*}{ LocUniv } & 3.CLAs & Q12,16 & IV2,6 & \multirow{3}{*}{$\begin{array}{l}\text { FIV9 } \\
\text { FIV3 } \\
\text { FMV2,5 }\end{array}$} & M1 & Q39 & confirmed \\
\hline & & & 4.VLAs & Q20,25 & IV10,15 & & M2 & Q40 & confirmed \\
\hline & & & 9.PrKn & Q7-Q10,Q38 & MV2,14,1 & & M3.1, 3.3 & Q3,Q41 & confirmed \\
\hline & \multirow{3}{*}{$5 . c$} & \multirow{3}{*}{ LTUs } & 3.CLAs & Q12,16 & IV2,6 & \multirow{3}{*}{$\begin{array}{l}\text { FIV9 } \\
\text { FIV3 } \\
\text { FMV2,5 }\end{array}$} & M1 & Q39 & null not rej. \\
\hline & & & 4.VLAs & Q20,25 & IV10,15 & & M2 & Q40 & confirmed \\
\hline & & & 9.PrKn & Q7-Q10,Q38 & MV2,14,1 & & M3.1, 3.3 & Q3,Q41 & confirmed \\
\hline & \multirow{3}{*}{ 5.d } & \multirow{3}{*}{ ORDU } & 3.CLAs & Q12,16 & IV2,6 & \multirow{3}{*}{\begin{tabular}{|l} 
FIV9 \\
FIV3 \\
FMV2,5
\end{tabular}} & M1 & Q39 & confirmed \\
\hline & & & 4.VLAs & Q20,25 & IV10,15 & & M2 & Q40 & confirmed \\
\hline & & & 9.PrKn & Q7-Q10,Q38 & MV2,14,1 & & M3.1, 3.3 & Q3,Q41 & confirmed \\
\hline \multirow{12}{*}{ RQ-3 } & \multirow{3}{*}{ 6.a } & \multirow{3}{*}{ ORDU } & 1.CLAs & Q11,15 & IV 1,5 & \multirow{3}{*}{\begin{tabular}{|l} 
FIV8 \\
FIV5 \\
FMV3,4,6,7,8
\end{tabular}} & M1 & Q39 & confirmed \\
\hline & & & 2.VLAs & Q19,24 & IV9,14 & & M2 & Q40 & null not rej. \\
\hline & & & 10.PrExp & Q33-Q37 & IV12,13,10,9,11 & & M3.1, 3.3 & Q3,Q41 & confirmed \\
\hline & \multirow{3}{*}{$6 . b$} & \multirow{3}{*}{ LocUniv } & 3.CLAs & Q12,16 & IV2,6 & \multirow{3}{*}{\begin{tabular}{|l} 
FIV9 \\
FIV3 \\
FMV3,4,6,7,8
\end{tabular}} & M1 & Q39 & confirmed \\
\hline & & & 4.VLAs & Q20,25 & IV 10,15 & & M2 & Q40 & confirmed \\
\hline & & & 10.PrExp & Q33-Q37 & IV12,13,10,9,11 & & M3.1, 3.3 & Q3,Q41 & confirmed \\
\hline & & & 5.CLAs & Q14,18 & IV4,8 & FIV7 & M1 & Q39 & confirmed \\
\hline & $6 . c$ & LTUs & 6.VLAs & Q22,23,27,28 & IV12,17,13,18 & FIV1,4 & M2 & Q40 & confirmed \\
\hline & & & 10.PrExp & Q33-Q37 & IV12,13,10,9,11 & FMV $3,4,6,7,8$ & M3.1, 3.3 & Q3,Q41 & confirmed \\
\hline & & & 7.CLAs & Q13,17 & IV3,7 & FIV6 & M1 & Q39 & null not rej. \\
\hline & $6 . d$ & InatSrc & 8.VLAs & $\mathrm{Q} 21,26$ & IV11,16 & FIV2 & M2 & Q40 & null not rej. \\
\hline & & & 10.PrExp & Q33-Q37 & IV12,13,10,9,11 & FMV3,4,6,7,8 & M3.1, 3.3 & Q3,Q41 & confirmed \\
\hline & & & 7.CLAs & Q13,17 & IV3,7 & FIV6 & M1 & Q39 & null not rej. \\
\hline & 7.a & InatSrc & 8.VLAs & $\mathrm{Q} 21,26$ & IV11,16 & FIV2 & M2 & $\mathrm{Q} 40$ & confirmed \\
\hline & & & 11.PILAs & Q29-Q32 & MV5,6,7,8 & FMV1 & M3.1, 3.3 & Q3,Q41 & confirmed \\
\hline & & & 3.CLAs & Q12,16 & IV2,6 & FIV9 & M1 & Q39 & null not rej. \\
\hline & 7.b & LocUniv & 4.VLAs & Q 20,25 & IV10,15 & FIV3 & M2 & Q40 & null not rej. \\
\hline & & & 11.PILAs & Q29-Q32 & MV5,6,7,8 & FMV1 & M3.1, 3.3 & Q3,Q41 & confirmed \\
\hline $\mathbb{R}$ & & & 5.CLAs & Q14,18 & IV 4,8 & FIV7 & M1 & Q39 & confirmed \\
\hline & 7.c & LTUs & 6.VLAs & $\mathrm{Q} 22,23,27,28$ & IV12,17,13,18 & FIV 1,4 & M2 & Q40 & confirmed \\
\hline & & & 11.PILAs & Q29-Q32 & MV5,6,7,8 & FMV1 & M3.1, 3.3 & Q3,Q41 & confirmed \\
\hline & & & 1.CLAs & Q11,15 & IV1,5 & FIV8 & M1 & Q39 & null not rej. \\
\hline & 7.d & ORDU & 2.VLAs & Q19,24 & IV9,14 & FIV5 & M2 & Q40 & null not rej. \\
\hline & & & 11.PILAs & Q29-Q32 & MV5,6,7,8 & FMV1 & M3.1, 3.3 & Q3,Q41 & null not rej. \\
\hline
\end{tabular}


Table 5.12 summarizes the results that concern to interaction effects. It shows that 10 out of 12 hypotheses that relate to interaction effects have been confirmed. All of the original research questions pertaining to interaction effects have been answered at least in part.

The interaction model generated a total of 192 interactions between input factors pertaining to knowledge inflow (FIV1 through FIV9) and moderating factors pertaining to internal knowledge (FMV1 through FMV8) ${ }^{26}$ Every interaction is associated with a unique combination of output variable, source of external knowledge, type of knowledge inflow (either contextual or vicarious) and type of internal knowledge. The interaction matrices in table 5.13 depict the hypotheses that were confirmed (the null hypothesis was rejected) by one or more of these combinations at the level of $\mathrm{p}<0.05 .{ }^{27}$ Yet, the interaction matrices as a whole appear quite sparse because no hypothesis pertaining to interactions could be confirmed under all sets of circumstances. Only 39 out of 192 possible interactions were found to be statistically significant at the level of $p<0.05$. An additional seven interactions were considered potentially significant by SPSS (see nonshaded interactions in interaction appendix G.7).

\footnotetext{
${ }^{26}$ FIV8, FMV6 and FMV7 were excluded from the interaction model because the integrated model indicated that they have less of impact on the performance of the national laboratories three critical missions than the other factors do. FIV8 pertains to contextual learning from other R\&D project groups within the national laboratories; it only impacts versatility of technology. FMV6 is associated with prior education at local universities; it only impacts user satisfaction. FMV7 is associated with prior education at foreign universities; it has no significant impact on any output variable.

${ }^{27}$ The null hypotheses could not be rejected under all sets of circumstances in only two cases: hypothesis $6 \mathrm{~d}$ and hypothesis $7 \mathrm{~d}$. Even here there are caveats. SPSS identified the interaction between VLAs with ORDUs and PILAs as a potentially significant factor for user satisfaction. However, the level significance was at $p=0.062$. According to appendix G.7, many interactions had a statistically significant impact on OV3.2, the probability of generating a patent. However, it has been determined in section 5.3 that knowledge inflows and internal knowledge were not major drivers of the propensity to generate a patent. The results for OV 3.2 have consequently been excluded from this dissertation.
} 
Table 5.13: Interaction Matrices for Missions 1, 2 and 3

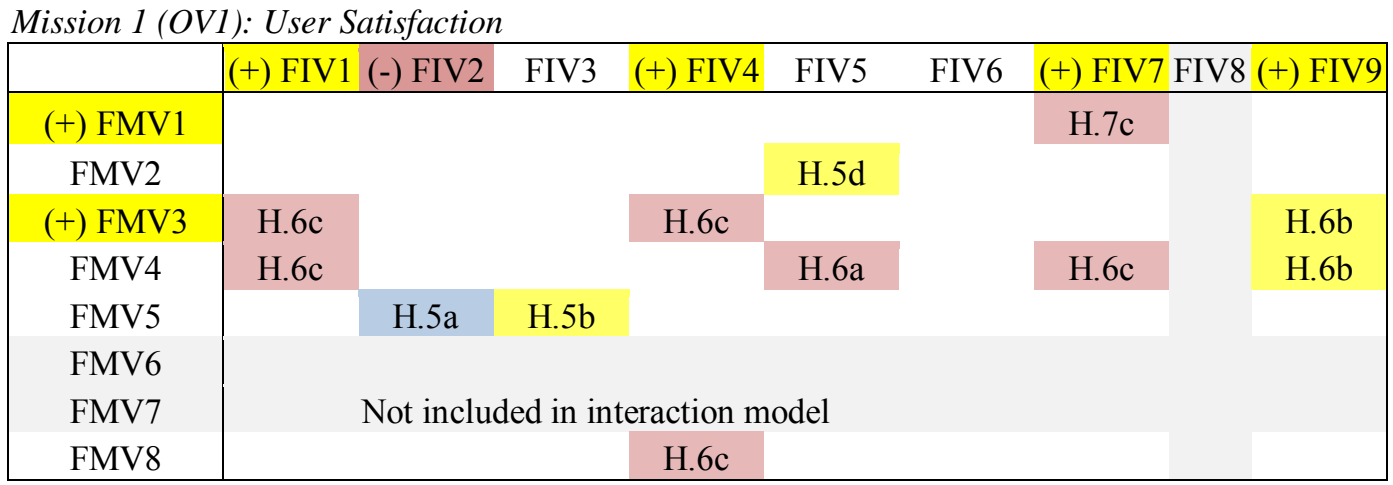

Mission 2 (OV2): Probability of Commercialization

\begin{tabular}{|c|c|c|c|c|c|c|c|c|}
\hline \multirow[b]{2}{*}{ FMV1 } & (+) FIV1 & FIV2 & FIV3 & \multicolumn{2}{|c|}{$(+)$ FIV4 (-) FIV5 } & \multirow[t]{2}{*}{ FIV6 } & \multicolumn{2}{|c|}{$(+)$ FIV7 FIV8 (+) FIV9 } \\
\hline & & H.7a & & & & & H.7c & \\
\hline FMV2 & & & & & H.5d & & & H. $5 b$ \\
\hline$(+)$ FMV3 & & & & & & & H.6c & H.6b \\
\hline FMV4 & & & & & & & & \\
\hline (+) FMV5 & H. $5 \mathrm{c}$ & H.5a & & H. $5 \mathrm{c}$ & H. $5 d$ & H.5a & H.5c & \\
\hline FMV6 & & & & & & & & \\
\hline FMV7 & & Not incl & ed in in & eraction $\mathrm{m}$ & odel & & & \\
\hline FMV8 & & & & & & & & \\
\hline
\end{tabular}

Mission 3 (OV3.1): Probability of Publication

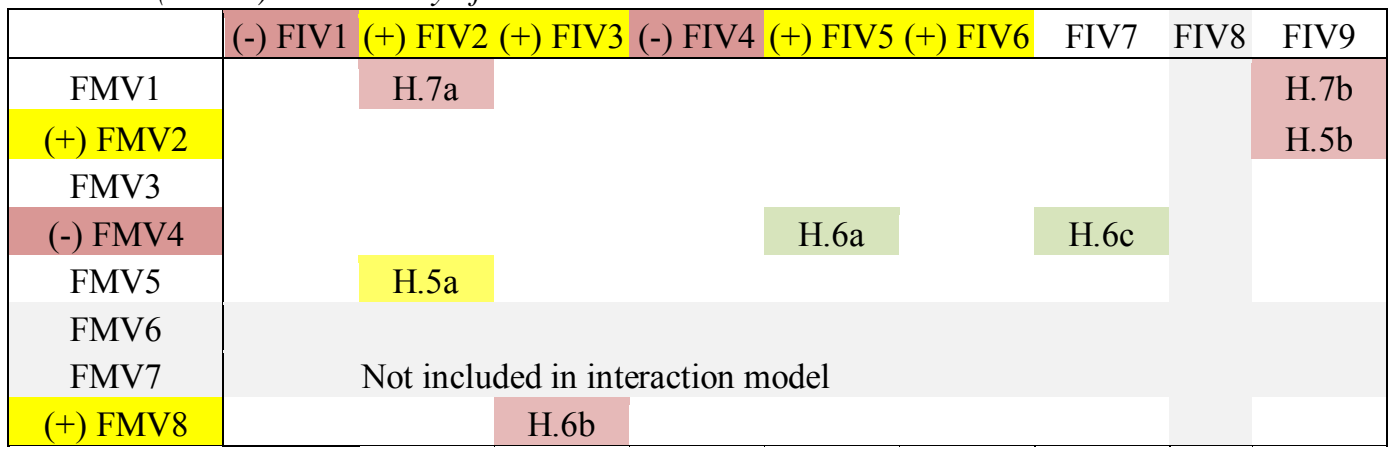

Mission 3 (OV3.3): Versatility of Technology

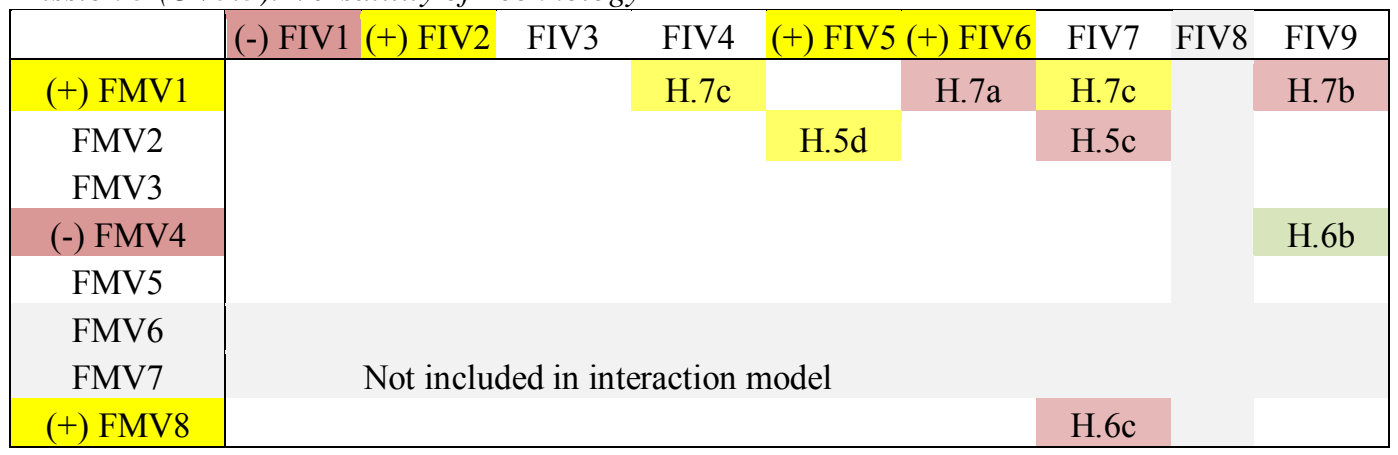


(+) Factor that is positively correlated to output

(-) Factor that is negatively correlated to output

H.xx Complementary interaction

H.xx Interaction where FMV has a negative impact

H.xx Interaction where FIV has a negative impact

H.xx Substitutive interaction

Not included in interaction model

Table 5.13 indicates which input factors (FIVs) and which moderating factors (FMVs) in the interaction model have a statistically significant impact on performance by themselves and which do not. Factors with $(+)$ have a positive impact; factors with (-) have a negative impact on performance; factors with no shading do not have a statistically significant impact on performance. As has been shown by the integrated model from section 5.3.2 and the correlation matrix from section 5.2, these factors do not necessarily align from mission to mission. 


\subsubsection{Types of Interactions}

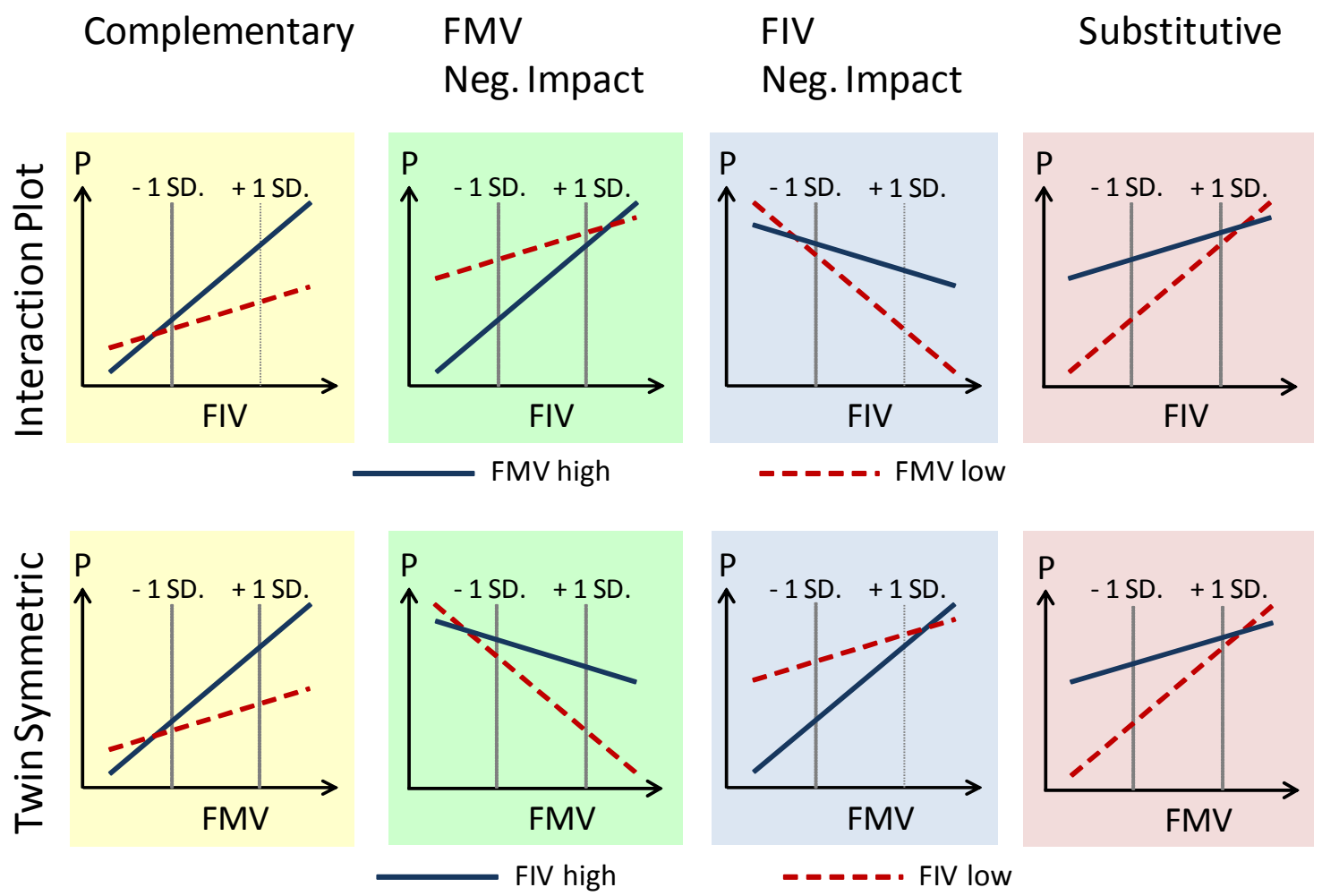

Figure 5.1: Types of interactions that were observed in this study

Figure 5.1 displays the four types of interaction that were observed in this study, as well as their symmetric twins. Issues associated with each type of interaction are discussed in this section. I also give an example of each kind of interaction.

\subsubsection{Complementary Interactions}

Complementary interactions have a positive impact on performance. Three types of complementary interactions were observed. In the first, neither the input factor nor the moderating factor has a negative impact on performance (i.e., the input factor by itself and the moderating factor by itself had a positive or a statistically insignificant impact on 
performance). This case is shown in the first column of figure 5.1 in the second type of interaction; the moderating factor had a negative impact on performance, whereas the input factor did not. This case is shown in the second column of figure 5.1. In the third type of interaction, the input factor had a negative impact on performance, whereas the moderating factor did not. This case is shown in the third column of figure 5.1.

\section{- 5.5.1.1.1 Neither the Input Factor nor the Moderating Factor has a Negative Impact on Performance.}

Let us first consider the case when neither the input factor by itself nor the moderating factor by itself had a negative impact on performance. In that case, over most of the domain of the input factor, performance was higher when the moderating factor was high, and performance increased more rapidly as a function of the input factor when the moderating factor was high. However, for a small fraction of the population at the lower

end of the domain of the input factor, the situation was different. Performance was higher when the moderating factor was low, even though performance increased more rapidly as a function of the input factor when the moderating factor was high.

The symmetric twin of the interaction plot told a similar story. Over most of the domain of the moderating factor, performance was higher when the input factor was high, and performance increased more rapidly as a function of the moderating factor when the input factor was high. However, for a small fraction of the population at the lower end of the domain of the moderating factor, the situation was different. Performance was higher when the input factor was low, even though performance increased more rapidly as a function of the moderating factor when the input factor was high. 
The normative implications for the managers in the national laboratories are straightforward. They need to increase the input factor and the moderating factor as much as possible. This is illustrated by the interaction between contextual learning about local universities (FIV9) and hiring people with prior work experience at local technology users (FMV3) into the R\&D project group. This interaction has a positive impact on the probability of commercializing technology. The analysis of this case is given below.

For a specific set of circumstances, hypothesis $6 \mathrm{~b}$ was confirmed (the null hypothesis was rejected) for Mission 2. Having at least one employee with prior work experience at a local technology user in the project team for the duration of the project enhances the project group's capacity to absorb knowledge that flows into the project group from local universities through contextual learning activities. Contextual learning from local universities has a positive impact on the probability of commercializing technology by itself. Having an employee with work experience at a local technology user in the project group enhances the positive impact of contextual learning from local universities.

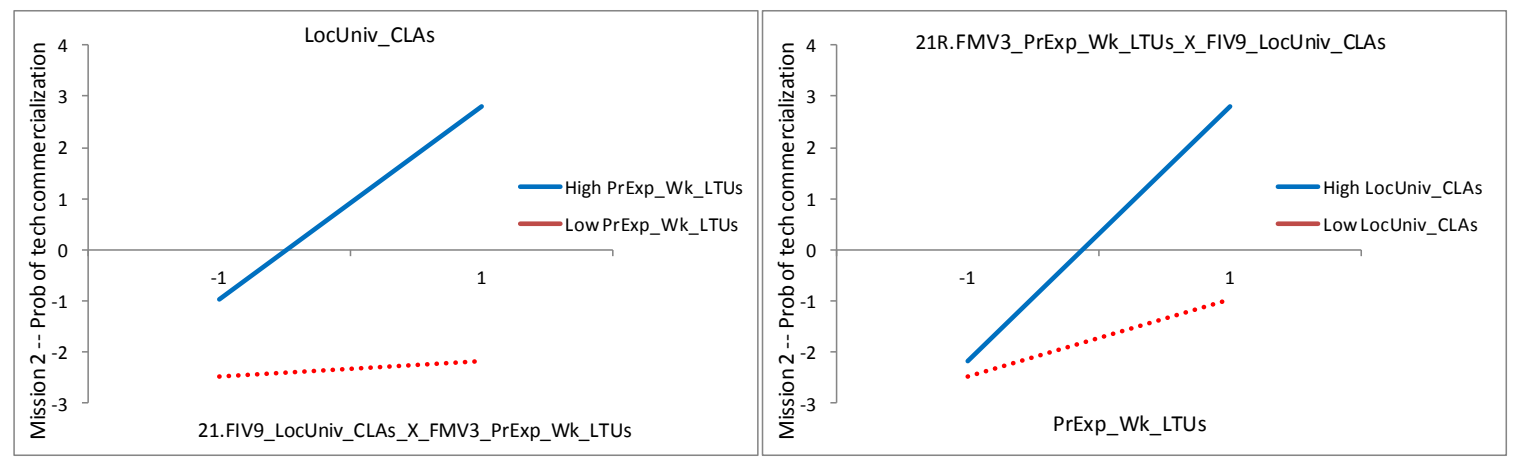

Figure 5.2: The impact of the interaction between contextual learning about local universities and having at least one team member with prior work experience at a local technology user on the probability of commercialization (on the left, and the symmetric interaction plot on the right). 
The interaction plots in figure 5.2 show that, over most of the domain of contextual learning from local universities, the probability of commercialization is higher and rises more rapidly as a function contextual learning when the number of project group members with prior work experience at local technology users is high, rather than when the number of project group members with work experience is low. The symmetric interaction plot in figure 5.2 suggests that, over most of the domain of the number of project group members with prior work experience at local technology users, the probability of commercialization is higher and rises more rapidly when the degree of contextual learning from local universities national laboratories is high, rather than when the degree of contextual learning from local universities national laboratories is low. This suggests that the national laboratories need to increase contextual learning activities with local universities and to hire people with work experience at local technology users into $\mathrm{R} \& \mathrm{D}$ project groups, if they want to increase the odds of commercialization of technology.

\section{- 5.5.1.1.2 The Moderating Factor has a Negative Impact on Performance, but the Input Factor Does Not.}

Next, let us consider the case when the impact on performance of the moderating factor was negative but that of the input factor was not. In that case, over most of the domain of the input factor, performance was higher when the moderating factor was low, and performance increased more rapidly as a function of the input factor when the moderating factor was high. However, for a small fraction of the population at the upper end of the domain of the input factor, the situation was different. Performance was higher when the 
moderating factor was high, and performance increased more rapidly as a function of the input factor when the moderating factor was high.

The symmetric twin of the interaction plot told a very different story. Performance decreases as the moderating factor increases. Over most of the domain of the moderating factor, performance was higher when the input factor was high, but performance decreased more rapidly as a function of the moderating factor when the input factor was low. However, for a small fraction of the population at the lower end of the domain of the moderating factor, the situation was different. Performance was higher when the input factor was low, even though performance decreased more rapidly as a function of the moderating factor when the input factor was low.

The normative implications of this scenario are slightly different from those of the case described above. The managers of the national laboratories need to increase the input factor as much as possible, but keep the moderating factor low. This situation is illustrated by the interaction between vicarious learning with other $R \& D$ project groups in the national laboratories (FIV5) and inviting people with prior work experience at other $R \& D$ project groups (FMV3) into the $R \& D$ project group. The analysis of this case is given below.

Hypothesis 6a was confirmed (the null hypothesis was rejected) for vicarious learning with another R\&D project group within the national laboratories for mission 3. Vicarious learning with other R\&D project groups within the national laboratories has a positive impact on the probability of generating a publication from a particular project. However, having employees with work experience in another $\mathrm{R} \& \mathrm{D}$ project group within the 
national laboratories in the project group for the duration of the project has a direct negative impact on the probability of generating publications from the project; it does not impede knowledge inflows from ORDUs. Therefore, this phenomenon is not a substitution effect.

The pair of interaction plots in figure 5.3 shows that, for most of the domain of vicarious learning with other R\&D project groups, the probability of publications is higher when the project group contains few or no employees with prior work experience at another $R \& D$ project group within the national laboratories. However, the probability of publication increases at a more rapid rate when the project group contains more employees with prior work experience at another project group. The probability of publication is higher when the number of team members with work experience at other $R \& D$ project groups is high, only if the degree of vicarious learning with other $R \& D$ project groups is very high. The symmetric interaction plot suggests that, if the degree of vicarious learning with the other $R \& D$ project group is low, then the probability of generating a publication decreases sharply as the number of group members with prior work experience at another R\&D project group increases. The probability of generating a publication is not particularly sensitive to the number of group members with prior work experience at another project group, if the degree of vicarious learning with other project groups is high. 

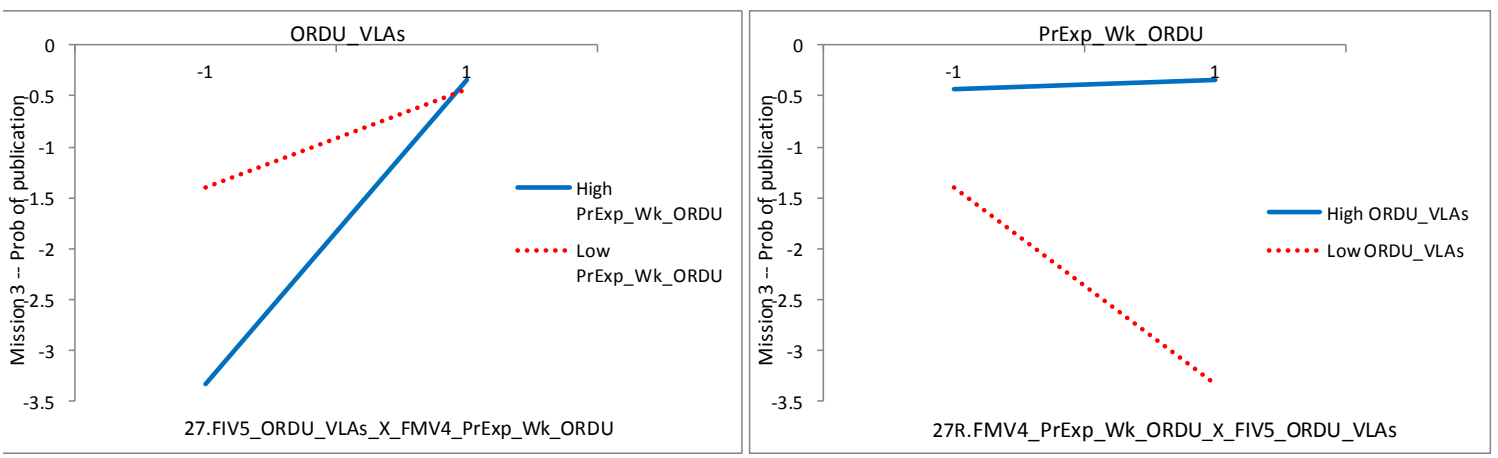

Figure 5.3: The impact of the interaction between vicarious learning with other R\&D project groups within the national laboratories and having at least one team member with prior work experience in another R\&D project group within the national laboratories on the probability of generating at least one publication from a project (on the left, and the symmetric interaction plot on the right).

\section{- 5.5.1.1.3 The Input Factor has a Negative Impact on Performance, but the Moderating Factor Does Not.}

Finally, let us consider the case when the input factor has a negative impact on performance, whereas the moderating factor did not. In that case, performance was inversely correlated to the input factor. Over most of the domain of the input factor, performance was higher when the moderating factor was high, but performance decreased more rapidly as a function of the input factor when the moderating factor was low. However, for a small fraction of the population at the lower end of the domain of the input factor, the situation was different. Performance was higher when the moderating factor was low, and performance decreased more rapidly as a function of the input factor when the moderating factor was low.

The symmetric twin of the interaction plot told a very different story. Performance increases as the moderating factor increases. Over most of the domain of the moderating factor, performance was higher when the moderating factor was low, but performance increased more rapidly as a function of the moderating factor when the input factor was 
high. However, for a small fraction of the population at the upper end of the domain of the moderating factor, the situation was different. Performance was higher when the input factor was high, and performance increased more rapidly as a function of the moderating factor when the input factor was high.

The normative implications of this scenario are slightly different from those of the case described above. The managers of the national laboratories need to keep the input factor low, but keep the moderating factor high. This situation is illustrated by the interaction between vicarious learning with other R\&D project groups in the national laboratories (FIV5) and having prior knowledge about the core technology within the project group before the project begins (FMV5). The analysis of this case is given below.

Hypothesis $5 \mathrm{~d}$ was confirmed (the null hypothesis was rejected) for Mission 2. Having prior knowledge about the core technology within the project group at the outset of the project increases the probability of commercializing technology. It also enhances the project group's capacity to absorb knowledge that flows into the project group from other $R \& D$ project groups within the national laboratories through vicarious learning activities. However, vicarious learning with other R\&D project groups (ORDUs) has a directly negative impact on the probability that a technology that is developed in a particular project group will be commercialized. Thus, prior knowledge about the core technology enhances the negative impact of vicarious learning with other R\&D project groups. It is not a substitute for vicarious learning with ORDUs. 


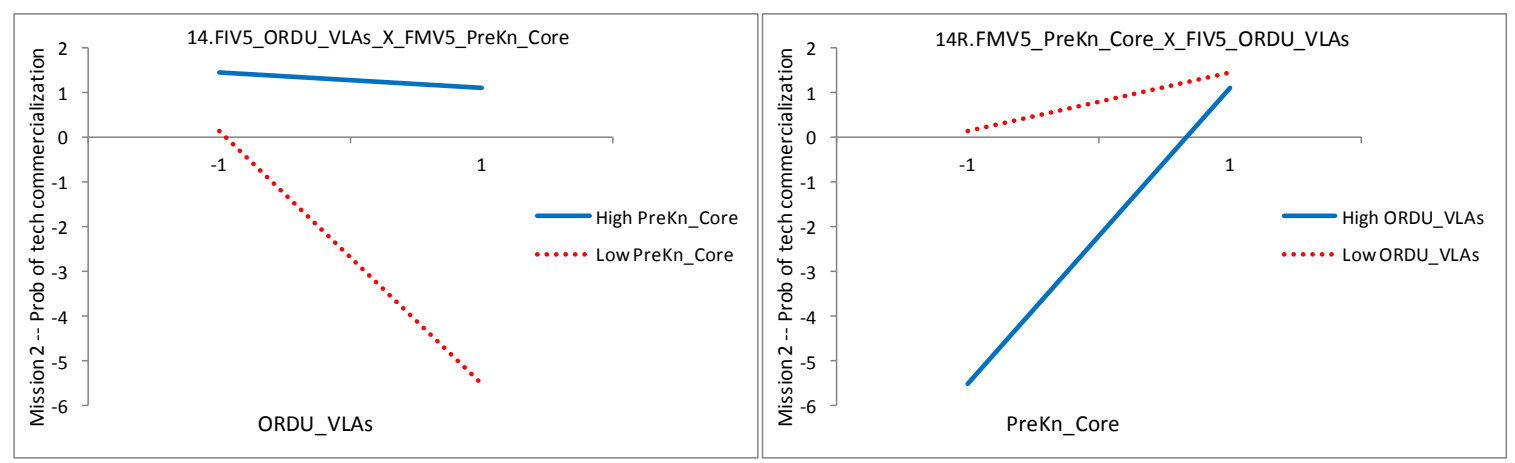

Figure 5.4: The impact of the interaction between vicarious learning with other R\&D project groups and prior knowledge of the core technology on the probability of commercializing technology (on the left, and the symmetric interaction plot on the right).

The interaction plots in figure 5.4 illustrate that performance is higher over most of the domain of vicarious learning with ORDUs when prior knowledge about the core technology is high, rather than when it is low. When prior knowledge about the core technology is low, then the probability of commercialization decreases at a very rapid rate as the degree of vicarious learning with ORDUs increases. This rate of decrease is significantly less when prior knowledge about the core technology is high. When vicarious learning with ORDUs is very low, then the probability of commercialization is actually higher if knowledge of about the core technology is high.

The symmetric plot suggests that the probability of commercialization is directly proportional to the degree of prior knowledge about the core technology. The probability of commercialization is higher over most of the domain of prior knowledge about the core technology when vicarious learning with LTUs is low. However, rate of increase in the odds of commercialization is higher when the degree of vicarious learning with ORDUs is high. When knowledge of about the core technology is very high, then the odds of commercialization are actually higher if vicarious learning with ORDUs is high. 


\subsubsection{Substitutive Interactions}

Substitutive interactions have a negative impact on performance. The input factors and the moderating factors of the substitutive interactions that were observed in this research all had a positive impact on performance or a statistically insignificant impact on performance. This case is shown in the fourth column of figure 5.1.

No substitutive interaction that was observed had an impact factor or a moderating factor with a negative impact on performance. Over most of the domain of the input factor, performance was higher when the moderating factor was high, but performance increased more rapidly as a function of the input factor when the moderating factor was low. However, for a small fraction of the population at the upper end of the domain of the input factor, the situation was different. Performance was higher when the moderating factor was low, and performance increased more rapidly as a function of the input factor when the moderating factor was low.

The symmetric twin of the interaction plot told a similar story. Over most of the domain of the moderating factor, performance was higher when the input factor was high, but performance increased more rapidly as a function of the moderating factor when the input factor was low. However, for a small fraction of the population at the upper end of the domain of the moderating factor, the situation was different. Performance was higher when the input factor was low, and performance increased more rapidly as a function of the moderating factor when the input factor was low. 
In the case of substitutive interactions, internal knowledge diminishes the project group's capacity to absorb external knowledge because the source of internal knowledge acts as a substitute for the knowledge inflow. However, a reduced absorptive capacity can also be attributed to other causes. For example, if a project group suffers from the Not-InventedHere Syndrome (NIH) (R. Katz \& Allen, 1982), then it is not likely to be open to knowledge from exogenous sources. In that case, the internal sources of knowledge would not be a substitute for knowledge inflows; instead, they would just be a barrier to knowledge inflows. This situation is illustrated by the interaction between external with local technology users (FIV1, FIV4, FIV7) and having prior knowledge about the core technology within the project group before the project begins (FMV5). The analysis of this case is given below.

Hypothesis $5 \mathrm{c}$ was confirmed (the null hypothesis was rejected) for mission 2. External learning with local technology users has a positive effect on the probability of commercializing technology. Having prior knowledge about the core technology in the project group also has a positive impact on the probability of commercialization. Yet the interaction between these two factors reduces the probability of commercialization. This suggests that having prior knowledge about the core technology in the project group at the outset of the project diminishes the project group's capacity to absorb knowledge that flows into the project group from local technology users through external learning activities, be they vicarious or contextual. It also does not matter whether the local technology users are end users or whether they have production units. Thus, having prior knowledge about the core technology in the project group may act as a substitute for engaging in external learning with local technology users. Alternatively, having prior 
knowledge about the core technology in the project group may be a source of NIH. Only an investigation into the specific situation will tell.

The interaction plots in figures 5.5 through 5.7 show that the probability of commercializing a technology is higher over most of the external learning domains that pertain to local technology users when prior knowledge of about the core technology is high. However, the probability of commercialization is increases more rapidly as a function of external learning from local technology users when prior knowledge about the core technology is low. At the very upper end of the external learning domain the probability of commercialization is actually higher when prior knowledge about the core technology is low. The symmetric plot suggests that the probability of commercializing a technology is higher over most of the domain knowledge about the core technology when external learning activities with is high. However, the probability of commercialization increases more rapidly as a function of prior knowledge about the core technology when external learning with local technology users is low. At the very upper end of the prior knowledge domain, the probability of commercialization is actually higher when the degree of external learning with local technology users is low. 

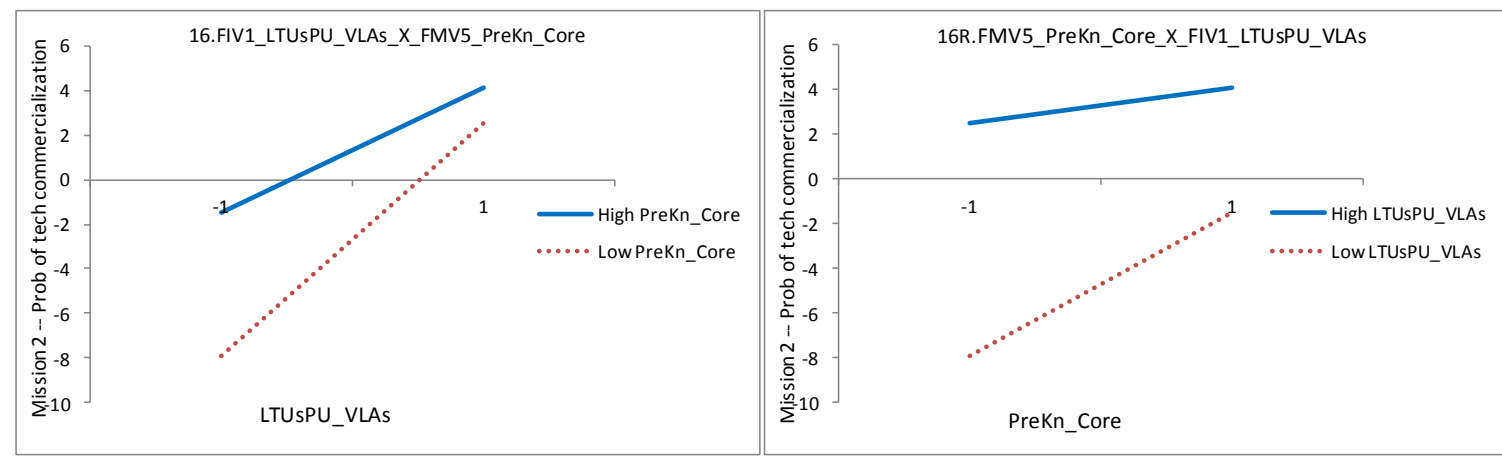

Figure 5.5: The impact of the interaction between vicarious learning with local technology users that have production units and prior knowledge of the core technology on the probability of commercializing technology (on the left, and the symmetric interaction plot on the right).
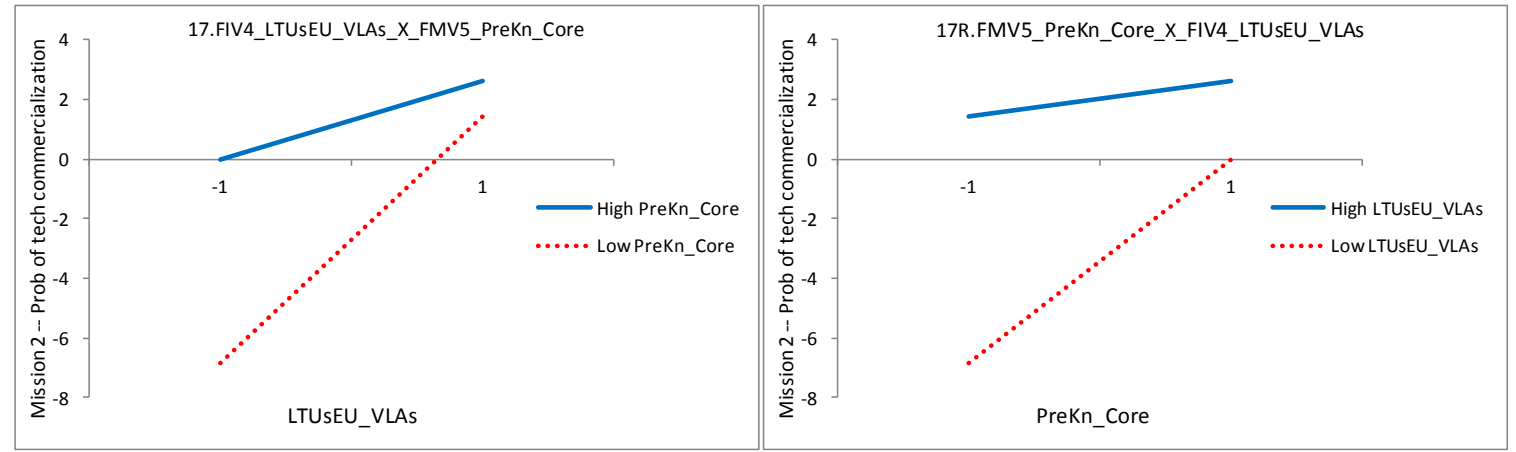

Figure 5.6: The impact of the interaction between vicarious learning with local technology users that are end users and prior knowledge of the core technology on the probability of commercializing technology (on the left, and the symmetric interaction plot on the right).

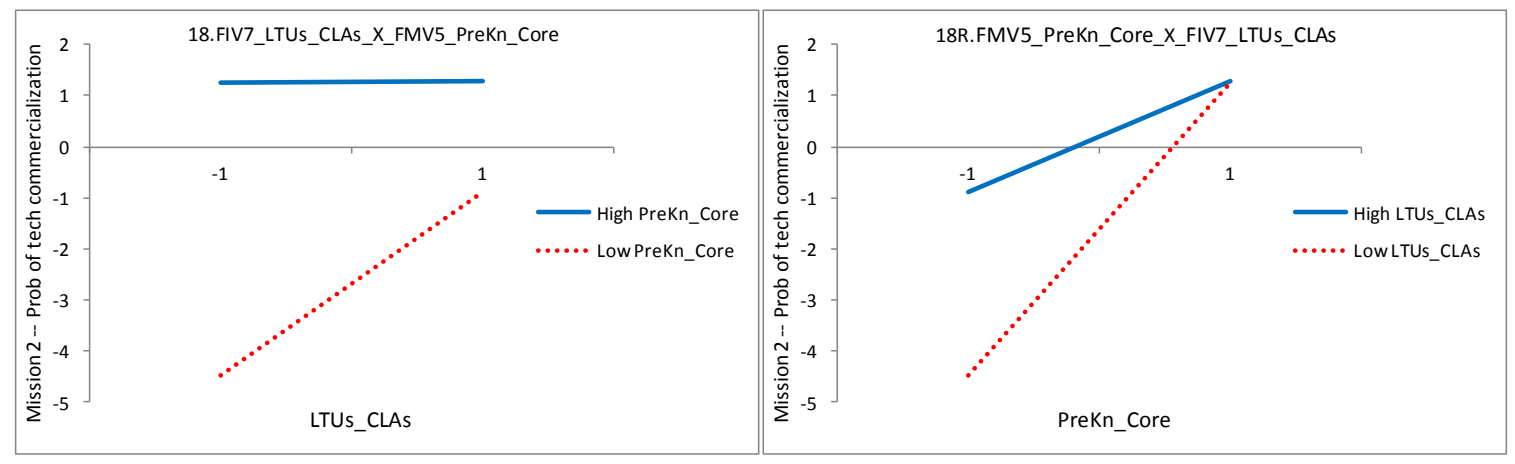

Figure 5.7: The impact of the interaction between contextual learning with local technology users and prior knowledge of the core technology on the probability of commercializing technology (on the left, and the symmetric interaction plot on the right). 


\subsubsection{Ranking Interaction Effects}

Table 5.14: Ranking Interaction Effects

Mission 1 (OV1): User Satisfaction

\begin{tabular}{|c|c|c|c|c|c|c|}
\hline Interaction: & $\mathrm{B}$ & S.E. & Beta & $\mathrm{t}$ & Sig. & $\begin{array}{c}\text { Interaction } \\
\text { Type }\end{array}$ \\
\hline 1. FIV9_LocUniv_CLAs_X_FMV4_PrExp_Wk_ORDU & .227 & .075 & .136 & 3.023 & .003 & Complementar \\
\hline 2. FIV3_LocUniv_VLAs_X_FMV5_PreKn_Core & .202 & .068 & .133 & 2.979 & .003 & Complementa \\
\hline 3. FIV5_O & 190 & .068 & .124 & 795 & .006 & Con \\
\hline 4. FIV2_InatSrc_VLAs_X_FMV5_PreKn_Core & .189 & .061 & .140 & 3.072 & & \\
\hline FIY & .179 & .063 & .131 & 2.852 & .005 & Complementa \\
\hline 6. FIV5_ORDU VLAs X FMV4 PrExp_Wk_ORDU & -.234 & .068 & -.157 & -3.441 & .001 & Sub \\
\hline 7. FIV1_LTUsPU_VLAs_X_FMV3_PrI & -.164 & .067 & -.108 & -2.440 & .016 & $\mathrm{Su}$ \\
\hline 8. FIV7_LTUs_CLAs_X_FMV4_PrExp_Wk_ORDU & -.158 & .065 & -.106 & -2.437 & & ve \\
\hline 9. FIV4_LTUsEU_VLAs_X_FMV3_PrE & -.155 & .067 & -.108 & -2.312 & .02 & \\
\hline 10. FIV1_LTUsPU_VLAs_X_FMV4_PrExp_Wk_ORDU & -.151 & .067 & -.101 & -2.268 & .02 & Substitutive \\
\hline 11. FIV7_LTUs_CLAs_X_FMV1_PILAs & -.149 & .065 & -.104 & -2.29 & .023 & Substitutive \\
\hline 12. FIV4 LTUsEU VLAs X FMV8 PrEx & -.144 & .065 & -.097 & -2.207 & .029 & Substitutive \\
\hline
\end{tabular}

Mission 2 (OV2): Probability of Commercialization

\begin{tabular}{|l|r|r|r|r|r|l|}
\hline \multicolumn{1}{|c|}{ Interaction: } & & & & & & \multicolumn{1}{|c|}{$\begin{array}{c}\text { Interaction } \\
\text { Type }\end{array}$} \\
\hline 13. FIV7_LTUs_CLAs_X_FMV3_PrExp_Wk_LTUs & 1.426 & .378 & 14.220 & 4.160 & .000 & Complementary \\
14. FIV5_ORDU_VLAs_X_FMV5_PreKn_Core & 1.332 & .500 & 7.088 & 3.789 & .008 & Input Factor \\
Neg. Impact \\
15. FIV6_InatSrc_CLAs_X_FMV5_PreKn_Core & 1.117 & .407 & 7.522 & 3.054 & .006 & Complementary \\
16. FIV5_ORDU_VLAs_X_FMV2_PreKn_PJ & .871 & .368 & 5.609 & 2.388 & .018 & Input Factor \\
& & & & & Neg. Impact \\
17. FIV9_LocUniv_CLAs_X_FMV3_PrExp_Wk_LTUs & .870 & .271 & 10.336 & 2.386 & .001 & Complementary \\
18. FIV9_LocUniv_CLAs_X_FMV2_PreKn_PJ & .674 .320 & 4.423 & 1.961 & .035 & Complementary \\
19. FIV4_LTUsEU_VLAs_X_FMV5_PreKn_Core & -1.41 .569 & 6.136 & .244 & .013 & Substitutive \\
20. FIV1_LTUsPU_VLAs_X_FMV5_PreKn_Core & -1.20 & .467 & 6.598 & .301 & .010 & Substitutive \\
21. FIV7_LTUs_CLAs_X_FMV5_PreKn_Core & -.895 & .408 & 4.812 & .409 & .028 & Substitutive \\
22. FIV7_LTUs_CLAs_X_FMV1_PILAs & -.842 & .375 & 5.043 & .431 & .025 & Substitutive \\
23. FIV2_InatSrc_VLAs_X_FMV5_PreKn_Core & -.833 & .370 & 5.061 & .435 & .024 & Substitutive \\
24. FIV2_InatSrc_VLAs_X_FMV1_PILAs & -.750 .322 & 5.408 & .472 & .020 & Substitutive \\
\hline
\end{tabular}


Mission 3 (OV3.1): Probability of Publication

\begin{tabular}{|c|c|c|c|c|c|c|}
\hline Interaction: & B & S.E. & Wald 1 & $\operatorname{Exp}(B)$ & Sig. & $\begin{array}{l}\text { Interaction } \\
\text { Type }\end{array}$ \\
\hline FIV7_LTUs_CLAs_X_F & .714 & .262 & 7.406 & 2.043 & \multirow{2}{*}{\multicolumn{2}{|c|}{\begin{tabular}{|l|l}
.006 & Mod. Fact. \\
Neg. Impact \\
.026 & Complementar
\end{tabular}}} \\
\hline FIV2_InatSrc_VLAs_X_FMV5_P & .587 & 7.264 & 4.941 & 1.799 & & \\
\hline$\Delta_{S} \gamma_{2}$ & .505 & .248 & 4.156 & 1.657 & & Neg. Im \\
\hline FIV9_LocUniv_CLAs_X & -.736 & .281 & 6.852 & .479 & & 9 Substitutive \\
\hline 9. FIV9_LocUniv_CLAs_X_FMV1_PIl & -.629 & .272 & 34 & .533 & & 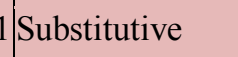 \\
\hline . FIV3_LocUniv_VLAs_X_FMV8_PrExp_ & -.586 & .274 & 4.581 & .55 & & 2 Substitutive \\
\hline 1. FIV2_InatSrc_VLAs_X_FMV1_PILAs & -.571 & .249 & 5.254 & 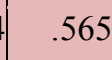 & & 2 Substitutive \\
\hline
\end{tabular}

Mission 3 (OV3.3): Versatility of Technology

\begin{tabular}{|l|c|c|c|c|c|l|}
\hline \multicolumn{1}{|c|}{ Interaction: } & B & S.E. & Beta & t & Sig. & $\begin{array}{c}\text { Interaction } \\
\text { Type }\end{array}$ \\
\hline 32. FIV4_LTUsEU_VLAs_X_FMV1_PILAs & .200 & .080 & .162 & 2.503 & .013 & Complementary \\
33. FIV7_LTUs_CLAs_X_FMV1_PILAs & .180 & .079 & .153 & 2.285 & .023 & Complementary \\
34. FIV9_LocUniv_CLAs_X_FMV4_PrExp_Wk_ORDU & .178 & .087 & .129 & 2.041 & .043 & Mod. Fact. \\
Neg. Impact \\
35. FIV5_ORDU_VLAs_X_FMV2_PreKn_PJ & .172 & .081 & .141 & 2.138 & .034 & Complementary \\
36. FIV7_LTUs_CLAs_X_FMV2_PreKn_PJ & -.234 .081 & -.184 & -2.895 & .004 & Substitutive \\
37. FIV6_InatSrc_CLAs_X_FMV1_PILAs & -.212 .076 & -.174 & -2.771 & .006 & Substitutive \\
38. FIV7_LTUs_CLAs_X_FMV8_PrExp_Wk_InatSrc & -.191 & .081 & -.149 & -2.358 & .019 & Substitutive \\
39. FIV9_LocUniv_CLAs_X_FMV1_PILAs & -.167 .077 & -.139 & -2.172 & .031 & Substitutive \\
\hline
\end{tabular}

Table 5.14 ranks the interactions that were statistically significant at the level of $p<0.05$ by magnitude of correlation coefficient. This ranking has been performed for OV.1, OV.2, OV3.1 and OV3.3; thus all three critical missions of the national laboratories are covered. Table 5.14 also identifies complementary interactions for which the input factor or the moderating factor has negative impact on performance. 
The ranking in table 5.14 has resulted in the following observations:

- When it comes to user satisfaction, all statistically significant interactions involving local technology users are substitutive.

- When it comes to user satisfaction, the strongest complementary interaction is between contextual learning about local universities and grafting someone with prior work experience at another $R \& D$ project group within the national laboratories into the project group.

- When it comes to the probability of commercialization, the interactions between the various knowledge inflows from local technology users and prior knowledge about the core technology tend to be substitutive. So is the interaction between the contextual learning about local technology users and project-internal learning activities.

- When it comes to the probability of commercialization, the strongest complementary interaction is between contextual learning about local technology users and grafting someone with prior work experience at a local technology user into the project group.

- When it comes to the probability of publication, all interactions involving local universities are substitutive.

- When it comes to versatility of technology, the two strongest complementary interactions are between knowledge inflows from local technology users and project-internal learning activities. The strongest substitutive interaction is 
between contextual learning about local technology users and externalized prior knowledge about subject matter that pertains to the project.

- All but one of the interactions for which either the input factor or the moderating factor has a negative impact on performance involve other $R \& D$ project groups within the national laboratories.

- All interactions for which the moderating factor has a negative impact on performance are related to grafting employees with prior work experience at other project groups within the national laboratories into the project group. (This observation is an artifact of the interaction model. The integrated model does not yield statistically significant evidence that grafting people with prior experience at other $R \& D$ units has a negative impact on performance.)

- Two out of three interactions for which the input factor has a negative impact on performance are related to external learning with other project groups within the national laboratories. Both of these interactions impact the probability of commercialization.

- Two out of three interactions for which the input factor has a negative impact on performance are related to knowledge inflows from other project groups within the national laboratories.

- Knowledge inflow from international sources by itself has a statistically significant negative impact on user satisfaction in the interaction model, but not in the integrated model. 


\section{INTERPRETATION AND CONCLUSIONS}

In this chapter, I use the qualitative data that was gathered in the interviews with project managers and project evaluators to interpret the quantitative data from chapter 5 . This approach leads to a series of conclusions, which are presented in this chapter. In some instances, the conclusions yield suggestions for further research, which are denoted in the form of specific propositions.

The remainder of this chapter is organized thematically. In section 6.1, I draw conclusions that are specific to NSTDA, the national laboratories of Thailand. In section 6.2, I present the overarching conclusion of this dissertation-a framework for knowledge flows for the part of the national innovation system that pertains to the national laboratories. In section 6.3, I conclude that absorption of knowledge is selective - it depends on the source of external knowledge, the source of internal knowledge, the interaction between those sources, the type of knowledge inflow and the mission to which it is applied. I argue that knowledge flows, as they pertain to the national laboratories, can be organized into knowledge subsystems of the national innovation systems, which can be managed at a relatively low level within the national laboratories. In section 6.4, I present the knowledge subsystems that are associated with each of the output variables of my research, and I draw conclusions that are specific to each of the three primary missions of the national laboratories. Section 6.5 discusses the alignment of the mission-specific criteria and their linkage to organizational ambidexterity. Finally, in section 6.6, I present conclusions about the knowledge 
subsystems of the national laboratories system that pertain to specific sources of knowledge, and I discuss the relative importance of external and internal sources of knowledge.

\subsection{CONCLUSIONS ABOUT NSTDA}

The analysis of the descriptive statistics in section 5.1 has yielded a series of statistically significant findings that concern NSTDA. ${ }^{28}$ Interview with project managers have enabled me to interpret these findings, which have led to the conclusions that are presented in this section.

Conclusion 6.1-1: Contextual learning activities with international sources are more prevalent within NSTDA than contextual learning activities with other R\&D project groups, local universities and local technology users.

Interviews with project managers provide the following explanation for conclusion 6.1-1. Before the beginning of an $\mathrm{R} \& \mathrm{D}$ project, the managers need to set up the project's goal and commit to specific deliverables. They subsequently generate research plans that allow them to match the tasks to be completed with the knowledge and skills that their team members possess. If the internal knowledge within individuals or the project groups is not sufficient for the team to complete the new project, then the team conducts a review of relevant technical literature (a form of contextual learning), in order to gain

\footnotetext{
${ }^{28}$ The statistical significance was determined by a t-test of select pairs of variables within the descriptive statistics.
} 
new ideas for the project. For example, the project group can rely on international online research databases as a source of explicit knowledge that can stimulate new ideas.

Conclusion 6.1-2: Grafting people with prior relevant experience in education is more prevalent than grafting people with prior relevant work experience at international sources, local technology users or other R\&D units within the national laboratories.

The interviews with the project managers suggest that, typically, most of their researchers graduate from universities both local and aboard. They also tend to have gained research experience in specific areas of technology from their research projects while studying at universities. The research skills from their education are considered a fundamental source of knowledge for their research projects.

Grafting people with prior relevant work experience into a project group tends to be less common than education abroad. International work experience of project members tends to come from collaborative projects with international institutes that occur on occasion. Grafting people with prior experience with other R\&D units also occurs on occasion when the project is initiated by top management or when the project managers have a strong connection with the other R\&D units. These two approaches make working across R\&D units possible. Grafting people from local technology users occurs when an LTU and the national laboratories are engaged in a collaborative project. 


\subsection{A FRAMEWORK FOR KNOWLEDGE FLOWS WITHIN THE NATIONAL INNOVATION SYSTEM}

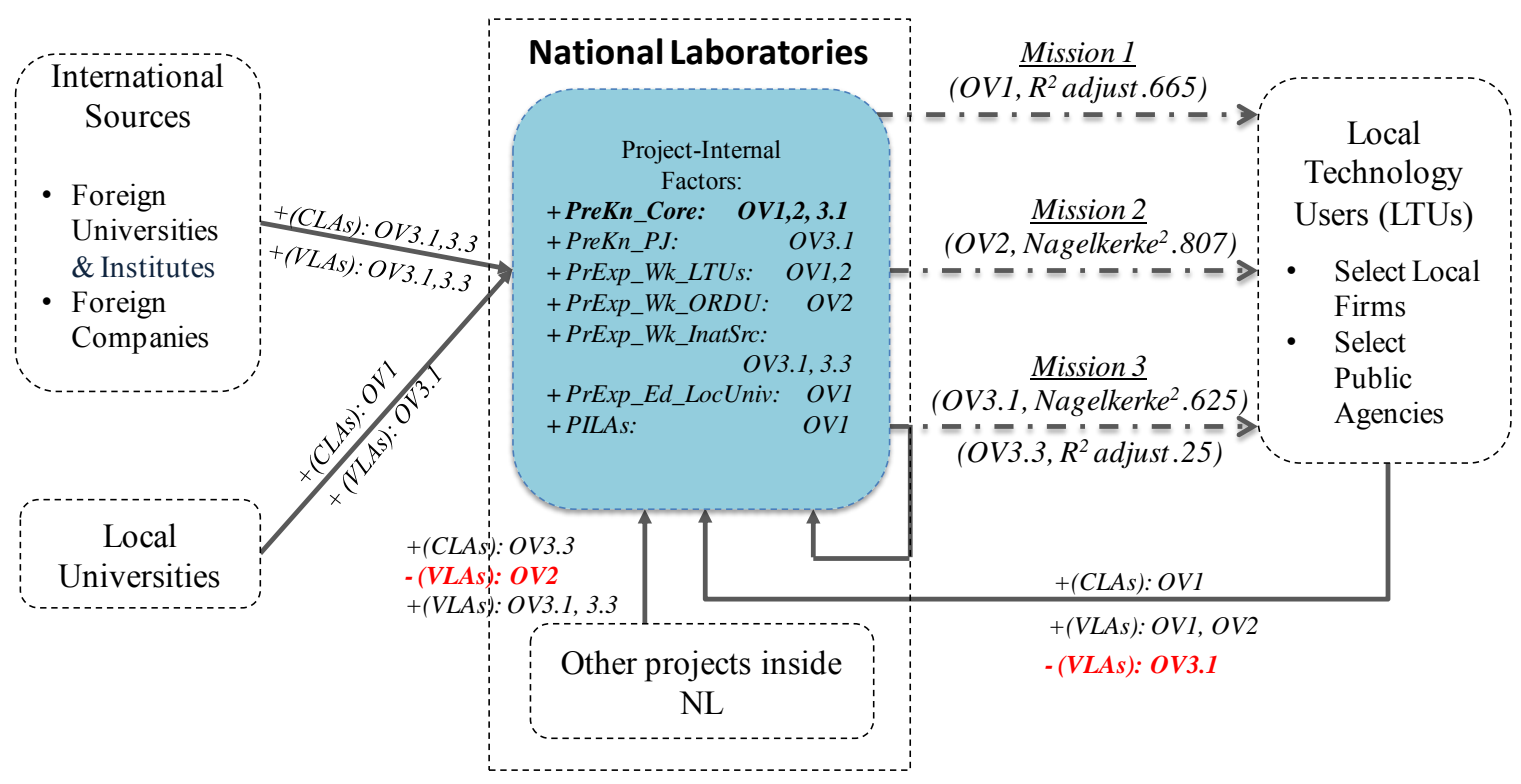

Figure 6.1: Knowledge flows within the national innovation system, which pertain to the national laboratories.

Figure 6.1 illustrates the overarching conclusion of this dissertation — the validation of the theoretical framework that was created from the literature review in chapter 2. Figure 6.1 is an extension of figure 2.5. It shows that all aspects of the theoretical framework from chapter 2 , which is presented in section 2.5 , have been validated empirically by confirming the majority of the hypotheses from chapter 3 . Figure 6.1 identifies which path for knowledge inflow contributes to which laboratory mission, which form of internal knowledge contributes to which mission, as well as the valence of these contributions. Figure 6.1 also denotes the valence of the interactions between the various knowledge inflows and the various forms of internal knowledge, as well as the output 
variables that they impact. Finally, figure 6.1 illustrates the complexity of the knowledge flows within the national innovation system that pertain to the national laboratories of a technology latecomer country. It suggests that the national laboratories cannot just implement one or two broad policy initiatives that will impact performance on a global scale without inducing collateral effects at the micro-level.

The results of my dissertation research show that the impact on performance of knowledge flows within the national innovation system that pertains to the national laboratories is nuanced and differentiated. For example, figure 6.1 suggests that the managers within the national laboratories have levers with which they can impact the performance of their institution and influence the national innovation system in the long run. One particular lever can impact more than one output variable, and one specific output variable can be influenced by more than one lever. The national laboratory system consequently consists of multiple subsystems, where each subsystem is associated with $a$ particular mission or with a specific source of knowledge. This system will henceforth be referred to as the National Laboratories Knowledge Management System (NLKMS), and its subsystems will henceforth be called the National Laboratories Knowledge Management Subsystems (NLKMSS). 


\subsection{SELECTIVE ABSORPTION OF KNOWLEDGE}

Cohen and Levinthal have argued that "the ability of a firm to recognize the value of new, external information, assimilate it, and apply it to commercial ends is critical to its innovative capabilities. [They] label this capability a firm's absorptive capacity and suggest that it is largely a function of the firm's level of prior related knowledge" (W. M. Cohen \& Levinthal, 1990, p. 128). In this dissertation, I have conducted research that has analyzed absorptive capacity in the environment of the national laboratories, using individual project groups as my unit of analysis. The results, which have been presented in chapter 5, suggest that absorptive capacity is an important component of managing knowledge within the national laboratory system of a technology latecomer country. In addition, I have found that capacity of R\&D project groups within the national laboratories to absorb knowledge from external sources is not just related to prior related knowledge; it is also a function of the source of external knowledge, the knowledge pathway into the project group; the source of complementary or substitutive knowledge that resides within the project group; and the mission to which the knowledge contributes.

The sparse interaction matrix in table 5.20 suggests that the capacity to absorb knowledge is quite selective. Only 39 of the 192 possible permutations for mechanisms to absorb knowledge from external sources actually have a statistically significant impact on performance. Yet, as table 5.21 shows, the statistical signals for the interactions, regardless whether they are substitutive or complementary, are relatively strong. This gives the managers of the national laboratories a toolkit of micro-levers with which they 
can selectively target a specific aspect of performance that they want to improve. Individual project groups can thus contribute to the performance of the national laboratories by pulling the appropriate lever.

It should also be noted that the statistically significant interactions do not occur in a random fashion. A few very distinct patterns of interactions have been identified in section 5.5.2. These patterns provide insight into the structure of the knowledge subsystems of the National Laboratories Knowledge Management System, whose existence has been proposed in figure 6.2. 


\subsection{MISSION-SPECIFIC CONCLUSIONS}

\subsubsection{Conclusions Pertaining to User Satisfaction (Mission 1)}

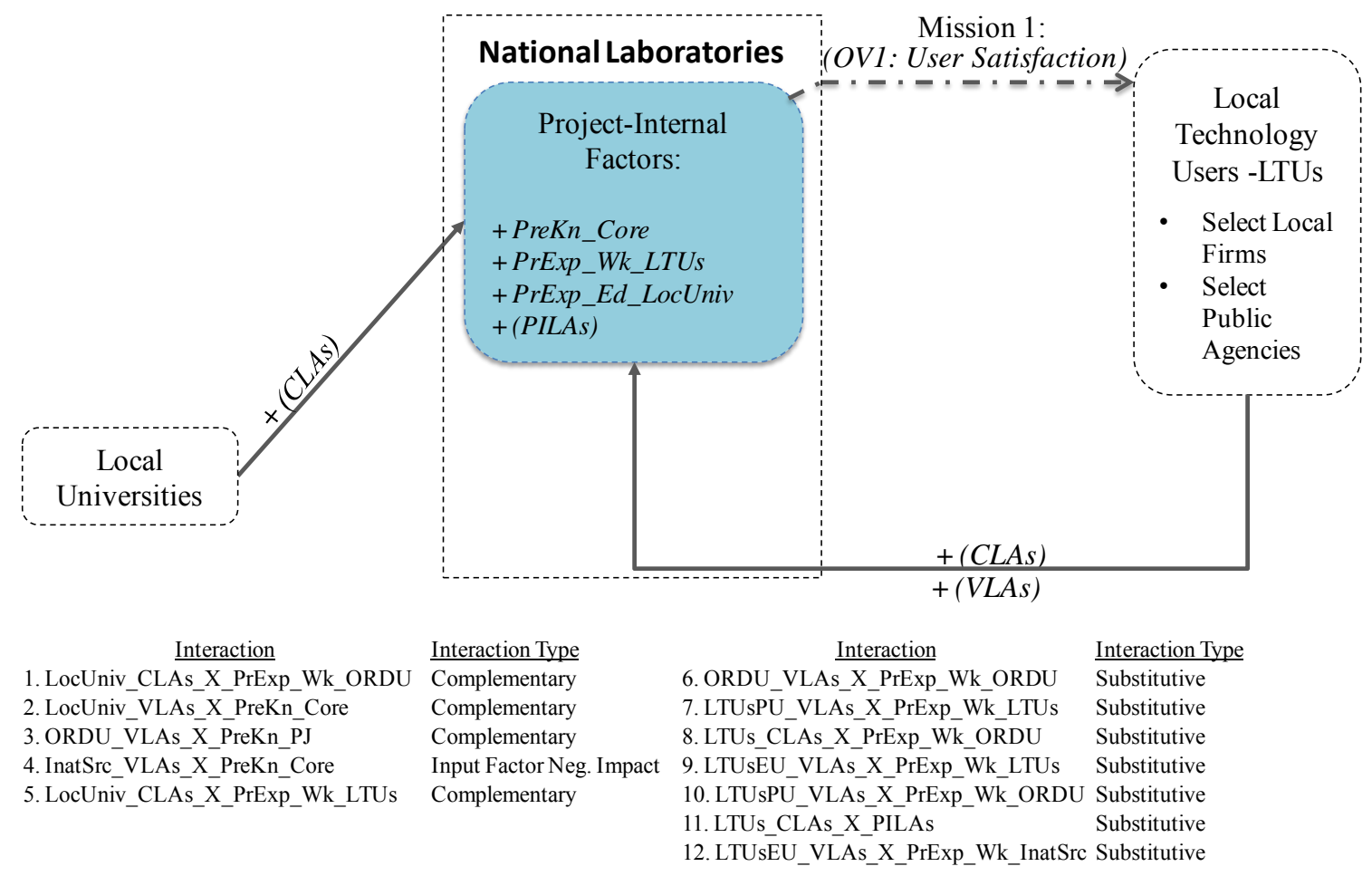

Figure 6.2: The knowledge management subsystem of the National Laboratory Knowledge Management System that contributes to user satisfaction

Figure 6.2 summarizes all the results that pertain to hypotheses $1 \mathrm{a}, 2 \mathrm{a}, 3 \mathrm{a}$ and $4 \mathrm{a}$ in section 5.4, as well as the results from the relative ranking of correlation coefficients that pertain to OV1 in section 5.4.5 and the results of running the interaction model for OV1 in section 5.5. Figure 6.2 depicts everything pertaining to knowledge flows within the national laboratory system and their impact on user satisfaction that my research has been 
able to verify to date at a level of statistical significance of $p<0.05$. I consequently propose that figure 6.2 represents a framework, which characterizes the subsystem of the national laboratories that governs user satisfaction.

The framework in figure 6.2 suggests that user satisfaction is primarily driven by three kinds of knowledge inflow from two exogenous sources: contextual and vicarious feedback from local technology users and contextual learning from local universities. Various internal sources of knowledge such as prior knowledge about the core technology, grafting people with prior work experience at LTUs, prior education at local universities and project-internal learning activities also contribute positively to user satisfaction. In the interaction model, vicarious learning with international sources is negatively correlated to user satisfaction at a level of statistical significance of $p<0.05$. (There is no statistically significant correlation between vicarious learning with international sources and user satisfaction in the integrated model.) Figure 6.2 also lists all the interactions pertaining to user satisfaction that are complementary (are positively correlated to OV1) or substitutive (negatively correlated to OV1). One interaction - the one between vicarious learning with international sources and prior knowledge about the core technology (interaction no.4) - is negatively complementary; it decreases the negative impact that vicarious learning with international sources has on the user satisfaction.

The following conclusions can be drawn from figure 6.2. 
Conclusion 6.4.1-1: Engagement with local technology users increases user satisfaction. All input factors pertaining to engagement with LTUs (VLAs with LTUs that have production units, VLAs with end users, CLAs with LTUs of all kinds and grafting people with work experience at LTUs) had a strong positive correlation with user satisfaction. This conclusion is consistent with prior findings related to user innovation (e.g., von Hippel, 1988, 1989, 2005).

Conclusion 6.4.1-2: When it comes to user satisfaction, at least one of the following is true: 1) internal knowledge gained from project-internal learning activities (interaction no. 11), or from grafting people with prior experience at other $R \& D$ project groups within the NLs (see interactions $6,8 \& 10$ ), LTUs (see interactions $7 \&$ 9), and international sources (see interaction no. 12) are substitutes for external learning with LTUs; or 2) the project group suffers from the Not-Invented-Here syndrome.

Interviews with the project managers suggest the grafting someone with prior work experience at LTUs into the project group is a true substitute for engaging in external learning with the LTUs, vicarious learning in particular (see interactions $7 \& 9$ ). The grafted person has engaged in vicarious learning activities at the LTU and brings the tacit knowledge that he/she has acquired through VLAs into the project group, where it is shared with the other team members through prolonged socialization. I call this phenomenon vicarious learning by proxy; it has been observed in the semiconductor industry, where technology supplier firms hire senior technical personnel from leadingedge chipmakers as marketing representatives (Weber, 2002; Yang et al., 2012). 
The interviews with the project managers suggest that the other ostensible substitution effects could be caused by NIH. For example, project-internal learning might make the project group feel that it has no need to engage in contextual learning about the LTUs (interaction no. 11). Furthermore, grafting people with work experience at international sources (interaction no. 12), or other R\&D project groups (see interactions $6 \& 10$ ), into the project group may make the project group feel it no longer needs to engage in vicarious learning with the LTUs. I consequently propose the following for further study:

Proposition 6.4.1-1: Project-internal learning activities (see interaction no.11) and grafting people with work experience at international sources (see interaction no.12) or other R\&D project groups within the national laboratories (see interactions $6,8 \& 10$ ), can be a source of the Not-Invented-Here syndrome.

Conclusion 6.4.1-3: Factors that enhance user satisfaction are local. All factors that increase user satisfaction have their origins within Thailand. The sources of knowledge that contribute to user satisfaction are local technology users, local universities and the R\&D project groups themselves. The channels for inflow vary. Knowledge from LTUs enters the project group via VLAs, CLAs and grafting. Knowledge from local universities comes from contextual learning or from team members who were educated there. Prior knowledge about the core technology exists in the project group at the outset of the project. Knowledge from international sources has no direct impact on user satisfaction.

Interviews with the project managers support this conclusion, and they yield the following explanation of why user satisfaction has local roots. The LTUs, to a large 
degree, drive development at the national laboratories because they do not have the time, the expertise and the financial resources to do it themselves. The LTUs primary mission is to serve the customers in Thailand, and most of the production units of the LTUs are in Thailand. It is therefore very efficient for the LTUs to procure, allocate and coordinate resources locally. Some LTUs do have significant export businesses, but these tend to provide products with a relatively low value added. Most of the LTUs have not yet made the investments that would allow them to generate high value-added products that could compete with the products from developed nations.

\subsubsection{Conclusions Pertaining to Commercialization (Mission 2)}

Figure 6.3 summarizes all the results that pertain to hypotheses $1 b, 2 b, 3 b$ and $4 b$ in section 5.4, as well as the results from the relative ranking of correlation coefficients that pertain to OV2 in section 5.4.5 and the results of running the interaction model for OV2 in section 5.5. Figure 6.3 depicts everything pertaining to knowledge flows within the national laboratory system and their impact on the probability of commercialization that my research has been able to verify to date at a level of statistical significance of $p<0.05$. I consequently propose that figure 6.3 represents a framework, which characterizes the subsystem of the national laboratories that governs commercialization. 


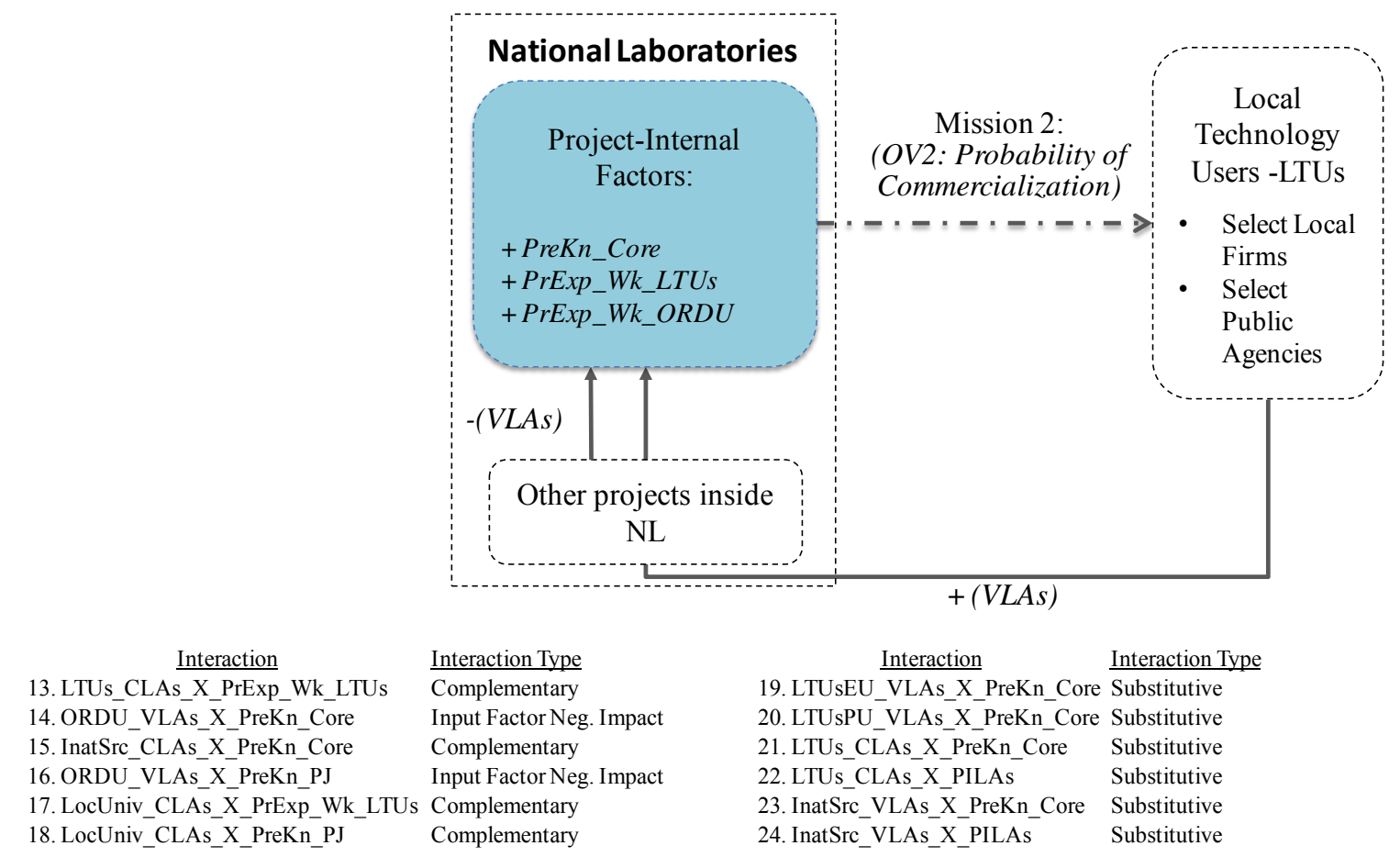

Figure 6.3: The knowledge subsystem of the national laboratory system that contributes to commercialization of technology

The framework in figure 6.3 suggests that the probability of commercialization is primarily driven by two kinds of knowledge inflow from two exogenous sources: vicarious feedback from local technology users, which is positively correlated to OV2, and vicarious learning from other R\&D project groups within the national laboratories, which is negatively correlated to OV2. Various internal sources of knowledge such as prior knowledge about the core technology, grafting people with prior work experience at LTUs and grafting people with prior work experience at other R\&D groups within the national laboratories also contribute positively to the probability of commercialization. Figure 6.3 also lists all the interactions pertaining to the probability of commercialization that are complementary (positively correlated to OV2) or substitutive (negatively 190 
correlated to OV2). Two interactions (14 \& 16) are negatively complementary; the moderating factor in these interactions decreases the negative impact that vicarious learning with other $\mathrm{R} \& \mathrm{D}$ project groups has on the probability of commercialization.

The data from Chapter 5 suggest that, like user satisfaction, commercialization is driven, to a large degree, by local technology users. In particular, the probability of commercialization is enhanced if knowledge is acquired through vicarious learning or through grafting someone with work experience at an LTU. Yet, the interactions between those sources of knowledge have no significant impact on commercialization. I consequently draw the following conclusions for VLAs and their impact on commercialization.

Conclusion 6.4.2-1: Engaging with local technology users through VLAs or vicarious learning by proxy enhances the project group's ability to commercialize. However, these activities are not substitutes.

The data from section 5.5 show that prior knowledge about the core technology by itself enhances the probability of commercialization. Yet, if anything, prior knowledge about the core technology acts as a substitute for VLAs with LTUs. Interviews with the project managers suggest that prolonged experience in working on the core technology gives the project team a better understanding of user needs. This leads to the following conclusion. 
Conclusion 6.4.2-2: When it comes to commercialization, prior knowledge about the core technology is a true substitute for vicarious learning activities with LTUs (see interactions $19 \& 20$ ).

However, given that NIH is a possible alternative for true substitution, I suggest that the following proposition be tested by further study.

Proposition 6.4.2-1: Project managers in the national laboratories, who overwhelmingly come from an engineering background, have a world view that is driven by technology push. Their view of the market for the technology that is under development could consequently be biased towards technology push. Prior knowledge about the core technology could therefore diminish the project group's capacity to absorb contextual knowledge about LTUs and their interest to engage in vicarious learning with LTUs (see interactions 19 through 21).

Contextual learning about local technology users has no statistically significant impact on the probability of commercializing a technology by itself. The interviews with project managers provide the following explanation for this result. Most of the knowledge that is required for commercialization is tacit and thus cannot be transferred readily by CLAseither externalization of knowledge or vicarious learning is inherently required (Nonaka, 1994; Szulanski, 1996). Nonetheless, vicarious learning by proxy could in principle enhance any positive impact that CLAs with LTUs have (see interaction no.13). The following conclusion can consequently be drawn. 
Conclusion 6.4.2-3: Grafting people with prior work experience at an LTU into the project group enhances the positive impact on commercialization of contextual learning about LTUs (see interaction no. 13). Interviews with the project managers suggest that the people who were grafted into the project group help with the interpretation of data that is acquired through contextual learning activities.

Commercialization of technology requires diversity of knowledge, some of which may be found in ORDUs. For example, the data from interaction model suggests that grafting people with prior work experience at other $R \& D$ project groups tends to enhance commercialization of technology. By contrast, vicarious learning with other R\&D project groups has a negative impact on commercializing the technology under development. Prior knowledge about the core technology or externalize prior knowledge about subject matter pertaining to the project decreases the negative impact that vicarious learning with ORDUs has on commercialization of technology (see interactions $14 \& 16$ ). The interaction between vicarious learning with ORDUs and grafting people with prior work experience at ORDUs into the project group is not statistically significant.

One may infer from the data in chapter 5 that project-internal knowledge is a necessary, but insufficient condition for developing technology for commercialization. Additional knowledge that is required for commercialization resides within other $\mathrm{R} \& \mathrm{D}$ project groups, particularly in project groups who are currently commercializing technology or have done so in the past. This knowledge can either be brought into the project group by vicarious learning with other R\&D units within the national laboratories, or through vicarious learning by proxy, i.e. by grafting people with prior work experience at ORDUs 
into the project group. In the former case, the members of the project group exchange ideas about commercialization with their peers from other project groups. In the latter case, some of these peers from these ORDUs are brought into the project group prior to the inception of the project.

Data from the interviews with project managers provide an explanation as to why vicarious learning with other $\mathrm{R} \& \mathrm{D}$ project groups in the national laboratories is detrimental to commercialization, whereas the grafting people with prior work experience at other R\&D project groups enhances it. Project managers consistently stressed time pressure as an important factor in commercialization of technology in their interviews. Some of them suggested that the LTUs perceive the market windows for the products that use technology that is under development at the national laboratories is very short. The LTUs make more money on these products if the NLs deliver the technology sooner. The $R \& D$ project groups within the NLs consequently need to integrate any missing crucial knowledge in a timely manner. Bringing this knowledge into the project group and spreading it around before the outset of the project (e.g., Huber, 1991) fulfills this requirement. Engaging in VLAs with ORDUs does not because the socialization associated with VLAs is inherently time-consuming and distracts from vital activities in a deadline-driven project (Nonaka, 1994; Szulanski, 1996; Hatch \& Mowery, 1998). VLAs with ORDUs may even delay the actual delivery date for the technology under development. Furthermore, bringing a person with prior work experience at another R\&D unit into the project group before the outset of the project may enhance that person's commitment of to the project. 
The following conclusion about integrating knowledge from other R\&D units within the national laboratories into the project group can consequently be drawn.

Conclusion 6.4.2-3: If commercialization of technology occurs under time pressure, then grafting rather than vicarious learning is the better choice for bringing tacit knowledge from other $R \& D$ units into the project group.

The data in chapter 5 suggest that commercialization, like user satisfaction, has primarily local roots. The following conclusion regarding the impact of local knowledge on the ability to commercialize technology can be drawn.

Conclusion 6.4.2-4: Factors that enhance the probability of commercialization are local. All factors that increase the probability of commercialization have their origins within Thailand. The sources of knowledge that enhance commercialization of technology are local technology users, local universities and the R\&D project groups themselves. The channels for inflow differ slightly from those that enhance user satisfaction. Knowledge from LTUs that enhances commercialization enters the project group via VLAs and grafting, but not CLAs. Local universities are less important for commercialization of technology than they are for user satisfaction, but prior externalized knowledge about the project and grafting people with prior work experience at LTUs are complementary to whatever impact local universities have on commercialization (see interactions $18 \& 17$ ). Knowledge from international sources by itself has no direct impact on commercialization of technology. However, the interaction model suggests that prior knowledge about the core technology (see interaction no.23) and project-internal learning 
activities (see interaction no.24) are potential substitutes for whatever impact international sources have on commercialization. The interviews with the project managers gave no indication as to whether these sources of internal knowledge are true substitutes or whether they are symptoms of NIH.

Interviews with the project managers suggest that local sources of knowledge primarily contribute to commercialization of technology for similar reasons similar to why they contribute to user satisfaction. The LTUs, to a large degree, drive commercialization of technology that is developed at the national laboratories because they do not have the time, the expertise and the financial resources to develop the technology themselves. The LTUs primary mission is to serve the customers in Thailand, and most of the production units of the LTUs are in Thailand. It is therefore very efficient for the LTUs to procure, allocate and coordinate resources locally. Some LTUs do have significant export businesses, but these tend to provide products with a relatively low value added. Most of the LTUs have not yet made the investments that would allow them to generate high value-added products that could compete with the products from developed nations. 


\subsubsection{Conclusions Pertaining to a Long-term R\&D Capability (Mission 3)}

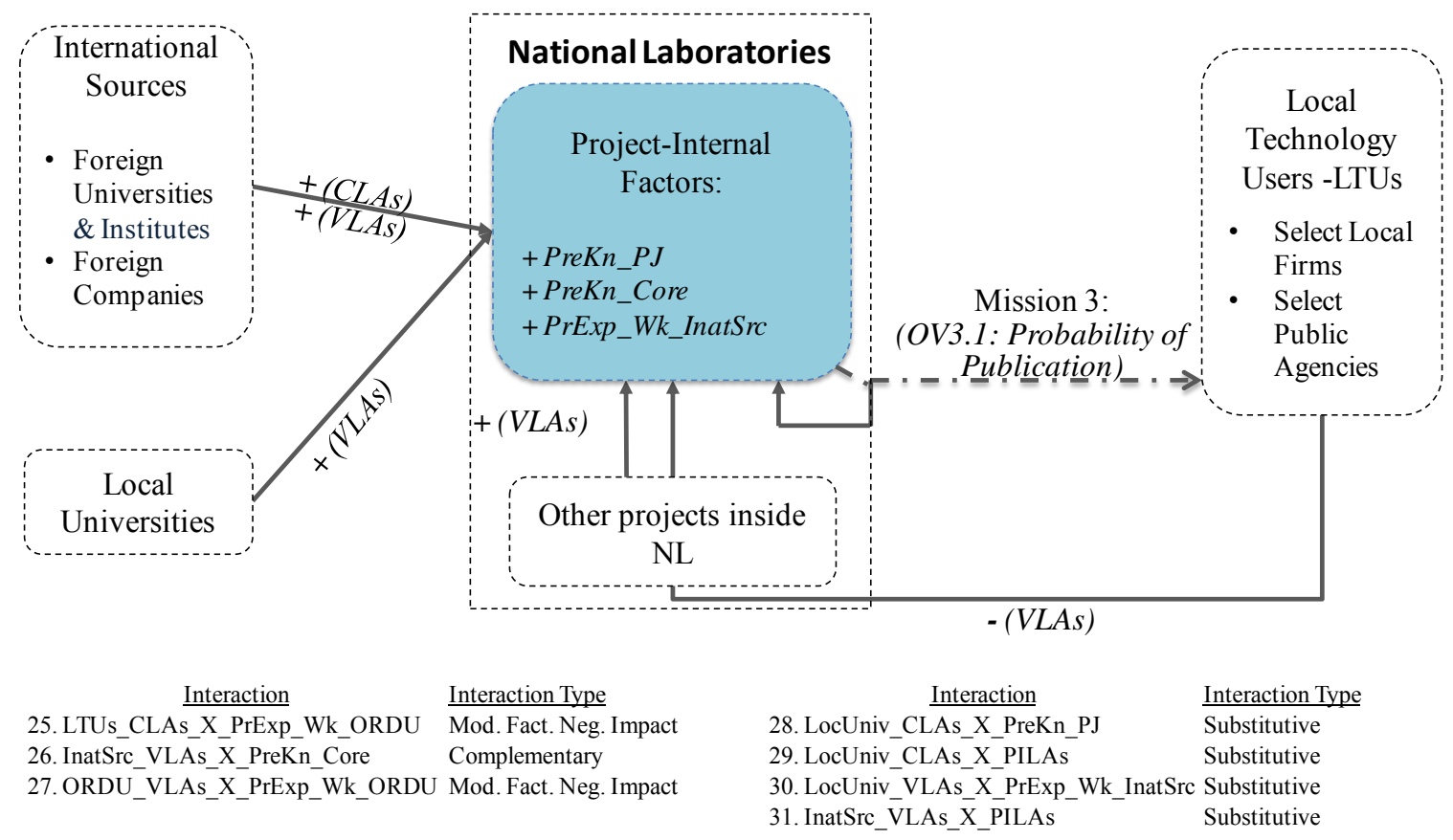

Figure 6.4: The knowledge management subsystem of the National Laboratory Knowledge Management System that affects the probability of generating a publication from a particular project

Figure 6.4 summarizes all the results that pertain to hypotheses $1 \mathrm{c}, 2 \mathrm{c}, 3 \mathrm{c}$ and $4 \mathrm{c}$ in section 5.4, as well as the results from the relative ranking of correlation coefficients that pertain to OV3.1 in section 5.4.5 and the results of running the interaction model for OV3.1 in section 5.5. Figure 6.4 depicts everything pertaining to knowledge flows within the national laboratory system and their impact on the probability of publication that my research has been able to verify to date at a level of statistical significance of $\mathrm{p}<0.05$. I consequently propose that figure 6.4 represents a framework, which characterizes the subsystem of the national laboratories that governs the probability of publication. 
The framework in figure 6.4 suggests that the probability of publication is primarily driven by five kinds of knowledge inflow from four exogenous sources: contextual learning about and vicarious learning with international sources, vicarious learning with local universities, vicarious learning with other R\&D project groups within the national laboratories and vicarious feedback from local technology users. The first four of these knowledge inflows have a positive impact on the probability of publication, whereas the impact of VLAs with LTUs is negative. Various internal sources of knowledge such as prior externalized knowledge about subject matter pertaining to the project, prior knowledge about the core technology and grafting people with prior work experience at international sources contribute positively to the probability of publication.

In the interaction model, grafting people with work experience at other R\&D units within the national laboratories into the project group is negatively correlated to the probability of publication at a level of statistical significance of $\mathrm{p}=0.88$; it has no statistical significance in the integrated regression model. Figure 6.4 also lists all the interactions pertaining to probability of publication that are complementary (positively correlated to OV3.1) or substitutive (negatively correlated to OV3.1). Two interactions (no. 25 \& 27) are negatively complementary; the knowledge inflow ameliorates the negative impact that grafting people with work experience at other R\&D project groups within the national laboratories has on the probability of publication.

According to the ranking of correlation coefficients in section 5.4.5, the external sources of knowledge that have the biggest positive impact on the probability of publication are international sources of knowledge, local universities and other R\&D project groups 
within the national laboratories. The most important internal sources of knowledge that have a positive impact on the probability of commercialization are prior externalized knowledge about the project, prior knowledge about the core technology, and prior work experience at international sources. Some of the interactions between these factors are substitutive or complementary; others are statistically insignificant.

The data from sections 5.4 and 5.5 lead to the following conclusion regarding the impact of knowledge from international sources on the probability of publication.

Conclusion 6.4.3-1: In order to increase the probability of publication, knowledge from international sources can be brought into the project group through vicarious learning or by proxy through grafting people with prior work experience at international sources. However, grafting people with work experience international sources is not a substitute for vicarious learning with international sources.

The interviews with the project managers have generated significant insight into the organizational processes behind this conclusion. The reliance on international sources of knowledge results from the realization that the cutting edge of science and technology is still overseas. As a consequence, the project groups within the national laboratories orient themselves toward international sources. They identify the most important sources and their critical activities through contextual learning. They subsequently engage in vicarious learning activities with the international sources to bring advanced foreign knowledge and essential capabilities into the project group. Prior knowledge about the core technology enhances the effectiveness of this effort (see interaction no. 26). Project- 
internal learning activities ostensibly act as a substitute for vicarious learning with international sources (see interaction no. 31), but the interviews revealed no explanation as to why this could be. The following alternative proposition must therefore be considered for further study.

Proposition 6.4.3-1: When it comes to generating publications, project-internal learning activities cause the Not-Invented-Here syndrome within project groups; they may simply act as a barrier to knowledge inflow from international sources (see interaction no. 31).

The data from sections 5.4 and 5.5 lead to the following conclusion regarding the impact of knowledge from international sources on the probability of publication.

Conclusion 6.4.3-2: Prior knowledge about the core technology enhances the positive impact of vicarious learning from international sources on the probability of publication (see interaction no.26).

This conclusion is in alignment within the classic literature on absorptive capacity (e.g., W. M. Cohen \& Levinthal, 1990). Prior knowledge about the core technology enables the project group to absorb related knowledge through vicarious learning with international sources. Once again, the realization that most advanced science and technology resides outside the national innovation system drives the need to engage in VLAs with international sources. 
The data from sections 5.4 and 5.5 show that vicarious learning with local technology users has the opposite effect on the probability of publication than it does on the probability of commercialization. This leads to the following conclusion.

Conclusion 6.4.3-3: Vicarious learning with local technology users has a detrimental impact on the probability of generating publications. Local technology users are deadline driven, and they tend to focus on the near term. This outlook distracts from research and development that generates publications, which takes time because it requires a greater degree of scientific evidence. Furthermore, engagement with LTUs is on a lower technical level; it does not require the advanced technical knowledge that leads to publications.

The data in sections 5.4 and 5.5 imply that, when it comes to publications, vicarious learning with local universities constitutes an important source of external knowledge.

Conclusion 6.4.3-4: $R \& D$ project groups within the national laboratories engage in vicarious learning with local universities when they have insufficient in house capabilities for developing a technology on their own, and engaging in VLAs with local universities tends to lead to joint publications. The interviews with project managers lead to the following conclusion as to why that might be. For example, a biotechnology that was developed at the national laboratories may undergo clinical tests at a local medical school. 
The data in sections 5.4 and 5.5 imply that prior work experience at international sources could act as a substitute for knowledge inflow from local universities (see interaction no. 30). Interviews with project managers suggest that such a substitution could come from an exchange program with an international source of knowledge such as well-known foreign university, foreign research institute or an R\&D facility that is owned by a foreign corporation.

According to section 5.4.6, prior explicit or externalized knowledge is the most prominent project-internal source of knowledge when it comes to the probability of publication. Interviews with project managers have led to the following conclusion as to why that is.

Conclusion 6.4.3-5: Prior explicit knowledge of subject matter pertaining to the project is required to generate a publication about the project, and prior explicit knowledge tends to come in the form publications. The skill to generate publications is already present at the outset of the project. Prior publication helps with future publication, which leads to the establishment of a publication culture. 


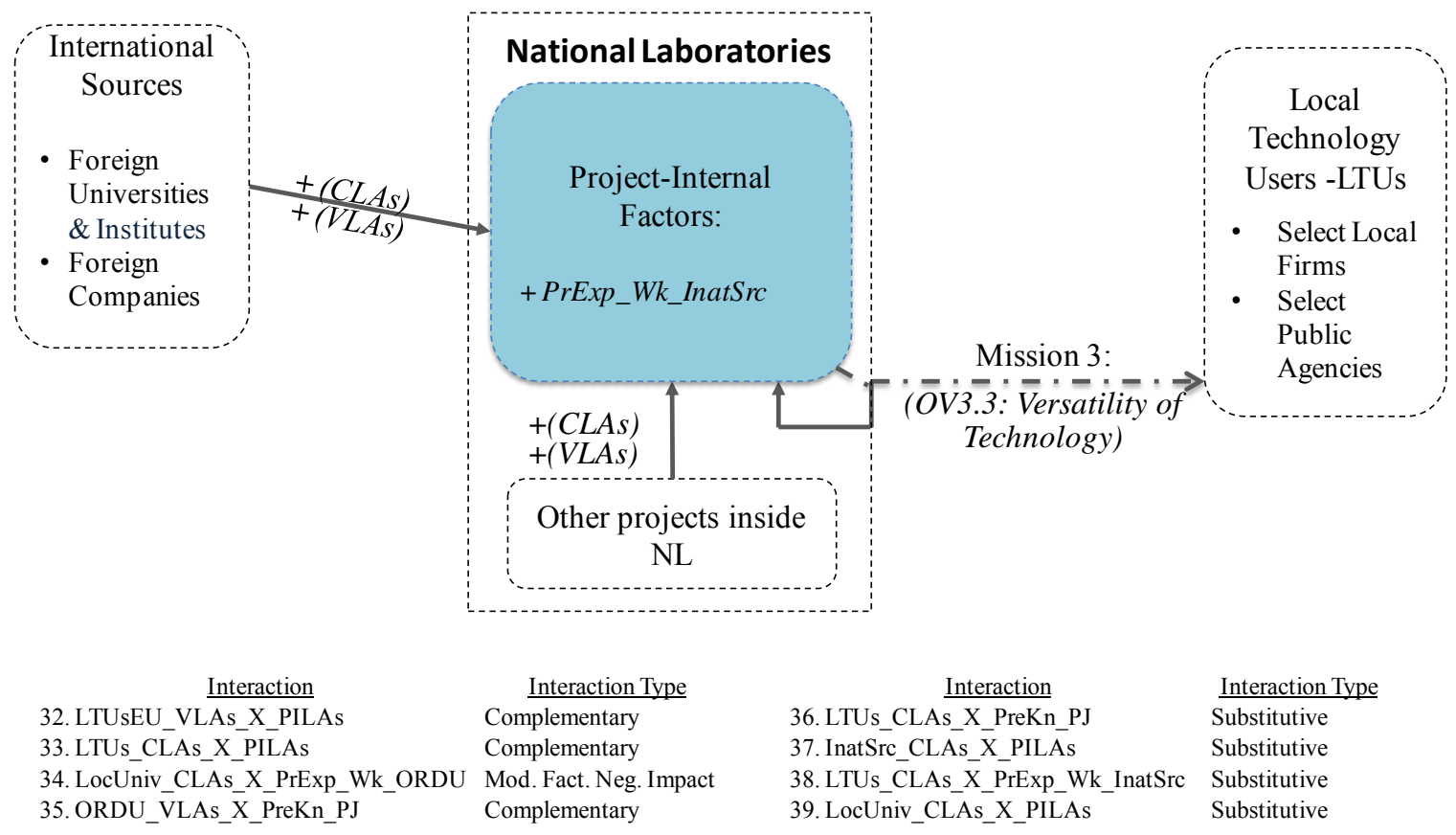

Figure 6.5: The knowledge management subsystem of the National Laboratory Knowledge Management System that contributes to versatility of technology

Figure 6.5 summarizes all the results that pertain to hypotheses $1 \mathrm{c}, 2 \mathrm{c}, 3 \mathrm{c}$ and $4 \mathrm{c}$ in section 5.4, as well as the results from the relative ranking of correlation coefficients that pertain to OV3.3 in section 5.4.5 and the results of running the interaction model for OV3.3 in section 5.5. Figure 6.5 depicts everything pertaining to knowledge flows within the national laboratory system and their impact on versatility of technology that my research has been able to verify to date at a level of statistical significance of $\mathrm{p}<0.05$. I consequently propose that figure 6.5 represents a framework, which characterizes the subsystem of the national laboratories that governs versatility of technology.

The framework in figure 6.5 suggests that versatility of technology is primarily driven by four kinds of knowledge inflow from two exogenous sources: contextual learning about 
and vicarious learning with international sources; and contextual learning about and vicarious learning with other R\&D project groups within the national laboratories. All four of these knowledge inflows have a positive impact on versatility of technology. One internal sources of knowledge also has a positive impact on versatility of technology: grafting people with prior work experience at international sources.

Figure 6.5 also lists all the interactions pertaining to versatility of technology that are complementary (positively correlated to OV3.3) or substitutive (negatively correlated to OV3.3). One interaction is negatively complementary; contextual learning about local universities enhances the negative impact that grafting people with work experience at other R\&D project groups within the national laboratories has on versatility of technology (see interaction no. 34). However, the negative impact of ORDUs on versatility of technology is only statistically significant at the level of $p<0.05$ in the interaction model.

According to the results from section 5.4, the sources of knowledge that have the biggest impact on the versatility of the technology under development come from outside the national innovation system. Grafting people with prior work experience at international sources and vicarious learning with international sources constitute the two factors that have the largest positive correlation to versatility of technology, but the interaction between these two factors has no statistically significant impact on versatility of technology. Contextual learning about international sources also has a positive impact on versatility of technology, but the interaction between contextual learning and grafting 
people with work experience at international sources is statistically insignificant as well. These observations lead to the following conclusion.

Conclusion 6.4.3-6: In order to increase the versatility of the technology under development, knowledge from international sources can be brought into the project group through vicarious learning or by proxy through grafting people with prior work experience at international sources.

The interviews with the project managers suggest that international sources play an important role in generating ideas for applications. In particular, they generate insight into how technologies that are related to the technology under development are applied in other countries.

The second most important source of knowledge pertaining to versatility of technology is other R\&D project groups within the national laboratories. According to interviews with the project managers, the primary role of engaging with these other project groups is to obtain complementary knowledge. If the project groups that interact with each other happen to design for different strategic objectives in different markets, then each team is more likely to learn about another application for their technology, and the combinative capabilities (Kogut \& Zander, 1992) of the national laboratories as a whole are enhanced. The following conclusion regarding versatility of technology can thus be drawn.

Conclusion 6.4.3-7: Engaging in external learning with other $R \& D$ project groups through VLAs or CLAs leads to new applications for the technology under development. 


\subsection{ORGANIZATIONAL AMBIDEXTERITY AND MISSION ALIGNMENT}

\subsubsection{Alignment of Output Variables}

Chapter five presented much evidence that the three basic missions of the national laboratories are not necessarily aligned. For example, the correlation matrix in table 5.9 shows a positive correlation between OV1 and OV2 and a positive correlation between OV3.1 and OV3.3. However, OV3.1 is inversely correlated with OV1 and OV2. This suggests that mission 1 (user satisfaction) is well aligned with mission 2 (commercialization), and that the two remaining output variables for mission 3 (building an R\&D capability for the future of the country) are well aligned. The inverse correlation between OV3.1 on the one hand and OV1 and OV2 on the other hand implies misalignment between mission 3 on the one hand and missions 1 and 2 on the other hand.

\subsubsection{Alignment of Factors}

The correlations between the output variables are consistent with what was observed about the input factors and moderating factors. With one exception, the following rules seem to hold for all factors in the correlation matrix, the knowledge inflow baseline, the project group baseline, the intra-organization baseline and the integrated model. The rules also hold in the interaction model, albeit with an additional exception. ${ }^{29}$

\footnotetext{
${ }^{29}$ In the interaction model project-internal learning activities are positively correlated to user satisfaction and to versatility of technology (with $\mathrm{p}<0.05$ ). In the integrated model, project-internal learning activities 
Rule [1, 2]: A factor that is positively correlated to user satisfaction (mission 1) can be positively correlated to the probability of commercializing a technology (mission 2), or not correlated to the probability of commercializing a technology (mission 2), but not negatively correlated to the probability of commercializing a technology (mission 2).

Rule [1, 3]: A factor that is positively correlated to user satisfaction (mission 1) can be negatively correlated to versatility of a technology or the probability of generating a publication (mission 3), or not correlated to versatility of a technology or the probability of generating a publication (mission 3), but not positively correlated to versatility of a technology or the probability of generating a publication (mission 3)

Rule [2, 3]: A factor that is positively correlated to the probability of commercializing a technology (mission 2) can be negatively correlated to versatility of technology or the probability of generating a publication (mission 3), or not correlated to versatility of technology or the probability of generating a publication (mission 3 ), but not positively correlated to versatility of technology or the probability of generating a publication (mission 3).

Rule [3, 3]: A factor that is positively correlated to the versatility of the technology under development (mission 3) can be positively correlated to the probability of

are correlated to user satisfaction with $\mathrm{p}<0.05$. There is no statistically significant correlation between project-internal learning activities and versatility of technology. 
generating a publication (mission 3), or not correlated to the probability of generating a publication (mission 3), but not negatively correlated to the probability of generating a publication (mission 3 ).

One can infer from the above rules that factors that help the national laboratories succeed at missions 1 and 2 can interfere with Mission 3, and conversely. This leads to the following conclusions.

Conclusion 6.5.2-1: Rule [3, 3] reinforces the notion that the output metrics for mission 3 (building an $R \& D$ capability for the future of the country) are well aligned.

Conclusion 6.5.2-2: Rule [1, 2] implies that mission 1 (user satisfaction) and mission 2 (commercializing technology) align well with each other.

Conclusion 6.5.2-3: According to rules $[1,3]$ and $[2,3]$, mission 3 (building an $R \& D$ capability for the future of the country) is misaligned with mission 1 (user satisfaction) and mission 2 (commercializing technology) at all levels.

Prior knowledge about core technology is the exception to the above rules in the correlation matrix and in all pertinent regression models. Prior knowledge about the core technology is positively correlated to user satisfaction, the probability of commercializing a technology and the probability of generating a publication. It is not correlated to the versatility of the technology under development. 


\subsubsection{Organizational Ambidexterity}

Organizational Ambidexterity has been defined as balancing the need to exploit against the need to explore (Tushman \& O'Reilly, 1996). It is a well-known challenge in most innovation-driven firms (Tushman \& O’Reilly, 1996; O'Reilly \& Tushman, 2004; Gibson \& Birkinshaw, 2004; Raisch \& Birkinshaw, 2008; O'Reilly \& Tushman, 2008; Ambos et al., 2008; Simsek, 2009; Raisch et al., 2009; Andriopoulos \& Lewis, 2009; Taylor \& Helfat, 2009; Rothaermel \& Alexandre, 2009; Cao et al., 2009; Jansen et al., 2009; Mom et al., 2009; O'Reilly \& Tushman, 2011), and has been observed in the university environment (Y.-C. Chang et al., 2009). However, it has yet to be studied or even identified in national laboratories.

Organizational ambidexterity presents a framework that can explain the alignment and misalignment of the output variables that have been studied as part of this dissertation. For example, mission 3 (building an R\&D capability) is designed to improve the national laboratories ability to explore. Alignment between OV3.1 and OV3.3 consequently

supports the ambidexterity framework. Mission 1 (user satisfaction) and mission 2 (commercialization) are clearly exploitative. From the point of view of ambidexterity alignment between these two missions is expected. The ambidexterity paradigm also suggests that there should be tension between the exploration-oriented missions the exploitative missions, and there is. This leads to the following conclusion.

Conclusion 6.5.3-1: The national laboratories face an ambidexterity challenge. 


\subsection{CONCLUSIONS ABOUT KNOWLEDGE INFLOWS AND INTERNAL KNOWLEDGE}

In sections 6.4, I drew conclusions that specifically concerned the three fundamental missions of the laboratories, and in section 6.5, I showed how these missions were either aligned or misaligned. In this section, I look at the national laboratory system from the point of view of knowledge inflow and internal knowledge, and I compare the relative impact that these two forms of knowledge have on performance.

\subsubsection{Conclusions about Knowledge Inflows.}

In sections 3.1 through 3.4 , I discussed the state of knowledge about knowledge inflows as it has been published in the academic literature, and I respectively proposed models for knowledge inflows from other R\&D project groups, from local universities, from local technology users and from international sources in these sections of my dissertation. Schematics for these models were depicted in figures $3.2,3.3,3.4$, and 3.5, respectively. I also proposed hypotheses 1 through 4 , respectively, to validate the models from sections 3.1 through 3.4. In section 5.4, I showed that most, but not all of these hypotheses were confirmed. In section 5.5, I revealed some key interactions that are associated with particular knowledge inflows. In this section, I combine the results from sections 5.4 and 5.5 with data from interviews with project managers to reach conclusions that pertain to knowledge inflows. I generate models of the knowledge subsystems of the national laboratory system that pertain to specific knowledge inflows, and I point out the differences between these models and the models that were originally proposed in 
sections 3.1 through 3.4. Most of the commonalities have already been discussed in the section on mission-specific conclusions (6.4).

\subsubsection{Conclusions Pertaining to Knowledge Inflows from Other R\&D Project Groups}

\section{within the National Laboratories}

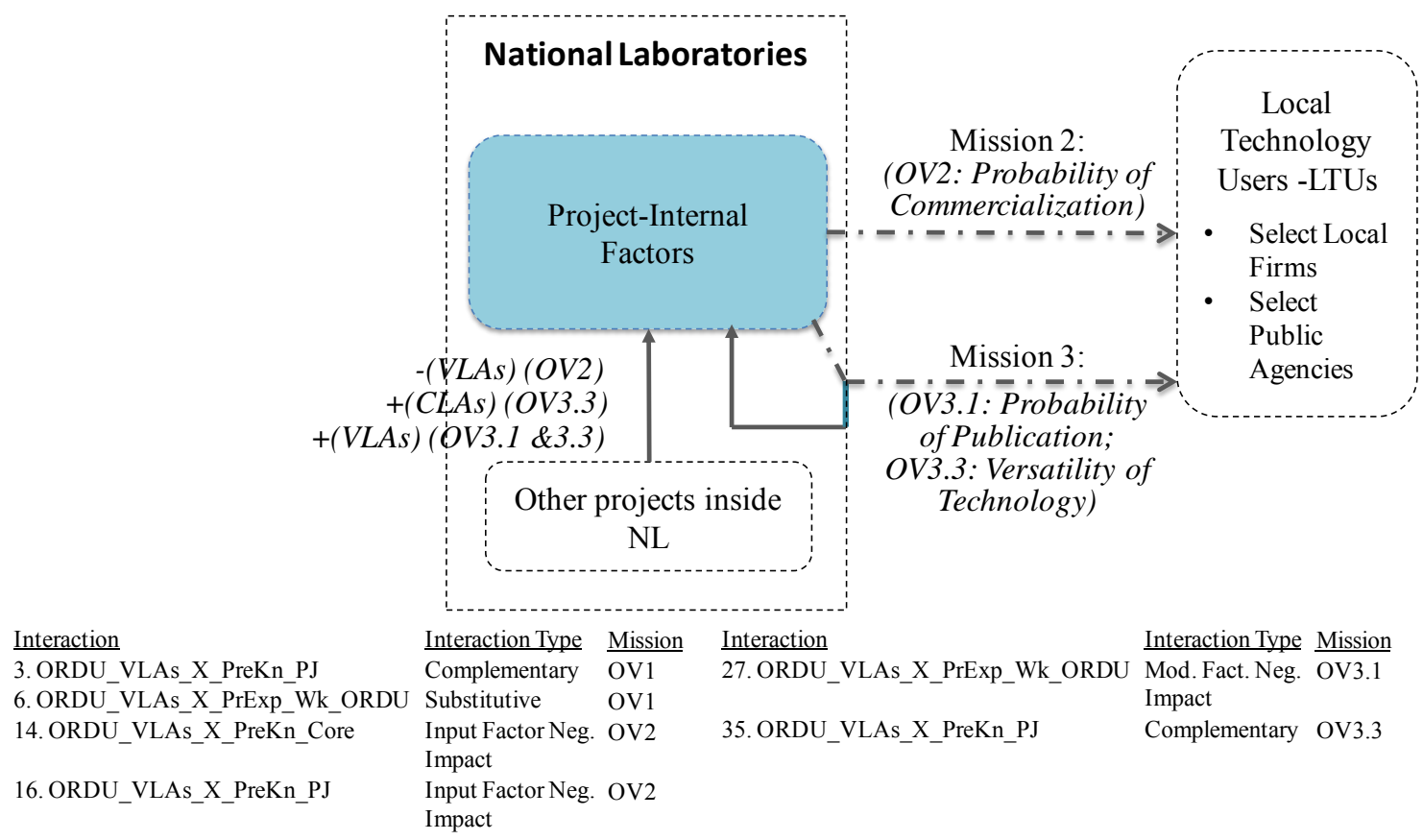

Figure 6.6: The knowledge management subsystem of the National Laboratory Knowledge Management System that pertains to knowledge inflows from other R\&D project groups within the national laboratories

Figure 6.6 depicts the knowledge subsystem of the national laboratory system that pertains to knowledge inflows from other $R \& D$ project groups within the national laboratories. It is derived from the results of testing hypotheses $1 \mathrm{a}, 1 \mathrm{~b}$ and $1 \mathrm{c}$, as well as from the output of the interaction model in section 5.5. Figure 6.6 has much in common 
with figure 3.2, but a comparison between the two figures also reveals some distinct differences. Figure 3.2 implies that both CLAs and VLAs with ORDUs should have a direct positive impact on all missions. However, in practice neither CLAs nor VLAs have a direct, significant impact on user satisfaction, and vicarious learning with ORDUs has a negative impact on the probability of commercialization (OV2). Only the interaction between vicarious learning with ORDUs and prior externalized knowledge about subject matter pertaining to the project has a positive impact on user satisfaction (see interaction no. 3). Nonetheless, in spite of these discrepancies, the existence of a subsystem of the national laboratories system that governs knowledge flows across R\&D project groups within the national laboratories has been verified, and the model from figure 3.2 has been validated to a significant degree.

\subsubsection{Conclusions Pertaining to Knowledge Inflows from Local Universities}

Figure 6.7 depicts the knowledge subsystem of the national laboratory system that pertains to knowledge inflows from local universities. It is derived from the results of testing hypotheses $2 \mathrm{a}, 2 \mathrm{~b}$ and $2 \mathrm{c}$, as well as from the output of the interaction model in section 5.5. Figure 6.7 has much in common with figure 3.3, and a comparison between the two figures only reveals one distinct difference-external learning with local universities has no direct statistically significant impact on the probability of commercializing a technology. Only two interactions pertaining to local universities have a significant impact on the probability of commercialization-1) the interaction between contextual learning about local universities and grafting people with prior work experience at local technology users into the project group (see interaction no. 17); and 2) 
the interaction between contextual learning about local universities and prior externalized knowledge about subject matter pertaining to the project (see interaction no. 18). In spite of this discrepancy, the existence of a subsystem of the national laboratories system that governs knowledge inflows from local technology users has been verified, and the model from figure 3.3 has been validated to a significant degree.

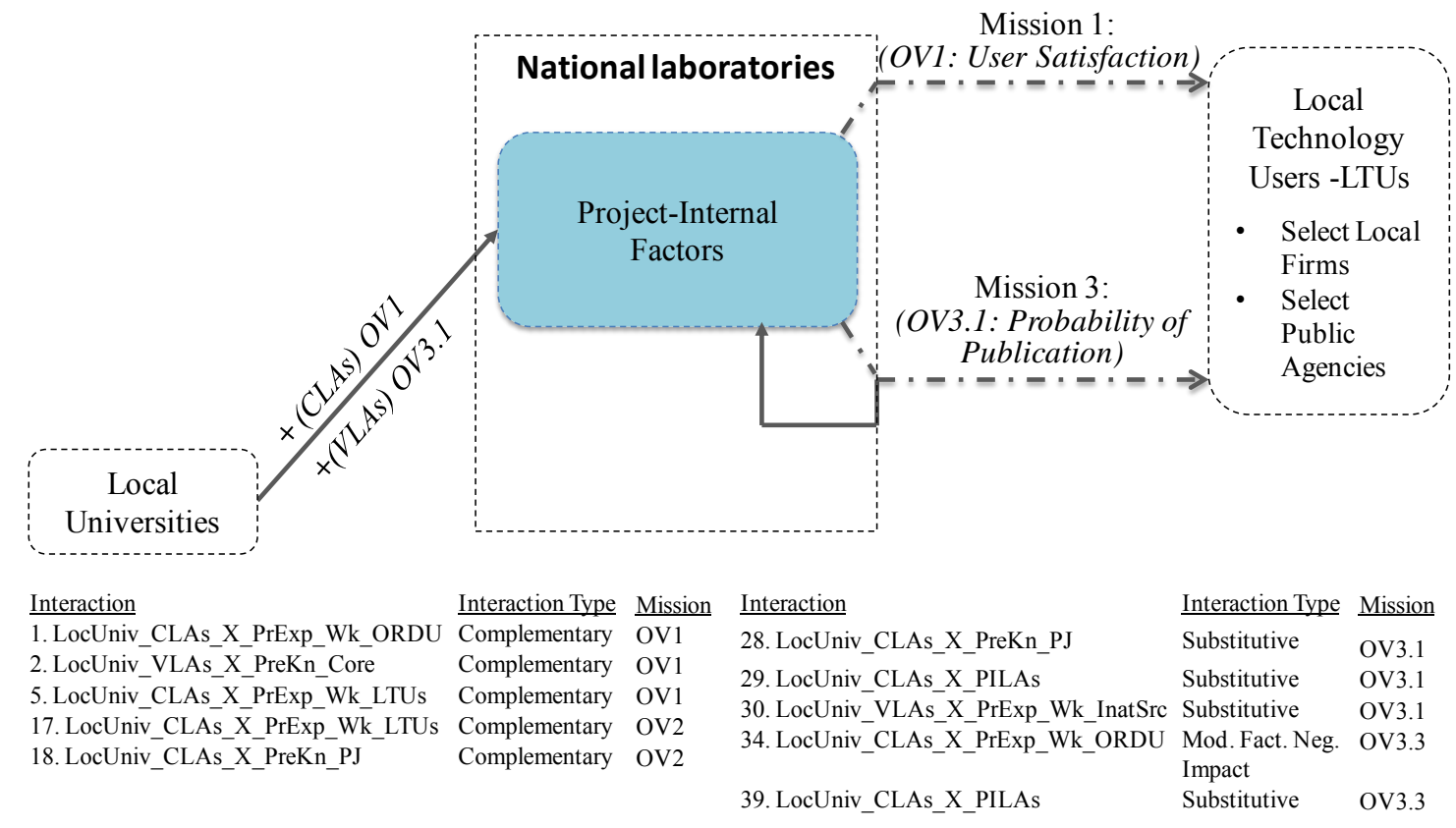

Figure 6.7: The knowledge management subsystem of the National Laboratory Knowledge Management System that pertains to knowledge inflows from local universities 


\subsubsection{Conclusions Pertaining to Knowledge Inflows from Local Technology Users}

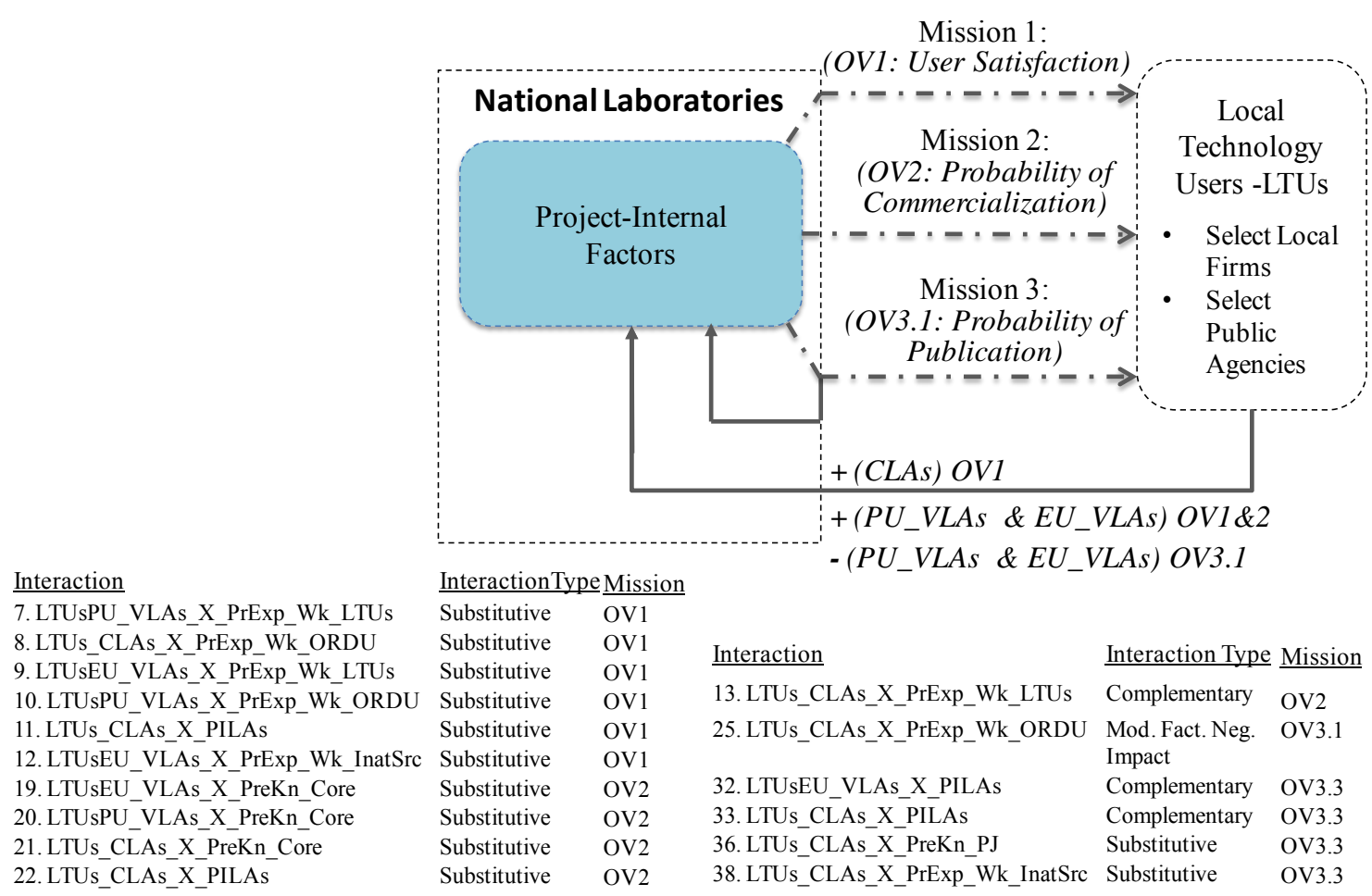

Figure 6.8: The knowledge management subsystem of the National Laboratory Knowledge Management System that pertains to knowledge inflows from local technology users

Figure 6.8 depicts the knowledge subsystem of the national laboratory system that pertains to knowledge inflows from local technology users. It is derived from the results of testing hypotheses $3 \mathrm{a}, 3 \mathrm{~b}$ and $3 \mathrm{c}$, as well as from the output of the interaction model in section 5.5. Figure 6.8 has much in common with figure 3.4 , and a comparison between the two figures only reveals one distinct difference-the impact of vicarious learning with local technology users on the probability of publication is negative. In spite of this discrepancy, the existence of a subsystem of the national laboratories system that governs 
knowledge inflows from local technology users has been verified, and the model from figure 3.4 has been validated to a significant degree.

\subsubsection{Conclusions Pertaining to Knowledge Inflows from International Sources}

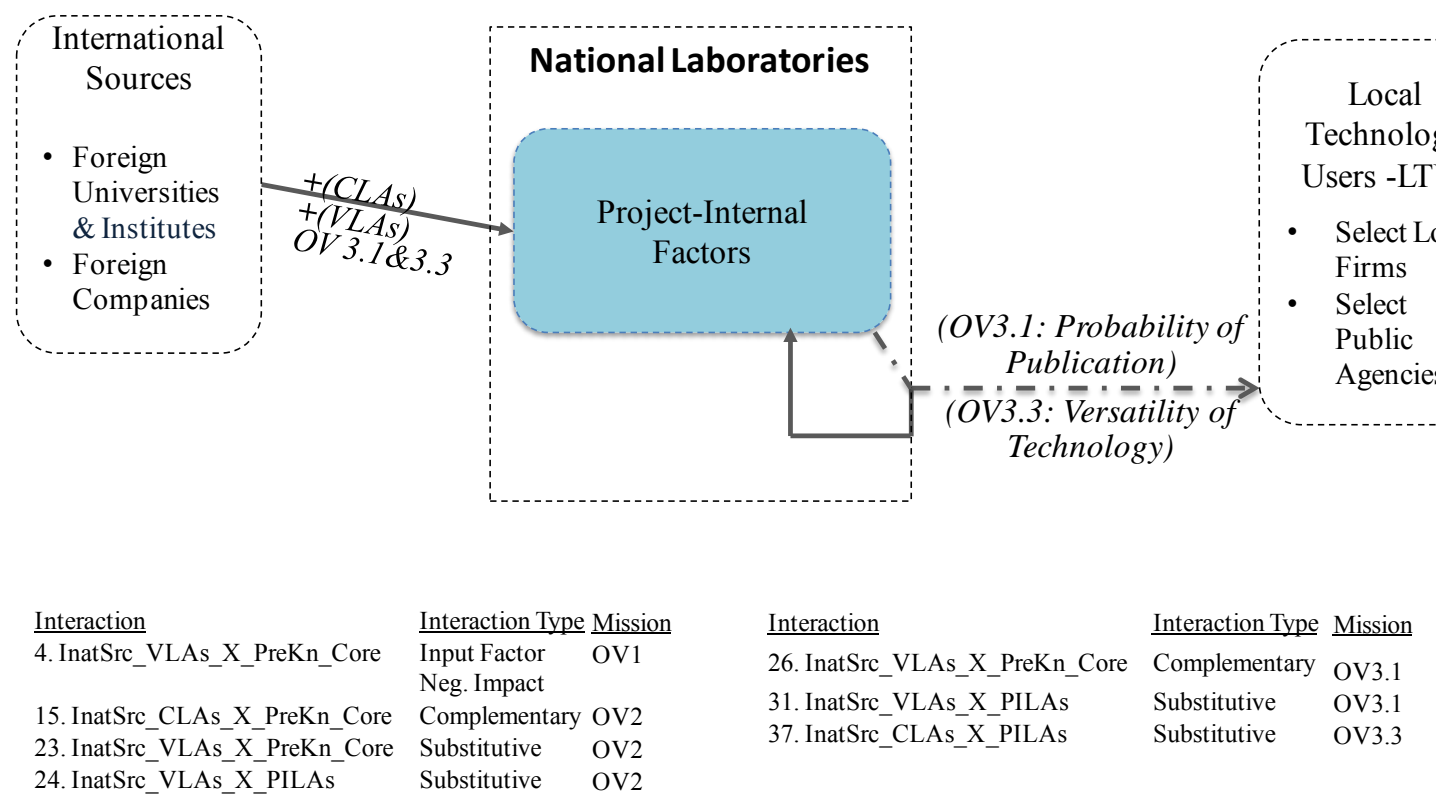

Figure 6.9: The knowledge management subsystem of the National Laboratory Knowledge Management System that pertains to knowledge inflows from international sources

Figure 6.9 depicts the knowledge subsystem of the national laboratory system that pertains to knowledge inflows from international sources. It is derived from the results of testing hypotheses $4 \mathrm{a}, 4 \mathrm{~b}$ and $4 \mathrm{c}$, as well as from the output of the interaction model in section 5.5. Figure 6.9 has much in common with figure 3.5, and a comparison between the two figures only reveals one distinct difference-external learning with local with international sources has no direct, statistically significant impact on user satisfaction and the probability of commercializing a technology. Only the interaction between contextual 
learning about international sources and prior knowledge of the core technology has a statistically significant impact on the probability of commercializing a technology (see interaction no. 15). In spite of this discrepancy, the existence of a subsystem of the national laboratories system that governs knowledge inflows from local technology users has been verified, and the model from figure 3.3 has been validated to a significant degree.

\subsubsection{Prior Knowledge about the Core Technology}

The approach identifying knowledge subsystems from section 6.6 .1 can also be used to draw specific conclusions about internal sources of knowledge, which, as shown in section 5.4, can have direct impact on performance. It may therefore be possible demonstrate the existence of knowledge subsystems that govern project-internal knowledge. However, the research described in this dissertation concerns itself primarily with knowledge inflows; project internal knowledge is mostly viewed as a way to enhance the capacity to absorb knowledge from external sources. Therefore characterizing the structure of knowledge subsystems for project-internal knowledge goes beyond the scope of this dissertation. 

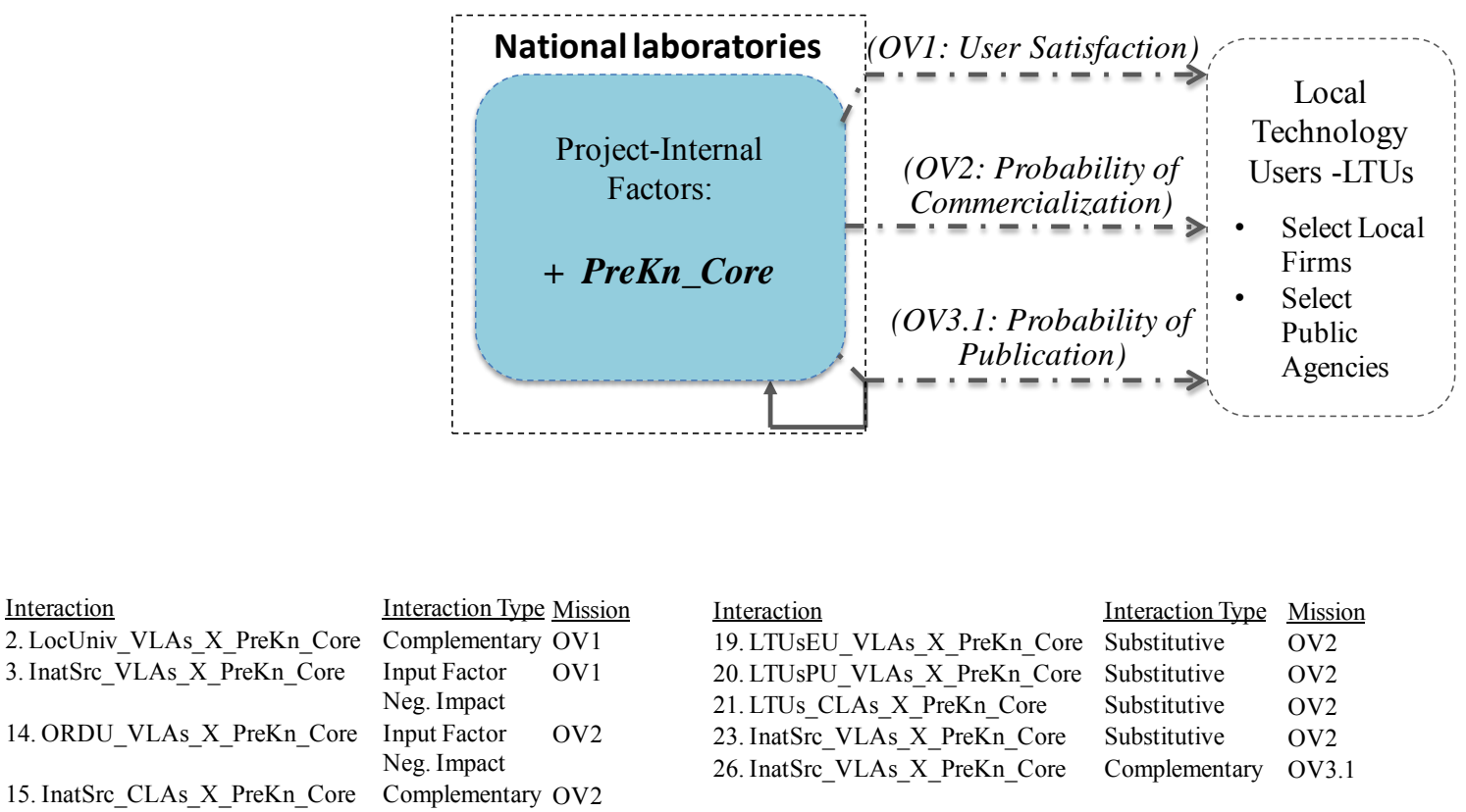

$\begin{array}{llll}\text { Interaction } & \text { Interaction Type } & & \text { Mission } \\ \text { 19. LTUsEU_VLAs_X_PreKn_Core } & \text { Substitutive } & & \text { OV2 } \\ \text { 20. LTUsPU_VLAs_X_PreKn_Core } & \text { Substitutive } & \text { OV2 } \\ \text { 21. LTUs_CLAs_X_PreKn_Core } & \text { Substitutive } & \text { OV2 } \\ \text { 23. InatSrc_VLAs_X_PreKn_Core } & \text { Substitutive } & \text { OV2 } \\ \text { 26. InatSrc_VLAs_X_PreKn_Core } & \text { Complementary } & \text { OV3.1 }\end{array}$

Figure 6.10: The knowledge management subsystem of the National Laboratory Knowledge Management System that pertains to prior knowledge about the core technology

There is one exception to this rule-prior knowledge about the core technology. A proposal for a knowledge subsystem that governs prior knowledge about the core technology is illustrated in figure 6.10. This form of knowledge has been shown to have a statistically significant positive impact on user satisfaction, the probability of commercialization and the probability of publication in the integrated regression models of these performance metrics, even though the last of these three performance metrics is misaligned with the first two.

Prior knowledge about the core technology has a negative complementary interaction with vicarious learning with other $R \& D$ project groups within the national laboratories, at 
least when it comes to the probability of commercialization (see interaction no. 14). When the level of prior knowledge about the core technology is low, then the probability of commercialization decreases very rapidly over the domain of vicarious learning with ORDUs. By contrast, if the level of knowledge of about the core technology is high, then the impact of vicarious learning with ORDUs on the probability of commercialization is negligible. It is thus in the national laboratories' interest to keep a high degree of knowledge about the core technology within the project groups so that the negative impact of vicarious learning with ORDUs is minimized for future projects.

Interviews with project managers suggest that the top management of the national laboratories is aware of the issue of inter-departmental barriers to knowledge, even though it does not know about the result of the study in this dissertation. The senior managers of the national laboratories would like to break down the barriers to knowledge flow between the various project groups within the national laboratories, and they also understand the potentially exceptional role that prior knowledge about the core technology could play in that context.

The management of the national laboratories is considering creating a special position called 'chief executive engineer' for every project. The chief executive engineer is supposed to be a person with a high degree of knowledge about the core technology of a project. His/her role will be to act as an intermediary between project groups. An overwhelming majority of project managers who commented on the position of chief executive engineer did so favorably, but they insisted that the chief executive engineer should have expertise in the core technology upon which the project depends. The 
project managers also suggested that the idea of a chief executive engineer has lots of support within NSTDA.

The results of my study show that having a chief executive engineer with a high degree of knowledge of the core technology under development in every project group could make the national laboratories significantly more ambidextrous. Vicarious learning with other R\&D project groups already enhances the exploratory component by increasing the probability of generating a publication. If the chief executive engineers can use their knowledge about the core technologies of their respective projects to mitigate the negative impact that vicarious learning with other $\mathrm{R} \& \mathrm{D}$ project groups has on the probability of commercialization of a technology, then they will enhance the exploitative component of the projects as well.

\subsubsection{The Relative Importance of Internal and External Learning}

Section 4.7.4 described the hierarchical approach to regression that was used to benchmark the explanatory and predictive power of five regression models for each output variable (see figure 4.2). The intent of this endeavor was to compare the impact of external learning, project-internal learning activities (PILAs), prior experiences, and prior knowledge on performance of $R \& D$ projects. The results of this benchmarking effort, which are described in section 5.3.1, have led to a series of conclusions about the relative impact of internal and external knowledge. 
Conclusion 6.6.3-1: Regardless of mission, knowledge inflows from outside the project group impact the performance of $R \& D$ projects more significantly than knowledge from inside the project group does.

Conclusion 6.6.3-2: Regardless of mission, knowledge inflows from outside the national laboratories impact the performance of R\&D projects more significantly than knowledge from inside the R\&D project group does. The impact of knowledge inflows from inside the national laboratories (other R\&D project groups) on the performance of a project is comparatively minor.

Conclusion 6.6.3-3: Utilizing both internal and external sources of knowledge increases the impact on performance dramatically.

According to interviews with project managers, most R\&D projects within the national laboratories cannot be completed solely on the basis of knowledge that is available in the project group that delivers the technology. Especially, delivering advanced technology requires advanced technological knowledge that is unavailable in the project group. Project managers tend to supervise research that is within their own area of technical expertise, so engaging with other R\&D units within the national laboratories should, in principle, be fruitful. However, in practice this does not turn out to be the case because project groups tend to work on projects that are highly specialized and not relevant to other projects. In addition, project groups within the national laboratories compete with each other for resources. Some project managers even claimed that they are not inclined to reveal secrets about their technology to other project groups. However, most of the 
advanced knowledge that is required to deliver advanced technology resides outside of the national laboratories. Therefore, the project group needs to acquire complementary knowledge outside the national laboratories. The synergy between internal and external knowledge improves performance. This state of affairs calls for a program for Open Innovation at the national laboratories, which is currently in the planning stage at NSTDA. 


\section{SUMMARY, CONTRIBUTIONS AND LIMITATIONS}

In this chapter, I summarize my research. I restate the research questions and report on how they have been addressed by the findings of my research. I also examine the theoretical and practical implications of the findings from my study. I discuss how this dissertation has contributed to academic research in various sub-fields of technology management and in other, related fields of study. In addition, I show how findings from this dissertation have revealed management practices that are particularly useful for national research laboratories in technological latecomer countries. I also discuss how findings from this dissertation may have implications for national policy in Thailand and other latecomer countries, yet I make the argument that the findings of my study can be generalized beyond technological latecomer countries and beyond the national laboratories setting, if proper follow-on studies are conducted. Finally, I identify some of my study's limitations, and I suggest how they can be overcome through further research using methods that I have in part developed in this dissertation.

\subsection{RESTATING THE RESEARCH GAPS AND THE RESEARCH QUESTIONS}

At the end of chapter 2, I identified a series of gaps in the academic literature that gave rise to the research questions that I have addressed in my dissertation. Most importantly, I discovered that no quantitative study on the impact of the four main sources of external knowledge (other R\&D project groups within the national laboratories; local universities; local technology users and international sources) and of the three main sources of internal knowledge (prior knowledge, prior experience, project-internal learning 
activities) on the performance of NLs in TLCs had ever been done. This primary research gap gave rise to the primary research question of my dissertation - to what degree does engagement with the external sources of knowledge affect the performance of national laboratories in technological latecomer countries?

In section 2.6, I broke down this overarching research question into four specific research questions.

- Research Question RQ-1 - What is the relative impact on the performance of national laboratories in latecomer countries of engaging a) with other project groups within the same organization; b) with the sources of foreign knowledge; c) with sources of user knowledge and d) with other sources of domestic knowledge?

- Research Question RQ-2 - What is the effect of a project group's prior knowledge on the relationship between the project group's degree of engagement with external sources of knowledge and the project's performance?

- Research Question RQ-3 - What is the effect of a project group's prior experience on the relationship between the project group's degree of engagement with external sources of knowledge and the project's performance?

- Research Question RQ-4 - What is the effect of a project group's internal learning capability on the relationship between the project group's degree of engagement with external sources of knowledge and the project's performance?

Hypotheses 1 through 4 were set up to address RQ-1 for the three basic missions of the national laboratories. Hypotheses 5, 6 and 7 were respectively set up to address RQ-2, 
RQ-3 and RQ-4. The results show all of the seven proposed hypotheses were statistically significant, under a variety of circumstances. The relative impact of the various knowledge inflows on four performance criteria (OV1, OV2, OV3.1 and OV3.3) has been discussed in section 5.4.5. The results that pertain to research questions RQ-2, RQ-3 and RQ-4 have been presented in section 5.5. I consequently argue that the primary research gap from section 2.6 has been closed, and its associated research questions have been answered. I consider this the primary contribution of my dissertation research.

However, as I have noted repeatedly in chapter 5, the results of my research are much more nuanced and differentiated than I had originally anticipated. Hypotheses 1 through 7 have been confirmed under special circumstances and I have been able to identify what these circumstances are (see Figures 6.2 through 6.10). I consider this a significant contribution of my research as well. Finally, the nuanced and differentiated results enable me to make additional, initially unforeseen contributions to academic theory, management practice and research methods, which are discussed in the following sections.

\subsection{ACADEMIC CONTRIBUTIONS}

The contributions of the empirical study in this dissertation span a variety of research streams within the field of technology management including R\&D management, technology transfer and new product development. This dissertation also contributes to the fields of organizational learning and the study of absorptive capacity by providing a 
more detailed understanding about how external sources of knowledge affect the performance of research and development projects within national laboratories.

\subsubsection{R\&D Management}

The findings of this dissertation present an academic contribution to the literature on R\&D management, and the study of R\&D management is one of the central aspects of technology management. Of late, two research streams have been increasing in importance in the $\mathrm{R} \& \mathrm{D}$ management literature: Open Innovation and organizational ambidexterity. My dissertation research speaks to both streams of literature.

\subsubsection{R\&D Management and Open Innovation}

Organizations, in particular high-tech firms, have opened their boundaries to external knowledge and tried to identify strategies to access knowledge resources externally (Chesbrough, 2003; Chesbrough et al., 2006; Gassmann, 2006). This phenomenon was initially explored in studies that are described in the literature on Open Innovation (Chesbrough, 2003; Chesbrough et al., 2006; Gassmann, 2006). The principles that were identified in these studies have also been shown to apply to more traditional and mature industries (Chesbrough \& Crowther, 2006), but have never been demonstrated in public organizations. Yet, like many firms in private industry, the national laboratories in technology latecomer countries link up and interact with external entities to initiate, import, modify or diffuse new technologies (Freeman, 1992, Mazzoleni \& Nelson, 2007, Intarakumnerd et al., 2002). 
This dissertation makes an academic contribution in refining a framework of how national laboratories link and interact with external entities (see Figure 6.1). This framework enhances the understanding of how the Open Innovation approach is practiced in national laboratories. This dissertation also develops a benchmarking method to quantify quantitative data to confirm the impacts of engaging with external sources of knowledge on the performance of national laboratories (see section 5.3). Thus, this dissertation provides both framework and quantitative data to confirm that the principle of Open Innovation applies to the NLs of TLC.

\subsubsection{Identifying the Ambidexterity Challenge in the National Laboratories}

My dissertation has shown that the national laboratories face a significant ambidexterity challenge (section 6.5), just like private corporations do (Tushman \& O’Reilly, 1996; O'Reilly \& Tushman, 2004; Gibson \& Birkinshaw, 2004; Raisch \& Birkinshaw, 2008; O'Reilly \& Tushman, 2008; Ambos et al., 2008; Simsek, 2009; Raisch et al., 2009; Andriopoulos \& Lewis, 2009; Taylor \& Helfat, 2009; Rothaermel \& Alexandre, 2009; Cao et al., 2009; Jansen et al., 2009; Mom et al., 2009; O'Reilly \& Tushman, 2011). Mission 1 (user satisfaction) and mission 2 (commercialization of technology), which are clearly exploitative, are not well aligned with mission 3 (generating and R\&D capability for the country), which enables exploratory activities. Further research should determine whether practices that have enhanced organizational ambidexterity (e.g., d'Arbeloff, 1996; Simsek, 2009; Carmeli \& Halevi, 2009) in private industry also apply to public institutions like the national laboratories (Y.-C. Chang et al., 2009). 


\subsubsection{Technology Transfer}

In the technology transfer literature, the NLs are considered as a source of technology for private industry (W. M. Cohen et al., 2002). Therefore, the direction of knowledge flow discussed in technology transfer literature tends to focus on how knowledge flows out of the national laboratories and in to industries. However, in technological latecomer countries both the NLs and private industrial firms are likely to have insufficient resources to research and develop their technology internally. They NLs rely on knowledge from external sources, both foreign and domestic, just like their counterparts in private industry rely on the NLs for technology. Yet, the relationship between knowledge flows into the NLs and knowledge transfer out of the NLs is not well understood, primarily because very few academic studies of this topic have been performed. This dissertation has enhanced our understanding of how knowledge that flows into the NLs in TLCs impacts technology transfer out of the NLs (Figures 6.2 through 6.4). It consequently contributes to closing this gap in the academic literature.

\subsubsection{New Product Development}

This study has increased our understanding about how NLs enable or participate in new product and new service development (NPSD) process. In NPSD literature, the outflow of knowledge from NLs links to the NPSD process at various stages (R. G. Cooper \& Kleinschmidt, 1986; R. G. Cooper, 1994; Ulrich \& Eppinger, 1995; H. Kim \& Park, 2010). Also, user requirements and user feedback may flow back into the labs to help the NLs develop technology that is suitable for current and future demands by technology 
users (Gregersen, 1992). The findings of the empirical study in this dissertation, which has investigated the impact of knowledge inflows on the performance of the NLs, has been able to provide significant insight into how private firms can leverage NLs more effectively in their NPSD process.

It is well known that user engagement can lead to supplier innovations that tend to occur along dimensions of merit (von Hippel, 1988). I have shown that this is also true when the national laboratories are the supplier of technology and the local technology users develop the product. In addition, I have provided a theoretical framework that consists of a toolkit of micro-levers, which helps the laboratory managers them satisfy user needs pertaining to new product development or commercialize technology for new product development more effectively (figures 6.2 and 6.3).

\subsubsection{Organization Learning and Absorptive Capacity}

The study in this dissertation has been able to contribute to the field of organizational learning by enhancing our understanding of how engagement with external sources of knowledge impacts the performance of national laboratories in technology latecomer countries and perhaps elsewhere. For example, I have been able to build on the work of Bresman, 2010, by identifying a set of circumstances under which contextual learning has a greater impact on performance and another set of circumstances under which vicarious learning has a greater impact on performance. Furthermore, according to Argote and Miron-Spektor, 2011 (p. 1123), “organizational experience interacts with the context to create knowledge." My research has validated this principle for the national laboratories 
in technology latecomer countries, and I have identified the factors that determine the impact that knowledge creation has on organizational performance.

This dissertation may also be able to make contributions to the knowledge management literature. For example, a part of validating the overarching framework for knowledge flows in the national laboratory system (section 2.5) was the identification of knowledge subsystems within the national laboratory system, first by literature search (chapter 3) and subsequently by analysis of quantitative and qualitative data. Some of the subsystems that have been identified are mission specific (section 6.4); others are phenomena specific (section 6.6). These subsystems should in principle be easier to manage than the national laboratories system as a whole. However, they need to be characterized in further detail before they can be used as a framework for management practice.

The findings of the study in this dissertation have established that managing a diverse set of knowledge sources requires managers to differentiate between various kinds of absorptive capacity. In fact, the nature of absorptive capacity is highly selective. This discovery is perhaps the most important contribution of my dissertation research. The conclusion that is associated with this discovery has been stated in section 6.3: “... the capacity of $R \& D$ project groups within the national laboratories to absorb knowledge from external sources is not just related to prior related knowledge; it is also a function of the source of external knowledge, the knowledge pathway into the project group; the source of complementary or substitutive knowledge that resides within the project group; and the mission to which the knowledge contributes." I believe this discovery warrants 
further academic study so that the plethora of absorption mechanisms that have been identified in this dissertation can be characterized for use by practitioners.

\subsection{CONTRIBUTIONS TO MANAGEMENT PRACTICE}

Understanding the impact of engagement with external sources of knowledge on performance of research projects can help managers of research and development projects at national laboratories in technological latecomer countries design their strategy for engaging with external entities more effectively. Best practices for engaging with external entities, which allow managers at NLs in TLCs to learn about how to manage knowledge inflows, have been identified in this dissertation. The process of learning consists of deciding which external source of knowledge to tap, and identifying the best pathways for knowledge inflow into the national laboratories and the various project groups that actually work on R\&D projects (see Figures 6.6 through 6.10 , knowledge subsystems of the National Laboratories Knowledge Management System). My dissertation has also provided practical insights into how the performance of $R \& D$ projects is impacted when knowledge that has flowed in from external sources is combined with knowledge that is either already present within the group or evolving currently through internal learning processes (see Figures 6.2 through 6.5, knowledge subsystems of the National Laboratories Knowledge Management System that are mission specific). 
These insights enhance the ability of project managers to manage absorptive capacity within their groups. Once again, the toolkit of micro-levers that my dissertation provides needs to be mentioned (figures 6.2 through 6.10). It indicates into which sources of external knowledge the project group should tap, and which internal source knowledge to encourage so that the inflow from the external source of knowledge can be absorbed. Finally, it should be noted that interviews with project managers and project evaluators have revealed an approach for ameliorating the ambidexterity challenge - the creation of the position of 'chief executive engineer' within each $R \& D$ project group (section 6.6.2).

\subsection{IMPLICATIONS FOR NATIONAL POLICY}

The study in this dissertation has investigated how the national laboratories in technological latecomer countries interact with their national innovation systems. Any significant findings of the study in this dissertation could consequently have implications for national policy. Based on the findings of this study, policymakers in a technological latecomer country may be able to make structural adjustments to the national laboratories or to some of the domestic entities with which they interact. These adjustments could potentially enhance and accelerate social and economic development of their nation. For example, NSTDA is currently launching an Open Innovation policy for the national laboratories to which the findings of this dissertation could in principle contribute. It is also not inconceivable that the findings of this study could induce modifications to 
foreign policy that increase the national absorptive capability by making the knowledge inflow from abroad more efficient and effective.

\subsection{LIMITATIONS}

The purpose of the research in this dissertation is to identify and determine the relative importance of the factors that contribute to the success of $R \& D$ projects within the national laboratories of technology latecomer countries. I test the impact on project performance of changes in the values of various input variables, moderating variables and control variables. In essence, I have conducted variance research (Mohr, 1982), which treats the national laboratories as a black box, rather than process research, which looks inside the black box (Zenobia \& Weber, 2012). ${ }^{30}$

The following limitations of my research are a consequence of its quantitative nature. Firstly, this study uses item scales to capture the complex behavior of R\&D project groups as they engage with external sources of knowledge. Research that uses item scales is designed to elicit information that has been mentioned in the existing literature. It may not capture some aspects of the behavior of the respondents that the research

\footnotetext{
30 "Process research is a style of inquiry that seeks to discover causal relationships and patterns in the sequence of events over time; it has often been used to study technology adoption (Downs \& Mohr, 1976; A. Langley \& Truax, 1994; Rogers, 2003; Van de Ven \& Huber, 1990). Mohr, 1982, contrasted process research with what he termed 'variance' research, the more familiar style of inquiry that seeks to determine covariance and correlation among variables, independent of their time order. Process research aims to construct theories that explain the time order of events; it does not strongly emphasize relationships among variables influencing the rate or outcome of these events (Mohr, 1982; Abbott, 1990). Process research is less structured and more qualitative in character than variance research. Some of the methods that have been used for process research include case studies, grounded theory, and sequence analysis (A Langley, 1999), and these methods have occasionally been applied in combination e.g., Leonard-Barton, 1990." (Zenobia \& Weber, 2012, p. 5)
} 
design does not anticipate. For example, the quality of engagement to external sources of knowledge is not directly measured in this study. A particular project group may engage with the external sources of knowledge very frequently, but the quality of knowledge inflows may be lower than that of another project group, which does not engage with the external sources very often. Secondly, this study uses a retrospective approach to collect data from R\&D project managers and project evaluators. This approach may cause bias and error in research results. However, using data from R\&D projects that have been completed in the past two years has minimized the bias and error resulting from data collection. Thirdly, the sample size of R\&D projects in this study may be not enough to capture with statistical significance the impact of all factors pertaining to absorptive capacity, which may complement or substitute the inflow of knowledge from external sources. Even though 39 statistically significant interactions between input factors and moderating factors have been identified, the interaction matrices in table 5.20 look rather sparse. A larger sample size may be required to characterize the influence of additional interactions.

Another limitation of my dissertation research results directly from its hierarchical approach to multiple regression (section 4.7.4 and figure 4.2 of my dissertation; Aiken \& West, 1991; J. Cohen et al., 2003, Espinosa et al., 2007). The premise of my research was that knowledge from various internal sources could enhance or diminish the capacity to absorb knowledge that flows in from external sources. Variables associated with knowledge inflows were consequently treated as input variables, and variables associated with internal knowledge were treated as moderating variables (see figure 4.1). Factor 
analysis minimized multi-collinearity and identified the input factors and moderating factors that respectively represented knowledge inflows and internal knowledge. I subsequently looked at the relative importance of knowledge from external sources and internal sources, by comparing the explanatory power of the knowledge inflow baseline model, the project group baseline model and the intra-organization baseline models (section 5.3). Hypotheses 1 through 7 were also tested by multiple regression analysis. The integrated model tested hypotheses 1 through 4 (section 5.4); the interaction model was used to test hypotheses 5 through 7 (section 5.5). I did not move to the next step of generating a structural equation model, which would have covered all interactions between all factors, because that step would have exceeded the scope of my dissertation research as originally proposed..

The survey portion of my research was constrained by the limitations of variance research. This approach did not let me provide a detailed characterization of the internal processes that govern R\&D within the national laboratories in Thailand. However, I was able to interview 123 project managers within NSTDA at the time I administered the survey to them. I was able to extract qualitative information from these interviews, which let me peek inside the black box of organizational learning in the national laboratories. Combining the insights gained from these interviews with the quantitative results from the survey enabled me to come to the conclusions that were presented in chapter 6 .

Unfortunately, for reasons of confidentiality, I was not able to record the interviews on audio, which prevented me from coding them, and going through the formal, inductive theory-building exercises that are associated with process research (e.g., Yin, 2008; 
Eisenhardt, 1989; Strauss \& Corbin, 1998; Miles \& Huberman, 1994). Thus, I recommend qualitative follow-on research to my dissertation, perhaps sequence analysis (Abbott, 1990; Miles \& Huberman, 1994; A Langley, 1999), to gain an in depth understanding of the internal mechanisms of research and development within the NSTDA. It may also be useful to conduct case study research (Yin, 2008) at NSTDA. Each knowledge subsystem would constitute a case, and the inner mechanisms of knowledge management within the national laboratories would be revealed by comparing and contrasting cases (Miles \& Huberman, 1994). Once these mechanisms have been have been identified and characterized, I recommend running a structural equation model on the data that I have collected with my questionnaire, so that the constructs that emerge from the case studies can be validated in a quantitative sense.

Another limitation of this dissertation pertains to generalizing it results beyond technology latecomer countries. According to Intarakumnerd et al., 2002 (in section 4.2), organizations in technological latecomer countries tend to possess very limited capabilities to facilitate and produce intensive technological learning. They tend to have lower capacity in absorbing knowledge inflows from external sources than organizations in developed countries. Therefore, the influence of knowledge inflows on organizational performance may be different in these countries. To generalize the theoretical framework beyond organizations in latecomer countries, additional research on the national laboratories in other countries may be required. Nonetheless, many of the recommendations and best practices that may emerge from my dissertation could be 
applicable in many countries, including countries that are not latecomers to advanced technological development.

It should be noted that important sources of external knowledge such as competitors, suppliers, regulations, other industries, consultants, consortia, start-ups and communities (e.g. McAdam et al., 2006; Laursen \& Salter, 2006; Ili et al., 2010) are not included in the scope of this study. My dissertation has focused on the four critical sources of external knowledge for $\mathrm{R} \& \mathrm{D}$ projects in national laboratories of technological latecomer countries. To generalize the framework of this dissertation beyond the national laboratories in technology latecomer countries, additional studies, which identify and compare the critical sources of external knowledge for national laboratories in latecomer countries to those of other countries, need to be done. Furthermore, the results of my study need to be compared to the results of studies that have been or will be conducted in settings other than the national laboratories (e.g., universities, research labs in private industry), in order to test whether the findings of this study also apply in other settings.

\subsection{METHODS CONTRIBUTION}

I would like to point out that my dissertation contains a vehicle for conducting much of the follow-on research that has been suggested above. I believe that the questionnaire that has been developed addresses issues that are common to many R\&D contexts; it can consequently be used as a benchmarking tool for knowledge flow and its impact on performance. The same approach to data analysis that was used in this dissertation could also be used to study other settings. 
Repeating the study that I have conducted for my dissertation at many settings is likely to generate insight into how knowledge flow impacts R\&D management in general. One could compare the various approaches to managing knowledge in the national laboratories of various latecomer countries (e.g. NSTDA versus TUSSIDE in Turkey), or the approaches that are used by national laboratories in countries that are at different stages of economic development (e.g. NSTDA versus KIST in Korea and the FraunhoferGesellschaft in Germany). Significant insight into managing knowledge within R\&D organizations may also be gained by comparing the approaches of national laboratories to corporate laboratories (e.g., the Fraunhofer-Gesellschaft versus IBM's Watson Laboratories). 


\section{REFERENCES}

Abbott, A. (1990). A primer on sequence methods. Organization Science, 1(4), 373-393.

Adler, P. S., \& Clark, K. B. (1991). Behind the learning curve: A sketch of the learning process. Management Science, 37(3), 267-281.

Agrawal, A. (2002). Putting patents in context: exploring knowledge transfer from MIT. Management Science, 48(1), 44-44.

Aiken, L. S., \& West, S. G. (1991). Multiple Regression: Testing and Interpreting Interactions. Newbury Park, CA: Sage Publications, Inc.

Allen, T. J. (1971). Communications, technology transfer, and the role of technical gatekeeper. $R \& D$ Management, $1(1), 14-21$.

Allen, T. J. (1977). Managing The Flow of Technology: Technology Transfer and The Dissemination of Technological Information within The $R \& D$ Organization. Cambridge Mass.: MIT Press.

Almeida, P., Dokko, G., \& Rosenkopf, L. (2003). Startup size and the mechanisms of external learning: increasing opportunity and decreasing ability? Research Policy, 32(2), 301-315.

Almeida, P., \& Kogut, B. (1997). The exploration of technological diversity and geographic localization in innovation: Start-up firms in the semiconductor industry. Small Business Economics, 9(1), 21-31.

Almeida, P., \& Kogut, B. (1999). Localization of knowledge and the mobility of engineers in regional networks. Management Science, 45(7), 905-917.

Ambos, T. C., Mäkel, K., Birkinshaw, J., \& D'Este, P. (2008). When does university research get commercialized? Creating ambidexterity in research institutions. Journal of Management Studies, 45(8), 1424-1447.

Ancona, D. G., \& Caldwell, D. F. (1992). Bridging the boundary: External activity and performance in organizational teams. Administrative Science Quarterly, 37(4), 634-665. 
Andriopoulos, C., \& Lewis, M. W. (2009). Exploitation-exploration tensions and organizational ambidexterity: Managing paradoxes of innovation. Organization Science, 20(4), 696-717.

Antal, A. B., \& Walker, E. M. (2011). Organizational learning from chinese returners: An exploratory study of the role of cross-cultural interactions. International Business and Management, 27, 151-175.

Argote, L., \& Ingram, P. (2000). Knowledge transfer: A basis for competitive advantage in firms. Organizational Behavior and Human Decision Processes, 82(1), 150169.

Argote, L., Ingram, P., Levine, J. M., \& Moreland, R. L. (2000). Knowledge transfer in organizations: Learning from the experience of others. Organizational Behavior and Human Decision Processes, 82(1), 1-8.

Argote, L., \& Miron-Spektor, E. (2011). Organizational learning: From experience to knowledge. Organization Science, 22, 1123-1137.

Arnold, E., Rush, H., Bessant, J., \& Hobday, M. (1998). Strategic planning in research and technology institutes. $R \& D$ Management, 28(2), 89-100

Arocena, R., \& Sutz, J. (2000). Looking at national systems of innovation from the South. Industry \& Innovation, 7(1), 55-75.

Arocena, R., \& Sutz, J. (2005). Innovation Systems and Developing Countries: Danish Research Unit for Industrial Dynamics (DRUID)

Backer, K. (2008). Open Innovation in Global Networks. Paris: OECD.

Bercovitz, J. (2006). Entpreprenerial universities and technology transfer: A conceptual framework for understanding knowledge-based economic development. The Journal of Technology Transfer, 31(1), 175-188.

Bessant, J. (1999). The rise and fall of 'Supernet': a case study of technology transfer policy for smaller firms. Research Policy, 28(6), 601-601.

Bohn, R. E. (1994). Measuring and managing technological knowledge. Sloan Management Review, 36(1), 61-73. 
Bouty, I. (2000). Interpersonal and interaction influences on informal resource exchanges between R\&D researchers across organizational boundaries. The Academy of Management Journal, 43(1), 50-65.

Bresman, H. M. (2005). Learning Strategies and Performance in Organizational Teams. Massachusetts Institute of Technology, Sloan School of Management.

Bresman, H. M. (2010). External learning activities and team performance: A multimethod field study. Organization Science, 21(1), 81-96.

Burns, R., \& Burns, R. P. (2008). Business Research Methods and Statistics Using SPSS. Thousand Oaks, CA Sage Publications Limited.

Cao, Q., Gedajlovic, E., \& Zhang, H. (2009). Unpacking organizational ambidexterity: Dimensions, contingencies and synergistic effects. Organization Science, 20(4), 781-796.

Carayannis, E. G., \& Gover, J. (2002). The SEMATECH-Sandia National Laboratories partnership: a case study. Technovation, 22(9), 585-591.

Carmeli, A., \& Halevi, M. Y. (2009). How top management team behavioral integration and behavioral complexity enable organizational ambidexterity: The moderating role of contextual ambidexterity. The Leadership Quarterly, 20(2), 207-218.

Carson, S. J. (2007). When to give up control of outsourced new product development. Journal of Marketing, 71, 49-66.

Cattell, R. B. (1966). The scree test for the number of factors. Multivariate Behavioral Research, 1(2), 245-276.

Chaminade, C., \& Vang, J. (2008). Upgrading in asian clusters. Science Technology \& Society, 13(1), 61.

Chang, P. L., \& Hsu, C. W. (1998). The development strategies for Taiwan's semiconductor industry. IEEE Transactions on Engineering Management, 45(4), $349-356$.

Chang, Y.-C., Yang, P. Y., \& Chen, M.-H. (2009). The determinants of academic research commercial performance: Towards an organizational ambidexterity perspective. Research Policy, 38(6), 936-946. 
Chapple, W., Lockett, A., Siegel, D., \& Wright, M. (2005). Assessing the relative performance of UK university technology transfer offices: parametric and nonparametric evidence. Research Policy, 34(3), 369-384.

Chen, X., \& Sun, C. (2000). Technology transfer to China: alliances of Chinese enterprises with western technology exporters. Technovation, 20(7), 353-362.

Chesbrough, H. W. (2002). Graceful exits and missed opportunities: Xerox's management of its technology spin-off organizations. Business History Review, 76(4), 803-837.

Chesbrough, H. W. (2003). Open Innovation: The New Imperative for Creating and Profiting from Technology. Boston Mass.: Harvard Business School Press.

Chesbrough, H. W., \& Crowther, A. K. (2006). Beyond high tech: early adopters of Open Innovation in other industries. $R \& D$ Management, 36(3), 229-236

Chesbrough, H. W., \& Garman, A. R. (2009). How Open Innovation can help you cope in lean times. Harvard Business Review, 87(12), 68-76.

Chesbrough, H. W., \& Rosenbloom, R. S. (2002). The role of the business model in capturing value from innovation: evidence from Xerox Corporation's technology spin-off companies. Industrial and Corporate Change, 11(3), 529-555

Chesbrough, H. W., Vanhaverbeke, W., \& West, J. (2006). Open Innovation: Researching a New Paradigm. New York: Oxford University Press, USA.

Chiang, Y. H., \& Hung, K. P. (2010). Exploring open search strategies and perceived innovation performance from the perspective of inter-organizational knowledge flows. $R \& D$ Management, 40(3), 292-299.

Christensen, J. L. (1992). The role of finance in national systems of innovation. In National Systems of Innovation: Towards a Theory of Innovation and Interactive Learning (pp. 146-168). London: Pinter.

Cohen, J., Cohen, P., West, S., \& Aiken, L. (2003). Applied Multiple Regression Correlation Analysis for The Behavioral Sciences. Mahwah N.J.: L. Erlbaum Associates.

Cohen, M. D., \& Bacdayan, P. (1994). Organizational routines are stored as procedural memory: Evidence from a laboratory study. Organization Science, 5(4), 554-568. 
Cohen, W. M., \& Levinthal, D. A. (1990). Absorptive capacity: a new perspective on learning and innovation. Administrative Science Quarterly, 35(1), 128-152.

Cohen, W. M., Nelson, R. R., \& Walsh, J. P. (2002). Links and impacts: the influence of public research on industrial R\&D. Management Science, 48(1), 1-23.

Cooke, P. (2005). Regionally asymmetric knowledge capabilities and open innovation: Exploring 'Globalisation 2'--A new model of industry organisation. Research Policy, 34(8), 1128-1149

Cooper, D. R., \& Emory, C. W. (1995). Business Research Methods. Chicago: Richard D. Irwin Inc.

Cooper, R. G. (1994). Perspective third-generation new product processes. Journal of Product Innovation Management, 11(1), 3-14.

Cooper, R. G., \& Kleinschmidt, E. J. (1986). An investigation into the new product process: steps, deficiencies, and impact. Journal of Product Innovation Management, 3(2), 71-85.

Cummings, J. N. (2004). Work groups, structural diversity, and knowledge sharing in a global organization. Management Science, 50(3), 352-364.

d'Arbeloff, A. (1996). Teradyne: Corporate Management of Disruptive Change. Cambridge, Massachusetts: Harvard Business School.

Dahlman, C. J., \& Frischtak, C. (1990). National Systems Supporting Technical Advance in Industry: The Brazilian Experience: World Bank Industry and Energy Dept., Press.

Dahlman, C. J., \& Nelson, R. (1995). Social absorption capability, national innovation systems and economic development. In Social Capability and Long-term Growth: Basingstoke, Macmillan Press.

Daim, T. U. (1998). Technology Evaluation and Acquisition Strategies and Their Implications in The U.S. Electronics Manufacturing Industry. Portland State University, Portland.

Dalum, B. (1992). Export specialisation, structural competitiveness and national systems of production. reprinted in National Systems of Innovation: Toward a Theory of Innovation and Interactive Learning, Lundvall,B. 2010, 195-217. 
Darr, E. D., Argote, L., \& Epple, D. (1995). The acquisition, transfer, and depreciation of knowledge in service organizations: Productivity in franchises. Management Science, 41(11), 1750-1762.

Davis, J., \& Harrizon, S. (2001). Edison in The Boardroom How Leading Companies Realize Value from Their Intellectual Assets. New York: Wiley.

Dawson, J. (2006). Interpreting interaction effects: http://www.jeremydawson.co.uk/slopes.htm.

De Clercq, D., \& Dimov, D. (2008). Internal knowledge development and external knowledge access in venture capital investment performance. Journal of Management Studies, 45(3), 585-612.

Decter, M. (2007). University to business technology transfer in UK and USA comparisons. Technovation, 27(3), 145-155.

del Campo, A. A., Sparks, A., Hill, R. C., \& Keller, R. T. (1999). The transfer and commercialization of University-Developed medical imaging technology: Opportunities and problems. IEEE Transactions on Engineering Management, 46(3), 289-289.

Dodgson, M., \& Bessant, J. R. (1996). Effective Innovation Policy: a New Approach: Routledge.

Dodgson, M., Gann, D., \& Salter, A. (2006). The role of technology in the shift towards open innovation: The case of Procter \& Gamble. $R \& D$ Management, 36(3), 333346.

Dong-Won, K., \& Leslie, S. W. (1998). Winning markets or winning Nobel Prizes? KAIST and the challenges of late industrialization. Osiris, 13, 154-185.

Downs, G. W., Jr.;, \& Mohr, L. B. (1976). Conceptual issues in the study of innovations. Administrative Science Quarterly, 21, 700-714.

Dunteman, G. H. (1989). Principal Components Analysis. Newbury Park: Sage Publications.

Edmondson, A. C. (1999). Psychological safety and learning behavior in work teams. Administrative Science Quarterly, 44(2), 350-383. 
Edmondson, A. C., Winslow, A. B., Bohmer, R. M. J., \& Pisano, G. P. (2003). Learning how and learning what: Effects of tacit and codified knowledge on performance improvement following technology adoption. Decision Sciences, 34(2), 197-224.

Eisenhardt, K. M. (1989). Building Theories from Case Study Research. The Academy of Management Review, 14(4), 532-550.

Elton, J. J., Shah, B. R., \& Voyzey, J. N. (2002). Intellectual property: partnering for profit; companies could earn up to 10 percent of their operating income from the sale of patents and proprietary processes. But how? The McKinsey Quarterly, 59.

Encarnação, J. L. (2007). Bringing investors to R\&D and innovation exploitation closing the "last mile" in the innovation process (Publication. Retrieved March, 2011, from Technical University of Darmstadt, Department of Computer Science.: http://ec.europa.eu/research/conferences/2007/fst/presentations/day10/morning/p4 14-jose-encarnacao/encarnacao_07-10-10-lisbon.pdf.

Epple, D., Argote, L., \& Devadas, R. (1991). Organizational learning curves: A method for investigating intra-plant transfer of knowledge acquired through learning by doing. Organization Science, 58-70.

Espinosa, J. A., Slaughter, S. A., Kraut, R. E., \& Hersleb, J. E. (2007). Familiarity, complexity, and team performance in geographically distributed software development. Organization Science, 18(4), 613-630.

Etzkowitz, H. (2003). Research groups as 'quasi-firms': the invention of the entrepreneurial university. Research Policy, 32(1), 109-121.

European_Commission. (2009). Living labs for user-driven open innovation: an overview of the living labs methodology, activities and achievements (Publication. Retrieved March, 2011, from European Commission: http://www.scribd.com/doc/28137438/Living-Labs-for-user-driven-openinnovation

Fagerberg, J., Srholec, M., \& Knell, M. (2007). The competitiveness of nations: Why some countries prosper while others fall behind. World Development, 35(10), 1595-1620.

Farhang, M. (1997). Managing technology transfer to China Conceptual framework and operational guidelines. International Marketing Review, 14(2), 92-92. 
Faulkner, W., \& Senker, J. (1995). Policy and management issues in company links with academic and government laboratories: A cross-technology study. The Journal of High Technology Management Research, 6(1), 95-112.

Feldman, M., Feller, I., Bercovitz, J., \& Burton, R. (2002). Equity and the technology transfer strategies of American research universities. Management Science, 48(1), $105-121$.

Feller, I., Ailes, C. P., \& Roessner, D. (2002). Impacts of research universities on technological innovation in industry: evidence from engineering research centers. Research Policy, 31(3), 457-457.

Fey, C. F., \& Birkinshaw, J. (2005). External sources of knowledge, governance mode, and R\&D performance. Journal of Management, 31(4), 597-621.

Field, A. P. (2005). Discovering Statistics Using SPSS: SAGE Publications Ltd.

Fraunhofer. (2011). Business model. Retrieved March, 2011, from http://www.fraunhofer.de/en/about-fraunhofer/business-model.html

Freeman, C. (1992). Formal scientific and technical institutions in the national system of innovation. In K. Pavitt (Ed.), National Systems of Innovation: Towards a Theory of Innovation and Interactive Learning (pp. 169-187). London: Pinter.

Freeman, C. (1995). The 'National System of Innovation' in historical perspective. Cambridge Journal of Economics, 19(1), 5-24.

Fu, X., Pietrobelli, C., \& Soete, L. (2011). The Role of foreign technology and indigenous innovation in the emerging economies: Technological change and catching-up. World Development, 39(7), 1204-1212.

Fuld, L. M. (1988). Monitoring the Competition: Find out What's Really Going on Over There: Wiley.

Furman, J. L., \& Hayes, R. (2004). Catching up or standing still?: National innovative productivity among 'follower' countries, 1978-1999. Research Policy, 33(9), 1329-1354.

Furman, J. L., Porter, M. E., \& Stern, S. (2002). The determinants of national innovative capacity. Research Policy, 31(6), 899-933. 
Gassmann, O. (2006). Opening up the innovation process: towards an agenda. $R \& D$ Management, 36(3), 223-228

Gassmann, O., Sandmeier, P., \& Wecht, C. H. (2006). Extreme customer innovation in the front-end: learning from a new software paradigm. International Journal of Technology Management, 33, 46-46.

Geisler, E. (1995). Industry-university technology cooperation: a theory of interorganizational relationships. Technology Analysis \& Strategic Management, 7(2), 217-229.

Gelsing, L. E. (1992). Innovation and the development of industrial networks. reprinted in National Systems of Innovation: Toward a Theory of Innovation and Interactive Learning, Lundvall,B. 2010, 191-132.

Gibson, C. B., \& Birkinshaw, J. (2004). The antecedents, consequences and mediating role of organizational ambidexterity. Academy of Management Journal, 47(2), 209-226.

Gil, Y., Bong, S., \& Lee, J. (2003). Integration model of technology internalization modes and learning strategy: globally late starter Samsung's successful practices in South Korea. Technovation., 23(4), 333-333.

Gilad, B., \& Gilad, T. (1988). The Business Intelligence System: A New Tool for Competitive Advantage. New York, NY: American Management Association.

Godin, B. (2007). Science, accounting and statistics: the input-output framework. Research Policy, 36(9), 1388-1403.

Gregersen, B. (1992). The public sector as a pacer in national systems of innovation. reprinted in National Systems of Innovation: Toward a Theory of Innovation and Interactive Learning, Lundvall,B. 2010, 133-150.

Griffith, T. L., \& Sawyer, J. E. (2009). Multilevel knowledge and team performance. Journal of Organizational Behavior, 31(7), 1003-1031.

Gu, S. (1999). Implications of National Innovation Systems for Developing Countries: managing change and complexity in economic development. United Nations University, Institute for New Technologies Discussion Papers. 
Guan, J. C., Mok, C. K., Yam, R. C. M., Chin, K. S., \& Pun, K. F. (2006). Technology transfer and innovation performance: Evidence from Chinese firms. Technological Forecasting and Social Change, 73(6), 666-678.

Haas, M. R., \& Hansen, M. T. (2005). When using knowledge can hurt performance: the value of organizational capabilities in a management consulting company. Strategic Management Journal, 26(1), 1-24.

Haas, M. R., \& Hansen, M. T. (2007). Different knowledge, different benefits: toward a productivity perspective on knowledge sharing in organizations. Strategic Management Journal, 28(11), 1133-1153.

Hadjimanolis, A., \& Dickson, K. (2001). Development of national innovation policy in small developing countries: the case of Cyprus. Research Policy, 30(5), 805-817.

Hair, J. F., Anderson, R. E., Tatham, R. L., \& William, C. (1995). Multivariate Data Analysis. Englewood Cliffs, NJ: Prentice Hall.

Hansen, M. T. (1999). The search-transfer problem: the role of weak ties in sharing knowledge across organization subunits. Administrative Science Quarterly, 44(1), 82-85.

Harryson, S. J., Dudkowski, R., \& Stern, A. (2008). Transformation networks in innovation alliances: The development of Volvo C70. Journal of Management Studies, 45, 745-773.

Hatch, N. W., \& Mowery, D. C. (1998). Process innovation and learning by doing in semiconductor manufacturing. Management Science, 44(11), 1461-1477.

Hemmert, M. (2004). The impact of internationalization on the technology sourcing performance of high-tech business units. Journal of Engineering and Technology Management, 21(3), 149-174.

Hemphill, T. (2006). Economic considerations in cooperative research and development agreements (CRADA): The case of Taxol, NIH, and technology transfer. Technology in Society., 28(3), 321-321.

Herzog, P. (2008). Open and Closed Innovation: Different Cultures for Different Strategies. Wiesbaden, Germany: Gabler Verlag. 
Hill, S. A., \& Birkinshaw, J. (2008). Strategy-organization configurations in corporate venture units: Impact on performance and survival. Journal of Business Venturing, 23, 423-444.

Hipkin, I. (2004). Determining technology strategy in developing countries. Omega, $32(3), 245-260$.

Hoekman, B. M., Maskus, K. E., \& Saggi, K. (2005). Transfer of technology to developing countries: unilateral and multilateral policy options. World Development, 33(10), 1587-1602.

Hong, J. C. (1994). Technology transfer and human resource development. Industrial and Commercial Training, 26(11), 17-21.

Hou, C. M., \& Gee, S. (1993). National systems supporting technical advance in industry: the case of Taiwan. In R. R. Nelson (Ed.), National Innovation Systems: A Comparative Analysis (pp. 384-413): Oxford University Press.

Howells, J. (1990). The Internationalization of R \& D and the development of global research networks. Regional Studies, 24, 495-512.

Huber, G. P. (1991). Organizational learning: The contributing processes and the literatures. Organization Science, 2(1), 88-115.

Ili, S., Albers, A., \& Miller, S. (2010). Open innovation in the automotive industry. $R \& D$ Management, 40(3), 246-255.

Intarakumnerd, P., Chairatana, P., \& Tangchitpiboon, T. (2002). National innovation system in less successful developing countries: the case of Thailand. Research Policy, 31(8-9), 1445-1457.

Jansen, J. J. P., Tempelaar, M. P., van den Bosch, F. A. J., \& Volberda, H. W. (2009). Structural differentiation and ambidexterity: The mediating role of integration mechanisms. Organization Science, 20(4), 797-811.

Johnson, B. H. (1992). Institutional learning. reprinted in National Systems of Innovation: Toward a Theory of Innovation and Interactive Learning, Lundvall,B. 2010, 24-45.

Johnson, R. A., \& Wichern, D. W. (2007). Applied Multivariate Statistical Analysis (6th Edition). Upper Saddle River, NJ: Prentice Hall. 
Jolliffe, I. T. (1972). Discarding variables in a principal component analysis, I: artificial data. Applied Statistics, 21, 160-173.

Jolliffe, I. T. (1986). Principal Component Analysis. New York: Springer.

Judd, C. M., Smith, E. R., \& Kidder, L. H. (1991). Research Methods in Social Relations (6th ed.). Orlando, FL: Harcourt Brace Jovanovich College Publishers.

Kaiser, H. F. (1960). The application of electronic computers to factor analysis. Educational and Psychological Measurement., 20, 141-151.

Katz, J. M., \& Bercovich, N. A. (1993). National systems of innovation supporting technical advance in industry: the case of Argentina. In R. R. Nelson (Ed.), National Innovation Systems: A Comparative Analysis (pp. 451-475): Oxford University Press.

Katz, R., \& Allen, T. J. (1982). Investigating the Not Invented Here (NIH) syndrome: A look at the performance, tenure, and communication patterns of $50 \mathrm{R} \& \mathrm{D}$ Project Groups. $R \& D$ Management, 12(1), 7-20.

Keller, W. (1996). Absorptive capacity: On the creation and acquisition of technology in development. Journal of Development Economics, 49(1), 199-227.

Kim, H., \& Park, Y. (2010). The effects of open innovation activity on performance of SMEs: the case of Korea. International Journal of Technology Management, 52(3), 236-256.

Kim, L. (1980). Stages of development of industrial technology in a developing country: a model. Research Policy, 9(3), 254-277.

Kim, L. (1993). National system of industrial innovation: dynamics of capability building in Korea. In R. R. Nelson (Ed.), National Innovation Systems: A Comparative Analysis (pp. 357-383). New York: Oxford University Press, USA.

Kim, L. (1997). Imitation to Innovation: The Dynamics of Korea's Technological Learning. Boston: Harvard Business Press.

King, D., \& Nowack, M. L. (2003). The impact of government policy on technology transfer: An aircraft industry case study. Journal of Engineering and Technology Management, 20(4), 303-303. 
KIST. (2011). Korea Institute of Science and Technology - Mission. Retrieved March, 2011, from http://www.kist.re.kr/en/ki/vi.jsp

Kogut, B., \& Zander, U. (1992). Knowledge of the firm, combinative capabilities, and the replication of technology. Organization Science, 3(3), 383-397.

Kreiner, K., \& Schultz, M. (1993). Informal collaboration in R \& D: The formation of networks across organizations. Organization Studies, 14(2), 189-209.

Kulve, H., \& Smit, W. A. (2003). Civilian-military co-operation strategies in developing new technologies. Research Policy, 32(6), 955-970.

Lall, S. (1992). Technological capabilities and industrialization. World Development, 20(2), 165-186.

Lall, S., \& Narula, R. (2004). Foreign direct investment and its role in economic development: do we need a new agenda? European Journal of Development Research, 16(3), 447-464.

Lane, P. J., \& Lubatkin, M. (1998). Relative absorptive capacity and interorganizational learning. Strategic Management Journal, 19(5), 461-477.

Langley, A. (1999). Strategies for theorizing from process data. The Academy of Management Review, 24(4), 691-710.

Langley, A., \& Truax, J. (1994). A process study of new technology adoption in smaller manufacturing firms. Journal of Management Studies, 31(5), 619-652.

Lapré, M. A., Mukherjee, A. S., \& Van Wassenhove, L. N. (2000). Behind the learning curve: Linking learning activities to waste reduction. Management Science, 46(5), 597-611.

Laursen, K., \& Salter, A. (2006). Open for innovation: the role of openness in explaining innovation performance among U.K. manufacturing firms. Strategic Management Journal, 27(2), 131-150.

Lee, J., \& Win, H. N. (2004). Technology transfer between university research centers and industry in Singapore. Technovation, 24(5), 433-442.

Lee, K., \& Lim, C. (2001). Technological regimes, catching-up and leapfrogging: findings from the Korean industries. Research Policy, 30(3), 459-483. 
Leonard-Barton, D. (1990). A dual methodology for case studies: Synergistic use of a longitudinal single site with replicated multiple sites. Organization Science, 1(3), 248-266.

Lichtenthaler, U. (2005). External commercialization of knowledge: Review and research agenda. International Journal of Management Reviews, 7(4), 231-255

Lichtenthaler, U. (2006a). External technology commercialisation as an alternative mode of technology marketing. International Journal of Technology Marketing, 1(4), 411-430.

Lichtenthaler, U. (2006b). Leveraging Knowledge Assets: Success Factors of External Technology Commercialization: WHU-Otto Beisheim School of Management.

Lichtenthaler, U. (2008). Leveraging technology assets in the presence of markets for knowledge. European Management Journal, 26(2), 122-134

Liu, H., \& Jiang, Y. (2001). Technology transfer from higher education institutions to industry in China: nature and implications. Technovation., 21(3), 175-175.

Lofsten, H., \& Lindelof, P. (2003). Determinants for an entrepreneurial milieu: Science Parks and business policy in growing firms. Technovation, 23(1), 51-64.

Lundvall, B. A. (1992a). National Systems of Innovation: Towards a Theory of Innovation and Interactive Learning. London: Anthem Press.

Lundvall, B. A. (1992b). User-producer relationships, national systems of innovation and internationalisation. In B. A. Lundvall (Ed.), National Systems of Innovation: Towards a Theory of Innovation and Interactive Learning (pp. 45-67). London: Anthem Press.

Lundvall, B. A. (2010). National Systems of Innovation: Toward a Theory of Innovation and Interactive Learning. London: Anthem Press.

Lundvall, B. A., Johnson, B., Andersen, E. S., \& Dalum, B. (2002). National systems of production, innovation and competence building. Research Policy, 31(2), 213231.

Lyles, M. A., \& Salk, J. E. (1996). Knowledge acquisition from foreign parents in international joint ventures: an empirical examination in the Hungarian context. Journal of International Business Studies, 877-903. 
MacCormack, A., Verganti, R., \& Iansiti, M. (2001). Developing products on "Internet time": The anatomy of a flexible development process. Management Science, $71(1), 133-150$.

Madhavaram, S., \& McDonald, R. E. (2004). Knowledge grafting: Acquiring knowledge through hiring - An application in sales. Paper presented at the American Marketing Association 2004 Winter Educators Conference Proceedings, Chicago, IL.

Markman, G. D., Phan, P. H., Balkin, D. B., \& Gianiodis, P. T. (2005). Entrepreneurship and university-based technology transfer. Journal of Business Venturing, 20(2), 241-263.

Matusik, S. F. (2002). An empirical investigation of firm public and private knowledge. Strategic Management Journal, 23(5), 457-467.

Matusik, S. F., \& Heeley, M. B. (2005). Absorptive capacity in the software industry: Identifying dimensions that affect knowledge and knowledge creation activities. Journal of Management, 31(4), 549-549.

Mazzoleni, R., \& Nelson, R. (2007). The roles of research at universities and public labs in economic catch-up. Research Policy, 36(10), 1512-1528.

McAdam, R., Reid, R., \& Keogh, W. (2006). Technology and market knowledge creation and idea generation: an integrated quality approach. International Journal of Technology Management, 34(3/4), 340-340.

Miles, M. B., \& Huberman, A. M. (1994). Qualitative Data Analysis. Newbury Park, CA: Sage.

Mohr, L. B. (1982). Explaining Organizational Behavior: The Limits and Possibilities of Theory and Research. San Francisco: Jossey-Bass.

Mom, T. J. M., van den Bosch, F. A. J., \& Volberda, H. W. (2009). Understanding variation in managers' ambidexterity: Investigating direct and interaction effects of formal structural and personal coordination mechanisms. Organization Science, 20(4), 812-828.

Moorman, C., \& Miner, A. S. (1998). Organizational improvisation and organizational memory. Academy of Management Review, 23(4), 698-723. 
Mowery, D. C., \& Oxley, J. E. (1995). Inward technology transfer and competitiveness: the role of national innovation systems. Cambridge Journal of Economics, 19(1), 67-67.

Mowery, D. C., Oxley, J. E., \& Silverman, B. S. (1996). Strategic alliances and interfirm knowledge transfer. Strategic Management Journal, 17, 77-91.

Mowery, D. C., \& Sampat, B. N. (2005). Universities in national innovation systems. In The Oxford Handbook of Innovation (pp. 209-239). Oxford: Oxford University Press.

Murphy, K. R., \& Davidshofer, C. O. (1991). Psychological Testing: Principles and Applications. Englewood Cliffs, NJ: Prentice-Hall, Inc.

Nag, R., Corley, K. G., \& Gioia, D. A. (2007). The intersection of organizational identity, knowledge, and practice: attempting strategic change via knowledge grafting. Academy of Management Journal, 50(4), 821-847.

Nardo, M., Saisana, M., Saltelli, A., \& Tarantola, S. (2005). Tools for Composite Indicators Building. Ispra (VA), Italy: European Communities.

Narula, R. (2004). Understanding absorptive capacities in an "Innovation Systems" context: Consequences for economic and employment growth. DRUID Working Paper.

Nass, L. L., Pereira, P. A. A., \& Ellis, D. (2007). Biofuels in Brazil: An overview. Crop Science, 47(6), 2228-2237.

Nelson, R. R. (1993). National Innovation Systems: A Comparative Analysis. New York: Oxford University Press.

Nelson, R. R., \& Rosenberg, N. (1993). Technical innovation and national systems. In R. R. Nelson (Ed.), National Innovation Systems: A Comparative Analysis (pp. 321). New York: Oxford University Press, USA.

Nemanich, L. A., Keller, R. T., Vera, D., \& Chin, W. W. (2010). Absorptive capacity in R\&D project teams: A conceptualization and empirical test. IEEE Transactions on Engineering Management, 57(4), 674-688.

Niosi, J., Saviotti, P., Bellon, B., \& Crow, M. (1993). National systems of innovation: in search of a workable concept. Technology in Society, 15(2), 207-227. 
Nonaka, I. (1994). A dynamic theory of organizational knowledge creation. Organization Science, 5(1), 14 - 37.

NSTDA. (2011). Strategic Planning Alliance II (2011-2016 yr.). Retrieved March, 2011, from http://www.nstda.or.th/industrial-research

O'Reilly, C. A., \& Tushman, M. L. (2004). The ambidextrous organization. Harvard Business Review, 82(4), 74-81.

O'Reilly, C. A., \& Tushman, M. L. (2008). Ambidexterity as a dynamic capability: Resolving the innovator's dilemma. Research in Organizational Behavior, 28, 185-206.

O'Reilly, C. A., \& Tushman, M. L. (2011). Organizational ambidexterity in action: How managers explore and exploit. California Management Review, 53(4), 5-22.

OECD. (1997). National Innovation Systems. Paris: Organisation for Economic Cooperation and Development.

Oliver, A. L., \& Liebeskind, J. P. (1997). Three levels of networking for sourcing intellectual capital in biotechnology: implications for studying interorganizational networks. International Studies of Management \& Organization, 27(4), 76-103.

Park, W. G. (1998). A theoretical model of government research and growth. Journal of Economic Behavior \& Organization, 34(1), 69-85.

Pavitt, K. (1998). The social shaping of the national science base. Research Policy, 27(8), 793-805.

Pennington, D. C. (2003). Essential Personality: A Hodder Arnold Publication.

Petroni, G., \& Verbano, C. (2000). The development of a technology transfer strategy in the aerospace industry: the case of the Italian Space Agency. Technovation, 20(7), 345-351.

Phillips, R. (2002). Technology business incubators: how effective as technology transfer mechanisms? Technology in Society., 24(3), 299-316.

Piller, F. T., \& Walcher, D. (2006). Toolkits for idea competitions: a novel method to integrate users in new product development. $R \& D$ Management, 36(3), 307-318. 
Ploykitikoon, P. (2012). Dissertation Proposal: The Impact of Knowledge Inflows on the Performance of National Laboratories in Technological Latecomer Countries. Portland State University, Portland.

Ploykitikoon, P., \& Daim, T. U. (2010). Technology transfer strategy: review of successful research centres in the USA and Taiwan. International Journal of Technology, Policy and Management, 10(3), 227-238.

Porter, M. E. (1980). Competitive Strategy: Techniques for Analyzing Industry and Competitors. New York: Free Press

Raisch, S., \& Birkinshaw, J. (2008). Organizational ambidexterity: Antecedents, outcomes and moderators. Journal of Management, 34(3), 375-409.

Raisch, S., Birkinshaw, J., Probst, G., \& Tushman, M. L. (2009). Organizational ambidexterity: Balancing exploitation an exploration for sustained performance. Organization Science, 20(4), 685-695.

Reichstein, T., \& Salter, A. (2006). Investigating the sources of process innovation among UK manufacturing firms. Industrial and Corporate Change, 15(4), 653682.

Rivette, K. G., \& Kline, D. (2000). Rembrandts in the Attic: Unlocking the Hidden Value of Patents. Boston, MA: Harvard Business School Press.

Rogers, E. M. (2003). Diffusion of Innovations (5th ed.). New York: Free Press.

Rogers, E. M., Takegami, S., \& Yin, J. (2001). Lessons learned about technology transfer. Technovation, 21(4), 253-261.

Roper, S., \& Love, J. H. (2006). Innovation and regional absorptive capacity: the labour market dimension. The Annals of Regional Science, 40(2), 437-447.

Rosenkopf, L., \& Almeida, P. (2003). Overcoming local search through alliances and mobility. Management Science, 49(6), 751-766.

Rosenkopf, L., \& Tushman, M. L. (1998). The coevolution of community networks and technology: Lessons from the flight simulation industry. Industrial and Corporate Change, 7(2), 311-346. 
Rothaermel, F. T., \& Alexandre, M. T. (2009). Ambidexterity in technology sourcing: The moderating role of absorptive capacity. Organization Science, 20(4), 759780 .

Salicrup, L. A., \& Fedorkova, L. (2006). Challenges and opportunities for enhancing biotechnology and technology transfer in developing countries. Biotechnology Advances, 24(1), 69-79.

Sammon, W. L., Kurland, M. A., \& Spitalnic, R. (1984). Business Competitor Intelligence: Methods for Collecting, Organizing, and Using Information. New York: John Wiley \& Sons Inc.

Sedaitis, J. (2000). Technology transfer in transitional economies: a test of market, state and organizational models. Research Policy., 29(2), 135-135.

Segelod, E. (2001). Learning through grafting in ventures in new areas. Scandinavian Journal of Management, 17(3), 305-328.

Shane, S. (2002). Selling university technology: patterns from MIT. Management Science, 48(1), 122-137.

Siegel, D. (2004). Toward a model of the effective transfer of scientific knowledge from academicians to practitioners: Qualitative evidence from the commercialization of university technologies. Journal of Engineering and Technology Management, 21(1), 115-115.

Simango, C. C. B. (2000). Corporate strategy R\&D and technology transfer in the European pharmaceutical industry: research findings. European Business Review, 12(1), 28-28.

Simonin, B. (1999). Ambiguity and the process of knowledge transfer in strategic alliances. Strategic Management Journal, 20(7), 595.

Simsek, Z. (2009). Organizational ambidexterity: Towards a multilevel understanding. Journal of Management Studies, 46(4), 597-624.

Spann, M. S., Adams, M., \& Souder, W. E. (1995). Measures of technology transfer effectiveness: key dimensions and differences in their use by sponsors, developers and adopters. IEEE Transactions on Engineering Management, 42(1), 19-29.

Stevens, J. J. (2011). Interaction effects in regression. Retrieved May, 2011, from http://pages.uoregon.edu/stevensj/MRA/interaction.pdf 
Stevens, J. P. (1992). Applied Multivariate Analysis For The Social Sciences. Hillsdale, NJ: L. Erlbaum Associates.

Strauss, A. L., \& Corbin, J. (1998). Basics of Qualitative Research: Techniques and Procedures for Developing Grounded Theory, 2nd ed. . Thousand Oaks, CA.: Sage.

Suskie, L. A. (1996). Questionnaire Survey Research: What Works. 2nd Edition. Tallahassee, FL: Resources for Institutional Research.

Szulanski, G. (1996). Exploring internal stickiness: Impediments to the transfer of best practice within the firm. Strategic Management Journal, 17, 27.

Taylor, A., \& Helfat, C. E. (2009). Organizational linkages for surviving technological change: Complementary assets, middle management and ambidexterity. Organization Science, 20(4), 718-739.

Teubal, M. (1993). The innovation system of Israel: description, performance and outstanding issues. In R. R. Nelson (Ed.), National Innovation Systems: A Comparative Analysis (pp. 476-502). New York: Oxford University Press, USA.

Todorova, G., \& Durisin, B. (2007). Absorptive capacity: Valuing a reconceptualization. The Academy of Management Review, 32(3), 774-786.

Tong, X., \& Frame, J. D. (1994). Measuring national technological performance with patent claims data. Research Policy, 23(2), 133-141.

Trochim, W. M. K., \& Donnelly, J. P. (2001). Research Methods Knowledge Base: Atomic Dog Pub.

Tushman, M. L., \& Katz, R. (1980). External communication and project performance: An investigation into the role of gatekeepers. Management Science, 1071-1085.

Tushman, M. L., \& O’Reilly, C. A. (1996). Ambidextrous organizations: Managing evolutionary and revolutionary change. California Management Review, 38(4), 829.

Ulrich, K., \& Eppinger, S. D. (1995). Product Design and Development. New York: McGraw-Hill/Irwin. 
UNCTAD. (2005). Transnational Corporations and The Internationalization of $R \& D$. New York and Geneva: United Nationals Conference on Trade and Development, United Nation.

UNESCO. (2011). Global investment in $R \& D$ (Vol. 20). Montreal, Canada: Institute for Statistics, United Nations Educational, Scientific and Cultural Organization.

Utterback, J. M. (1975). The role of applied research institutes in the transfer of technology in Latin America. World Development, 3(9), 665-673.

Van de Ven, A. H., \& Huber, G. P. (1990). Longitudinal field research methods for studying processes of organizational change. Organization Science, 1(3), 213219.

von Hippel, E. (1986). Lead users: a source of novel product concepts. Management Science, 32(7), 791-805

von Hippel, E. (1987). Cooperation between rivals: informal know-how trading. Research Policy, 16(6), 291-302.

von Hippel, E. (1988). The Sources of Innovation: Oxford University Press New York.

von Hippel, E. (1989). New product ideas from lead users. Research-Technology Management, 32(3), 24-27

von Hippel, E. (1994). Sticky information and the locus of problem solving: Implications for innovation. Management Science, 40(4), 429-439

von Hippel, E. (2005). Democratizing Innovation. Cambridge Mass.: MIT Press.

Weber, C. W. (2002). Knowledge transfer and the limits to profitability: An empirical study of problem-solving practices in the semiconductor industry. IEEE Transactions on Semiconductor Manufacturing, 15(4), 420-426.

West, J., \& Bogers, M. (2011). Profiting from external innovation: A review of research on Open Innovation. SSRN eLibrary.

Williamson, O. E. (1981). The economics of organization: The transaction cost approach. American Journal of Sociology, 87(3), 548. 
Wong, P. K. (2003). From using to creating technology: the evolution of Singapore's national innovation system and the changing role of public policy. Competitiveness, FDI and Technological Activity in East Asia, 191-238.

Wong, S. (2004). Distal and local group learning: Performance trade-offs and tensions. Organization Science, 15(6), 645-656.

Yang, J., Weber, C. M., \& Gabella, P. (2012). Enabling collaborative solutions in the semiconductor manufacturing ecosystem. Paper presented at the Proceedings of IEEE/SEMI-ASMC, Saratoga Springs, NY, USA.

Yin, R. K. (2008). Case Study Research: Design and Methods (Vol. Vol. 5). Thousand Oaks, CA: SAGE Publications, Incorporated.

Zahra, S. A., \& George, G. (2002). Absorptive capacity: A review, reconceptualization, and extension. Academy of Management Review, 27(2), 185-203.

Zenobia, B. A., \& Weber, C. M. (2012). Bridging the gap between artificial market simulations and qualitative research in diffusion of innovation. International Journal of Innovation and Technology Management, 9(4), 1-22.

Zucker, L. G., Darby, M. R., \& Armstrong, J. S. (2002). Commercializing knowledge: University science, knowledge capture, and firm performance in biotechnology. Management Science, 48(1), 138-138.

Zucker, L. G., Darby, M. R., \& Brewer, M. B. (1998). Intellectual human capital and the birth of US biotechnology enterprises. American Economic Review, 88(1), 290306.

Zuniga, M. P., \& Guellec, D. (2009). Who licenses out patents and why? Lessons from a business survey. STI Working Papers: Organisation for Economic Co-operation and Development (DSTI/DOC(2009)5), 34. 


\section{APPENDICES}

\section{APPENDIX A: 17 PATHWAYS TO FACILITATE KNOWLEDGE TRANSFER FROM TECHNOLOGY PRODUCERS TO LTUS}

\begin{tabular}{|c|c|}
\hline Pathways & Author (s) \\
\hline Licensing* & $\begin{array}{l}\text { Rogers et al., 2001; Petroni \& Verbano, 2000; King \& Nowack, } \\
\text { 2003; Feller et al., 2002; Agrawal, 2002; Feldman et al., 2002; } \\
\text { Shane, 2002; Chapple et al., 2005; J. Lee \& Win, 2004; Siegel, } \\
\text { 2004; Bercovitz, 2006; del Campo et al., } 1999\end{array}$ \\
\hline Cooperative $\mathbf{R} \& \mathbf{D}^{*}$ & $\begin{array}{l}\text { Rogers et al., 2001; Carayannis \& Gover, 2002; Agrawal, 2002; } \\
\text { del Campo et al., 1999; Guan et al., 2006; Liu \& Jiang, } 2001\end{array}$ \\
\hline Contract research* & J. Lee \& Win, 2004 \\
\hline Joint research* & $\begin{array}{l}\text { Zucker et al., 2002; Kulve \& Smit, 2003; J. Lee \& Win, 2004; } \\
\text { Liu \& Jiang, } 2001\end{array}$ \\
\hline Consulting* & Agrawal, 2002; Guan et al., 2006 \\
\hline Seminars and conferences* & Agrawal, 2002; J. Lee \& Win, 2004 \\
\hline Training* & Hong, 1994; Guan et al., 2006 \\
\hline Direct selling* & J. Lee \& Win, 2004 \\
\hline Tech \& business incubator* & Phillips, 2002; Lofsten \& Lindelof, 2003; Markman et al., 2005 \\
\hline $\begin{array}{l}\text { Tech \& science park and R\&D } \\
\text { facility* }\end{array}$ & $\begin{array}{l}\text { Lofsten \& Lindelof, 2003; Petroni \& Verbano, 2000; Markman } \text { et } \\
\text { al., 2005; Liu \& Jiang, 2001; Feller } \text { et al., } 2002\end{array}$ \\
\hline Spin off & $\begin{array}{l}\text { Rogers et al., 2001; Sedaitis, 2000; Bercovitz, 2006; del Campo } \\
\text { et al., 1999; J. Lee \& Win, } 2004\end{array}$ \\
\hline Publications & Rogers et al., 2001; Agrawal, 2002; Decter, 2007 \\
\hline Patents & Agrawal, 2002; Decter, 2007 \\
\hline Prototyping & Feller et al., 2002 \\
\hline Tech\& Industry consortia & Bessant, 1999; Hemphill, 2006; J. Lee \& Win, 2004 \\
\hline $\begin{array}{l}\text { Meeting and knowledge } \\
\text { exchange }\end{array}$ & Rogers et al., 2001; Feller et al., 2002; Agrawal, 2002 \\
\hline Vertical Partners & del Campo et al., 1999 \\
\hline
\end{tabular}

Asterisks '*' refer to 10 channels for external technology commercialization of NLs 


\section{APPENDIX B: QUESTIONNAIRE FOR PROJECT MANAGERS (POST-}

\section{VALIDATION)}

This questionnaire is a part of a doctoral research in Engineering and Technology Management at Portland State University. The research investigates the impact of knowledge inflows into a project on research and development organizations. We ask you to participate in your role as a project manager in such an organization. Your responses will help us to better understand how knowledge inflows affect research and development organizations.

\section{B.1 General information interviewed by Pattravadee: Total 10 questions.}

Project title Project ID

Project manager Tel

\begin{tabular}{l} 
QUESTIONs \\
\hline 1. R\&D strategy: \\
Based on the OECD's taxonomy of R\&D activity (OECD, \\
1981, pp. 53-55), I classify the maturity of a research and \\
development project as follows: \\
a. A project is in the basic research stage if it consists of \\
"experimental or theoretical work undertaken primarily to acquire \\
new knowledge of the underlying foundations of phenomena and \\
observable facts, without any particular application or use in view" \\
(OECD, 1981, p. 54).
\end{tabular}

b. A project in the applied research stage is "also [an] original investigation undertaken in order to acquire new knowledge. It is however, directed primarily towards a specific practical aim or objective" (OECD, 1981, p. 54).

c. A project is in the development and demonstration stage, if it consists of "systematic work,..., which is directed to producing new materials, products, and devices, to installing new processes, systems, and services, and to improving substantially those already produced or installed" (OECD, 1981, p. 55).

Please classify the project by stage of technological development by using the definitions from below.

2. Please classify the project by technology type.

a. Basic Research

b. Applied Research

c. Development and Demonstration

d. Other (please identify).
a. Biotechnology
b. Materials technology
c. Electronics \& computer technology
d. Software technology
e. Nanotechnology 


\begin{tabular}{|c|c|}
\hline QUESTIONs & ANSWERS \\
\hline & 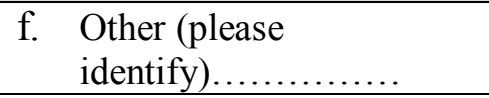 \\
\hline \multirow[t]{4}{*}{$\begin{array}{l}\text { 3. Please identify as many strategic programs of NSTDA as } \\
\text { possible, to which the output of this project can be applied. }\end{array}$} & $\begin{array}{l}\text { a. The Rice Program } \\
\text { b. The Tapioca Program } \\
\text { c. The Rubber Program } \\
\text { d. The Seed Program } \\
\text { e. The Plants for the Future } \\
\text { Program } \\
\text { f. The Animal Production } \\
\text { and Animal Health } \\
\text { grogram } \\
\text { The Food Innovation } \\
\text { Program }\end{array}$ \\
\hline & $\begin{array}{ll}\text { h. } & \text { The Newly Emerging } \\
\text { Disease - Re-emerging } \\
\text { Disease Program } \\
\text { i. Preventive, predictive and } \\
\text { personalized medicine } \\
\text { j. Healthcare practice and } \\
\text { medical devices } \\
\text { k. The Genotype Technology } \\
\text { Program } \\
\text { 1. Assistive Devices and } \\
\text { Technologies for People } \\
\text { with Disabilities and The } \\
\text { Elderly Program }\end{array}$ \\
\hline & $\begin{array}{l}\text { m. The Sustainable } \\
\text { Environment Program } \\
\text { n. The Resource and Energy } \\
\text { Efficiency Program } \\
\text { o. The Renewable Energy } \\
\text { and New Technology } \\
\text { Research Program } \\
\text { p. The Technology for Rural } \\
\text { Development Program } \\
\text { q. The Bio-resources } \\
\text { Program }\end{array}$ \\
\hline & $\begin{array}{ll}\text { r. } & \text { The Hard Disk Drive } \\
\text { Industry Research } \\
\text { Program } \\
\text { s. The Air-conditioning and } \\
\text { Refrigerator Industry } \\
\text { Program } \\
\text { t. The Automotive and } \\
\text { Automotive Parts Industry } \\
\text { Program }\end{array}$ \\
\hline
\end{tabular}




\begin{tabular}{|c|c|}
\hline QUESTIONs & ANSWERS \\
\hline & 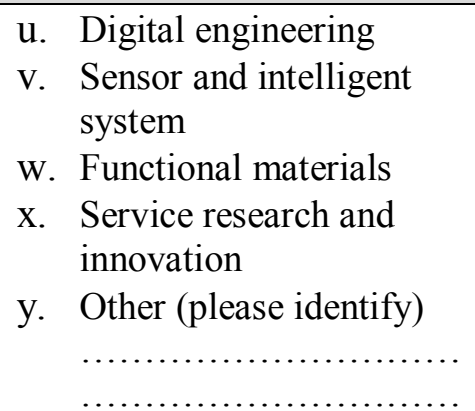 \\
\hline $\begin{array}{l}\text { Project members } \\
\text { 4. Number of full-time members working on this project } \\
\text { 5. with Ph.D. as the highest degree } \\
\text { 6. with Masters as the highest degree }\end{array}$ & $\begin{array}{l}\text { Total } \ldots \ldots \ldots \ldots \ldots \text { people } \\
\ldots \ldots \ldots \ldots \ldots \ldots \ldots \ldots \\
\ldots \ldots \ldots \ldots \ldots \ldots \ldots \ldots \ldots\end{array}$ \\
\hline $\begin{array}{l}\text { Prior knowledge (before the start of this project): } \\
\text { 7. How long was your group developing technology that is } \\
\text { directly relevant or useful to this project? }\end{array}$ & $\begin{array}{ll}\text { a. } & \text { Never } \\
\text { b. } & <1 \text { year } \\
\text { c. } & 1 \text { to }<3 \text { years } \\
\text { d. } & 3 \text { to }<5 \text { years } \\
\text { e. } & 5 \text { to }<7 \text { years } \\
\text { f. } & >7 \text { years }\end{array}$ \\
\hline $\begin{array}{l}\text { 8. How many journal publications that were directly relevant } \\
\text { or useful to this project did your project group generate } \\
\text { before this project began? }\end{array}$ & $\begin{array}{ll}\text { a. } & \text { Never } \\
\text { b. } & 1 \text { issue } \\
\text { c. } & 2 \text { issues } \\
\text { d. } & 3 \text { issues } \\
\text { e. } & 4 \text { issues } \\
\text { f. } & >4 \text { issues }\end{array}$ \\
\hline $\begin{array}{l}\text { 9. How many conference proceedings that were directly } \\
\text { relevant or useful to this project did your project group } \\
\text { generate before this project began? }\end{array}$ & $\begin{array}{ll}\text { a. } & \text { Never } \\
\text { b. } & 1 \text { issue } \\
\text { c. } & 2 \text { issues } \\
\text { d. } & 3 \text { issues } \\
\text { e. } & 4 \text { issues } \\
\text { f. } & >4 \text { issues }\end{array}$ \\
\hline $\begin{array}{l}\text { 10. How many patents that were directly relevant or useful } \\
\text { to this project did your project group generate before this } \\
\text { project began? }\end{array}$ & $\begin{array}{ll}\text { a. } & \text { Never } \\
\text { b. } & 1 \text { issue } \\
\text { c. } & 2 \text { issues } \\
\text { d. } & 3 \text { issues } \\
\text { e. } & 4 \text { issues } \\
\text { f. } & >4 \text { issues }\end{array}$ \\
\hline
\end{tabular}




\section{B.2 Activities pertaining to obtaining knowledge of this project: Total 29 questions}

The answers to the following questions will be measured by using psychometric scales, Likert scales, ranging from 1 to 6 . Please state your opinions by answering the following questions.

\begin{tabular}{|c|c|c|c|c|c|c|}
\hline Questions & $\begin{array}{c}\text { Almost } \\
\text { never } \\
\text { (1) }\end{array}$ & $\begin{array}{l}\text { Very } \\
\text { rarely } \\
\text { (2) }\end{array}$ & $\begin{array}{l}\text { On } \\
\text { oc- } \\
\text { casion } \\
\text { (3) }\end{array}$ & $\begin{array}{l}\text { Some } \\
\text { what } \\
\text { fre- } \\
\text { quently } \\
\text { (4) }\end{array}$ & $\begin{array}{l}\text { Very } \\
\text { fre- } \\
\text { quently } \\
(\mathbf{5})\end{array}$ & $\begin{array}{r}\text { Almost } \\
\text { always } \\
\text { (6) }\end{array}$ \\
\hline $\begin{array}{l}\text { 11. At least some members of our project } \\
\text { group looked for technical ideas in } \\
\text { internal reports inside NSTDA. }\end{array}$ & & & & & & \\
\hline $\begin{array}{l}\text { 12. At least some members of our project } \\
\text { group looked for technical ideas in } \\
\text { papers, reports and websites published } \\
\text { by universities inside Thailand. }\end{array}$ & & & & & & \\
\hline $\begin{array}{l}\text { 13. At least some members of our project } \\
\text { group looked for technical ideas in } \\
\text { papers, reports and websites that were } \\
\text { published by foreign universities and } \\
\text { foreign-owned companies. }\end{array}$ & & & & & & \\
\hline $\begin{array}{l}\text { 14. To understand the needs of our } \\
\text { targetedcustomers, at least some } \\
\text { members of our project group looked } \\
\text { for technical requirements in industry } \\
\text { newsletters, bulletins, websites and } \\
\text { trade journals. }\end{array}$ & & & & & & \\
\hline $\begin{array}{l}\text { 15. At least some members of our project } \\
\text { group looked for data on what other } \\
\text { teams inside NSTDA were doing on } \\
\text { similar or complementary projects. }\end{array}$ & & & & & & \\
\hline $\begin{array}{l}\text { 16. At least some members of our project } \\
\text { group looked for data on what other } \\
\text { teams at universities inside Thailand } \\
\text { were doing on similar or } \\
\text { complementary projects. }\end{array}$ & & & & & & \\
\hline $\begin{array}{l}\text { 17. At least some members of our project } \\
\text { group looked for data on what other } \\
\text { teams at foreign universities and } \\
\text { foreign-owned companies were doing } \\
\text { on similar or complementary projects. }\end{array}$ & & & & & & \\
\hline $\begin{array}{l}\text { 18. At least some members of our project } \\
\text { group looked for data on what our } \\
\text { targeted customers were doing on } \\
\text { similar or complementary projects. }\end{array}$ & & & & & & \\
\hline
\end{tabular}




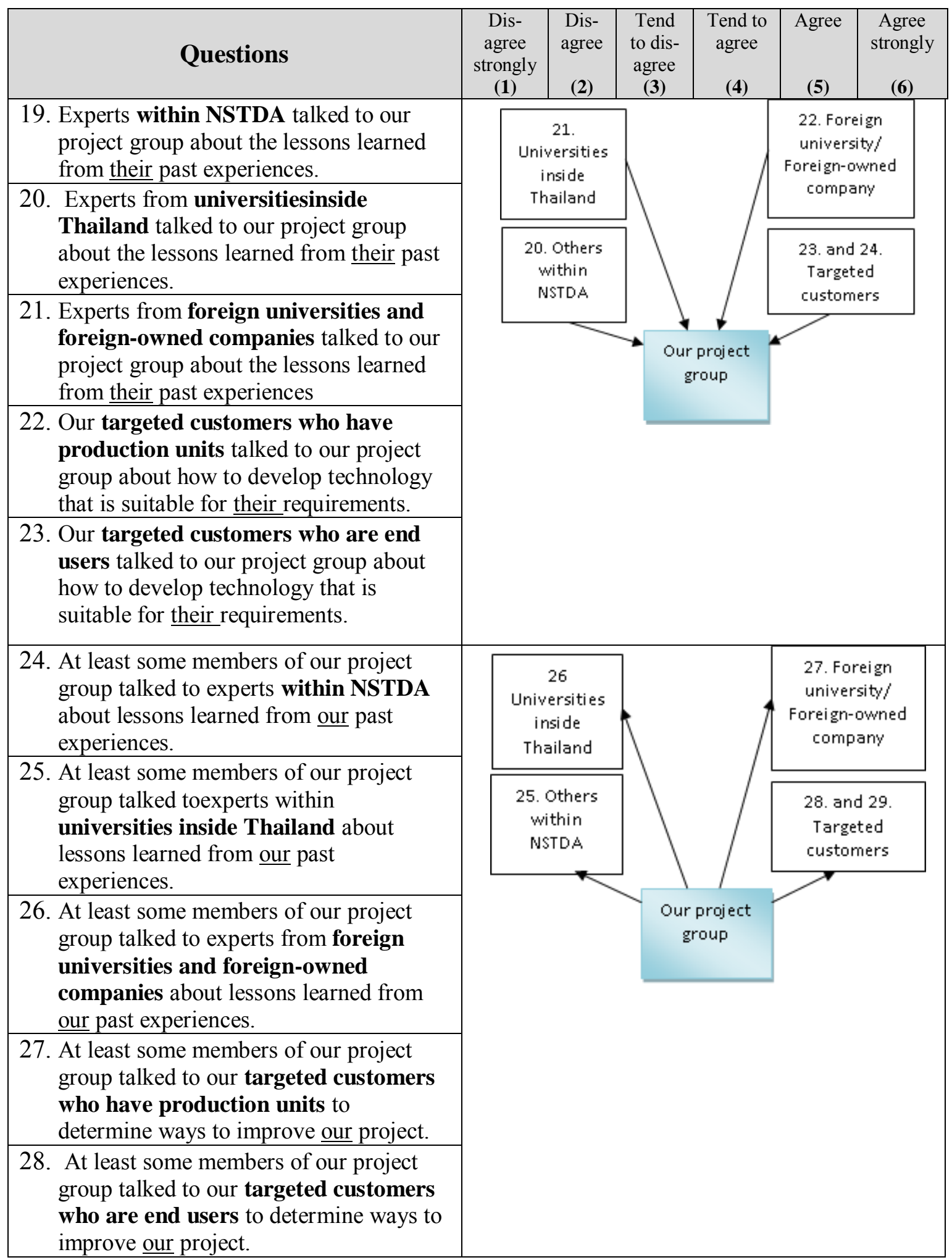




\begin{tabular}{|c|c|c|c|c|c|c|}
\hline Questions & $\begin{array}{c}\text { Dis- } \\
\text { agree } \\
\text { strongly } \\
\text { (1) }\end{array}$ & $\begin{array}{c}\text { Dis- } \\
\text { agree } \\
\text { (2) }\end{array}$ & $\begin{array}{l}\text { Tend } \\
\text { to dis- } \\
\text { agree } \\
\text { (3) }\end{array}$ & $\begin{array}{c}\text { Tend } \\
\text { to } \\
\text { agree } \\
\text { (4) }\end{array}$ & $\begin{array}{l}\text { Agree } \\
\text { (5) }\end{array}$ & $\begin{array}{c}\text { Agree } \\
\text { strongly } \\
\text { (6) }\end{array}$ \\
\hline \multicolumn{7}{|l|}{$\begin{array}{l}\text { 29. Our project group took time to figure out } \\
\text { ways to improve our work process. }\end{array}$} \\
\hline \multicolumn{7}{|l|}{$\begin{array}{l}\text { 30. Our project group took time to monitor our } \\
\text { project's work progress. }\end{array}$} \\
\hline \multicolumn{7}{|l|}{$\begin{array}{l}\text { 31. Individuals within our project group spoke } \\
\text { up to challenge technical assumptions } \\
\text { concerning issues that were under } \\
\text { discussion among members of our project } \\
\text { group. }\end{array}$} \\
\hline \multicolumn{7}{|l|}{$\begin{array}{l}\text { 32. The project group implemented suggestions } \\
\text { made by team members. }\end{array}$} \\
\hline \multicolumn{7}{|l|}{$\begin{array}{l}\text { 33. At least one of our project group members } \\
\text { has had very extensive educational } \\
\text { experience ata foreign university on } \\
\text { subject matter that is relevant to this project. }\end{array}$} \\
\hline \multicolumn{7}{|l|}{$\begin{array}{l}\text { 34. At least one of our project group members } \\
\text { had very extensive educational experience } \\
\text { ata domestic university on subject matter } \\
\text { that is relevant to this project. }\end{array}$} \\
\hline \multicolumn{7}{|l|}{$\begin{array}{l}\text { 35. At least one of our project group members } \\
\text { had very extensive working experience } \\
\text { abroad on subject matter that relevant to } \\
\text { this project. }\end{array}$} \\
\hline \multicolumn{7}{|l|}{$\begin{array}{l}\text { 36. At least one of our project group members } \\
\text { had very extensive working experience } \\
\text { with our targeted customers on subject } \\
\text { matter that is relevant to this project. }\end{array}$} \\
\hline \multicolumn{7}{|l|}{$\begin{array}{l}\text { 37. At least one of our project group members } \\
\text { had very extensive working experience } \\
\text { with other projects within NSTDA on } \\
\text { subject matter that is relevant to this project. }\end{array}$} \\
\hline \multicolumn{7}{|l|}{$\begin{array}{l}\text { 38. Prior to the start of our project, our project } \\
\text { group generated a lot of patents and } \\
\text { publications that are relevant to this project. }\end{array}$} \\
\hline $\begin{array}{l}\text { 39. Based on the results of this project, do you } \\
\text { think that the targeted customers of this } \\
\text { project will have another collaborative } \\
\text { project with your project group in the near } \\
\text { future? }\end{array}$ & & & & & & \\
\hline
\end{tabular}




\section{B.3 General information about the expected results of this project}

\begin{tabular}{|c|c|}
\hline QUESTIONs & ANSWERS \\
\hline $\begin{array}{l}\text { 40. Has any income (in kind or in cash) resulted from this } \\
\text { project? And, is any income expected to result from this project? }\end{array}$ & $\begin{array}{l}\ldots \ldots \ldots \text { Yes/No............. } \\
\ldots \ldots \ldots \text { Yes/No........... }\end{array}$ \\
\hline $\begin{array}{l}\text { 41. Have any publications in peer-reviewed journals resulted } \\
\text { from this project? Have you submitted any manuscripts for } \\
\text { publication in peer-reviewed journals? And, do you expect this } \\
\text { project to yield any publications in peer-reviewed journals? }\end{array}$ & $\begin{array}{l}\ldots \ldots \ldots \text { Yes } / \text { No............ } \\
\ldots \ldots \ldots . \text { Yes/No........... } \\
\ldots \ldots \ldots . \text { Yes/No............ }\end{array}$ \\
\hline $\begin{array}{l}\text { 42. Did any patents result from this project? Have you filed for } \\
\text { any patents that are based on work that was conducted for this } \\
\text { project? And, do you expect this project to yield any patents? }\end{array}$ & $\begin{array}{l}\ldots \ldots \ldots \text { Yes/No........... } \\
\ldots \ldots \ldots . \text { Yes/No.......... } \\
\ldots \ldots \ldots . \text { Yes/No............ }\end{array}$ \\
\hline
\end{tabular}




\section{APPENDIX C: DATA ANALYSIS}

The appendix presents the details of statistical tools that are used in Chapter 5.

\section{C.1 Exploratory Factor Analysis}

Exploratory factor analysis can be used to "analyze the underlying pattern for a number of variables. It determines whether the variables can be condensed or summarized in a smaller set of factors or constructs. The exploratory factor analysis has "three main uses: (1) to understand the structure of the latent variable (2) to construct a questionnaire to measure and underlying variables and (3) to reduce a data set to a more manageable size while retaining as much of the original information as possible" (Field, 2005, p. 619) Also, this study will measure factor loading of each item. Field (2005) states "the factor loading can be thought of as the Pearson correlation between a factor and a variable. ... If we square the factor loading we obtain a measure of the substantive importance of a particular variable to a factor" (Field, 2005, p. 622). Thus, the item or variable will be measured to identify the importance of that specific variable to a latent factor in this study. 


\section{C.2 Correlation Analysis}

\section{C.2.1 Peason's Correlation Coefficient}

To assess the degree of interdependence between variables, this study will consider both statistical significance and the correlation coefficient. Pearson's correlation coefficient is the most common measure of effect size. It is controlled to lie between -1 and 1 (Field, 2005, p. 111). The effect size provides an objective measure between variables. J. Cohen et al., 2003, suggested the value of \pm .10 for small size effect that can explain $1 \%$ of the total variance, \pm .30 for medium effect that the effect can explain $9 \%$ of the total variance, \pm .50 for large effect that accounts for $25 \%$ of total variance, and the value of .00 for no effect (cited by Field, 2005, p. 32).This study will also identify the size of effects on each pair of variables to ensure the importance of the effects before doing more analysis. This correlation matrix will be extremely useful for getting an idea of the relationships between dependent variables and independent variables.

\section{C.2.2 Statistical Significance}

"One-tailed tests should be used when there is a specific direction to the hypothesis being tested, and two-tailed tests should be used when a relationship is expected, but the direction of the relationship is not predicted" (Field, 2005, p. 125). In this study, I use two-tailed tests for analysis of Pearson's correlation coefficient because the direction of external engagement on projects' performance may be presented in both positive and 
negative directions. Also, the cut-off point of less than .05 is the general criterion for statistical significance (Field, 2005).

\section{C.3 Regression Analysis: multiple regression and logistic regression}

To determine the relative impact of the independent variables on the dependent variable, this study use regression analyses of multiple regression and logistic regression. "Multiple regression is an extension of simple regression in which an outcome is predicted by a linear combination of two or more predictor variables.

The form of the model is $\mathbf{Y}_{\mathbf{i}}=\left(\mathbf{b}_{\mathbf{0}}+\mathbf{b}_{1} \mathbf{X}_{1}+\mathbf{b}_{2} \mathbf{X}_{2}+\ldots+\mathbf{b}_{\mathbf{n}} \mathbf{X}_{\mathbf{n}}\right)+\boldsymbol{\varepsilon}_{\mathbf{i}}$ in which the outcome is denoted as $\mathrm{Y}$, and each predictor is denoted as $\mathrm{X}$.

Each predictor has a regression coefficient $b_{i}$ associated with it, and $b_{0}$ is the value of the outcome when all predictors are zero" (Field, 2005, p. 738). From the model, $b_{i}$ can be used to define the relative importance of the predictor on the outcome. It means for every a unit change in $\mathrm{X}_{\mathrm{i}}, \mathrm{Y}_{\mathrm{i}}$ goes up by about $\mathrm{b}_{\mathrm{i}}$. Also, comparing $\mathrm{b}_{\mathrm{i}}$ of the predictors will see the relative impact of the predictors on the outcome.

Logistic regress is "a version of multiple regression in which the outcome is dichotomous" (Field, 2005, p. 736). 


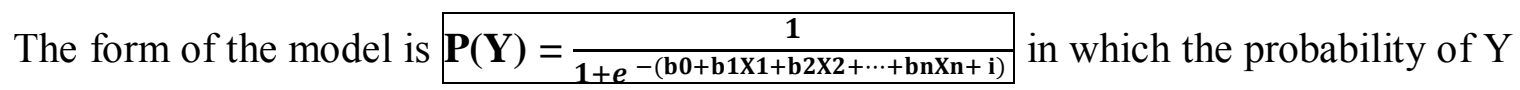
occurring is denoted as $\mathrm{P}(\mathrm{Y}), e$ is the base of natural logarithms, and the other coefficients are the same as in multiple regression (Field, 2005, p. 220).

From the model, to interpret logistic regression we use the value of $\exp b_{i}$ or $\operatorname{Exp}\left(B_{i}\right)$ in the regression table. $\operatorname{Exp}\left(B_{i}\right)$ is an indicator of the change in odds resulting from a unit change in the predictor and is similar to $b_{i}$ in multiple regression. "If the value of $\operatorname{Exp}\left(B_{i}\right)$ greater than 1 then it indicates that as the predictor increase the odds of the outcome occurring increase (Field, 2005, p. 225). For example, if the value of $\operatorname{Exp}\left(B_{i}\right)$ is 54.36 for the impact of engagement with LTUs on the success in technology commercialization, it means the odds of a project succeeded in technology commercialization are 54.36 times greater for a project who had the degree of engagement with LTUs of 5 in Likert scale, than for a project whose the degree of engagement was 4 in Likert scale (adapted from Burns \& Burns, 2008, p. 574).

In the regression analysis, this study also applies backward stepwise method in the model that includes many predictors in the analysis, in particular, the model that includes variables pertaining to interaction variables. The backward method calculates the contribution of each predictor on the outcome by comparing the significance value or the t-test of each predictor against a removal criterion. If a predictor meets the removal criterion or does not improve the prediction power of the model, then it is removed from the analysis. Then the model re-assessed the remaining predictors. Field (2005) also mentioned "the backward method runs lower risk of missing a predictor that predicts the 
outcome than the forward method" (Field, 2005, pp. 160-161) and it works when there are many predictors in the model.

\section{C.3.1 $R^{2}$}

"The correlation coefficient squared or the coefficient of determination $\left(\mathrm{R}^{2}\right)$ is a measure of the amount of variability in one variable that s explained by the other" (Field, 2005, p. 128). If we square a correlation coefficient between a pair of variables, the value of $\mathrm{R}^{2}$ will tells us how much of the variability in one variable can be explained by the other. This study will use $\mathrm{R}^{2}$ to tell us how much the effects of the variability in a dependent variable can be explained by an independent variable.

In logistic regression, Cox \& Snell $\mathrm{R}^{2}$ and Nagelkerke's $\mathrm{R}^{2}$ attempt to imitate the $\mathrm{R}^{2}$ in a multiple regression. However, "based on 'likelihood', the maximum of Cox \& Snell $\mathrm{R}^{2}$ can be (and usually is) less than 1.0 , making it difficult to interpret. Nagelkerke's $\mathrm{R}^{2}$ modification ranges from 0 to 1 is a more reliable measure of the relationship" (Burns \& Burns, 2008, p. 580). The value of Cox \& Snell $R^{2}$ and Nagelkerke's $R^{2}$ can indicate percentage of variation in the dependent variable is explained by the logistic model. Also, normally the Nagelkerke's $\mathrm{R}^{2}$ is higher than the Cox \& Snell $\mathrm{R}^{2}$.

\section{C.3.2 Adjusted $\boldsymbol{R}^{2}$}

The adjusted $\mathrm{R}^{2}$ can be used to assess how well the model is able to predict the outcome in a different sample. Field, 2005 (p. 171) mentions cross-validation is a way to assess the accuracy of a model across different samples. He also mentions "if a model can be 
generalized, then it must be capable of accurately predicting the same outcome variable from the same set of predictors in a different group of people. If the model is applied to a different sample and there is a severe drop in its prediction power, then the model clearly does not generalize." In regression, the value of adjusted $\mathrm{R}^{2}$ should be very close to the value of $R^{2}$. "The value of $R^{2}$ presents how much of the variance in the outcome is accounted for by the regression model from the sample. The value of adjusted $\mathrm{R}^{2}$ presents how much the variance in the outcome would be accounted for if the model is derived from the population from which the sample was taken ... the comparable value indicates that the cross-validity of the model is very good" (Field, 2005, p. 172). In case that "the value of adjusted $R^{2}$ is smaller than the value of $R^{2}$, the reduction shows if the model were derived from the population rather than a sample. It would account for less variance in the outcome at the reduction value" (Field, 2005, p. 188). In addition, the value of $\mathrm{R}^{2}$ typically increases when we add more independent variables in the model. Increasing the

$\mathrm{R}^{2}$ doesn't mean that the model increases the power to predict the outcome. Adjusted $\mathrm{R}^{2}$ is used to compensate for the addition of variables to the model. When there are numbers of independent variables, the value of adjusted $\mathrm{R}^{2}$ should be reported for the explanatory power of the model.

\section{C.3.3 F-Ratio}

The F-ratio is a measure of the ratio of the variation explained by the model and the variation explained by observed data (Field, 2005, p. 150 and 323). That means F-ratio is "a measure of how much the model has improved the prediction of the outcome compared to the level of inaccuracy of the model" (Field, 2005, p. 150). Field, 2005, also 
mentions a good model should have F-ratio greater than 1. It means the improvement in prediction from the model should be large and the difference between the model and the observe data should be small. The increasing of F-ratio can interpret as the model significantly improves the ability to predict the dependent variable (Field, 2005, p. 190). In logistic regression, "chi-square statistic measures the difference between the model as it currently stands and the model when only the constant is included" (Field, 2005, p. 237). Also, if the value of chi-square is significant at lower than .05 level, we can say that overall the model is predicting the outcome significantly better than it was with only the constant included. "The model chi-square is an analogous of the F-test for the linear regression" (Field, 2005, p. 238). Accordingly, chi-square statistic will be used to assess how much better the model predicts the outcome variable in logistic regression.

\section{C.4 Interaction Effects}

Interaction effects represent the combined effects of variables on the criterion or dependent measure (Aiken \& West, 1991). "When an interaction effect is present, the impact of one variable depends on the level of the other variable. Part of the power of multiple regression is the ability to estimate and test interaction effects when the predictor variables are either categorical or continuous” (J. J. Stevens, 2011).

To test whether or not moderating variables including prior experience, prior knowledge, and PILAs impact the relationship between the engagement with external sources of knowledge and project performance, this study will use multiple regression analyses and 
follow the procedure of analysis in the interaction effects by Aiken \& West, 1991; Lichtenthaler, 2006b; Dawson, 2006.

The regression equation that contains the interaction would be written as:

$\mathbf{Y}=\mathbf{b}_{\mathbf{0}}+\mathbf{b}_{\mathbf{1}} \mathbf{X}+\mathbf{b}_{\mathbf{2}} \mathbf{Z}+\mathbf{b}_{\mathbf{3}}(\mathbf{X} * \mathbf{Z})$------- (Aiken \& West, 1991, p. 9)

$\mathrm{Y}=$ Dependent variable (DV)

$\mathrm{X}=$ Independent variable (IV)

$\mathrm{Z}=$ Moderating variable $(\mathrm{MV})$

$\mathrm{b}_{0}=$ Intercept $/$ Constant

$\mathrm{b}_{1}=$ Unstandardised regression coefficient of IV

$\mathrm{b}_{2}=$ Unstandardised regression coefficient of MV

$\mathrm{b}_{3}=$ Unstandardised regression coefficient of interaction

In these following examples, I create a set of invented data in table VII, and then follow the processes of Dawson, 2006, and Aiken \& West, 1991 to present two examples of how to calculate the interaction effect. The processof Dawson, 2006 helps in the generation of data in a spreadsheet as presented in table C.1 and C.3. The process suggested by Aiken \& West, 1991 helps in the presentation of two simple slops, see figure C.1.

Table C.1: An example of input statistical data for equation (adapted from Dawson, 2006)

\begin{tabular}{|c|c|}
\hline \multicolumn{2}{|l|}{ Unstandardised Regression Coefficients: } \\
\hline Independent variable $\left(b_{1}\right)$ & 1.069 \\
\hline Moderator $\left(\mathrm{b}_{2}\right)$ & 0.352 \\
\hline Interaction $\left(b_{3}\right)$ & -0.195 \\
\hline Intercept / Constant $\left(\mathrm{b}_{0}\right)$ & 2.658 \\
\hline \multicolumn{2}{|l|}{ Means / SDs of variables: } \\
\hline Mean of independent variable $\left(\right.$ Mean $\left._{\mathrm{X}}\right)$ & 0 \\
\hline SD of independent variable $\left(S_{X}\right)$ & 1 \\
\hline Mean of moderator $\left(\right.$ Mean $\left._{z}\right)$ & 0 \\
\hline $\mathrm{SD}$ of moderator $\left(\mathrm{S}_{\mathrm{Z}}\right)$ & 1.645 \\
\hline
\end{tabular}


Table C.2: an example of calculation (adapted from Dawson, 2006)

\begin{tabular}{|c|c|c|}
\hline & nt variable & nt variable \\
\hline $\begin{array}{l}\text { Low } \\
\text { moderating } \\
\text { variable }\end{array}$ & $\begin{array}{r}Y_{L L}=b_{0}+b_{1}\left(\text { Mean }_{x}-S_{X}\right)+b_{2}(\text { Mea } \\
\left.S_{Z}\right)+b_{3}\left(\left(\text { Mean }_{X}-S_{X}\right)^{*}\left(\text { Mean }_{Z}-\right.\right. \\
=0\end{array}$ & $\begin{array}{r}\mathrm{Y}_{\mathrm{LH}}=\mathrm{b}_{0}+\mathrm{b}_{1}\left(\text { Mean }_{\mathrm{X}}+\mathrm{S}_{\mathrm{X}}\right)+\mathrm{b}_{2}(\mathrm{Me} \\
\left.\mathrm{S}_{\mathrm{Z}}\right)+\mathrm{b}_{3}\left(\left(\text { Mean }_{\mathrm{X}}+\mathrm{S}_{\mathrm{X}}\right)^{*}\left(\text { Mean }_{\mathrm{Z}}\right.\right.\end{array}$ \\
\hline $\begin{array}{l}\text { High } \\
\text { moderating } \\
\text { variable }\end{array}$ & $\begin{array}{r}\mathrm{Y}_{\mathrm{HL}}=\mathrm{b}_{0}+\mathrm{b}_{1}\left(\text { Mean }_{\mathrm{X}}-\mathrm{S}_{\mathrm{X}}\right)+\mathrm{b}_{2}\left(\text { Mean }_{\mathrm{Z}}+\right. \\
\left.\mathrm{S}_{\mathrm{Z}}\right)+\mathrm{b}_{3}\left(\left(\text { Mean }_{\mathrm{X}}-\mathrm{S}_{\mathrm{X}}\right)^{*}\left(\text { Mean }_{\mathrm{Z}}+\mathrm{S}_{\mathrm{Z}}\right)\right) \\
=2.489 \\
\end{array}$ & $\begin{array}{r}\mathrm{Y}_{\mathrm{HH}_{\mathrm{H}}}=\mathrm{b}_{0}+\mathrm{b}_{1}\left(\text { Mean }_{\mathrm{X}}+\mathrm{S}_{\mathrm{X}}\right)+\mathrm{b}_{2}\left(\text { Mean }_{\mathrm{Z}}+\right. \\
\left.\mathrm{S}_{\mathrm{Z}}\right)+\mathrm{b}_{3}\left(\left(\text { Mean }_{\mathrm{X}}+\mathrm{S}_{\mathrm{X}}\right)^{*}\left(\text { Mean }_{\mathrm{Z}}+\mathrm{S}_{\mathrm{Z}}\right)\right) \\
=3.985\end{array}$ \\
\hline
\end{tabular}

Table C.3: X and Y coordinates (adapted from Dawson, 2006)

\begin{tabular}{|lrr|}
\hline & X & Y \\
\hline Low moderating with low independent variable & -1 & 0.689 \\
Low moderating with high independent variable & 1 & 3.468 \\
High moderating with low independent variable & -1 & 2.489 \\
High moderating with high independent variable & 1 & 3.985 \\
\hline
\end{tabular}

Also, Aiken \& West, 1991 (p. 14) suggested a procedure to interpret the interaction effects by generating simple linear equations and simple slops as follows:

$$
\begin{aligned}
& \text { From } \begin{array}{r}
\mathrm{Y}=\mathrm{b}_{0}+\mathrm{b}_{1} \mathrm{X}+\mathrm{b}_{2} \mathrm{Z}+\mathrm{b}_{3}\left(\mathrm{X}^{*} \mathrm{Z}\right) \\
\mathrm{Y}_{\mathrm{Z}_{-} \text {LOW }}=2.658+1.069 \mathrm{X}+.0352 \mathrm{Z}+\left(-.195\left(\mathrm{X}^{*} \mathrm{Z}\right)\right)
\end{array} \\
& \text { At } \mathrm{Z}=\mathrm{S}_{\mathrm{Z}_{-} \text {LOW }}=0-1.645: \mathbf{Y}_{\mathrm{Z}_{-} \text {LOW }}=\mathbf{1 . 3 8 9 X + \mathbf { 2 . 0 7 9 }} \\
& \mathrm{Y}_{\mathrm{Z}_{-} \text {HIGH }}=2.658+1.069 \mathrm{X}+.0352 \mathrm{Z}+\left(-.195\left(\mathrm{X}^{*} \mathrm{Z}\right)\right) \\
& \text { At } \mathrm{Z}=\mathrm{S}_{\mathrm{Z}_{-} \text {HIGH }}=0+1.645: \mathbf{Y}_{\mathbf{Z}_{-} \text {HIGH }}=\mathbf{. 7 4 8 X}+\mathbf{3 . 2 3 7}
\end{aligned}
$$




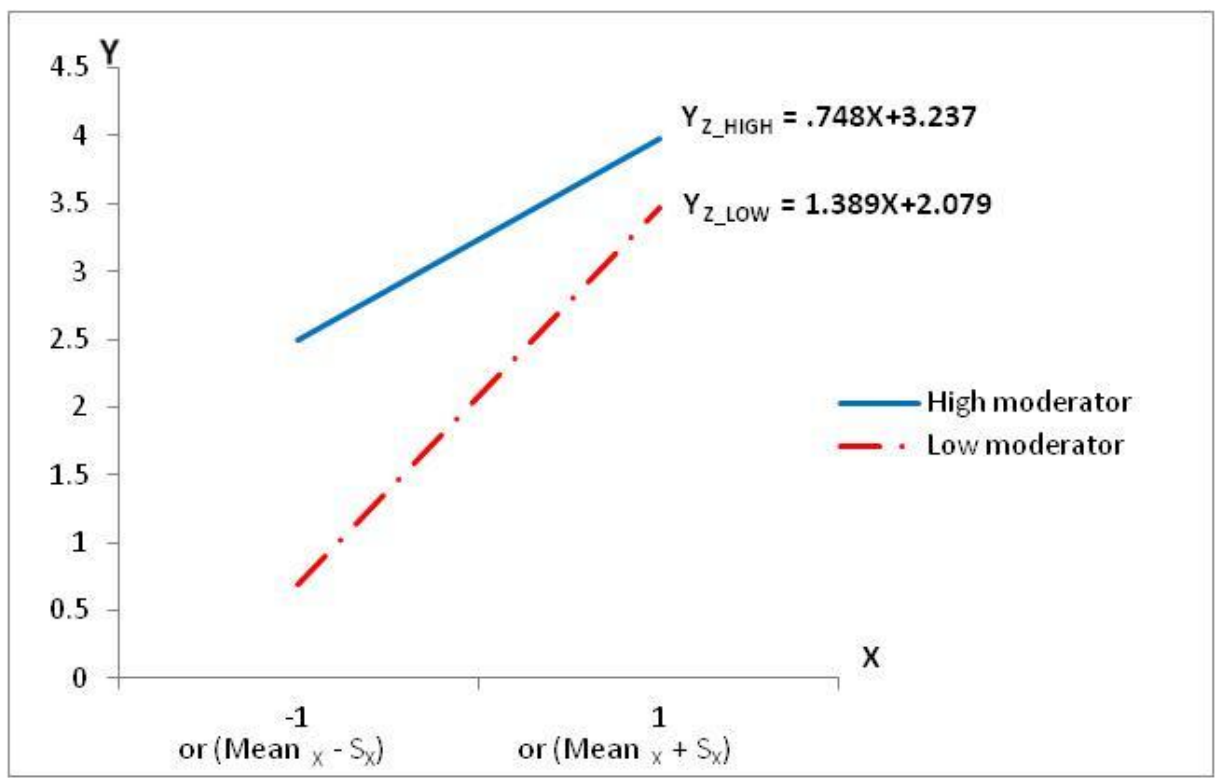

Figure C.1: An example of simple slopes for interaction analysis (adapted from Aiken \& West, 1991)

\section{C.5. Benchmarking Metrics for Regression Models}

\section{C.5.1 Benchmarking Metrics for Multiple-Regression Models}

- $\mathrm{R}^{2}$ is a measure of how much the effects of the variability in a dependent variable can be explained by a set of independent variables (IVs).

- Adjusted $\mathrm{R}^{2}$ is used to compensate $\mathrm{R}^{2}$ when there are numbers of IVs in the model. As adding more IVs, $\mathrm{R}^{2}$ normally increase. If the additional IVs have little correlations to output, adjusted $\mathrm{R}^{2}$ should be reported for the explanatory power of the model 
- F-ratio is a measure of how much the model has improved the prediction of the outcome compared to the level of inaccuracy of the model. If the model significantly improves the ability to predict the outcome, F-ratio should be greater than 1 at significant level lower than .05

\section{C.5.2 Benchmarking Metrics for Logistic Regressions}

- Cox \& Snell $\mathrm{R}^{2}$ is a version of $\mathrm{R}^{2}$ for logistic regression, but the maximum of Cox \& Snell $\mathrm{R}^{2}$ usually is less than 1.0. This makes it difficult to interpret.

- Nagelkerke's $R^{2}$ is also a version of $R^{2}$ for logistic regression. The value of Nagelkerke's $\mathrm{R}^{2}$ ranges from 0 to 1 and is more reliable than Cox \& Snell $\mathrm{R}^{2}$. The value of Nagelkerke's $R^{2}$ can indicate percentage of variation in the outcome explained by the logistic model.

- Chi-square is a version of F-ratio for logistic regression. Chi-square presents the improvement in prediction of the outcome between the model as it currently stands and the model when only the constant is included.

- \% correct is a measure of how much the model can correctly classify cases. 


\section{APPENDIX D: VERSATILITY OF TECHNOLOGY}

The figure below presents a process for transformation of scale from objective data into an ordinal scale ${ }^{31}$. Multiple choices of industry applications for versatility of technology (OV3.3) are described in appendix B. The number of strategic programs in which the output of the project can be applied is translated into an ordinal scale that consists of the following six classes: 1 means the output could not be applied in any strategic program; 2 means the output could be applied in one strategic program; 3 means the output could be applied in two strategic programs, 4 means the output could be applied in three strategic programs, 5 means the output could be applied in 4 strategic programs, and 6 means the output could be applied in more than four strategic programs.

\begin{tabular}{|c|c|c|}
\hline Valid & Frequency & $\%$ \\
\hline 0 & 7 & 3.4 \\
\hline 1 & 54 & 26 \\
\hline 2 & 76 & 36.5 \\
\hline 3 & 41 & 19.7 \\
\hline 4 & 13 & 6.3 \\
\hline 5 & 9 & 4.3 \\
\hline 6 & 3 & 1.4 \\
\hline 7 & 1 & 0.5 \\
\hline 9 & 2 & 1 \\
\hline 10 & 1 & 0.5 \\
\hline 14 & 1 & 0.5 \\
\hline Total & 208 & 100 \\
\hline \multicolumn{3}{|c}{} \\
Mean = 2.37 \\
Min=0, Max = 14 \\
SD. = 1.712 \\
N=208 \\
\hline
\end{tabular}

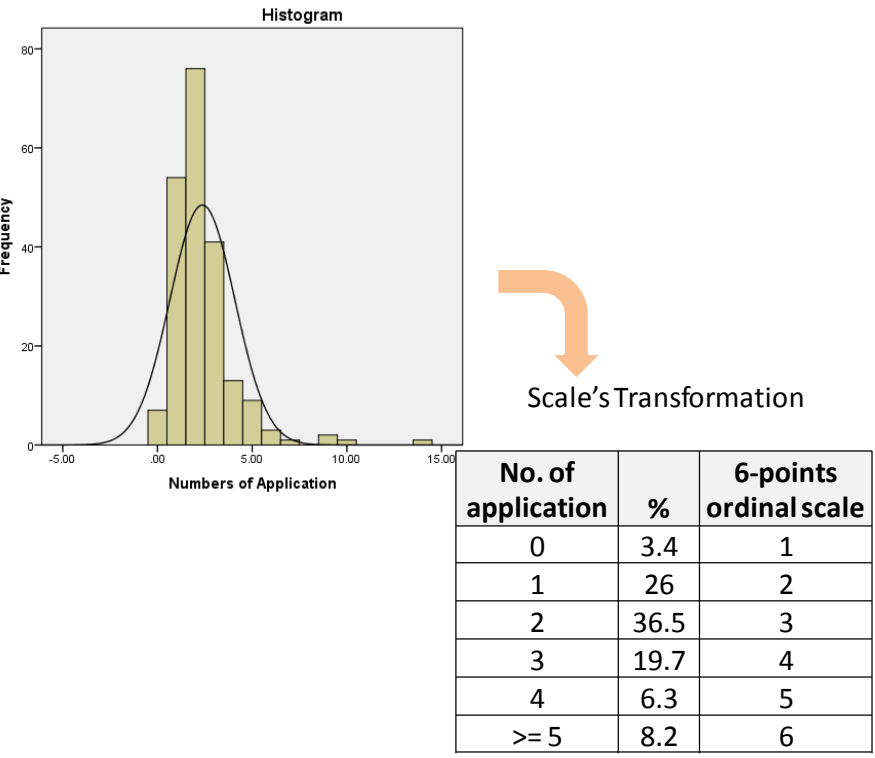

(Suskie, 1996)

\footnotetext{
${ }^{31}$ In the ordinal scale, the difference between point 1 and 2 is not necessarily the same as the distance between point 3 and 4, but the values need to be totally ordered (Suskie, 1996).
} 


\section{APPENDIX E: CORRELATION MATRIX}

\section{Mission 1: User Satisfaction [OV1]}

Mission 2: Probability of Commercialization of Technology [OV2]

Mission 3.1: Probability of Generating Publication [OV3.1]

Mission 3.2: Probability of Generating a Patent [OV3.2]

Mission 3.3: Versatility of Technololgy [OV3.3]

Contextual learning with other R\&D units 1 [IV1_ORDU_CLA1]

Contextual learning with local universities 1 [IV2_LocUniv_CLA1]

Contextual learning with inter sources 1 [IV3_InatSrc_CLA1]

Contextual learning with technology users 1 [IV4_LTUs_CLA1]

Contextual learning with other R\&D units 2 [IV5 ORDU CLA2]

Contextual learning with local universities 2 [IV6_LocUniv_CLA2]

Contextual learning with inter sources 2 [IV7_InatSrc_CLA2]

Contextual learning with technology users 2 [IV8_LTUS_CLA2]

Vicarious learning with other R\&D units 1 [IV9_ORDU_VLA1]

Vicarious learning with local universities 1 [IV10_LocUniv_VLA1]

Vicarious learning with inter sources 1 [IV11_InatSrc VLA1]

Vicarious learning with production units 1 [IV12_LTUSPU_VLA1]

Vicarious learning within end users 1 [IV13_LTUSEU_VLA1]

Vicarious learning with other R\&D units 2 [IV14_ORDU_VLA2]

Vicarious learning with local universities 2 [IV15_LocUniv_VLA2]

learning with production units 2 [IV17_LTUSPU_VLA2]

Vican lous learning within end users 2 [IV18_LTUSEU_VLA2]

Prior knowledge in core technology [MV1_PreKn_Core]

Prior knowledge in journal publications [MV2_P
Prior knowledge in patents [MV4_PreKn_Pat]

\section{Project internal learning activities 1 [MV5_PILA1]}

Project internal learning activities 2 [MV6_PILA2]

Project internal learning activities 3 [MV7_PILA3]

Project internal learning activities 4 [MV8_PILA4]

Prior experience in education from international sources of knowledge [MV9_PrExp_Ed_InatSrc] Prior experience in education from local sources of knowledge [MV10_PrExp_Ed_LocUniv]

Prior experience in working from international sources of knowledge [MV11_PrExp_Wk_InatSrc]

Prior experience in working with local technology users [MV12 PrExp_Wk_LTUs]

Prior experience in working with other R\&D units [MV13_PrExp_Wk ORDU]

Prior knowledge level of project group [MV14_PreKn_Lev]

*. Correlation is significant at the 0.05 level (2-tailed).

\begin{tabular}{|c|c|c|c|c|c|c|c|c|c|c|c|c|c|c|c|c|}
\hline OV1 & OV2 & OV3.1 & OV3.2 & OV3.3 & IV1 & \begin{tabular}{|l|l|} 
IV2 \\
\end{tabular} & IV3 & IV4 & IV5 & IV6 & IV7 & \begin{tabular}{|l|l} 
IV8 \\
\end{tabular} & IV9 & \begin{tabular}{|l|l|} 
IVV10 \\
\end{tabular} & \begin{tabular}{|l|l} 
IV11 \\
\end{tabular} & \begin{tabular}{|l|l|} 
IV12 \\
\end{tabular} \\
\hline 1 & & & & & & & & & & & & & & & & \\
\hline $.580^{\circ}$ & 1 & & & & & & & & & & & & & & & \\
\hline$-.206^{*}$ & $-389^{\circ}$ & 1 & & & & & & & & & & & & & & \\
\hline-.077 & -.162 & .167 & 1 & & & & & & & & & & & & & \\
\hline-.061 & -.123 & $.224^{\prime \prime}$ & .050 & 1 & & & & & & & & & & & & \\
\hline-.100 & -.006 & .098 & .034 & .119 & 1 & & & & & & & & & & & \\
\hline .125 & .104 & .042 & -.014 & -082 & $209^{\circ}$ & 1 & & & & & & & & & & \\
\hline-.031 & -.141 & $286^{\circ}$ & .081 & $.139^{\circ}$ & -.048 & .126 & 1 & & & & & & & & & \\
\hline $.428^{*}$ & $.257^{\circ}$ & -.114 & .065 & -.071 & -.035 & .065 & .105 & 1 & & & & & & & & \\
\hline-.070 & -.098 & $.144^{\circ}$ & .082 & $.214^{\prime \prime}$ & $.614^{\circ}$ & $.238^{\prime \prime}$ & $.149^{\circ}$ & -.112 & 1 & & & & & & & \\
\hline .085 & .002 & $217^{\circ}$ & .090 & .064 & .143 & $.568^{*}$ & 132 & .080 & $.324^{\circ}$ & 1 & & & & & & \\
\hline-.037 & -.067 & $.371^{\prime \prime}$ & .035 & "193" & .035 & .094 & $690^{\prime \prime}$ & .065 & .142 & $.204^{\prime \prime}$ & 1 & & & & & \\
\hline $.465^{\prime \prime}$ & $.319^{\circ}$ & -.134 & .069 & -.084 & -.083 & .029 & .130 & $.625^{*}$ & .003 & .131 & $.194^{\circ}$ & 1 & & & & \\
\hline-.061 & -.152 & $.247^{\circ}$ & .087 & .118 & $.417^{\circ}$ & .072 & $.149^{\circ}$ & .091 & $.452^{\circ}$ & $.159^{\circ}$ & $.224^{\circ}$ & $.170^{\circ}$ & 1 & & & \\
\hline-.006 & .054 & . $181^{\prime \prime}$ & .012 & .066 & .124 & $.343^{*}$ & -.028 & .057 & $.233^{\circ}$ & .476 & .035 & .062 & $.233^{\prime \prime}$ & 1 & & \\
\hline$-.233^{*}$ & -202 & .289" & -.132 & $.238^{\prime \prime}$ & .092 & .069 & . $187^{\prime \prime}$ & $-.184 "$ & .060 & .116 & .272 & -.120 & .036 & .152 & 1 & \\
\hline $.582^{*}$ & $.626^{\circ}$ & -.215 & -.038 & -.085 & .003 & .014 & $-.146^{\circ}$ & $.319^{\prime \prime}$ & -.045 & .048 & -.003 & $.449^{\circ}$ & .028 & $.140^{\circ}$ & -129 & r \\
\hline $.492^{\prime \prime}$ & $.406^{\circ}$ & -.292 & .031 & .002 & -.019 & .115 & -198 & $.202^{\prime \prime}$ & .024 & .157 & -184 & $.244^{\prime \prime}$ & -.114 & .064 & $-239^{*}$ & $.444^{\circ}$ \\
\hline-.113 & $-.187^{\circ}$ & $.214^{\prime \prime}$ & $.180^{\circ}$ & $.216^{\prime \prime}$ & $.378^{\circ}$ & .077 & $.174^{\circ}$ & -.018 & $.476^{\circ}$ & $.201^{\prime \prime}$ & $.213^{\circ}$ & .086 & $.765^{\prime \prime}$ & $.249^{\prime \prime}$ & \begin{tabular}{|l|l|}
-.014 \\
\end{tabular} & -.025 \\
\hline-.004 & -.021 & $244^{\circ}$ & .085 & .108 & $.193^{\circ}$ & $.351^{\prime \prime}$ & .098 & .054 & $.255^{\circ}$ & $.407^{*}$ & .079 & -.006 & $.183^{\prime \prime}$ & .804 & $.144^{\circ}$ & .088 \\
\hline$-.150^{\circ}$ & -.157 & $281^{\prime \prime}$ & -.058 & $.169^{\circ}$ & .103 & .044 & $.241^{\prime \prime}$ & -.184 & .066 & .100 & $.248^{\circ}$ & -.137 & .010 & .123 & $.756 "$ & -.132 \\
\hline $.620^{\circ}$ & $.658^{\circ}$ & $-238^{\prime \prime}$ & -.038 & -.071 & -.053 & -.014 & $-.166^{\circ}$ & $.329^{\prime \prime}$ & -.103 & .007 & -.039 & $.465^{\circ}$ & -.085 & .042 & $-.210^{*}$ & $.898^{*}$ \\
\hline $.524^{* \prime}$ & $.465^{\circ}$ & $-.329^{\prime}$ & -.042 & -.011 & -.083 & .036 & $-235 "$ & $.241^{*}$ & -.055 & .085 & $-251^{\circ}$ & $.255^{\circ}$ & $-.224 "$ & -0.065 & $-.310^{*}$ & $.389^{*}$ \\
\hline $.276^{*}$ & $.219^{\circ}$ & .129 & .081 & .099 & .061 & .070 & .065 & .055 & -.031 & .152 & .160 & .070 & $.152^{\circ}$ & .026 & $-.153^{\circ}$ & $.274^{*}$ \\
\hline-.097 & -.108 & $.418^{\circ}$ & -.096 & $.160^{\circ}$ & .052 & -.050 & $.257^{\prime \prime}$ & $\mid-157^{*}$ & .049 & .094 & .321 & -.065 & .081 & .023 & $.185^{\prime \prime}$ & .016 \\
\hline-.067 & .043 & -.016 & .116 & .084 & .071 & .087 & .001 & .064 & .088 & .167 & .044 & .085 & .018 & .079 & .010 & .070 \\
\hline .081 & -.028 & .087 & .046 & .088 & -.015 & .008 & .112 & $.197^{*}$ & .030 & .131 & .148 & .171 & $.179^{\prime \prime}$ & .133 & $.242^{*}$ & .089 \\
\hline .136 & .134 & .055 & .017 & .023 & .007 & -.026 & .083 & $.244^{*}$ & -.082 & .043 & .142 & .204 & $.148^{\circ}$ & .079 & $.211^{*}$ & $.238^{*}$ \\
\hline $.152^{\circ}$ & .096 & .031 & .034 & $.137^{\circ}$ & -.003 & .032 & $.137^{\circ}$ & $.249^{*}$ & -.013 & .066 & .086 & .165 & $.146^{\circ}$ & .134 & .192" & .236 \\
\hline .123 & .035 & .085 & -.020 & $.224 "$ & -.039 & .049 & $203 "$ & $.185^{*}$ & -.001 & .068 & $.210^{\circ}$ & .177 & .104 & .018 & $.243^{*}$ & .159 \\
\hline-.094 & -.115 & $204^{\circ}$ & .061 & .122 & -.004 & -.094 & $266 "$ & -.030 & -.025 & .014 & $.273^{\circ}$ & -.039 & .086 & \begin{tabular}{|l|}
-.006 \\
\end{tabular} & $.274^{*}$ & -.026 \\
\hline $.238^{\prime \prime}$ & .145 & -.018 & .093 & -.018 & -.007 & .123 & .033 & $.279^{*}$ & -.007 & .070 & -.015 & $.267^{\circ}$ & .028 & $.269^{\prime \prime}$ & -.054 & $.249^{*}$ \\
\hline-.019 & .048 & $.193^{\circ}$ & -.120 & $.242^{\prime \prime}$ & - -119 & -.124 & $.151^{\circ}$ & -.065 & -.160 & -.010 & $.277^{\circ}$ & -.081 & $-.159^{\circ}$ & .098 & $.484^{*}$ & .047 \\
\hline $.481^{*}$ & $.481^{\circ}$ & \begin{tabular}{|l|}
-.173 \\
\end{tabular} & -.133 & .013 & -.087 & -.003 & -.043 & $.318^{* \prime}$ & $-.223^{\circ}$ & -.059 & .048 & $.307^{\circ}$ & -.119 & .005 & -.122 & $.441^{\circ}$ \\
\hline .055 & .150 & -.037 & .057 & -.004 & $.451^{\circ}$ & \begin{tabular}{|l}
.133 \\
\end{tabular} & .041 & .097 & $.338^{\circ}$ & .025 & .030 & .155 & $.366^{\prime \prime}$ & .062 & -.066 & .070 \\
\hline .000 & -.047 & $249^{\prime \prime}$ & -.093 & .085 & .146 & .002 & $246^{\prime \prime}$ & -.081 & .124 & .134 & $.311^{\circ}$ & .012 & $.149^{\circ}$ & .057 & $.156^{\circ}$ & $.138^{\circ}$ \\
\hline
\end{tabular}


Appendix E: Correlation Matrix (cont.)

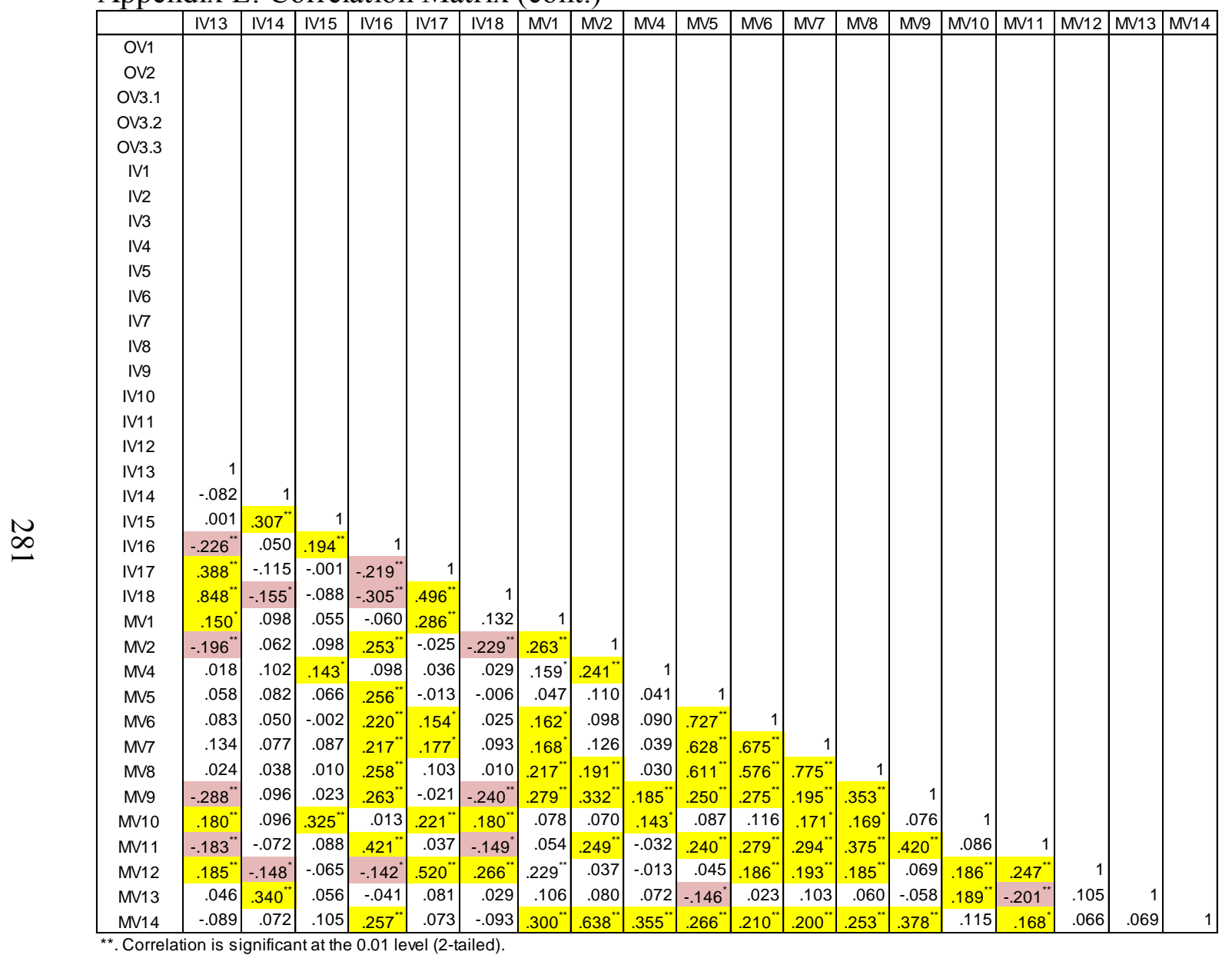

Correlation is significant at the 0.05 level (2-tailed). 


\section{APPENDIX F: FACTOR ANALYSIS}

\begin{tabular}{|c|c|c|c|c|c|c|c|c|c|c|c|c|c|c|c|c|c|}
\hline $\begin{array}{r}\text { Factors } \\
\text { Cronbach's Alpha }\end{array}$ & $\begin{array}{c}\text { FMV1 } \\
0.887\end{array}$ & $\begin{array}{l}\text { FIV1 } \\
0.946\end{array}$ & $\begin{array}{l}\text { FIV2 } \\
0.859\end{array}$ & $\begin{array}{l}\text { FIV3 } \\
0.891\end{array}$ & $\begin{array}{l}\text { FIV4 } \\
0.916\end{array}$ & $\begin{array}{l}\text { FIV5 } \\
0.867\end{array}$ & $\begin{array}{l}\text { FIV6 } \\
0.816\end{array}$ & \begin{tabular}{|c|} 
FMV2 \\
0.773
\end{tabular} & $\begin{array}{l}\text { FIV7 } \\
0.769\end{array}$ & $\begin{array}{c}\text { FIV8 } \\
0.76\end{array}$ & $\begin{array}{l}\text { FIV9 } \\
0.723\end{array}$ & FMV3 & FMV4 & FMV5 & FMV6 & FMV7 & FMV8 \\
\hline Descriptive statistics: Min & -2.442 & -2.129 & -1.680 & -1.826 & -2.073 & -1.736 & -3.210 & -1.639 & -2.762 & -2.330 & -2.032 & -2.096 & -2.133 & -2.767 & -3.720 & -2.793 & -2.969 \\
\hline Descriptive statistics: Max & 2.341 & 2.386 & 2.928 & 3.046 & 2.488 & 3.260 & 2.175 & 2.393 & 2.569 & 3.947 & 3.939 & 2.247 & 2.502 & 1.697 & 1.990 & 1.686 & 3.082 \\
\hline
\end{tabular}

\section{Variables:}

MV7_PILA3

MV8_PILA4

MV5 PILA1

MV6 PILA2

IV12_LTUsPU_VLA1

IV17_LTUsPU_VLA2

IV16 InatSrc VLA2

IV11 InatSrc VLA1

IV10_LocUniv_VLA1

IV15_LocUniv_VLA2

IV13 LTUsEU VLA1

IV18 LTUsEU VLA2

IV14_ORDU_VLA2

IV9 ORDU VLA1

IV3 InatSrc CLA1

IV7_InatSrc_CLA2

MV2_PrKn_Jr

MV14 PrKn Lev

IV4 LTUs CLA1

IV8_LTUs_CLA2

IV1_ORDU_CLA1

IV5 ORDU CLA2

IV2 LocUniv CLA1

IV6_LocUniv_CLA2

MV12_PrExp_Wk_LTUs

MV13 PrExp Wk ORDU

MV1 PrKn Core

MV10_PrExp_Ed_LocUniv

MV9_PrExp_Ed InatSrc

MV11_PrExp_Wk_InatSrc

$\%$ of Total Variance

\begin{tabular}{l|l|l}
.899 & \\
.847 & \\
.805 & \\
.793 & \\
& \\
.909 \\
.892 \\
\\
\end{tabular}

Cumulative $\%$ of Variance

\begin{tabular}{l|l}
10.383 & 17.38 \\
\hline
\end{tabular}

6.678

Extraction Method: Principal Component Analysis.

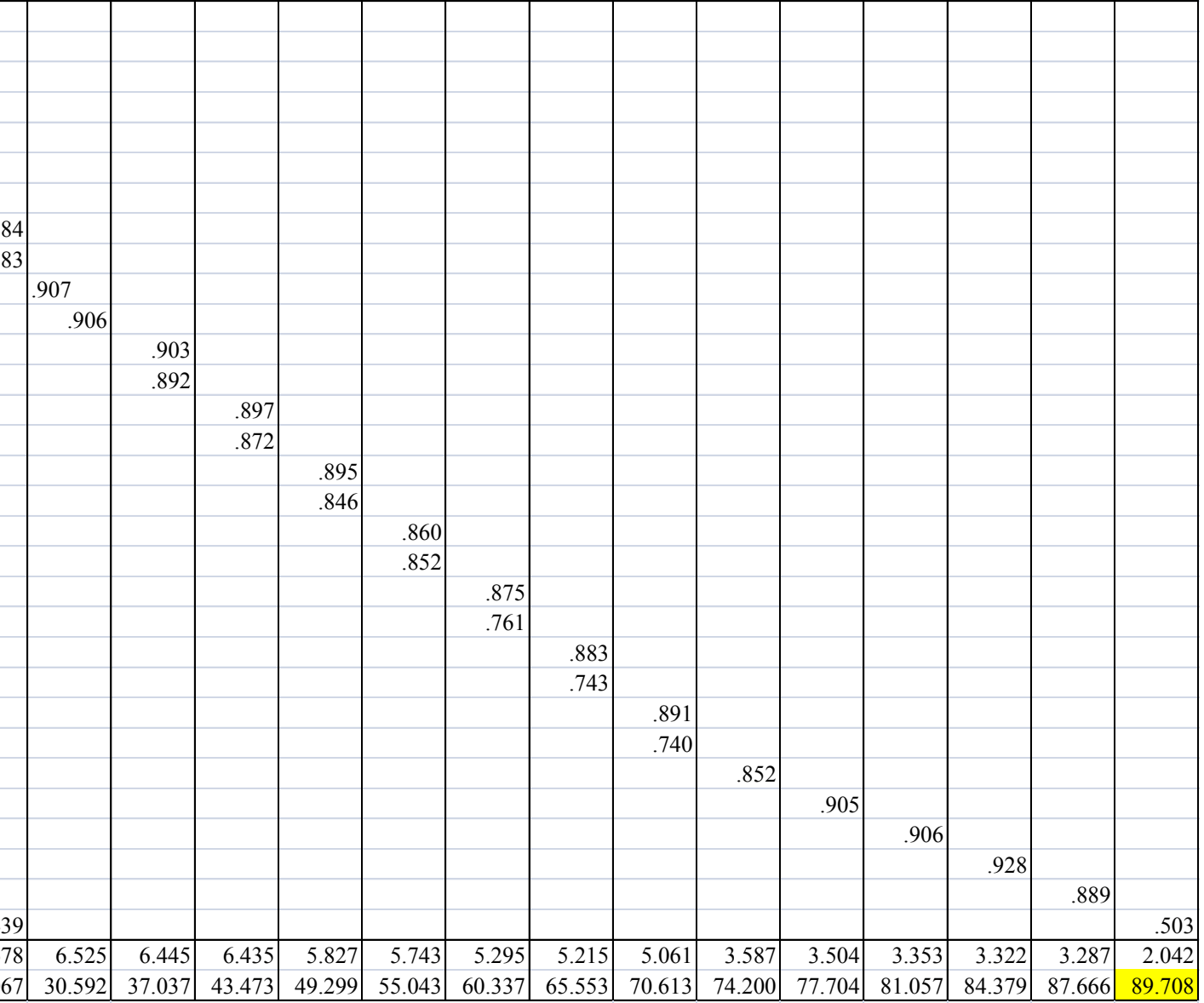

Rotation Method: Varimax with Kaiser Normalization. 


\section{APPENDIX G: REGRESSION ANALYSIS}

\section{G.1 Regression Analysis for Mission-1: User Satisfaction}

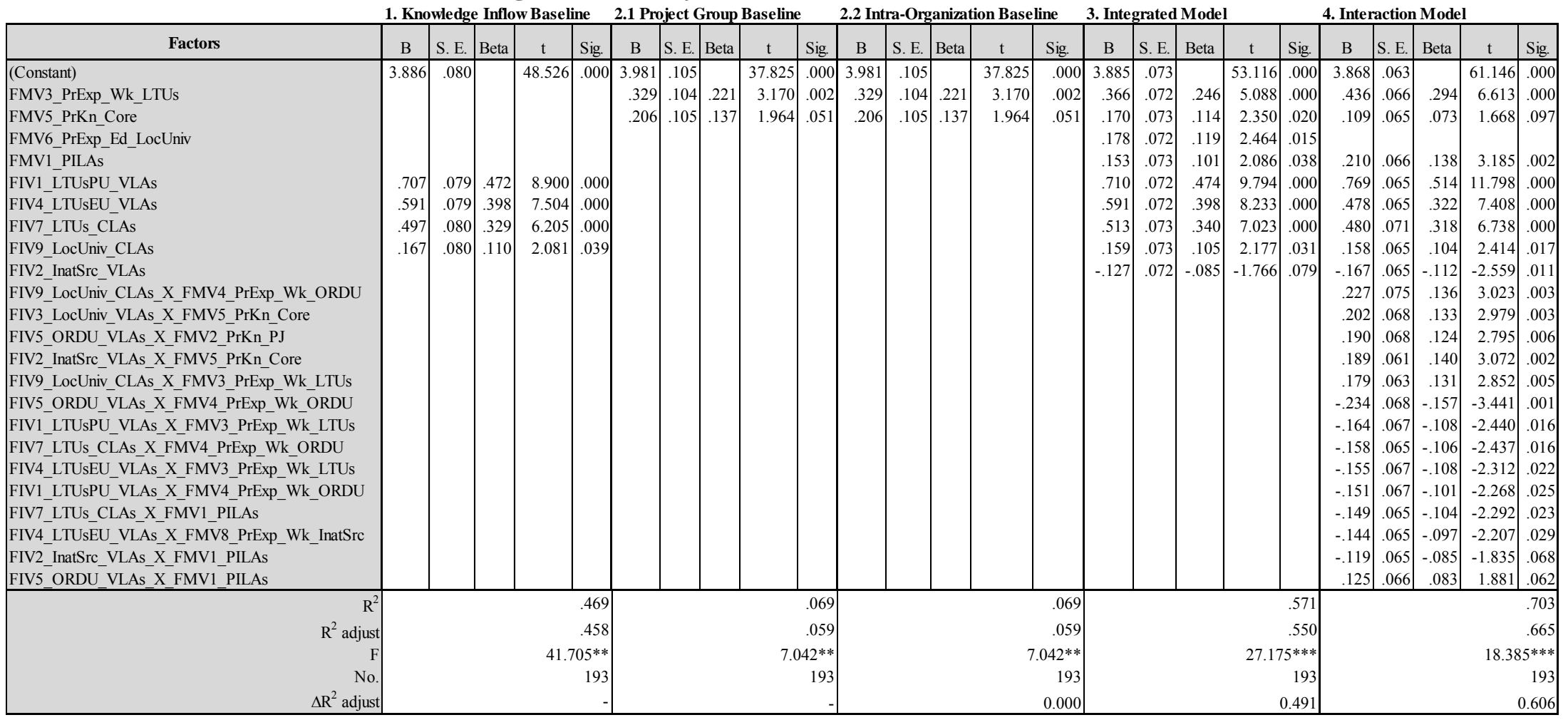

\section{Note:}

1) The lower sample size of 193 samples results from respondents not being able to answer the question pertaining to mission 1 (OV1) in the survey.

2) In model 4, the three factors excluded before regression include a) FIV8_ORDU_CLAs and its interactions, b) FMV6_PrExp_Ed_LocUniv and its interactions, and c) FMV7 PrExp Ed InatSrc and its interactions, because they tend to have less power to predict output variables in all models.

3) Some variables with $p>.05$ are included in the regression because they still improve the prediction power of the model or do not meet the removal criterion of stepwise backward, see appendix C.3. 


\section{G.2 Regression Analysis for Mission 2: Probability of Commercialization of Technology}

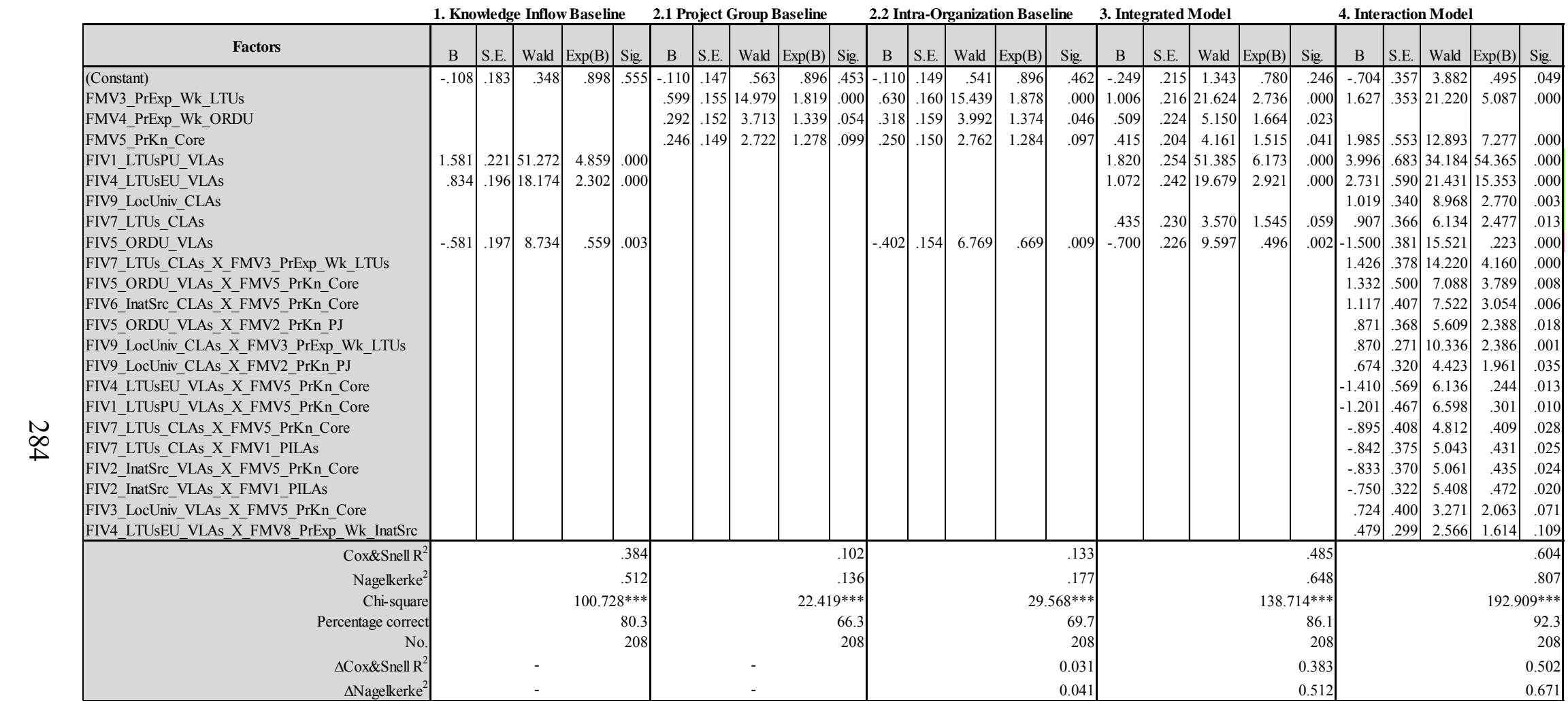

Note:

1) In model 4, the three factors excluded before regression include a) FIV8_ORDU_CLAs and its interactions, b) FMV6_PrExp_Ed_LocUniv and its interactions, and c) FMV7 PrExp Ed InatSrc and its interactions, because they tend to have less power to predict output variables in all models.

2) Some variables with $p>. \overline{0} 5$ are included in the regression because they still improve the prediction power of the model or do not meet the removal criterion of stepwise backward, see appendix C.3. 


\section{G.3 Regression Analysis for Mission-3--Criterion-1: Probability of Generating a Publication}

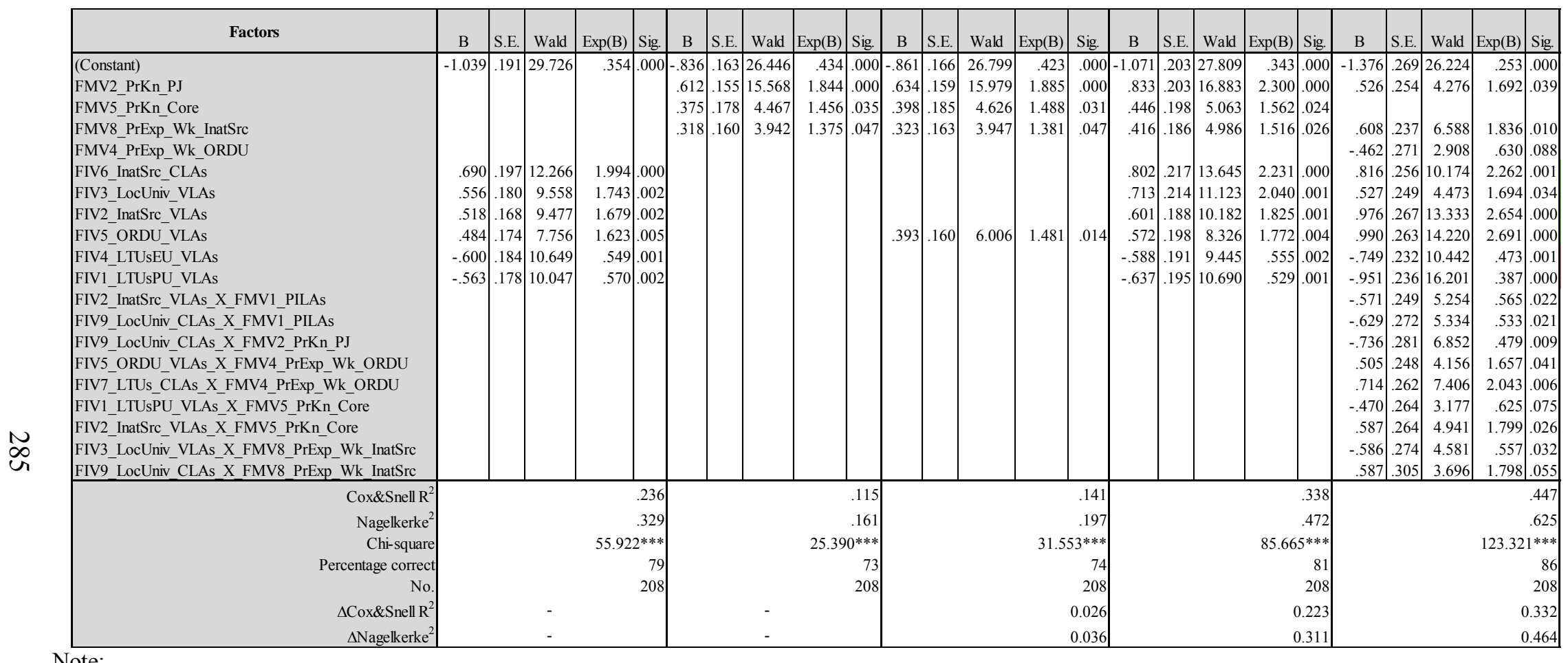

Note:

1) In model 4, the three factors excluded before regression include a) FIV8_ORDU_CLAs and its interactions, b) FMV6_PrExp_Ed_LocUniv and its interactions, and c) FMV7 PrExp Ed InatSrc and its interactions, because they tend to have less power to predict output variables in all models.

2) Some variables with $\mathrm{p}>. \overline{0} 5$ are included in the regression because they still improve the prediction power of the model or do not meet the removal criterion of stepwise backward, see appendix C.3. 


\section{G.4 Regression Analysis for Mission-3--Criterion-2: Probability of Generating a Patent}

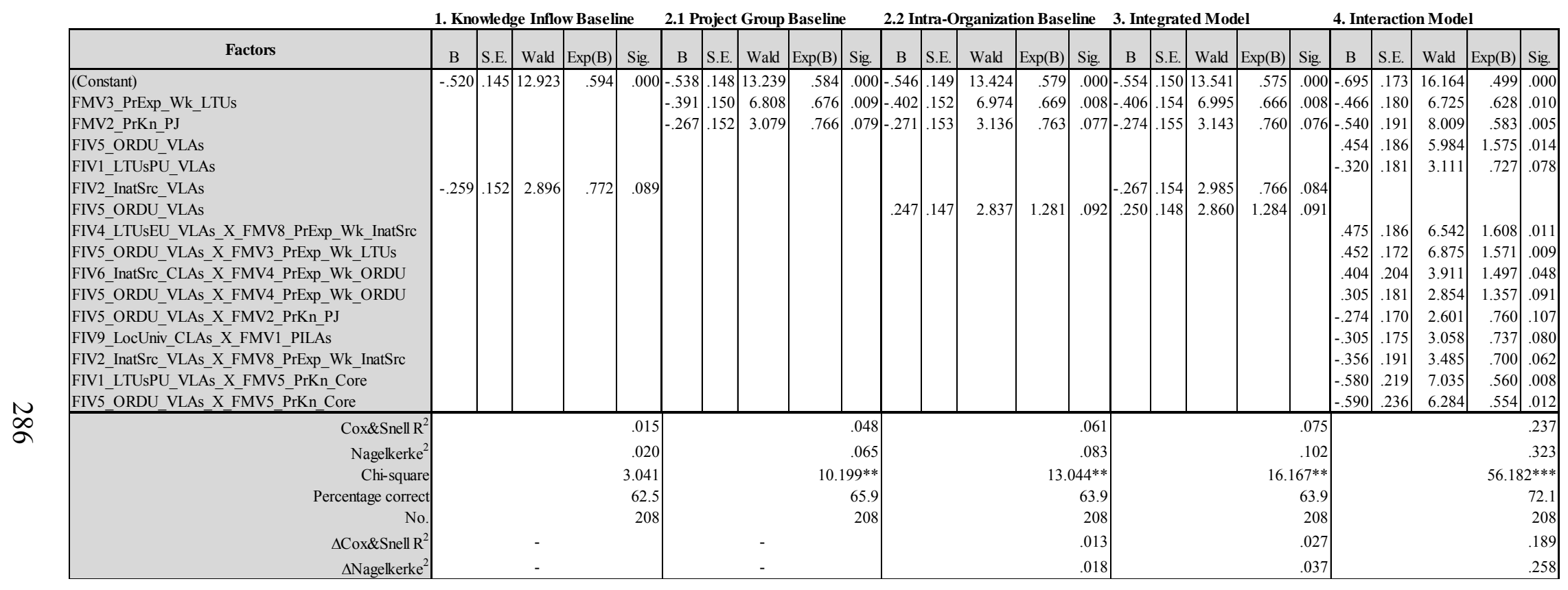

Note:

1) In model 4, the three factors excluded before regression include a) FIV8_ORDU_CLAs and its interactions, b) FMV6_PrExp_Ed_LocUniv and its interactions, and c) FMV7_PrExp_Ed_InatSrc and its interactions, because they tend to have less power to predict output variables in all models.

2) Some variables with $p>.05$ are included in the regression because they still improve the prediction power of the model or do not meet the removal criterion of stepwise backward, see appendix C.3.

3) There are many variables with $p>.05$ in the regression. Also, in model 1 , the Chi-Square is not significant at the level of $p<0.05$. This observation suggests that generating a patent is not a strong function of knowledge inflows and is excluded from further analysis, see section 5.3.1. 


\section{G.5 Regression Analysis for Mission-3--Criterion-3: Versatility of Technology}

\begin{tabular}{|c|c|c|c|c|c|c|c|c|c|c|c|c|c|c|c|c|c|c|c|c|c|c|c|c|c|}
\hline \multirow[b]{2}{*}{ Factors } & \multicolumn{10}{|c|}{ 1. Knowledge Inflow Baseline 2.1 Project Group Baseline } & \multicolumn{5}{|c|}{ 2.2 Intra-Org. Baseline } & \multicolumn{5}{|c|}{ 3. Integrated Model } & \multicolumn{5}{|c|}{ 4. Interaction Model } \\
\hline & $\mathrm{B}$ & S. E. & Beta & $\mathrm{t}$ & Sig. & $\mathrm{B}$ & S. E. & Beta & $\mathrm{t}$ & Sig. & $\mathrm{B}$ & S. E. & Beta & $\mathrm{t}$ & Sig. & $\mathrm{B}$ & S. E. & Beta & $\mathrm{t}$ & Sig. & $\mathrm{B}$ & S. E. & Beta & $\mathrm{t}$ & Sig. \\
\hline (Constant) & 3.240 & .082 & & 39.295 & .000 & 3.240 & \begin{tabular}{|c|}
.084 \\
\end{tabular} & & 38.774 & .000 & 3.240 & .082 & & 39.533 & .000 & 3.240 & .080 & & 40.400 & .000 & 3.240 & $\mid .074$ & & 43.674 & 4.000 \\
\hline FMV8_PrExp_Wk_InatSrc & & & & & & .262 & .084 & .212 & 3.122 & .002 & .262 & .082 & .212 & 3.183 & .002 & .262 & .080 & .212 & 3.253 & .001 & .335 & .077 & .271 & 4.354 & 4.000 \\
\hline FMV1_PILAs & & & & & & .139 & .084 & .113 & 1.662 & .098 & .139 & .082 & .113 & 1.695 & .092 & .139 & .080 & .113 & 1.732 & .085 & .219 & .079 & .178 & 2.782 & 2.006 \\
\hline FMV4_PrExp_Wk_ORDU & & & & & & & & & & & & & & & & & & & & & -.168 & .079 & $\mid-.136$ & $5-2.124$ & 4.035 \\
\hline FIV2_InatSrc_VLAs & .208 & .083 & 168 & 2.515 & .013 & & & & & & & & & & & .208 & .080 & .168 & 2.586 & .010 & .215 & $\mid .076$ & .174 & 2.820 & 0.005 \\
\hline FIV5_ORDU_VLAs & .185 & .083 & .150 & 2.235 & .027 & & & & & & .185 & .082 & .150 & 2.249 & .026 & .185 & .080 & .150 & 2.298 & .023 & .154 & $\mid .076$ & .125 & 2.024 & 4.044 \\
\hline FIV8_ORDU_CLAs & .185 & .083 & .149 & 2.233 & .027 & & & & & & .184 & .082 & .149 & 2.246 & .026 & .184 & .080 & .149 & 2.295 & .023 & & & & & \\
\hline FIV6_InatSrc_CLAs & .167 & .083 & .135 & 2.022 & .044 & & & & & & & & & & & .167 & .080 & .135 & 2.079 & .039 & .155 & .077 & .125 & 2.019 & 9.045 \\
\hline FIV3_LocUniv_VLAs & & & & & & & & & & & & & & & & & & & & & .145 & .078 & .117 & 1.865 & 5.064 \\
\hline FIV1_LTUsPU_VLAs & & & & & & & & & & & & & & & & & & & & & -.178 & .078 & $|-.144|$ & -2.284 & 4.023 \\
\hline FIV4_LTUsEU_VLAs_X_FMV1_PILAs & & & & & & & & & & & & & & & & & & & & & .200 & .080 & .162 & 2.503 & 3.013 \\
\hline FIV7_LTUs_CLAs_X_FMV1_PILAs & & & & & & & & & & & & & & & & & & & & & .180 & .079 & .153 & 2.285 & 5.023 \\
\hline FIV1_LTUsPU_VLAs_X_FMV2_PrKn_PJ & & & & & & & & & & & & & & & & & & & & & .123 & .071 & .113 & 1.723 & 3.086 \\
\hline FIV5_ORDU_VLAs_X_FMV2_PrKn_PJ & & & & & & & & & & & & & & & & & & & & & .172 & .081 & .141 & 2.138 & 8.034 \\
\hline FIV9_LocUniv_CLAs_X_FMV4_PrExp_Wk_ORDU & & & & & & & & & & & & & & & & & & & & & .178 & .087 & .129 & 2.041 & 1.043 \\
\hline FIV7_LTUs_CLAs_X_FMV2_PrKn_PJ & & & & & & & & & & & & & & & & & & & & & -.234 & .081 & $\mid-.184$ & -2.895 & 5.004 \\
\hline FIV6_InatSrc_CLAs_X_FMV1_PILAs & & & & & & & & & & & & & & & & & & & & & -.212 & .076 & -.174 & -2.771 & 1.006 \\
\hline FIV7_LTUs_CLAs_X_FMV8_PrExp_Wk_InatSrc & & & & & & & & & & & & & & & & & & & & & -.191 & .081 & -.149 & -2.358 & 8.019 \\
\hline FIV9_LocUniv_CLAs_X_FMV1_PILAs & & & & & & & & & & & & & & & & & & & & & -.167 & .077 & -.139 & -2.172 & 2.031 \\
\hline$x=2=2 x=2$ & & & & & .091 & & & & & .058 & & & & & .102 & & & & & .149 & & & & & .311 \\
\hline $\mathrm{R}^{2}$ adjust & & & & & .073 & & & & & .048 & & & & & .085 & & & & & .123 & & & & & .250 \\
\hline & & & & & $999^{* *}$ & & & & & $56^{* *}$ & & & & 5.777 & $77 * * *$ & & & & 5.85 & $57 * * *$ & & & & 5.05 & $56^{* * *}$ \\
\hline No. & & & & & 207 & & & & & 207 & & & & & 207 & & & & & 207 & & & & & 207 \\
\hline$\Delta \mathrm{R}^{2}$ adjust & & & & & & & & & & & & & & & 0.037 & & & & & 0.075 & & & & & 0.202 \\
\hline
\end{tabular}

Note:

1) In model 4, the three factors excluded before regression include a) FIV8_ORDU_CLAs and its interactions, b) FMV6_PrExp_Ed_LocUniv and its interactions, and c) FMV7_PrExp_Ed_InatSrc and its interactions, because they tend to have less power to predict output variables in all models.

2) Some variables with $p>.05$ are included in the regression because they still improve the prediction power of the model or do not meet the removal criterion of stepwise backward, see appendix C.3. 


\section{G.6 Integrated Model of Knowledge Inflows and Internal Knowledge for Hypotheses 1 to 4}

\begin{tabular}{|c|c|c|c|c|c|c|c|c|c|c|c|c|c|c|c|c|c|c|c|c|}
\hline \multirow[t]{3}{*}{$\begin{array}{l}\text { Model- } \\
\text { Mission- }\end{array}$} & \multicolumn{5}{|c|}{$\begin{array}{l}\text { 3.Integrated Model } \\
\text { 1: User Satisfaction }\end{array}$} & \multicolumn{5}{|c|}{$\begin{array}{c}\text { 3.Integrated Model } \\
\text { 2: Commercialization of Tech. }\end{array}$} & \multicolumn{5}{|c|}{$\begin{array}{l}\text { 3.Integrated Model } \\
\text { 3.1: Probability of Publication }\end{array}$} & \multicolumn{5}{|c|}{$\begin{array}{c}\text { 3.Integrated Model } \\
\text { 3.3 Versatility of Technology }\end{array}$} \\
\hline & \multicolumn{2}{|c|}{ Unstd. Coeff. } & \multirow{2}{*}{\begin{tabular}{|c|}
$\begin{array}{c}\text { Std. } \\
\text { Coeff. }\end{array}$ \\
Beta \\
\end{tabular}} & \multirow[b]{2}{*}{$\mathrm{t}$} & \multirow[b]{2}{*}{ Sig. } & \multirow[b]{2}{*}{ B } & \multirow[b]{2}{*}{ S.E. } & \multirow[b]{2}{*}{ Wald } & \multirow[b]{2}{*}{$\operatorname{Exp}(\mathrm{B})$} & \multirow[b]{2}{*}{ Sig. } & \multirow[b]{2}{*}{ B } & \multirow[b]{2}{*}{ S.E. } & \multirow[b]{2}{*}{ Wald } & \multirow[b]{2}{*}{$\operatorname{Exp}(\mathrm{B})$} & \multirow[b]{2}{*}{ Sig. } & \multicolumn{2}{|c|}{ Unstd. Coeff. } & \multirow{2}{*}{\begin{tabular}{|c|}
$\begin{array}{c}\text { Std. } \\
\text { Coeff. }\end{array}$ \\
Beta \\
\end{tabular}} & \multirow[b]{2}{*}{ t } & \multirow[b]{2}{*}{ Sig. } \\
\hline & B & S.E. & & & & & & & & & & & & & & B & S. E. & & & \\
\hline (Constant) & 3.885 & .073 & & 53.116 & .000 & -.249 & .215 & 1.343 & .780 & .246 & -1.071 & .203 & 27.809 & .343 & .000 & 3.240 & .080 & & 40.400 & .000 \\
\hline FMV1_PILAs & 0.153 & .073 & .101 & 2.086 & 0.038 & & & & & & & & & & & .139 & .080 & .113 & 1.732 & .085 \\
\hline FMV2_PrKn_PJ & & & & & & & & & & & .833 & .203 & 16.883 & 2.300 & .000 & & & & & \\
\hline FMV3_PrExp_Wk_LTUs & .366 & .072 & .246 & 5.088 & .000 & 1.006 & .216 & 21.624 & 2.736 & .000 & & & & & & & & & & \\
\hline FMV4_PrExp_Wk_ORDU & & & & & & .509 & .224 & 5.150 & 1.664 & .023 & & & & & & & & & & \\
\hline FMV5_PrKn_Core & .170 & .073 & .114 & 2.350 & .020 & .415 & .204 & 4.161 & 1.515 & .041 & .446 & .198 & 5.063 & 1.562 & .024 & & & & & \\
\hline FMV6_PrExp_Ed_LocUniv & .178 & .072 & .119 & 2.464 & .015 & & & & & & & & & & & & & & & \\
\hline FMV7_PrExp_Ed_InatSrc & & & & & & & & & & & & & & & & & & & & \\
\hline FMV8 PrExp Wk InatSrc & & & & & & & & & & & .416 & .186 & 4.986 & 1.516 & .026 & .262 & .080 & .212 & 3.253 & .001 \\
\hline FIV1_LTUsPU_VLAs & .710 & .072 & .474 & 9.794 & .000 & 1.820 & .254 & 51.385 & 6.173 & .000 & -.637 & .195 & 10.690 & .529 & .001 & & & & & \\
\hline FIV2_InatSrc_VLAs & -.127 & .072 & -.085 & -1.766 & .079 & & & & & & .601 & .188 & 10.182 & 1.825 & .001 & .208 & .080 & .168 & 2.586 & .010 \\
\hline FIV3_LocUniv_VLAs & & & & & & & & & & & .713 & .214 & 11.123 & 2.040 & .001 & & & & & \\
\hline FIV4_LTUsEU_VLAs & .591 & .072 & .398 & 8.233 & .000 & 1.072 & .242 & 19.679 & 2.921 & .000 & -.588 & .191 & 9.445 & .555 & .002 & & & & & \\
\hline FIV5_ORDU_VLAs & & & & & & -.700 & .226 & 9.597 & .496 & .002 & .572 & .198 & 8.326 & 1.772 & .004 & .185 & .080 & .150 & 2.298 & .023 \\
\hline FIV6_InatSrc_CLAs & & & & & & & & & & & .802 & .217 & 13.645 & 2.231 & .000 & .167 & .080 & .135 & 2.079 & .039 \\
\hline FIV7_LTUs_CLAs & .513 & .073 & .340 & 7.023 & .000 & .435 & .230 & 3.570 & 1.545 & .059 & & & & & & & & & & \\
\hline FIV8_ORDU_CLAs & & & & & & & & & & & & & & & & .184 & .080 & .149 & 2.295 & .023 \\
\hline FIV9_LocUniv_CLAs & .159 & .073 & .105 & 2.177 & .031 & & & & & & & & & & & & & & & \\
\hline & $\mathrm{R}^{2}$ & & .571 & & & Cox\&S & $11 R^{2}$ & 0.485 & & & Cox\&Sne & $\overline{1 \mathrm{R}^{2}}$ & 0.338 & & & $\overline{R^{2}}$ & & .149 & & \\
\hline & $\mathrm{R}^{2}$ adjust & & .550 & & & Nagelke & ke's $R^{2}$ & 0.648 & & & Nagelkerl & e's $R^{2}$ & 0.472 & & & $\mathrm{R}^{2}$ adjust & & .123 & & \\
\hline & $\mathrm{F}$ & & $27.175^{*}$ & & & $\begin{array}{l}\text { Chi-squ } \\
\% \text { corre }\end{array}$ & & $\begin{array}{l}138.714 \\
86.1\end{array}$ & & & $\begin{array}{l}\text { Chi-squar } \\
\% \text { correct }\end{array}$ & & $\begin{array}{l}85.665^{* *} \\
81.3\end{array}$ & & & $\mathrm{~F}$ & & $5.857 * *$ & & \\
\hline & No. & & 193 & & & No. & & 208 & & & No. & & 208 & & & & & 207 & & \\
\hline & ? $\mathrm{R}^{2}$ adju & & 0.491 & & & ?Cox\& & ell $R^{2}$ & 0.383 & & & ?Cox\&Sn & ell $R^{2}$ & 0.223 & & & $? \mathrm{R}^{2}$ adjus & & 0.075 & & \\
\hline & & & & & & ?Nagelk & rke's & 0.512 & & & ?Nagelke & ke's & 0.311 & & & & & & & \\
\hline
\end{tabular}

Note:

1) Some variables with $p>.05$ are included in the regression because they still improve the prediction power of the model or do not meet the removal criterion of stepwise backward, see appendix C.3.1)

2) Mission 3.2 (probability of generating a patent) is excluded from the analysis because is not a strong function of knowledge inflows, see section 5.3.1 and table 


\section{G.7 Regression analysis for Interaction Model}

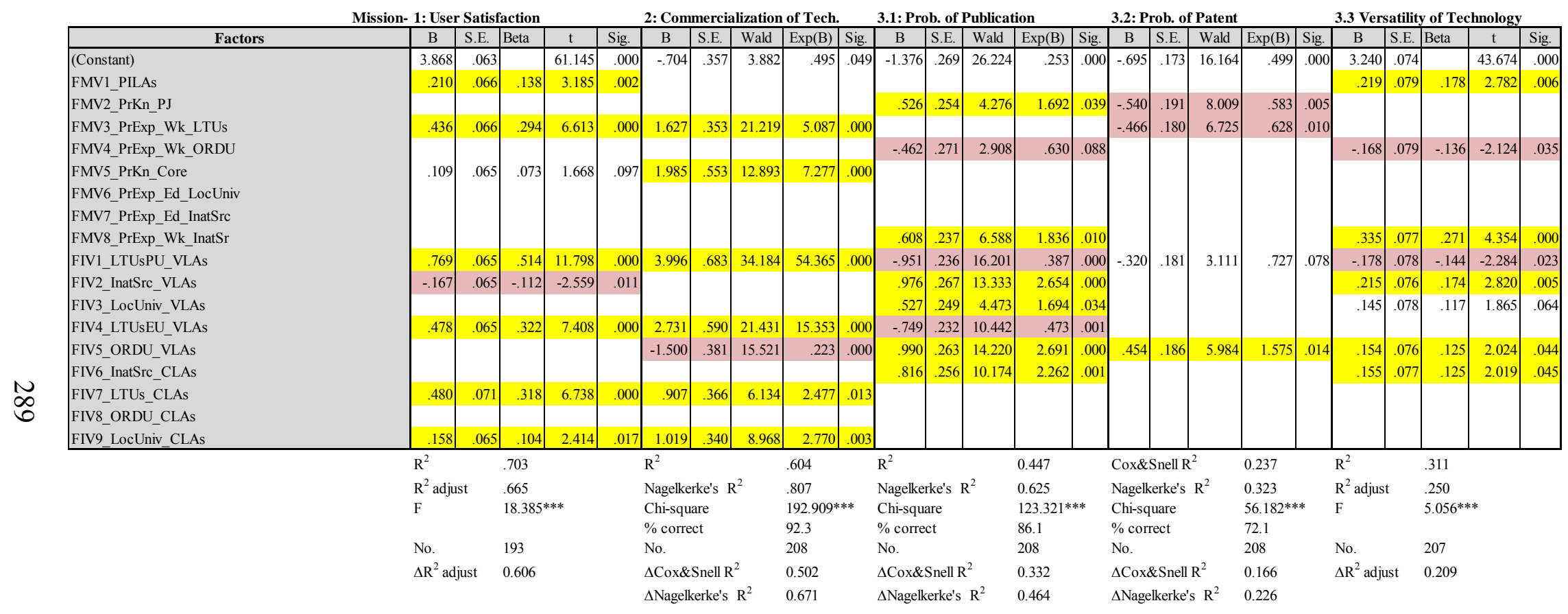




\section{G.7 Regression analysis for Interaction Model (cont.)}

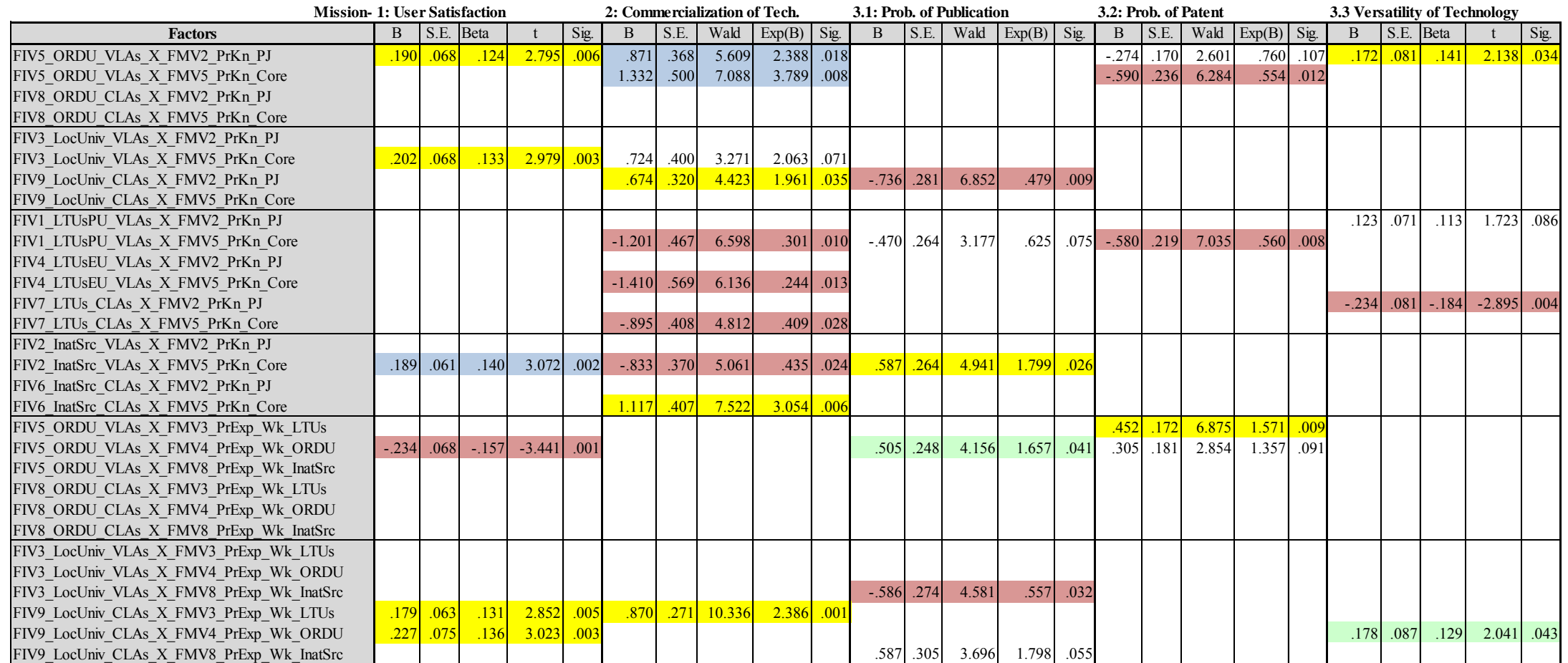




\section{G.7 Regression analysis for Interaction Model (cont.)}

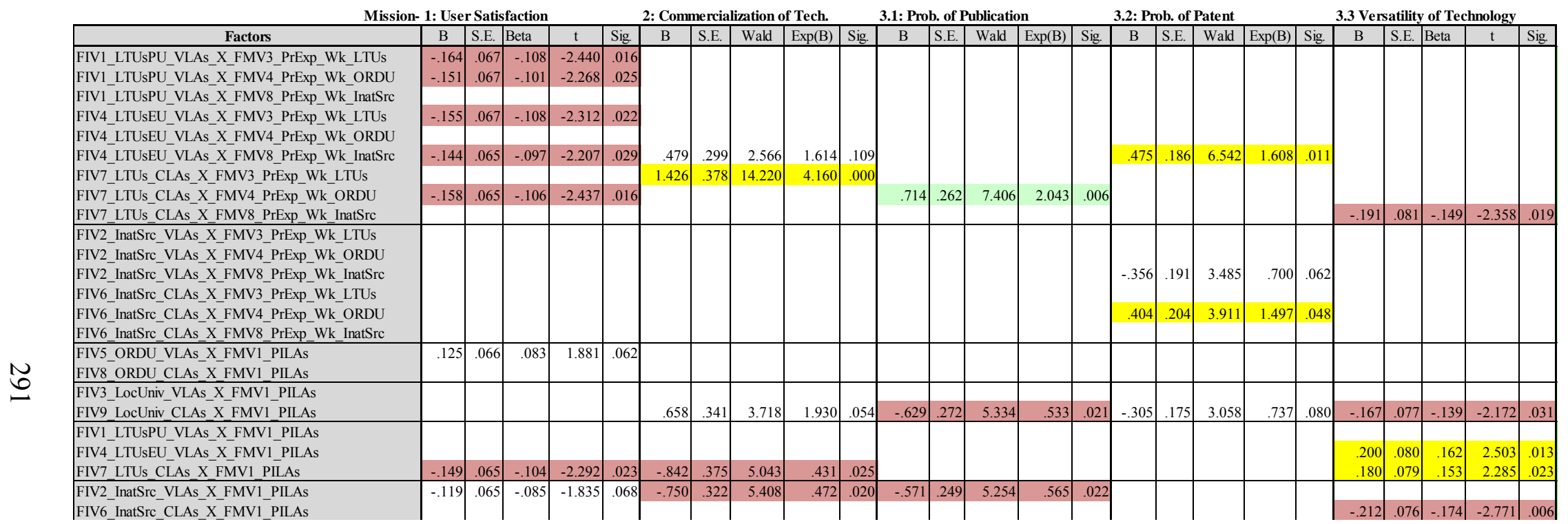

Note:

1) The three factors excluded before regression include a) FIV8_ORDU_CLAs and its interactions, b) FMV6_PrExp_Ed_LocUniv and its interactions, and c) FMV7_PrExp_Ed_InatSrc and its interactions, because they tend to have less power to predict output variables in all models.

2) Some variables with $p>.05$ are included in the regression because they still improve the prediction power of the model or do not meet the removal criterion of stepwise backward, see appendix C.3. 